NASA

Technical Memorandum 88929
USAAVSCOM

Technical Report 86-C-29

\title{
Unsteady Flows in a Single-Stage Transonic Axial-Flow Fan Stator Row
}

Michael D. Hathaway

Propulsion Directorate

U.S. Army Aviation Research and Technology Activity-AVSCOM

Lewis Research Center

Cleveland, Ohio

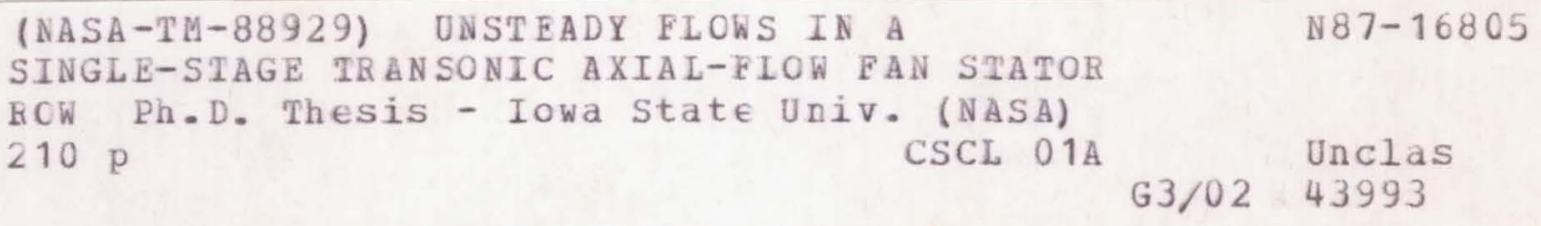

December 1986 
Unsteady Flows in a Single-Stage

Transonic Axial-Flow Fan Stator Row

Michael Hathaway

Propulsion Directorate

U.S. Army Aviation Research and Technology Activity - AVSCOM Lewis Research Center

Cleveland, Ohio

Detailed measurements of the unsteady velocity field within the stator row of a transonic axial-flow fan were acquired using a laser anemometer. Measurements were obtained on axisymmetric surfaces located at 10 and 50 percent span from the shroud, with the fan operating at maximum efficiency at design speed. The ensemble-average and variance of the measured velocities are used to identify rotor-wake-generated (deterministic) unsteadiness and "turbulence," respectively. Correlations of both deterministic and turbulent velocity fluctuations provide information on the characteristics of unsteady interactions within the stator row. These correlations are derived from the Navier-Stokes equation in a manner similar to deriving the Reynolds stress terms, whereby various averaging operators are used to average the aperiodic, deterministic, and turbulent velocity fluctuations which are known to be present in multistage turbomachines. The correlations of deterministic and turbulent velocity fluctuations throughout the axial fan stator row are presented. In particular, amplification and attenuation of both types of unsteadiness are shown to occur within the stator blade passage. 
TABLE OF CONTENTS

Page

SYMBOLS AND NOTATION

v

I. INTRODUCTION 1

II. RELATED RESEARCH 4

A. Experimental Research 4

B. Modeling Efforts 11

III. RESEARCH FACILITY 16

A. Compressor Test Facflity 16

$\begin{array}{lr}\text { B. Research Compressor } & 18\end{array}$

C. Laser Anemometer System 21

1. Optical configuration 25

2. Flow seeding 27

3. Laser optics cart and traversing mechanism 30

4. Laser anemometer signal processor 33

5. Compressor rotor shaft-angle encoder 34

6. System computer 35

IV. EXPERIMENTAL PROCEDURE AND DATA REDUCTION 36

A. Experimental Procedure 38

1. Survey setup 39

2. Preliminary LFA setup 45

3. Data acquisition 49 
B. Data Reduction 52

1. Velocity components 54

2. Summary of average-passage model 61

3. Deterministic-velocity correlations 64

4. Turbulent-velocity correlations 67

$\begin{array}{ll}\text { V. PRESENTATION AND DISCUSSION OF DATA } & 68\end{array}$

$\begin{array}{ll}\text { A. Uncertainty Analysis } & 69\end{array}$

1. Precision uncertainties 72

2. Bias uncertainties 73

B. Description of the Measured Flow Field 75

1. Stator-relative time-averaged description of 76

2. Rotor-relative time-averaged description of $\begin{array}{ll}\text { measured flow field } & 81\end{array}$

3. Time resolved description of measured flow field 93

C. Unsteady-Velocity Correlations 108

$\begin{array}{ll}\text { 1. Deterministic-velocity correlations } & 109\end{array}$

2. Turbulent-velocity correlations 129

3. Comparison between deterministic- and turbulent-
velocity correlations
136

$\begin{array}{ll}\text { VI. SUMMARY AND CONCLUSIONS } & 140\end{array}$

$\begin{array}{ll}\text { VII. RECOMMENDATIONS FOR FURTHER RESEARCH } & 143\end{array}$

VIII. REFERENCES $\quad 145$

$\begin{array}{ll}\text { IX. ACKNOWLEDGMENTS } & 157\end{array}$

X. APPENDIX A: NASA DESIGN CODE RESULTS 158 
XI. APPENDIX B: STATOR- AND ROTOR-RELATIVE TIME AVERAGES 190

XII. APPENDIX C: ESTIMATION OF BOUNDS ON TURBULENCE COMPONENTS 193

XIII. APPENDIX D: WAKE ENHANCEMENT PROCEDURE 198 


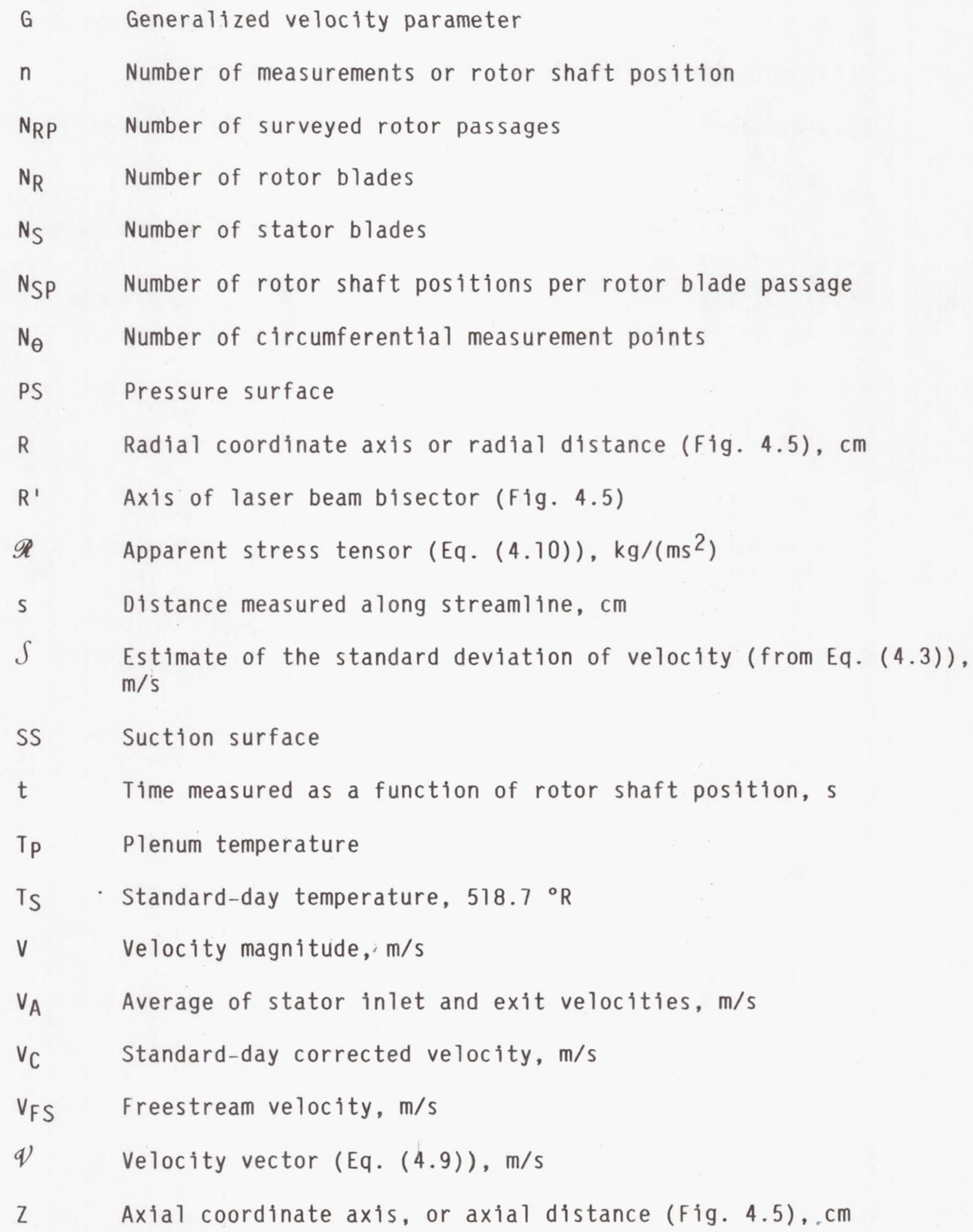


$\alpha$

${ }_{\text {B }} \quad$ Absolute flow angle, deg

$\gamma$

$\Gamma$

$\theta$

$\mu \quad$ True ensemble-average velocity (Eq. (4.2)), m/s

$\rho \quad$ Density

o

$\varphi \mathrm{R}$

$\varphi Z$

$\omega$

$\Omega$

I

IB Inner bound

E Stator row exit condition

m Measured component

OB Outer bound

R Radial component 
T Total of axial and tangential components

z Axial component

$\theta \quad$ Tangential component

1 Measured component in direction of first beam orientation angle

2 Measured component in direction of second beam orientation angle Superscripts

I Fluctuating component

$\sim \quad$ Ensemble average

an Temporal phase-lock average

"'m Spatial phase-1ock average

- $\quad$ Time average

A Aperiodic component

AX Axisymmetric component

I Component due to incident field

$\mathrm{R} \quad$ Rotor-relative parameter

U Component due to scattered field

S Stator-relative parameter 


\section{INTRODUCTION}

Unsteady interactions are known to affect various aspects of turbomachine performance, including blade loading [1], stage efficiency [2], heat transfer [3], noise generation [4], and energy transfer [5]. In fact, the fundamental mechanism for energy transfer in turbomachines is the unsteady throughflow [6]. However, virtually all existing turbomachine design systems are based on the assumption that the flow is steady in time. Consequently, extensive empirical correlations are usually relied upon to compensate for an inadequate understanding of the unsteady flow effects. Unfortunately, empirical correlations tend to be specific to a narrow class of turbomachines, and are usually only applicable for design point predictions. Furthermore, empirical correlations frequently include effects due to other flow phenomena, in addition to the flow phenomena the correlations were developed for. Nevertheless, it is obvious that some designers of turbomachines have an excellent intuitive feeling for the effects of many of the flow phenomena inherent in turbomachinery, as is evidenced by the high efficiencies obtained in modern turbomachines. Because of the limitations of the empirical correlations used in the design process these high efficiencies are generally limited to design point conditions and for turbomachines which are similar to previously designed turbomachines. Perhaps the key to improving our ability to predict the off-design performance of turbomachines, and to design turbomachines which are considerably different from our design based experience may be found through a better understanding of unsteady-flow interactions. Unfortunately, since current turbomachine design systems 
assume that the flow is steady, there is no provision for incorporating the effects of unsteady flows into these systems, except through the use of empirical correlations.

A recent publication by Adamczyk [7] described the development of a system of equations for simulating the flows in multistage turbomachinery, which he called the "average passage" form of the Navier-Stokes equations. This average passage system of equations provides a steady state description of the flow field in an "average passage" of any specific blade row. In a multistage turbomachine, the number of stator blades in successive stages usually differs. Rotor blade numbers also differ in different stages. Since stator (rotor) blade wake effects are influential in downstream stator (rotor) rows, different stator (rotor) blade numbers result in aperiodic flows in downstream stator (rotor) blade passages. An "average" of the flows in the different passages of a specific blade row is the "average passage" flow. The average passage system of equations is ideally suited for use in a turbomachine design system. Unlike current turbomachine design systems, however, the average passage system of equations includes terms which can account for the effects of the unsteady flows. These terms look, in form, much like Reynolds stress terms and include major contributors to the generation of nonaxisymmetric flows in multistage turbomachines. With respect to a given blade row, the terms identified through Adamczyk's derivation of the average passage system of equations account for the following nonaxisymmetric flows:

1. Spatial nonperiodicity of the flow in different blade passages of a specific blade row due to differing rotor or stator blade 
counts in successive stages (e.g., $\mathrm{N}_{\mathrm{S}}$ bladed stator row followed by an $\mathrm{N}_{\mathrm{S}}+1$ bladed stator row of a succeeding stage).

2. "Deterministic" unsteadiness, due to the relative motion between stator and rotor blade rows.

3. "Random" unsteadiness, due to any unsteadiness not correlated with the fundamental blade passing frequency, for example vortex shedding, global flow-field variations, and particle mixing.

It is important to note that these terms, as a whole, are what the empirical correlations used by current design systems have attempted to approximate. Therefore, even if the average passage system of equations are never incorporated into a design system, they provide a useful format for understanding the role of unsteady flows in generating nonaxisymmetric flows in multistage turbomachines.

The magnitudes and distributions of some of these terms have been determined from detailed laser anemometer measurements of the rotor-wakegenerated unsteady absolute velocity field throughout a single-stage transonic axial-flow fan. Since the data were acquired from an isolated stage the terms due to spatial nonperiodicity between blade passages are not present, as they would be in a typical multistage environment. Therefore, only the terms due to the deterministic and random unsteadiness will be presented herein. The relative importance of these terms is discussed, and some general suggestions for possible approaches to modeling these terms are provided. These data are for a loosely coupled fan (i.e., rotor/stator spacing is 85 percent of rotor chord), and therefore the strength of the rotor wakes are significantly diminished from what the stator would see in a more realistically coupled stage. The 
advantage of the wide spacing between blade rows is that it uncouples the potential flow-field effects from the rotor wake effects. Also presented are details of the kinematics of the passage of rotor wakes through the downstream stator row, as well as other relevant features of the stator flow field. 


\section{RELATED RESEARCH}

The number of research papers published during the last 30 years which deal with the effects of the unsteady flows generated as a result of the interaction between rotating and stationary blade rows is quite large. It is not unusual for these papers to be both experimental and theoretical or numerical in nature, and often the effects of both the deterministic and random (turbulent) unsteadiness are considered. As a result, the task of organizing these papers into specific categories is difficult.

Nevertheless, an attempt is made to organize the research papers dealing with unsteady blade row interactions into two categories: those papers which are primarily experimental in nature, or make their greatest contribution from measurements and those papers which are primarily either theoretical or numerical in nature (i.e., deal with modeling of the unsteady flows). This section is not intended to provide a complete compilation of all the unsteady flow research in turbomachinery over the last 30 years. It is designed to provide the reader with a representative sampling of past research related to the present research program.

\section{A. Experimental Research}

One of the earliest experimental research papers dealing with unsteady blade-row interactions was published in 1954 by Kofskey and Allen [8] who observed, through smoke visualization of the flow in a low-speed turbine, that thickening of the upstream stator suction surface boundary layer occurred at certain positions of the rotor blading. In 1966, Smith [9] described the process of wake chopping and attenuation, which indicated that a wake segment is modified by the chopping process, which 
disperses it, and by uneven energy distribution. In 1970, Kerrebrock and Mikolajczak [10] demonstrated that wake generated unsteadiness caused by intra-stator transport of rotor wakes would have a significant effect on the blade-to-blade stator exit temperature profile. Since the work of Kerrebrock and Mikolajczak, there has been an increasing number of papers published in the open literature which deal with blade row interaction effects.

The effect of blade row interactions on stage efficiency was demonstrated in 1974 by Yurinskiy and Shestachenko [2] who, using a rotating bar wake generator ahead of a turbine cascade, found increased (larger than steady flow values) total-pressure losses occurred for unsteady flow than when testing in steady flow. Hodson $[11,12]$ measured a 50 percent higher profile loss for a blade section in a turbine rotor than for that same section tested in a steady-state cascade. He proposed that the larger loss was due to a higher growth rate of the rotor suction surface boundary layer as a result of the interactions of the wakes of the upstream nozzle row. Similar results were found by Tanaka [13]; he measured a 1.1 to 1.25 times increase in the tota1-pressure loss coefficient of a lightly loaded cascade in a fluctuating flow over that in a steady flow. Tanaka also observed that the periodic fluctuations tended to suppress the growth of turbulence within the boundary layers, but that this effect reached saturation above 8 to 10 percent turbulence intensity. Okifshi et al. [14] proposed that, due to blade-row interaction effects, an appreciable portion of stator row loss can occur in the blade-to-blade free-stream region between the edges of the blade surface boundary layers. Dong et a1. [15] measured a 15 percent loss in the free-stream 
total pressure through a stator row. Hansen and Okilshi [16] indicate that the axial locations of the measurement stations used to assess rotor row and stator row loss values are important if a portion of the rotor wake mixing-out loss occurs within the stator "row," as defined by stator upstream and downstream measurement stations.

The effects of blade row interactions on blade surface boundary layers were studied by walker [17]. He observed that the stator suction surface boundary layer of a low-speed single-stage axial-flow compressor underwent periodically unsteady transition under the influence of the upstream rotor wakes. Evans [18] confirmed the observations of walker, and in addition found a much larger rate of boundary-layer growth on a stator blade disturbed by rotor wakes compared to a cascade blade in steady flow. Pfiel and Herbst [19]; Pfiel et al. [20] used a rotating bar wake generator to observe the effects of wakes on the boundary layer of a flat plate. They found that the wakes impinging on a flat plate forced the onset of transition to occur at shorter distances than for the undisturbed plate, and that the wakes also affected the location of the end of transition. Hansen and Okiishi [16] observed from surface hot-film measurements of the stator blade boundary layer of a low-speed axial-flow compressor that the rotor wake segments became wider, much as turbulent spots do, as they traveled downstream.

The effects of blade-row interactions on blade loading have been studied by Fleeter et a1. [21] in a large-scale low-speed single-stage axial-flow research compressor. Their data correlated quite well with an aerodynamic cascade traverse-gust analysis. They found that the unsteady pressure differential magnitude decreases in the chordwise direction, and 
attains a value very near zero at the blade trailing edge. Their observation is significant in that it reflects the validity of the Kutta condition for unsteady flows. Gallus et al. [1] measured the fluctuating pressures on the midspan profile surfaces of both rotor and stator blades for several points of operation. They found that the downstream cascade induces stronger potential flow interactions in the upstream cascade, and that stronger throttling leads to increased wake sizes and consequently stronger fluctuation forces. The wake interactions were observed to be the main source of fluctuating forces. Franke and Henderson [22] investigated the influence of solidity, incidence flow angle, and rotor-stator spacing on blade row interactions. They found a major influence of solidity at large values of incidence, where it is suspected that stall occurs. Some other investigation of the effects of blade row interactions on blade loading are listed in References 23 to 26 .

Blade row interactions have also been demonstrated to be a source of acoustic excitation in turbomachines. In 1977, Schmidt and 0ki1shi [27] found that the level of discrete frequency noise at the inlet of a multistage compressor could be varied appreciably by relative positioning of the stationary blade rows. Gallus et al. [4] found that the level of discrete frequency noise could be reduced considerably by only slight increases in the axial gap, within the range of small axial distances between blade rows. They also found that the wake shape influences the intensity of the various harmonics.

The effects of blade-row interactions on energy transfer has been investigated by Zierke and Okiishi [5] in a low-speed axial-flow research compressor. They found that rotor wakes which have interacted with stator 
or inlet guide vane wakes have lower total pressures than rotor wakes which have not interacted with stator or inlet guide vane wakes. They also found that periodic unsteadiness of total pressure is considerable downstream of a blade row that involves energy addition and loss, and is minimal downstream of a blade row that involves loss only. In $1985, \mathrm{Ng}$ and Epstein [28] confirmed, in a high-speed fan stage, the previous findings of Kerrebrock and Mikolajczak [10], by showing that the transport of rotor wakes through a downstream stator row resulted in a gapwise temperature nonuniformity at the stator exit of as much as 15 to $20{ }^{\circ} \mathrm{C}$.

The effects of blade-row interactions on heat transfer have been investigated by Dring et a1. [29] in a large-scale low-speed axial-flow turbine. They found that the unsteady wake passing affected the surface Stanton number. Doorly and 01dfield [3] used a rotating bar wake generator to investigate the effects of wake passing on a downstream rotor cascade. They observed that each wake produced a turbulent boundary-layer patch in the blade suction surface boundary layer, which is swept along the blade surface and is responsible for dramatic transient increases in heat transfer.

The general characteristics of wake-generated unsteadiness have been reported by many investigators. Joslyn et al. [30] measured the unsteadiness and three-dimensionality of the flow in a large-scale axial-flow turbine. They measured large increases in the pitch angle near the suction side of the rotor wake as the vane wakes periodically impacted on the rotor suction surface. Matsuuchi and Adachi [31] measured the three-dimensional unsteady flow inside a rotor blade passage of an axial-flow fan. They observed that the upstream stator wakes became 
deeper (and sometimes thicker) as they moved closer to the rotor blade pressure surface, that the stator wake decay characteristics within the rotor passage are very complex, and that the wake does not necessarily decay monotonically. The character of the blade wakes which are the primary source of blade-row interactions have been reported by many investigators [32-41].

Wake transport characteristics have also been studied by Dunker [42] who used a laser transit anemometer to map the unsteady flow field through a high-speed single-stage axial-flow compressor stator row. Dunker used contour maps of the turbulent kinetic energy to show the transport of rotor wakes through the stator row. Binder et al. [43] performed a similar experiment in a high-speed axial-flow turbine stage in which they observed an increase in the turbulence in the stator wake as a result of its being chopped by the rotor blades. Subsequently, Binder [44]; Binder et a1. [45] suggested that this increased turbulence in the chopped stator wake was a result of stator secondary vortex cutting by the downstream rotor blades, which caused a breakdown in the secondary vortex and a subsequent increase in turbulence. Hodson [46] measured the wake generated unsteadiness in the rotor passages of an axial-flow turbine. He showed that the level of periodic unsteadiness on the suction surface was 2.5 times that on the pressure surface, whereas the mean level of free-stream turbulence was only slightly higher. Hodson also observed that the energy of the turbulent fluctuations was greater than the energy of the periodic fluctuations on the pressure surface, and opposite on the suction surface. Hodson concluded that this was because the wakes behaved 
as negative jets, with high loss fluid being convected towards the suction surface.

In a multistage environment, the blade-row interactions are even more complex, and can result in unusual effects not observed in the single-stage environment. Wagner et al. [47] found that the periodic unsteadiness in an imbedded rotor or stator row was appreciable, depending on the extent of the wake interactions involved at the particular location considered. They were able to construct, from hot-wire data, sequential wake transport interaction plots throughout the compressor at various rotor/stator relative positions, which illustrated some of the possible wake interactions that can exist in multistage turbomachinery. In 1985, Tweedt et al. [48] demonstrated that complex interactions within multistage turbomachinery can result in unusual total-pressure distribution patterns depending on flow rates. The unusual total-pressure distributions resulted in a higher frequency interaction in the downstream blade row than would be expected from the number of blades present. Williams [49] observed that the turbulence introduced by rotor wakes persists in terms of identifiable velocity fluctuations for several stages before the rotor contributions are mixed out into unidentifiable random fluctuations. From a Fourier analysis of his results, williams identified discrete frequency levels generated from upstream blade rows as much as four stages downstream. He also observed that the strength of the periodic wave forms was a strong function of location within the passage, with the periodic high frequency wave forms being strongest in the stator wakes. 


\section{B. Modeling Efforts}

One of the earliest papers dealing with the modeling of blade-row interactions was published in 1953 by Kemp and Sears [50,51] who studied the aerodynamic interference between rotor and stator blade rows for incompressible inviscid flows by regarding each blade row as an infinite two-dimensional cascade. They obtained expressions for the unsteady components of lift and moment of the blades of each row, and they also calculated the effects of the stator wakes on the unsteady lift of rotor blades. They found lift fluctuation amplitudes of about 18 percent of the steady lift. The process of wake chopping by a thin airfoil was theoretically examined in 1958 by Meyer [52] who considered the wake as a negative jet carried with the free-stream. In 1965, Lefcort [53] extended the analysis of Meyer to include the case of a blade of finite thickness. Lefcort considered that the unsteady forces in turbomachines were due to four main effects: a circulation effect, a blade thickness effect, a wake effect, and a wake distortion effect. The above mentioned blade-row interaction models were all developed using the concepts of circulation theory presented by von Karman and Sears [54].

After these early developments, the focus of interest in unsteady airfoil theory became compressibility effects, and, later, cascade effects. The problem of a lifting airfoil passing through a gust pattern was examined by Horlock [55]. Using a heuristic approach, Horlock partially accounted for the second-order effects of small mean-flow incidence on the fluctuating lift. A similar approach was used by Naumann and Yeh [56] to account for small airfoil camber. These treatments, 
however, were incomplete in that they only accounted for the modified boundary condition at the airfoil surface while neglecting the coupling between the unsteady flow and the potential flow around the airfoil.

A complete theory that accounts for the dependence of the unsteady flow on the mean potential flow of the airfoil was developed by Goldstein and Atassi [57]. They used their theory to analyze the interaction between a periodic two-dimensional gust with an airfoil in uniform flow which showed that the unsteady velocity field associated with the oncoming gust was significantly distorted in both amplitude and phase by the steady potential field about the airfoil. Adamczyk [58] considered the effects of finite blade thickness, camber, and incidence, and used his theory to analyze the interaction between a one-dimensional gust and a cascade of compressor blades. A combined analytical and numerical approach was used to solve the field equations which govern the rotational and irrotational velocity fields. The results of Adamczyk's analysis showed a strong influence of mean loading on the unsteady force generated by the passage of the one-dimensional gust through the cascade of compressor blades.

One of the earliest attempts to develop a numerical method for solving the inviscid, compressible, two-dimensional, unsteady flow on a blade-to-blade stream surface through an axial compressor stage was in 1977 by Erdos and Alzner [59]. A comparison of their numerical results with experiment indicated that there was still much to be learned about the nature of blade-row interactions before a numerical solution scheme for a complete stage would be capable of predicting the actual flows. In 1982, Krammer [60] developed a time marching scheme for computing the unsteady blade forces in turbomachines, which he based on potential flow 
theory and simulated viscous wakes. Blade surfaces were modeled by vortex distributions and viscous wakes were simulated by contra-rotating vortex rows. Krammer was able to generate sequential pictures of the wake chopping and transport through the downstream blade row. However, his analysis only considered the case of an equal number of stator and rotor blades, and quantitative agreement with measurements was only fair. Hodson [61] solved the two-dimensional inviscid equations of motion using a finite volume scheme based upon the work of Denton [62] in order to calculate the unsteady flow generated by the interaction of upstream wakes with a moving blade row. The wakes were simulated by a velocity deficit Which was periodically moved across the inlet boundary of the computational domain at the relative speed of the wake generating blade row. Wake dissipation was modeled by an artificial viscosity, and contour plots of the calculated entropy levels were used to identify the wake regions. Hodson's analysis confirmed the existence of such phenomena as wake chopping, migration, and shearing. He concluded that many of the phenomena associated with rotor-stator wake interactions are dominated by inviscid rather than viscous effects.

In 1985, another attempt to numerically simulate the interactions between rotor and stator rows in a single stage turbomachine with equal numbers of rotor and stator blades was performed by Rai [63]. He compared numerical results with experimental data and concluded that, in the case of the time-averaged surface pressure distributions, there was good agreement. The comparisons between pressure amplitudes and phase relationships, however, were not very favorable. Joslyn et al. [64] described an inviscid method for modeling turbomachinery wake transport, 
which was based in part on the linear small-disturbance theory of Smith [65]. Their calculations compared favorably with smoke visualization experiments which showed the transport of chopped smoke-trace segments through a downstream rotor row. Unfortunately, they were unable to measure the actual wake fluid and instead attempted to simulate a wake using a smoke trace. Their experimental results must, therefore, be questioned as to their validity in modeling real wake transport phenomena, such as wake centrifugation.

Although most of the above mentioned analyses provide a great deal of insight into the characteristics of blade-row interactions, they are generally impractical for use in a turbomachinery design system. Usually the analyses are restricted to a single stage turbomachine with equal numbers of rotor and stator blades, and even then they require significant computer resources to solve the complete time-dependent flow field. For a turbomachine design engineer to use these models to predict the effects of unsteady flows throughout a typical multistage turbomachine would be a formidable task.

Perhaps the earliest effort to include the effects of blade-row interactions in a turbomachinery design system was attempted in 1954 by Smith [65] who considered the effects of secondary flows produced by upstream blade rows. In 1981 Adkins and Smith [66] included the effects of spanwise mixing, including wake centrifugation, which might also be considered an attempt at including blade row interactions. A more fundamental approach to modeling blade row interactions was presented by Mitchell [67]. Mitchell developed a three-dimensional nonaxisymmetric theory to analyze the interaction effects due to wakes between two blade 
rows in an axial-flow turbomachine. Mitchell's theory was based on lifting-line and nonaxisymmetric actuator disk principles, and assumed that the wake was a small three-dimensional perturbation from the free vortex condition. In 1979, Sehra [68] described a correlation method for introducing nonaxisymmetric blade row effects, including deterministic and turbulent unsteadiness, into the axisymmetric flow field computation for a highly loaded isolated blade row. Sehra's approach centered about the modeling of three important nonaxisymmetric phenomena (apparent stress, apparent entropy, and mean rothalpy) which control the time-mean momentum and energy transfer. Adamczyk [7] took a more rigorous mathematical approach to including the effects of nonaxisymmetric flows than had been previously attempted. Starting with the Navier-Stokes equation, Adamczyk considered a decomposition of the flow field into a steady-state blade-toblade periodic component, a blade-to-blade aperiodic component, a periodic unsteady component, and a random unsteady component. Then, in a manner similar to developing the Reynolds averaged Navier-Stokes equation, Adamczyk performed a series of averages on the Navier-Stokes equations to resolve, what he called, the average passage equation system. Adamczyk's average passage equation system was developed to simulate the flows in multistage turbomachinery. His average passage equation system reduces to the equation system developed by Sehra [68], and to the axisymmetric equations of motion, given the proper assumptions used to develop each. A model for closing the inviscid form of Adamczyk's averaged passage equation system was published by Adamczyk et al. [69], and the average passage equation system has been used to solve the inviscid flow through a counter-rotating propeller, see Celestina et al. [70]. 


\section{RESEARCH FACILITY}

The single-stage axial-flow compressor test facility of the National Aeronautics and Space Administration (NASA) Lewis Research Center was used to accomplish the research described in this dissertation. The test facility, research compressor, and laser anemometer system are described in this section.

\section{A. Compressor Test Facility}

A schematic diagram of the single-stage axial-flow compressor test facility at NASA Lewis is shown in Figure 3.1. The drive system for the compressor consists of a $3000 \mathrm{hp}$ electric motor with a variable-frequency power supply. Motor speed is controllable from 400 to $3600 \mathrm{rpm}$. The motor is coupled to a 5.52 gear ratio speed increaser gear box that in turn drives the rotor. The facility was sized for a maximum flow rate of $100 \mathrm{lb} / \mathrm{sec}$ with atmospheric air as the working fluid. Air is drawn into the facility from an inlet located on the roof of the building. The air next passes through a flow measuring station consisting of a thin-plate orifice, through inlet butterfly valves, and into a plenum chamber. The

air is is then accelerated to the compressor test section via a nozzle, through the test compressor, and into a collector through a sleeve throttle valve. The air subsequently passes through a spray water cooler and is exhausted back into the atmosphere or through an altitude exhaust system. The airflow may be controlled through either the upstream butterfly valves or the downstream collector valve. For the present investigation the air 


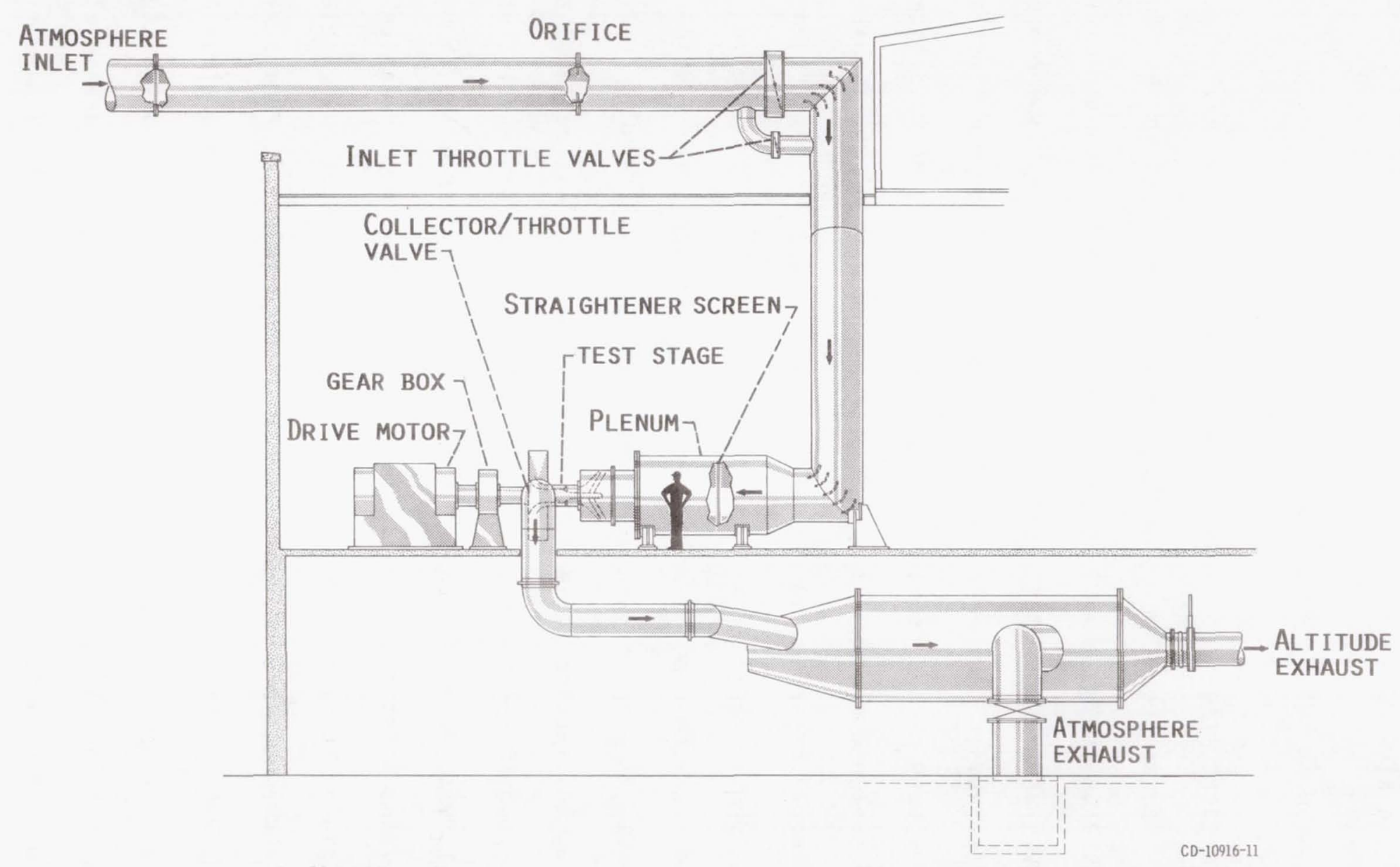

Figure 3.1 Schematic diagram of NASA Lewis single-stage compressor test facility 
was exhausted back into the atmosphere and the collector valve was used to control the airflow.

\section{B. Research Compressor}

The first stage of a NASA Lewis designed two-stage axial-flow fan was used as the research compressor to accomplish the research described in this dissertation. A complete description of the aerodynamic design of the full two-stage fan is provided in References 71 and 72 . Therefore, only a brief description of the relevant design parameters of the first stage geometry, used as the research compressor in the present investigation, will be provided herein. A sketch of the flow path of the research compressor is presented in Figure 3.2 , and the coordinates of the flow path are provided in Appendix A.

The research compressor was designed with wide axial spacing between blade rows ( 85 percent rotor axial chord at midspan) in order to reduce blade-row-interaction noise. The first-stage rotor was designed as a lowaspect-ratio (1.56) damperless fan with a design pressure ratio of 1.63 at a mass flow of $33.25 \mathrm{~kg} / \mathrm{sec}$. The design rotational speed is $16043 \mathrm{rpm}$, which yields a design tip speed of $429 \mathrm{~m} / \mathrm{sec}$. The inlet relative Mach number at the rotor tip is 1.38. The first-stage rotor has 22 blades of multiple-circular-arc design. The rotor solidity varies from 3.114 at the hub to 1.290 at the tip. The rotor inlet and exit tip diameters are 51.1 and $49.5 \mathrm{~cm}$ respectively, and the rotor inlet and exit hub/tip radius ratios are 0.375 and 0.478 respectively. The running rotor tip clearance is $0.5 \mathrm{~mm}$. An example of the first-stage rotor blade sections at three spanwise locations is shown in Figure 3.3 . 


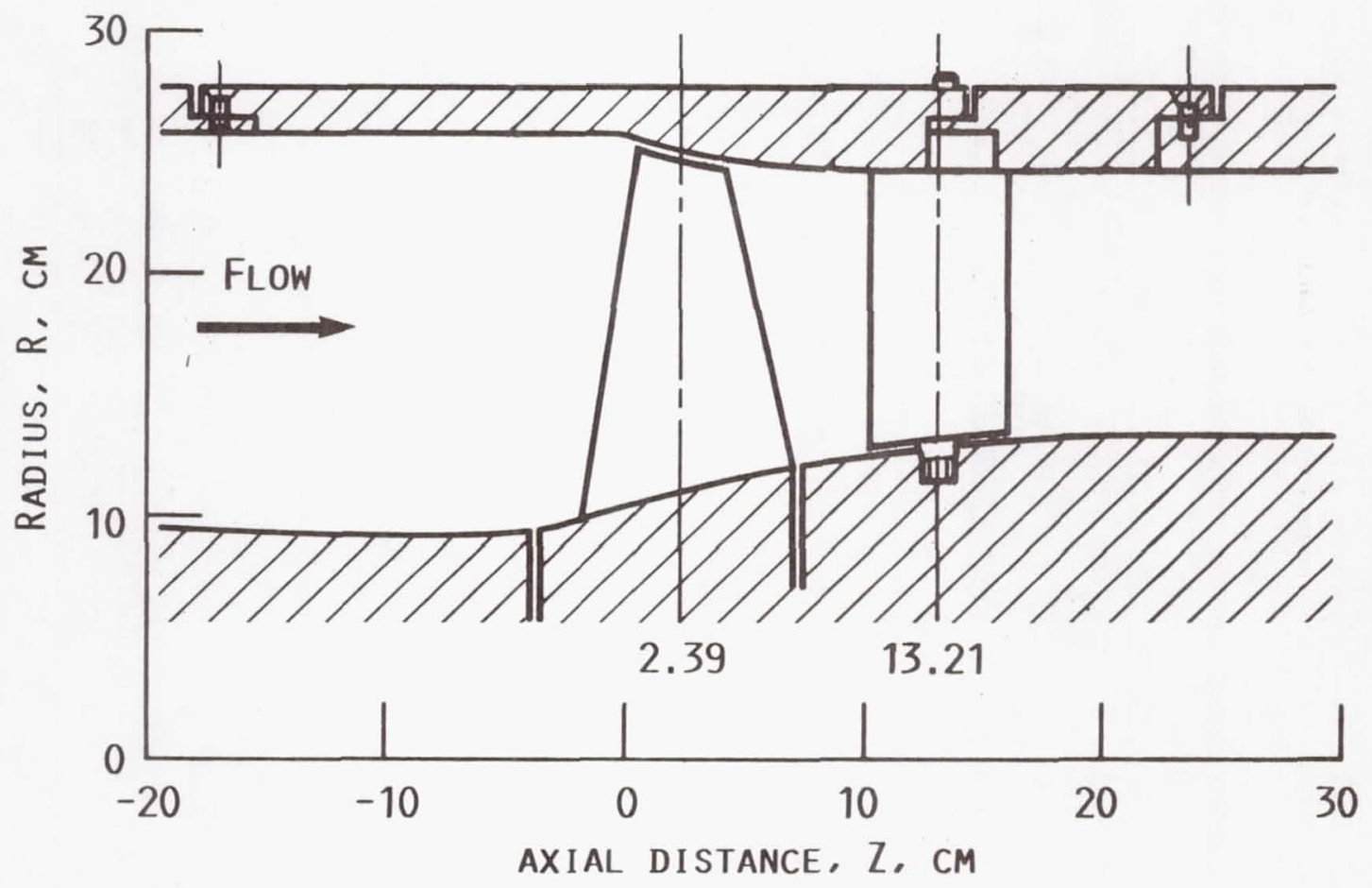

Figure 3.2 Meridional-plane view of research compressor flow path 


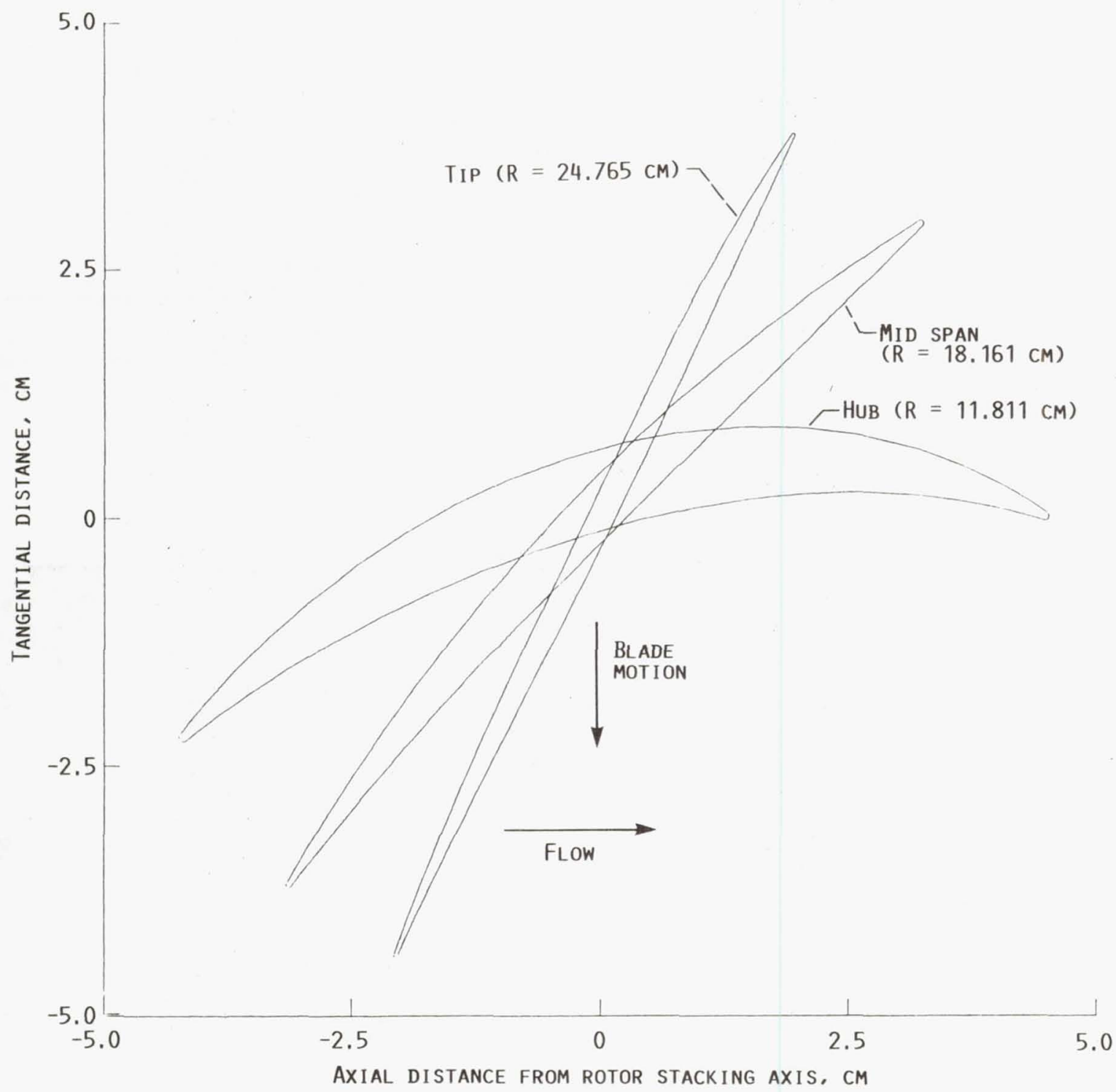

Figure 3.3 Representative rotor blade sections at three spanwise locations 
The first-stage stator was designed to discharge fluid axially. The stator consists of 34 double-circular-arc designed blades which vary in solidity from 2.485 at the hub to 1.271 at the tip. The stator tip diameter is constant at $48.7 \mathrm{~cm}$ and the inlet and exit hub/tip radius ratios are 0.500 and 0.530 respectively. An example of the stator blade sections at three spanwise locations is shown in Figure 3.4.

A summary of the relevant design parameters of the single-stage research compressor is provided in Table 3.1, and a complete listing of the input parameters to the aerodynamic design code [73] which was used to design the first-stage geometry is provided in Appendix A. Also included in Appendix A are the output tables from the design code which include velocity diagram information on the axisymmetric design streamlines at each axial computational station and complete blade manufacturing coordinates at each of the design blade section radii for both the first-stage rotor and stator.

\section{Laser Anemometer System}

A laser fringe-type anemometer (LFA) system developed at NASA Lewis for use in high-speed turbomachinery was used as the principal measuring instrument to accomplish the research described in this dissertation. A detailed description of the basic anemometer system, as originally designed, is reported in References 74 and 75 . Because of minor changes in some of the optical components and system layout which have occurred since the system was originally designed, a brief description of the current laser anemometer system is provided herein. A block diagram of the major components of the LFA system is provided in Figure 3.5. 


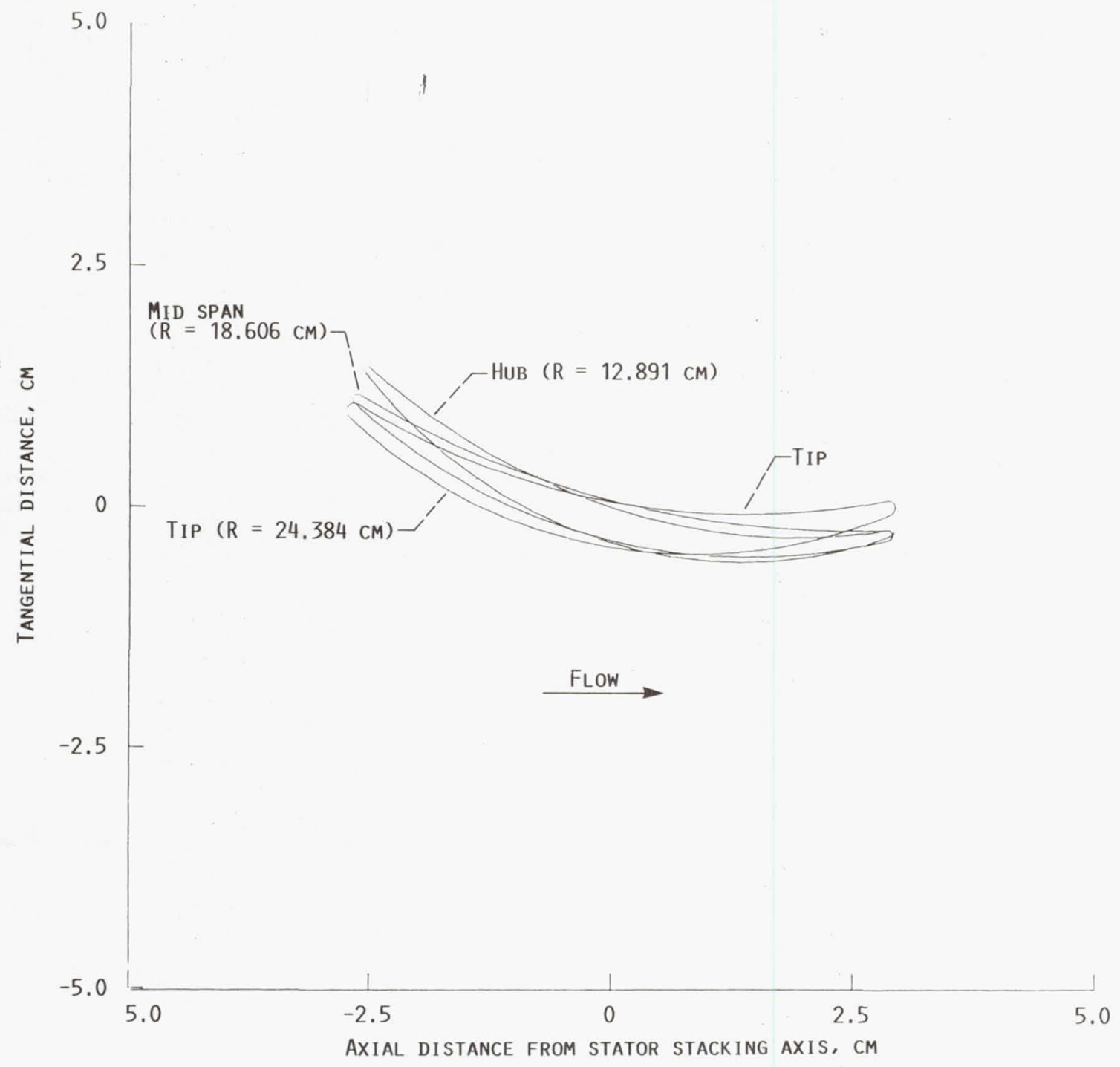

Figure 3.4 Representative stator blade sections at three spanwise locations 
Table 3.1. Summary of single-stage research compressor design parameters

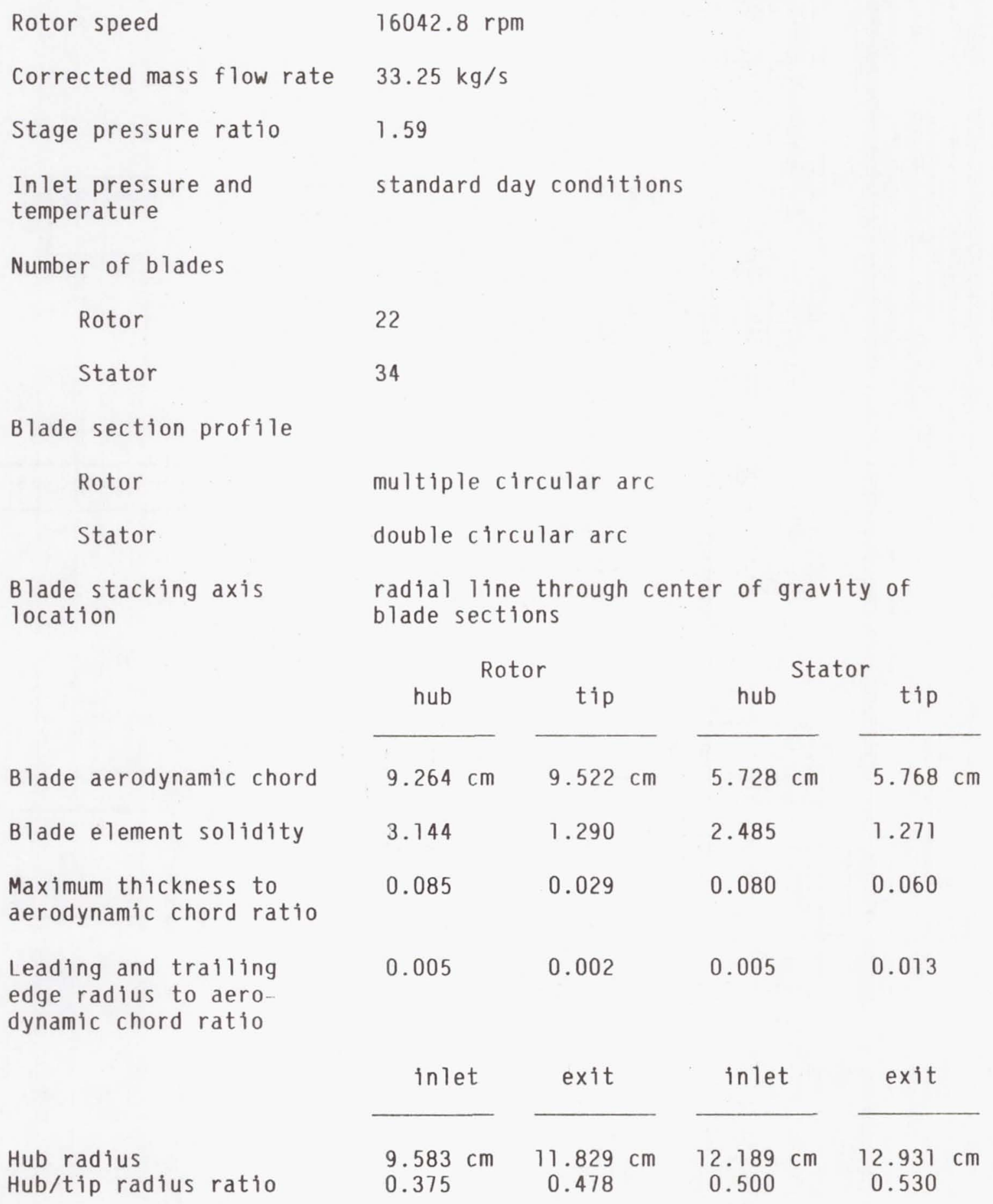




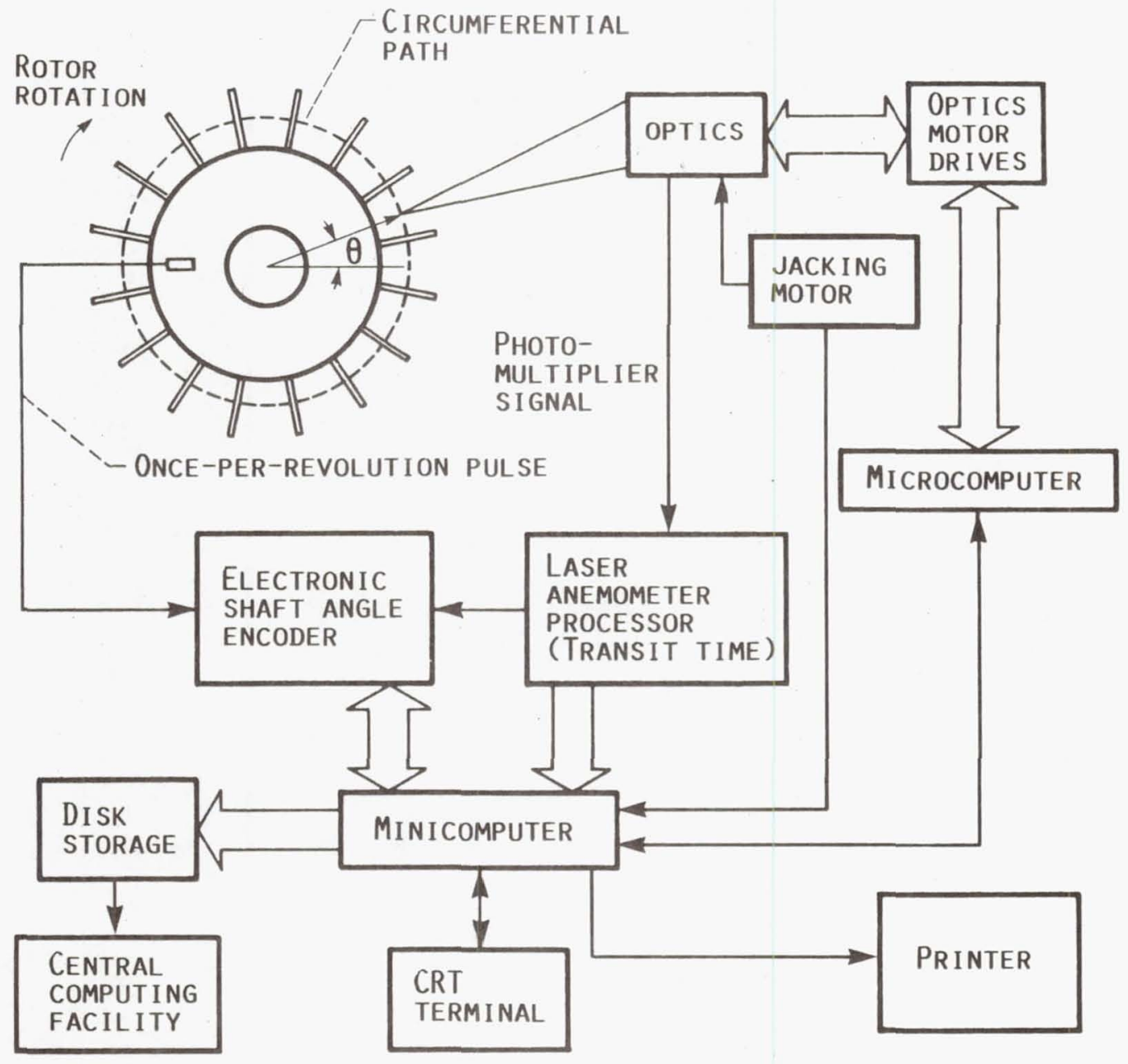

Figure 3.5 Block diagram of laser anemometer data acquisition system 


\section{Optical configuration}

The basic optical components of the laser anemometer system are shown in Figure 3.6. It is a single-channel, dual-beam, fringe type anemometer with on-axis backscatter collection optics. The $514.5 \mathrm{~nm}$ (green) line of an argon-ion laser operating at a power level of $1.5 \mathrm{~W}$ is used to generate the laser beam for the LFA system. After the beam leaves the laser a series of mirrors turns the laser beam through $180^{\circ}$ for compactness. The beam then passes through a collimator which is used to position the beam waist at the probe volume, and to adjust the diameter of the beam waist to the proper diameter. Because the LFA processing electronics requires at least 10 fringes, and the fringe spacing was $10.4 \mu \mathrm{m}$, a waist diameter of $125 \mu \mathrm{m}$ was selected. The beam then passes through a beam splitter which splits the beam into two parallel beams of equal intensity. Two more mirrors then direct the beam through a 200-mm-focal-length focusing lens ( $50 \mathrm{~mm}$ diameter) which causes the beams to converge and ultimately cross at the lens focal point. At the intersection where the two beams cross (called the probe volume) a pattern of bright and dark fringes are formed due to the constructive and destructive interference of the wave fronts of the two beams. The fringe pattern is perpendicular to the path of the bisector of the two beams which is perpendicular to the research compressor centerline. The probe volume length in the direction of the bisector of the two beams is $2 \mathrm{~mm}$.

Part of the light which is scattered from seed particles which cross the bright fringes of the probe volume is then collected through the 200-mm-focal-length focusing lens and directed to a 100-um-diameter pinhole in front of the photomultiplier tube (PMT). The focusing lens in 


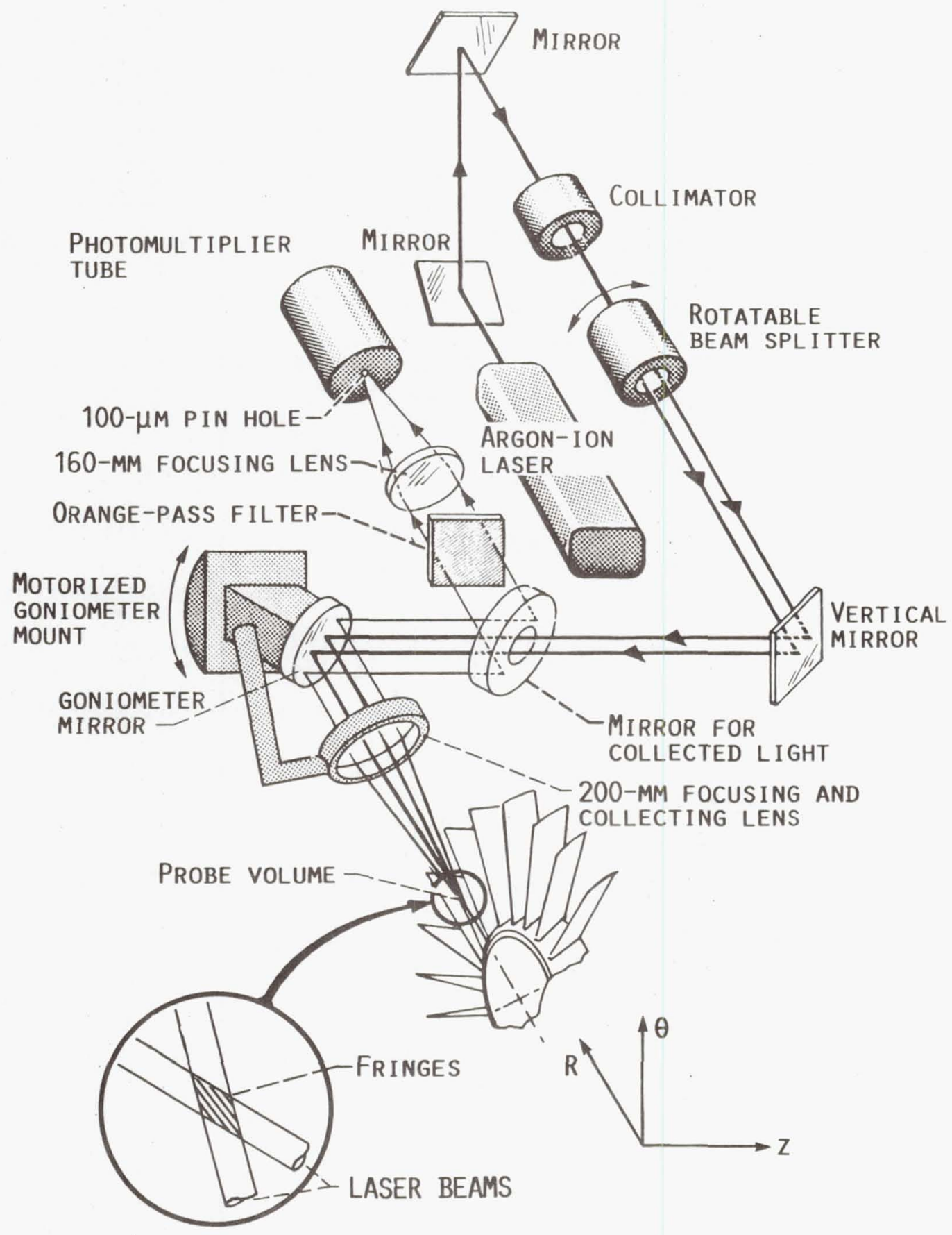

Figure 3.6 Layout of laser anemometer system optical components 
front of the photomultiplier tube is $50 \mathrm{~mm}$ in diameter, with a focal length of $160 \mathrm{~mm}$. The function of the orange-pass filter in front of the 160-mm-focal-length focusing lens is explained in the next section.

The final optical element in the laser beam paths prior to entering the research compressor flow path, not shown in Figure 3.6 , is a 3.2-mm-thick glass window in the compressor shroud. Two different laser windows were used; a "rotor window," see figure 3.7 , which extended from about 1.5 rotor chords upstream of the rotor leading edge to just past the stator leading edge, and a "stator window," see Figure 3.8 , which extended from just past the rotor trailing edge to about one-half stator chord downstream of the stator trailing edge. The rotor window covered a constant circumferential width of $20^{\circ}$. The stator window was cut to follow the stator blade suction and pressure surface contours so that an entire stator passage could be viewed. Both windows were contoured to follow the shroud inner flow path. The windows were made of chemically treated window glass and were pressure tested to 300 psig prior to their installation in the rig.

\section{Flow seeding}

The seed material used was Rhodamine $6 \mathrm{~g}$ in solution with ethylene glycol and benzyl alcohol [76]. This seed material has the characteristic of fluorescing orange light when 11 luminated by the green light of the argon-ion laser. The function, therefore, of the orange-pass filter in front of the 160-mm-focal-length focusing lens is to allow only the flourescent light emitted by the seed particles to reach the PMT. This reduces detection of unwanted scattered light and therefore allows measurements closer to solid surfaces. 


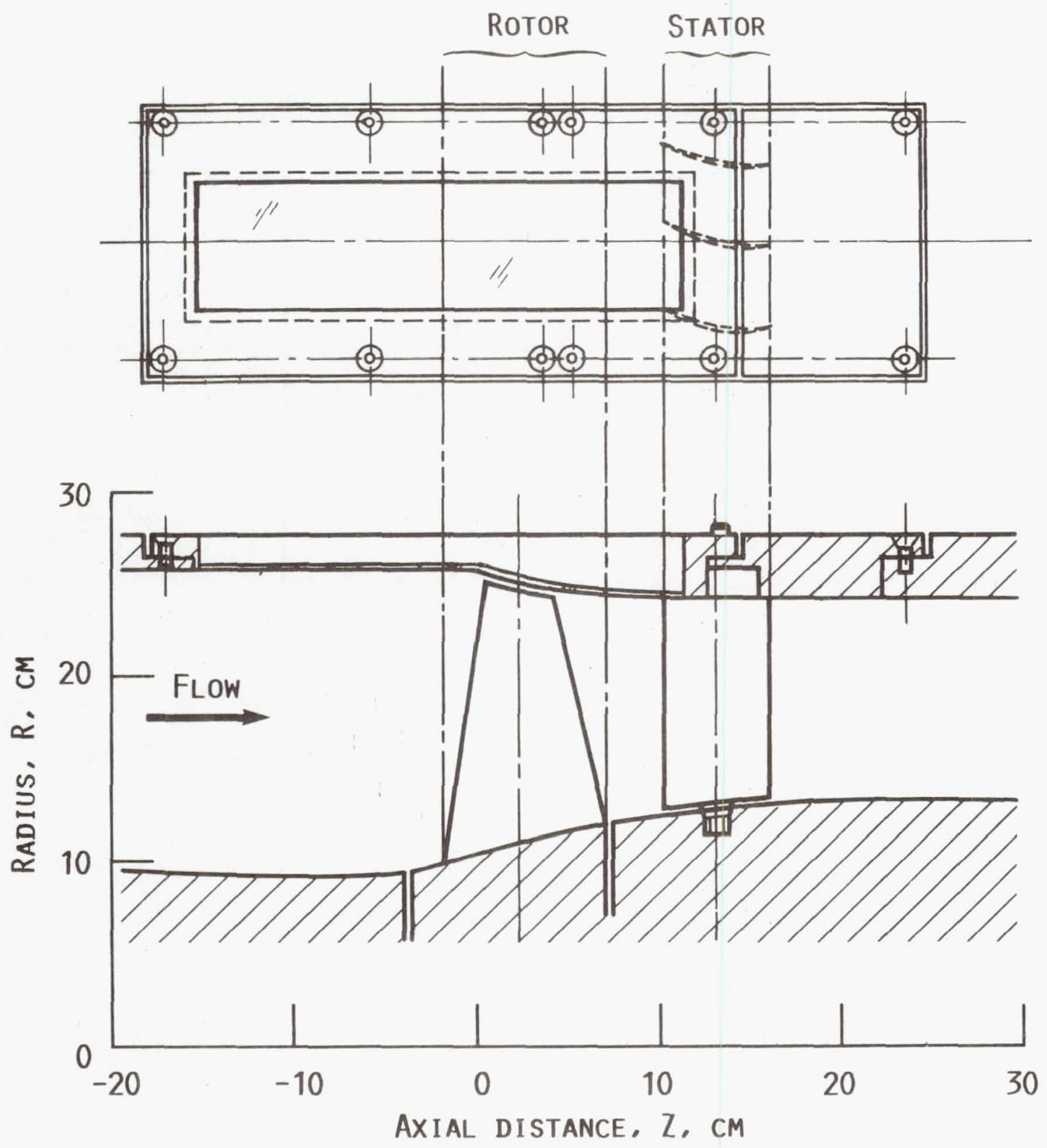

Figure 3.7 View of optical access through rotor window 


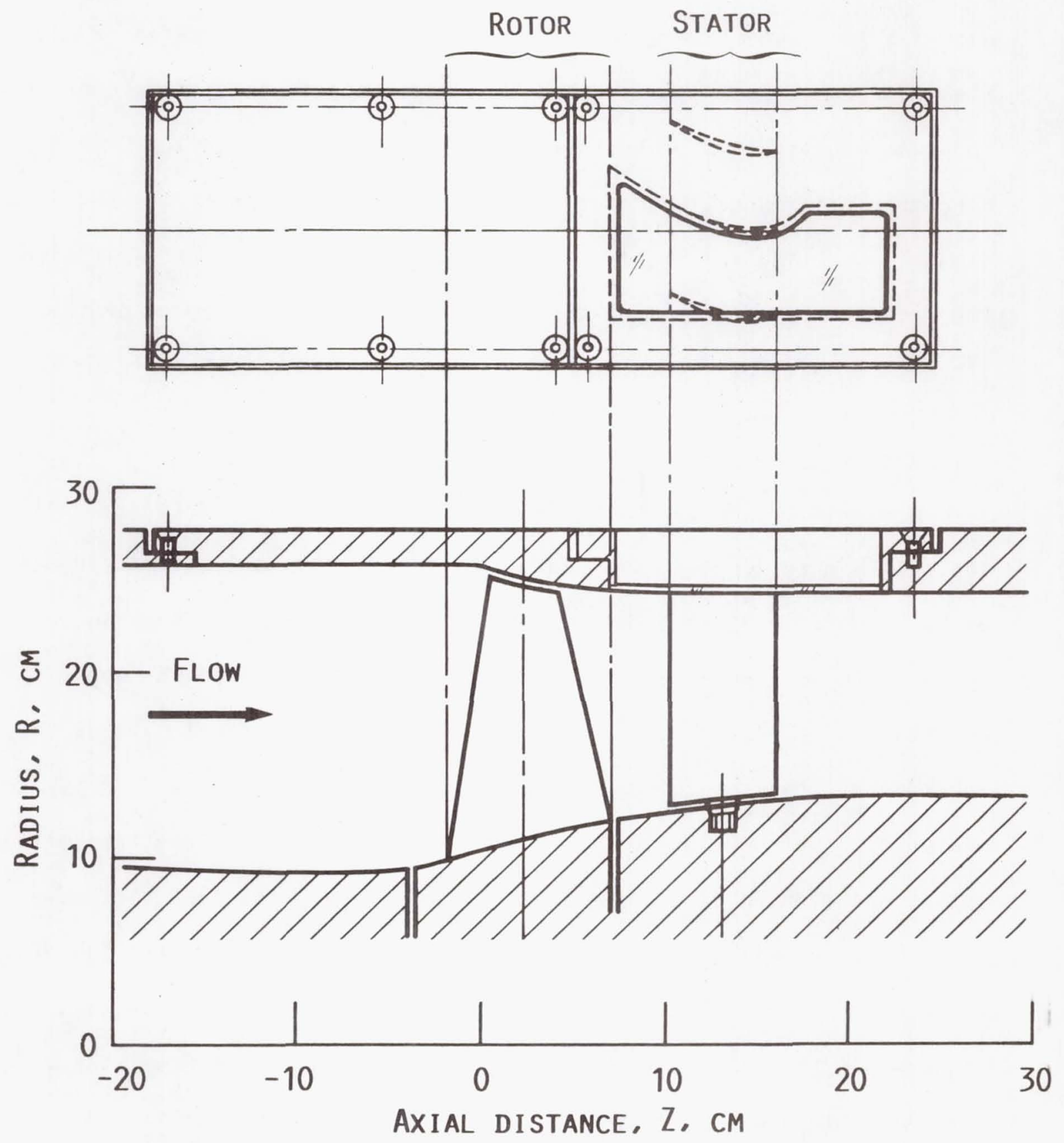

Figure 3.8 View of optical access through stator window 
A commercially available atomizer was used to atomize the seed solution and generate liquid seed particles, nominally 1.0 to $1.4 \mu \mathrm{m}$ in diameter [77], which were introduced into the research compressor flow field through a $6 \mathrm{~mm}$ tube located $35 \mathrm{~cm}$ upstream of the rotor. The seeder tube was mounted in a probe actuator which was mounted on top of a circumferential positioning pad. In this configuration it was possible to remotely position the seeder probe radially and circumferentially within the research compressor flow field to achieve optimum seeding of the streamtube which passed through the laser probe volume.

\section{Laser optics cart and traversing mechanism}

A sketch of the optics cart assembly is shown in Figure 3.9. All of the optics were located on a flat rigid metal table and secured in place using commercially available magnetic instrument bases. The beam splitter was mounted in a motorized rotator assembly which allowed the angle of orientation of the fringes to be rotated about the optical path of the input beams, thus enabling different components of the flow velocity to be measured. The focusing lens and final turning mirror of the transmitting optics are mounted on a motorized goniometer cradle so that they move together as a unit. The motorized goniometer allows the direction of the input beams to be directed off-radial in order to be able to access areas which would normally block the beam paths if they were transmitted radially into the compressor flow path.

A metal framework between the optics table and a large horizontal $x-y$ traversing table formed a channel in which the laser sat. The laser was secured to the bottom of the channel and the entire assembly was mounted 


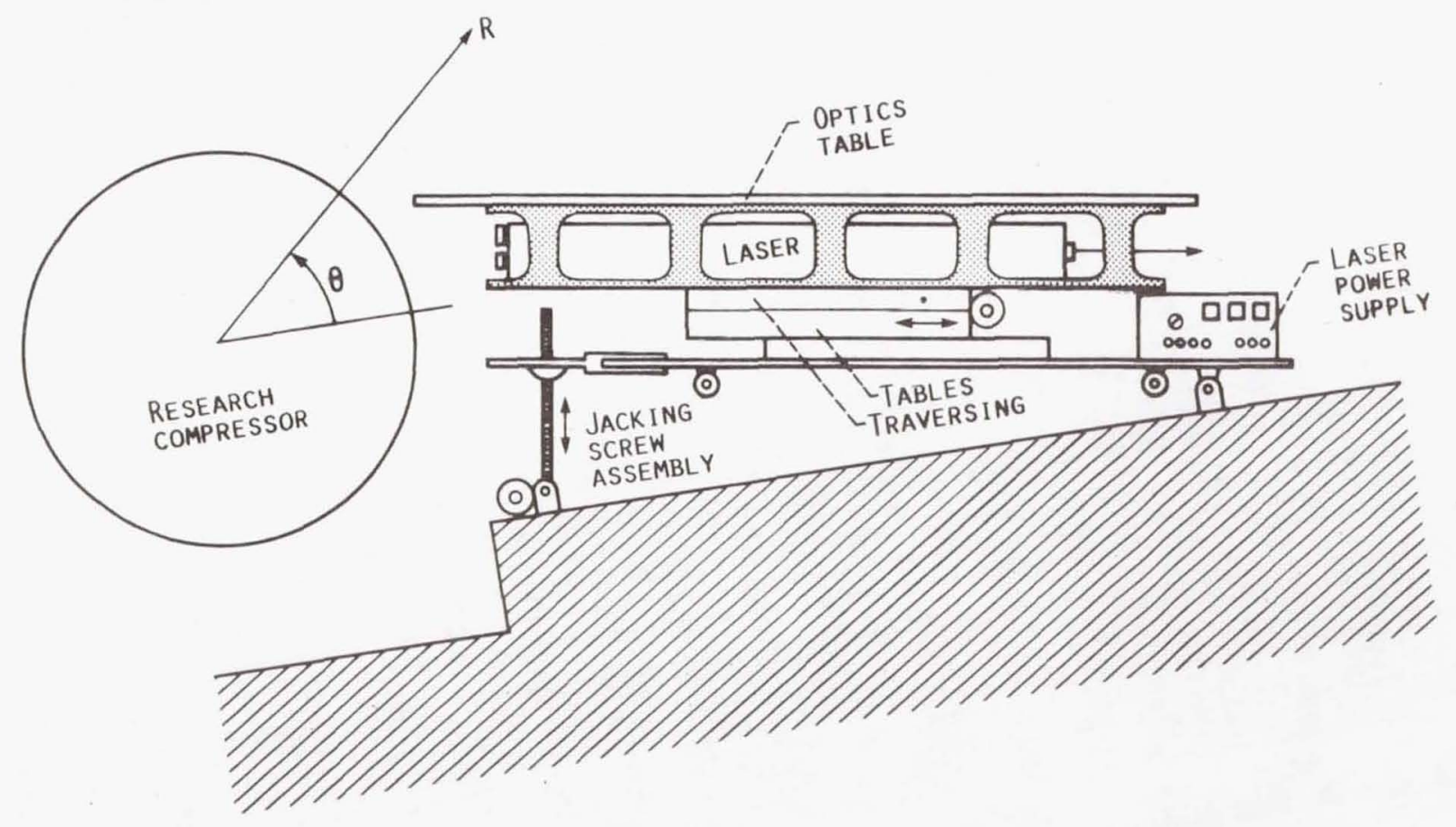

3.9 Schematic diagram of optics cart assembly 
on top of a wheeled metal cart. A motorized jacking mechanism at the front of the optics cart, in conjunction with the $x-y$ traversing tables and the motorized goniometer, enabled positioning of the probe volume at a particular axial, radial, and circumferential position within the compressor flow field, to within $\pm 0.05 \mathrm{~mm}$ axially, $\pm 0.05 \mathrm{~mm}$ radially, and $\pm 0.03^{\circ}$ circumferentially. The angular orientation of the laser beams in the $R-\theta$ plane could be controlled to within $\pm 0.01^{\circ}$ using the motorized goniometer, and the beam splitter enabled control of the angular orientation of the fringes in the $Z-\theta$ plane to within $\pm 0.03^{\circ}$ (refer to Fig. 3.6).

The optics cart was originally designed for surveying a rotor-only flow field which usually does not require circumferential traversing of the probe volume, since the rotor sweeps by the probe volume. However, the research described in this dissertation required surveying a stator flow field making circumferential traversing of the flow field necessary. The jacking screw mechanism, therefore, was adopted as a temporary modification to the optics cart to provide the capability for circumferentially traversing the probe volume through the stator flow field. A remotely controlled high-speed stepping motor was used to drive the jacking screw. Positioning of the jacking screw, however, was controlled by the operator and typically required about 30 seconds to position.

High-speed stepping motors were also used to drive the beam splitter, goniometer, and $x-y$ traversing table. An optical encoder attached to each motor shaft provided position feedback to each motor drive controller. 
The motor drives were of the accelerate-decelerate type (with regard to the output pulse train) and typically positioned the optics in about 1 second. Each motor had a "home" position to which it could be moved for remote position calibration. An 8 -bit-word microcomputer served as the interface between the motor drives and the data acquisition control minicomputer.

\section{Laser anemometer signal processor}

A commercially available counter-type laser anemometer signal processor with a $500-\mathrm{MHz}$ clock was used to process the signal bursts from the photomultiplier tube. The processor measures the transit time of a seed particle across eight fringes. To insure measurement validity and to help discriminate against noise, the processor performs several tests on each seed particle passing through the probe volume. One test is a $5 / 8$ comparison test where the transit times for crossing five and eight fringes is compared. The ratio of these times must be sufficiently close to the value of $5 / 8$ to be accepted. This test is used to reject measurements from seed particles which are accelerating as they pass through the laser probe volume. Another test performed by the processor is a sequence check such that during each signal burst the high-pass filtered signal from the photomultiplier tube must alternatively rise above a threshold level and fall below the zero level at each fringe in

order to be accepted. This test is used to reject extraneous signal noise and to reject signal bursts occurring from multiple particles or very large particles which pass through the laser probe volume. The processor also provides an additional test which attempts to discriminate signal 
bursts occurring from multiple particles or very large particles within the probe volume by requiring that the high-pass filtered signal from the photomultiplier tube does not rise above an overload level.

\section{Compressor rotor shaft-angle encoder}

The LFA system is free to acquire velocity measurements whenever a seed particle crosses the LFA probe volume, which results in the random acquisition of many velocity measurements during every rotor revolution. Therefore, a commercially available compressor rotor shaft-angle encoder was used to simplify the task of tagging each velocity measurement with the proper angular position of the rotor. The shaft-angle encoder provides a continuous measure of the rotor shaft position relative to a once-per-rev signal obtained from the rotor disk. When a velocity measurement occurs, the seed particle fringe-crossing frequency and corresponding rotor shaft position are simultaneously transmitted to the LFA system minicomputer which records them as a data pair.

The encoded angular position of the rotor is produced by a counter that is clocked by a frequency synthesizer. The frequency is adjusted near the beginning of each rotor revolution so that the number of counts for each revolution (selected by the operator) remains approximately constant. An optical sensor generates the once-per-rev pulse as a result of a passing target on the face of the rotor disk near the hub flow path. For the results cited in this dissertation the encoder counts per revolution (selected as 4400) was divided by four, which for the 22-bladed research rotor yielded 50 angular positions (shaft positions) per blade passage. 
It is important to note that the velocity measurements do not really occur at a discrete rotor shaft position, but rather occur anywhere within an interval between two adjacent rotor shaft positions. With 50 rotor shaft positions per blade passage, the interval length between shaft positions varies between $0.7 \mathrm{~mm}$ at the hub and $1.4 \mathrm{~mm}$ at the tip of the rotor blade. Therefore, in this dissertation the term shaft position is used with the understanding that measurements attributed to a rotor shaft position actually occur in an interval about that position. In order to prevent velocity data from being assigned to the wrong rotor shaft position, the data acquisition program discarded data acquired during any rotor revolution in which the encoder count for the succeeding revolution varied by more than \pm 20 counts from the desired count of 4400 . Thus, the actual average error in the rotor shaft position was less that \pm 0.0045 of a rotor shaft position.

\section{System computer}

A 16-bit-word minicomputer with $32 \mathrm{k}(\mathrm{k}=1024)$ words of core memory and hardware floating-point multiply-divide capability was used to provide automatic control of the LFA data acquisition process. The minicomputer used dual removable cartridge-type magnetic disk storage, with each disk having a capacity of 1.25 million 16-bit words. Two cathode-ray-tube type display terminals were used for monitoring the LFA data acquisition process. The minicomputer automatically controlled positioning of the laser probe volume and was interfaced to the laser anemometer signal processor and compressor rotor shaft angle encoder from which it acquired the fringe crossing frequency and rotor angular position, respectively. 


\section{EXPERIMENTAL PROCEDURE AND DATA REDUCTION}

The objective of the experimental procedure was to obtain spatially and "temporally" (i.e., rotor shaft position, not real time) detailed measurements of the rotor-wake-generated unsteady absolute-velocity field at selected sites within the research compressor stator row. With the compressor operating at design speed and maximum efficiency, a laser fringe-type anemometer (LFA) system was used to acquire ensemble-averaged measurements of the absolute velocities along two design axisymmetric stream surfaces through the stator blade row. A design axisymmetric stream surface refers to a surface of revolution on which LFA measurements were acquired, and does not represent an actual stream surface along which fluid particles travel. For each design axisymmetric stream surface, the absolute velocity measurements were acquired, spatially, from blade-to-blade across the stator pitch and from upstream through downstream of the stator blade row, and temporally, for a number of rotor shaft positions evenly distributed across several rotor pitches.

The 100 percent speed line operating characteristic of the research compressor is shown in Figure 4.1, which identifies the maximum efficiency point at which LFA survey data were acquired. From observations, the rotor speed was maintainable to within \pm 0.3 percent of design speed, and the corrected mass flow rate was maintainable to within $\pm 0.14 \mathrm{~kg} / \mathrm{sec}$. The corrected mass flow rate was calculated from a calibrated orifice plate located in the inlet ducting upstream of the plenum chamber. The overall pressure ratio was determined from a 5-element rake downstream of the stator and from the upstream plenum pressure. 

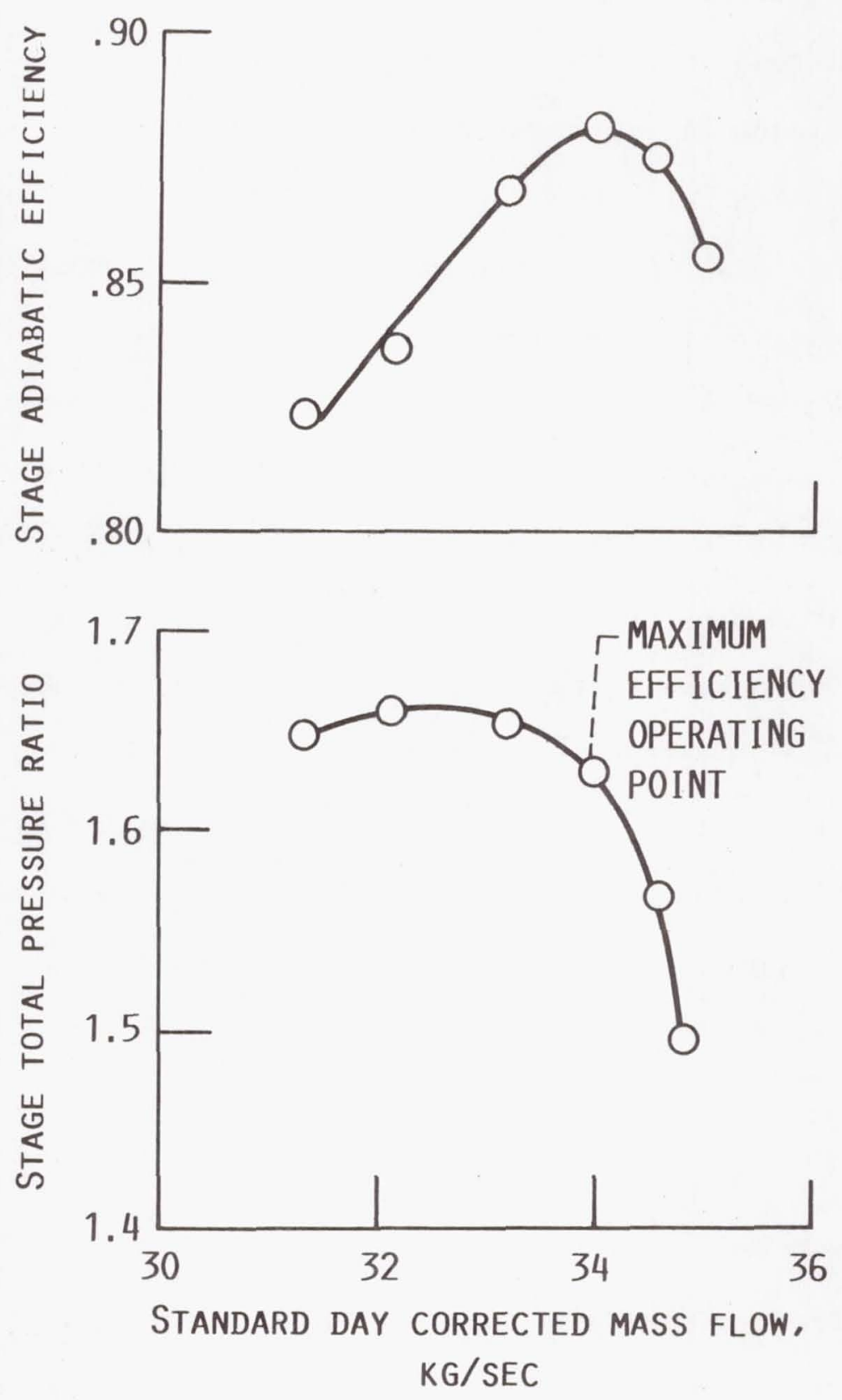

Figure 4.1 Research compressor stage 100 percent speed 1ine operating characteristic 
Extensive software written for the LFA-system minicomputer were used to support the data acquisition procedures. This software included programs to generate data files describing the research compressor flow path and the complete three-dimensional stator and rotor blade geometry, programs to allow the experimenter to prescribe complete survey information along selected design axisymmetric stream surfaces prior to beginning data acquisition, programs to allow remote positioning of the optics by the experimenter, programs to provide complete LFA-system computer control of the data acquisition procedures, and many other programs, some of which are briefly described in the succeeding sections.

Although extensive data reduction software was also available on the LFA-system minicomputer, its processing times were quite long and its memory was considerably limited as were printing and plotting capabilities. Therefore, the NASA Lewis central computing facilities were used for all reduction, tabulation, and plotting of the data presented herein. The data disks generated from the LFA-system minicomputer were copied to data tapes which could be read by the mainframe computer used to reduce the data.

\section{A. Experimental Procedure}

The experimental procedure consisted of setting up a survey file to prescribe the coordinates of points to be surveyed, following extensive setup procedures to insure accurate positioning of the probe volume, and the actual data acquisition procedures used to acquire the data. The survey setup, preliminary setup, and data acquisition procedures are described below. 


\section{Survey setup}

A computer program was used to set up the coordinates of the survey points at which laser anemometer data would be acquired prior to actually beginning data acquisition. The "survey setup program" generates a disk file consisting of the coordinates of the LFA survey points, specified along a selected design axisymmetric stream surface, and their required beam orientations. This survey file is then read by the data acquisition program which automatically sequences through the specified survey points and results in collection of the desired data.

Figure 4.2 is a meridional view of the research compressor flow path which shows the 10 and 50 percent stream surfaces along which the LA data were acquired. The dots are positioned at approximate axial locations of measurements. The complete LFA survey grids for the 10 and 50 percent stream surface surveys are shown in Figure 4.3 and the relative coordinates of the survey points are given in Table 4.1 and Table 4.2, respectively. The solid circles (dots) in Figure 4.3 indicate survey points where data were actually acquired, whereas the open circles indicate where data acquisition was attempted but data could not be acquired, or was of poor quality. Problems with window blockage, insufficient entrainment of seed particles across flow boundaries, seed particle accumulation on solid surfaces, separated flow regions, and very high flow unsteadiness contributed to an inability to acquire data at some of the survey points.

Each stator flow-field survey was divided into two separate surveys; an interblade-row survey, and an intrablade-row survey. The interbladerow survey consisted of nominally eight axial survey stations, six in 


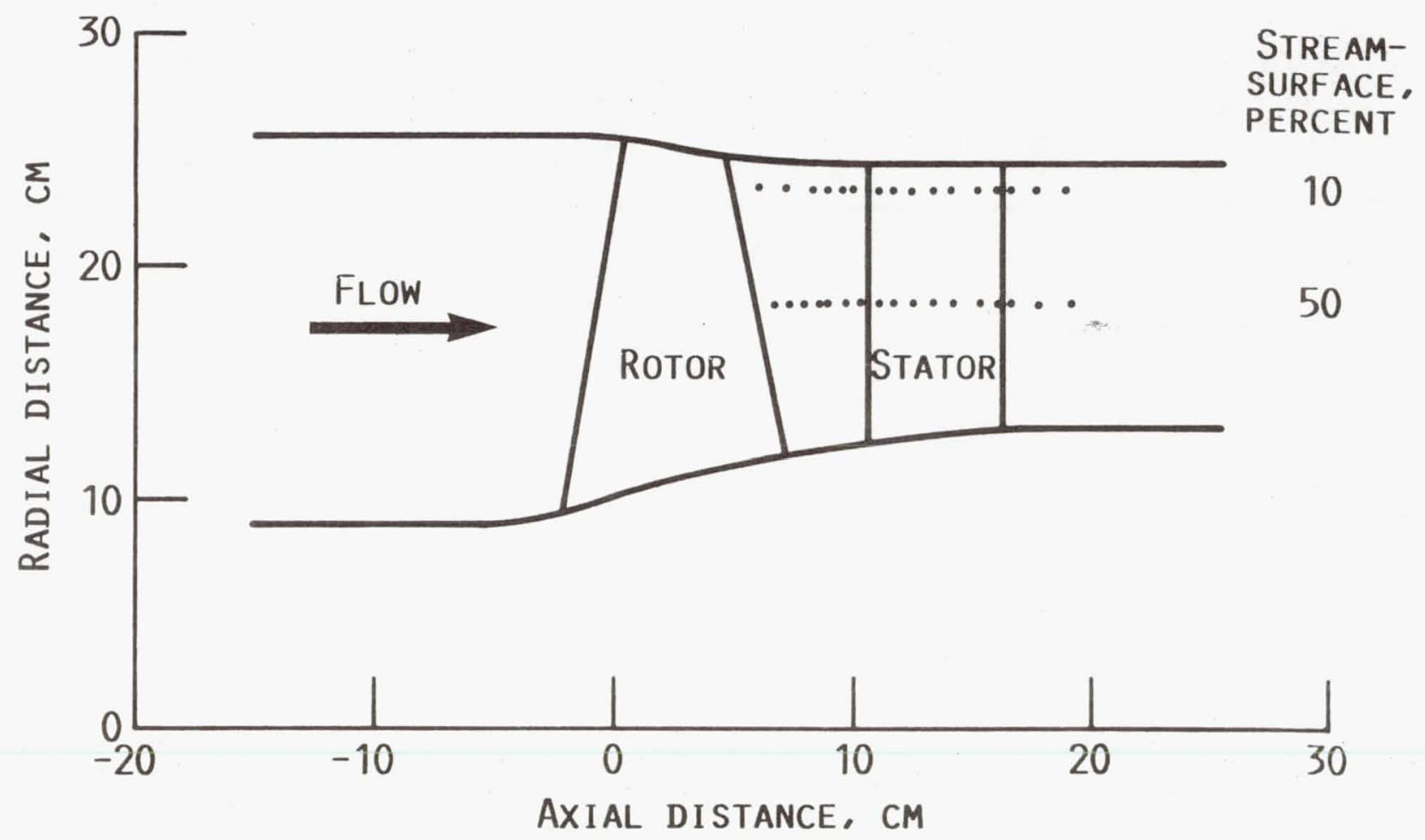

Figure 4.2 Meridional-plane view of research compressor flow path showing the 10 and 50 percent stream surfaces along which the laser anemometer data were acquired 


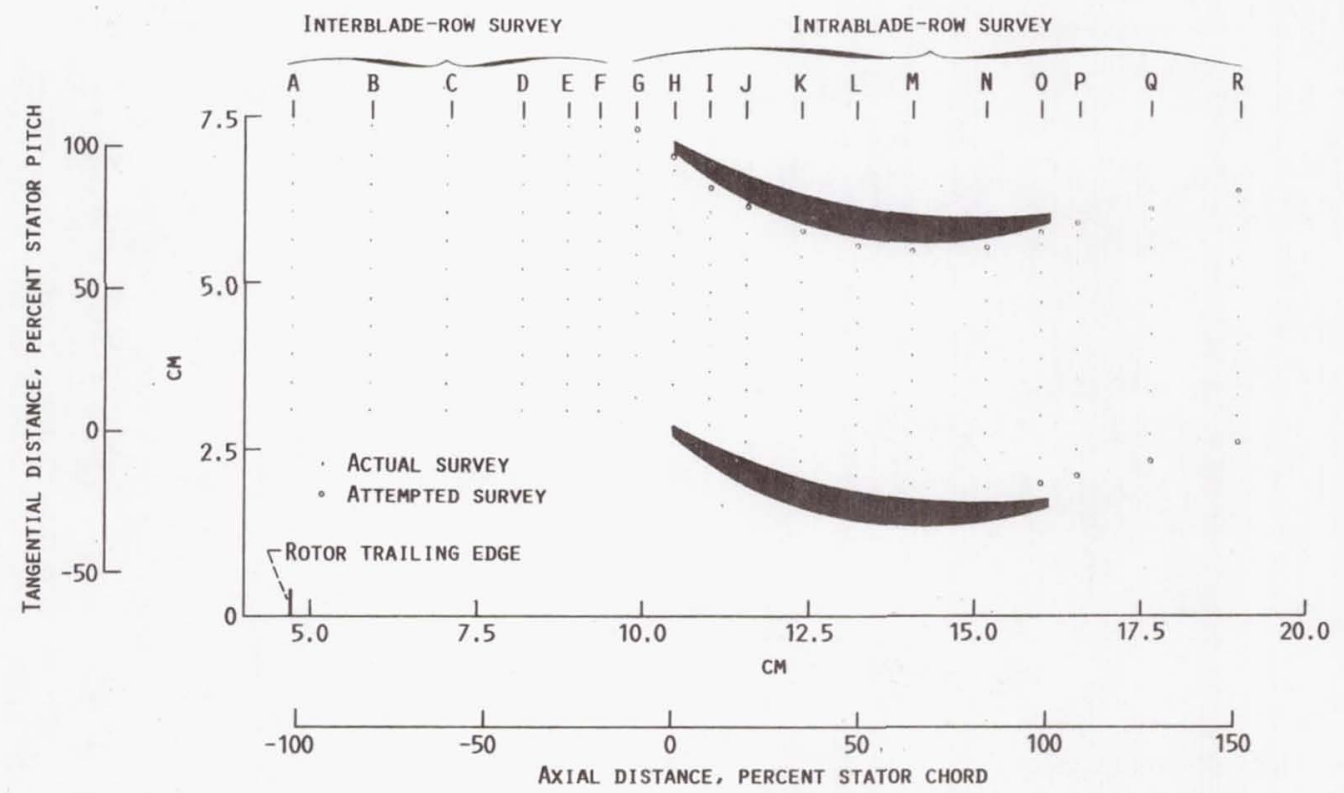

(A) 10\% STREAM SURFACE.

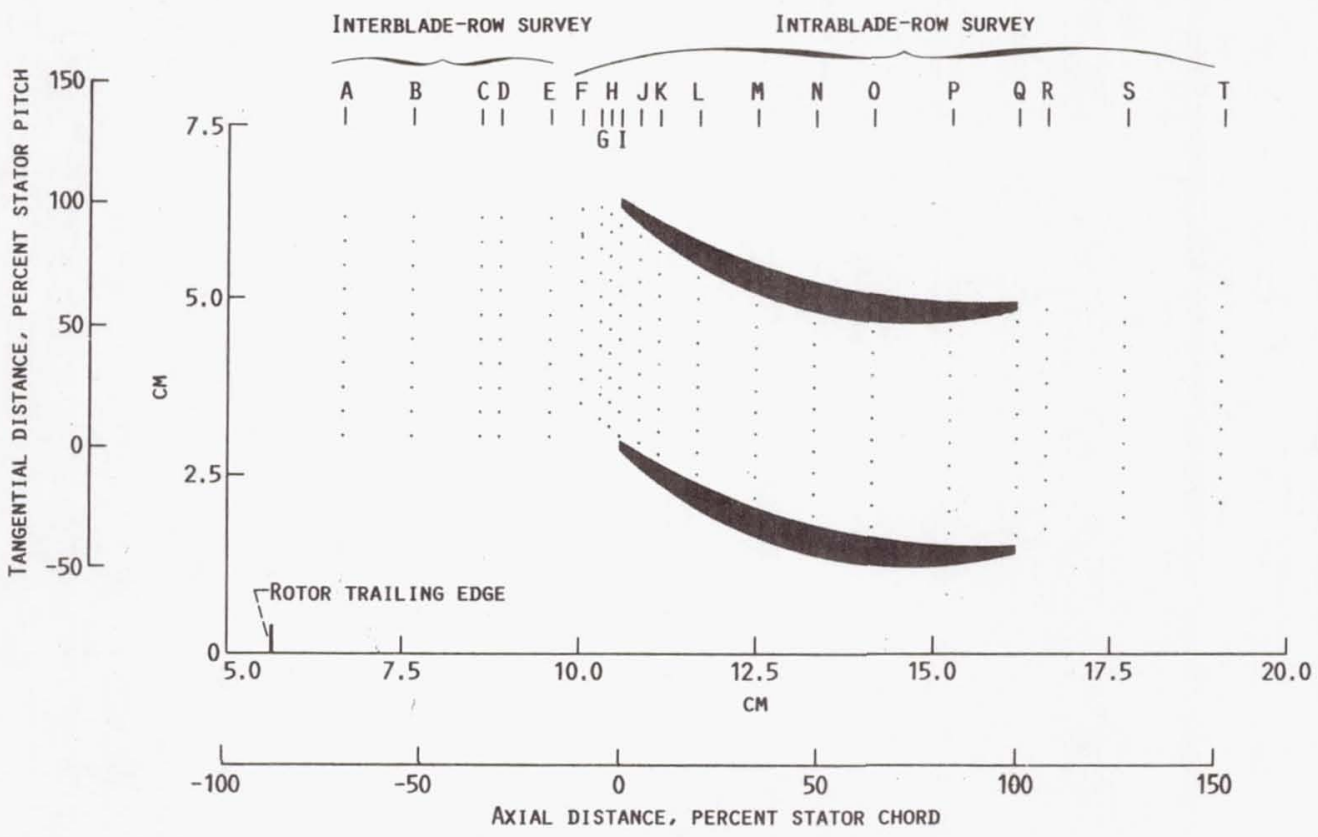

(B) $50 \%$ STREAM SURFACE.

Figure 4.3 Blade-to-blade view of the 10 and 50 percent stream surfaces showing the actual laser anemometer measurement survey grids 
Table 4.1. Relative coordinates of laser anemometer survey locations along the 10 percent stream surface (stator chord $=5.6 \mathrm{~cm}$ )

\begin{tabular}{|c|c|c|c|c|}
\hline & $\begin{array}{l}\text { AXIAL } \\
\text { SURVEY } \\
\text { STATION }\end{array}$ & $\begin{array}{l}\text { STATOR } \\
\text { CHORD } \\
\text { PERCENT }\end{array}$ & $\begin{array}{l}\text { INTERBLADE- } \\
\text { ROW GAP } \\
\text { PERCENT }\end{array}$ & $\begin{array}{l}\text { CIRCUMFERENTIAL } \\
\text { COORDINATE OF } \\
\text { SURVEY POINT }\end{array}$ \\
\hline $\begin{array}{l}\text { Interblade-row } \\
\text { survey }\end{array}$ & $\begin{array}{l}\text { A } \\
B \\
C \\
D \\
E \\
F \\
G \\
H \\
I \\
J \\
K \\
L \\
M \\
N \\
O \\
P \\
Q \\
R\end{array}$ & $\begin{array}{r}-104 \\
-82 \\
-62 \\
-41 \\
-28 \\
-20 \\
-10 \\
0 \\
10 \\
20 \\
35 \\
50 \\
65 \\
85 \\
100 \\
110 \\
130 \\
154\end{array}$ & $\begin{array}{r}0 \\
20 \\
40 \\
60 \\
\\
80 \\
\end{array}$ & $\begin{array}{l}5 \text { to } 95 \text { percent } \\
\text { of stator lead- } \\
\text { ing edge gap in } \\
10 \text { percent gap } \\
\text { increments }\end{array}$ \\
\hline
\end{tabular}


Table 4.2. Relative coordinates of laser anemometer survey locations along the 50 percent stream surface (stator chord $=5.6 \mathrm{~cm}$ )

\begin{tabular}{|c|c|c|c|c|}
\hline & $\begin{array}{l}\text { AXIAL } \\
\text { SURVEY } \\
\text { STATION }\end{array}$ & $\begin{array}{l}\text { STATOR } \\
\text { CHORD } \\
\text { PERCENT }\end{array}$ & $\begin{array}{l}\text { INTERBLADE- } \\
\text { ROW GAP } \\
\text { PERCENT }\end{array}$ & $\begin{array}{l}\text { CIRCUMFERENTIAL } \\
\text { COORDINATE OF } \\
\text { SURVEY POINT }\end{array}$ \\
\hline $\begin{array}{l}\text { Interblade-row } \\
\text { survey } \\
\text { Intrablade-row } \\
\text { survey }\end{array}$ & $\begin{array}{l}A \\
B \\
C \\
D \\
E \\
F \\
G \\
H \\
I \\
J \\
K \\
L \\
M \\
N \\
0 \\
P \\
Q \\
R \\
S \\
T\end{array}$ & $\begin{array}{r}-70 \\
-52 \\
-34 \\
-30 \\
-18 \\
-10 \\
-8 \\
-5 \\
0 \\
5 \\
10 \\
20 \\
35 \\
50 \\
65 \\
85 \\
100 \\
110 \\
130 \\
150\end{array}$ & $\begin{array}{l}20 \\
40 \\
40 \\
\\
80\end{array}$ & $\begin{array}{l}5 \text { to } 95 \text { percent } \\
\text { of stator lead- } \\
\text { ing edge gap in } \\
10 \text { percent gap } \\
\text { increments } \\
5 \text { to } 95 \text { percent } \\
\text { of local stator } \\
\text { gap in } 10 \text { percent } \\
\text { gap increments }\end{array}$ \\
\hline
\end{tabular}


the interblade-row gap between the rotor trailing edge and stator leading edge, and two at 0 and 10 percent of stator axial chord. The interbladerow gap is defined as the axial distance between the rotor trailing edge and stator leading edge at the radii corresponding to the design axisymmetric stream surface. At each of these axial survey stations, ten equally spaced circumferential survey points were specified across a stator circumferential gap. The stator circumferential gap varies with axial position and is defined as the circumferential distance across the stator flow field between the pressure and suction surfaces. Ahead of the stator leading edge, the circumferential survey points were specified from 5 to 95 percent of the stator leading edge circumferential gap in 10 percent gap increments. Therefore, upstream of the stator leading edge, the ten circumferential survey points were at the same absolute circumferential locations at each axial survey station. At the stator leading edge, and at all survey stations downstream of the stator leading edge, the circumferential survey points were specified from 5 to 95 percent of the local stator circumferential gap in 10 percent gap increments.

The intrablade-row survey consisted of nominally 15 axial survey stations between -10 to 154 percent of stator axial chord. At each of these axial stations there were ten circumferential survey points specified, equally spaced from 5 to 95 percent of local stator circumferential gap in 10 percent gap increments. Outside of the stator blade row the percent gap was referenced to the extension of the stator blade mean camber line. 
In order to verify matching between the data acquired for each survey, the 0 and 10 percent stator axial chord stations were surveyed twice, once for the interblade-row survey and again for the intrablade-row survey. The interblade-row surveys at 0 and 10 percent stator axial chord, however, could not be completed near the stator suction surface as the rotor window frame substantially blocked the collection of scattered light from seed particles. Therefore, only the interblade-row results upstream of -10 percent stator axial chord, in conjunction with the intrablade-row survey results, were used in constructing all data figures presented herein (see Fig. 4.3 and Tables 4.1 and 4.2 ).

\section{Preliminary LFA setup}

The LFA setup procedures, performed each day prior to beginning data acquisition, consisted of orienting the LFA system relative to the research compressor coordinate system, and orienting the LFA probe volume and rotor blades relative to the surveyed stator blade passage. The LFA system itself, with optics optimally aligned, was used in the following manner to accomplish the above mentioned LFA setup procedures. With the orange-pass filter removed from the optics path, thereby sensitizing the LA system to light scattered from metallic surfaces, the LFA probe volume was moved relative to known "sharp-edged" reference points until the output current from the PMT was maximized. At this point, from visual observation, the LFA probe volume was aligned to the known reference point.

To orient the LFA system to the research compressor coordinate system, the LFA system was positioned, in the above manner, such that the LFA probe volume was located at the upstream edge of the stator foot-ring, 
see Figure 3.2, the position of which was known relative to the research compressor coordinate system. The LFA system motor drive offsets were then updated, according to the difference in the measured and expected positions of the stator foot-ring reference point, such that the motor drive positioning program would reflect the probe volume position in the research compressor coordinate system.

To orient the LFA probe volume to the surveyed stator blade passage, the LFA system was positioned such that the probe volume was located at the leading and trailing edges of the lower surveyed stator blade at the radii which corresponded to the design stream surface along which the stator flow field was surveyed (refer to Figures 3.7 and 3.8 ). The laser system was then used, as described above, to determine when the LFA probe volume was positioned at the lower surveyed stator blade edges. A visual inspection was made for verification. By knowing the measured locations of the lower surveyed stator blade edges, at the radif corresponding to the design axisymmetric stream surface along which the stator flow field was surveyed, the position of the probe volume with respect to the surveyed stator blade passage could be determined with good precision. The final LFA setup procedure was to orient the rotor blades with respect to the surveyed stator blade passage. This was accomplished with the research compressor operating at design speed and at the desired survey flow conditions. Prior to determining the orientation of the rotor blades relative to the surveyed stator blade passage, the above determined stationary reference coordinates were remeasured, based on their measured nonrotating positions, to insure that they did not change after the research compressor was allowed to stabilize at the survey operating 
conditions. The LFA system was again used as a measuring tool, this time to determine the position of the rotor blades relative to the surveyed stator blade passage. The LFA probe volume was positioned at the radius which corresponded to the design stream surface along which the stator flow field was surveyed, and at the circumferential position which corresponded to the lower stator blade leading edge, as measured above. The probe volume was then moved axially away from the stator leading edge, towards the trailing edge plane of the rotor blade row, until the PMT output current was maximized, which in this case corresponded to the probe volume being positioned at the trailing edge plane of the rotor blade row. With the orange-pass filter removed from the optics path and the laser power and PMT high-voltage power supply properly adjusted, the data acquisition program was run to acquire and save on disk approximately 15000 measurements of the rotor blade trailing edge as it passed through the laser probe volume. As each measurement was acquired it was simultaneously tagged with the corresponding angular position of the rotor wheel (i.e., rotor shaft position) at which the measurement occurred. For this experiment there were 850 equally spaced rotor shaft positions distributed across 17 rotor blade passages, which resulted in 50 rotor shaft positions per rotor blade passage. Therefore, assuming that the LFA probe volume was optimally aligned to the rotor blade row trailing edge plane, there would be a clustering of measurements about every 50 shaft positions which correspond to the locations of the rotor blade edges. For all other shaft positions between rotor blade edges, the number of measurements would be zero. The shaft positions corresponding to the rotor blade edges could, therefore, be identified as the shaft positions 
which have the greatest number of measurements and which are spaced apart about every 50 shaft positions. These measured rotor trailing edge shaft positions were found to be consistently repeatable. By referencing these measured rotor trailing edge shaft positions to the blade passage in which they occurred (i.e., shaft positions from 1 to 50) an average rotor trailing edge shaft position was determined. This average rotor blade shaft position was used in subsequent surveys of the stator flow field to trigger the beginning of data acquisition, during every revolution of the rotor, to occur at the circumferential coincidence of the rotor trailing edge with the surveyed stator leading edge, and to offset each shaft position, as it was saved on disk, such that the coincident shaft position was identified as shaft position one, subsequent shaft positions were incremented from there. Therefore, for all subsequent experiments and displayed or saved results, shaft position one corresponds to circumferential coincidence of the rotor trailing edge with the surveyed stator leading edge.

Finally, the stator survey file was updated to reflect the measured locations of the surveyed stator blade edges and to reflect the current measured rotor trailing edge shaft position which would be used to trigger the beginning of data acquisition during each rotor revolution. This insured that the coordinates of all survey points were accurately positioned relative to the surveyed stator passage and that, for all survey points, the rotor blade trailing edges were accurately in sync with the lower surveyed stator blade leading edge. 


\section{Data acquisition}

The LFA system minicomputer was used to control the data acquisition procedures via an automated data acquisition program [75], which is set up to sequentially acquire data at each of the survey points specified in the survey file. At each of these survey points, the LFA system was free to acquire velocity measurements whenever a seed particle crossed the LFA probe volume, which resulted in the random acquisition of many velocity measurements during every rotor revolution. The seed particle fringe-crossing frequency, which is proportional to the particle velocity, was measured by the laser anemometer signal processor. A continuous measure of the rotor shaft position, relative to a once-per-rev signal obtained from the rotor disk, was provided by the compressor rotor shaft-angle encoder. When a velocity measurement occurred, the seed particle fringe-crossing frequency and corresponding rotor shaft position were simultaneously transmitted to the LFA system minicomputer which recorded them as a data pair. The actual recorded rotor shaft positions were referenced to the lower surveyed stator blade leading edge, as explained in the previous section.

At each survey point, nominally 30000 measurements (i.e., data pairs) were acquired at each of two fringe angles, oriented at $\pm 20^{\circ}$ of the time-averaged absolute flow angle in order to reduce flow angle biasing. The time-averaged absolute flow angle was previously determined from a series of short LFA experiments and was found to vary blade-to-blade by less than about $\pm 3^{\circ}$. Therefore, the circumferentially averaged values of the time-averaged absolute flow angle distributions were used to determine the fringe angle orientation at each axial survey station. The data at 
each survey point were recorded at one of 850 different rotor shaft positions, which were evenly distributed as 50 positions per blade passage across 17 of the 22 rotor blade passages.

After all the requested data for a particular survey point had been acquired, the following information was stored on the LFA system disk storage medium: the number of measurements, the sum of the seed particle fringe-crossing frequencies, and the sum of the frequencies squared, at each of the 850 rotor shaft positions. In addition, "background information" was also recorded on disk which included; the coordinates of the survey point position, the number of rotor shaft positions and rotor blades surveyed, the total number of measurements requested, the plenum temperature, and the research compressor operating conditions (i.e., pressure ratio, weight flow, and rotational speed). The LFA data were eventually transferred from the data disks to a data tape which could be read by the mainframe computer used to reduce the data.

As previously mentioned in the section describing the LFA setup procedures, the data for each stream surface survey were acquired in two parts, an interblade-row survey and an intrablade-row survey. The interblade-row surveys for each stream surface were accomplished in the fall season (i.e., October), about five months prior to beginning the intrablade-row surveys which were accomplished during the later part of the winter season (i.e., March). The reason for the large time difference between acquiring the interblade-row and intrablade-row surveys was due to facility scheduling and hardware availability problems. Fabrication of the stator window was not complete at the time the stator surveys were scheduled. Therefore, in order to keep on schedule, it was decided to go 
ahead and accomplish the interblade-row surveys with the rotor window in place. The rotor window, however, did not extend much past the stator leading edge (see Figure 3.7 ), and therefore the intrablade-row surveys had to be postponed until the stator window was available. Once the stator window was available, the intrablade-row surveys were initiated. An interblade-row survey required about 6 hours to complete, and an intrablade-row survey required about 12 hours to complete. Approximately 4 hours were required to complete the preliminary setup procedures. On the average, each survey point required about 3 min to complete, which included the time required to position the optics, write the data to disk, and print the survey log. In general, the data for each interblade-row and intrablade-row survey were acquired with the rig in continuous operation. However, brief shutdown periods were occasionally required in order to clean the laser window or to recheck reference points. Although a substantial span of time elapsed between completion of the interbladeand intrablade-row survey measurments, there appears to be good continuity between all results. In any case, the conclusions obtained from these survey results are specific to measurements acquired completely within either the interblade- or intrablade-row surveys, and therefore are not affected by any possible mismatch between these surveys.

The PMT supply voltage and laser power were set at nominally $1600 \mathrm{~V}$ and $1.5 \mathrm{~W}$, respectively, which resulted in a typical data rate of about 1000 measurements per second. However, the data rate varied from less than one measurement per second to as much as 2500 measurements per second, depending on various factors, such as; insufficient seed particle entrainment across flow boundaries which reduces seed particle density in 
the laser probe volume, proximity to solid surfaces and window fouling which degrades signal to noise ratio, and low velocity regions which reduce the number of seed particles crossing the probe volume per unit of time. In order to minimize the overall time to acquire data for a complete survey, data acquisition was suspended if the data rate could not be maintained above about 50 measurements per second, However, in cases where the data was considered important enough to acquire even though the data rate was below 50 measurements per second, the number of measurements requested was reduced to as few as 10000 in order to obtain some measure of the velocity and yet still minimize the overall data acquisition time.

\section{B. Data Reduction}

The first level of data reduction consisted of determining the velocity components which characterize the fundamental nature of the unsteady-deterministic and random features of the flow field. These velocity components were then used to calculate all other results presented herein, including the rotor-and stator-relative time-average velocities, and the velocity correlations associated with Adamczyk's average passage model. In order to facilitate interpretation of the results, a brief summary of Adamczyk's average passage model is presented herein. For all calculations, density fluctuations were neglected as there was no means of measuring the time-resolved density. The symbols used in the equations are defined in the Symbols and Notation section. The relationships between the actual laser anemometer measurements and the various averages used in the data reduction procedures are provided in Figure 4.4 which will be referred to in the ensuing sections. 


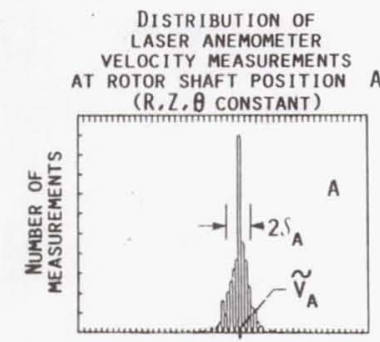

VELOCITY, V
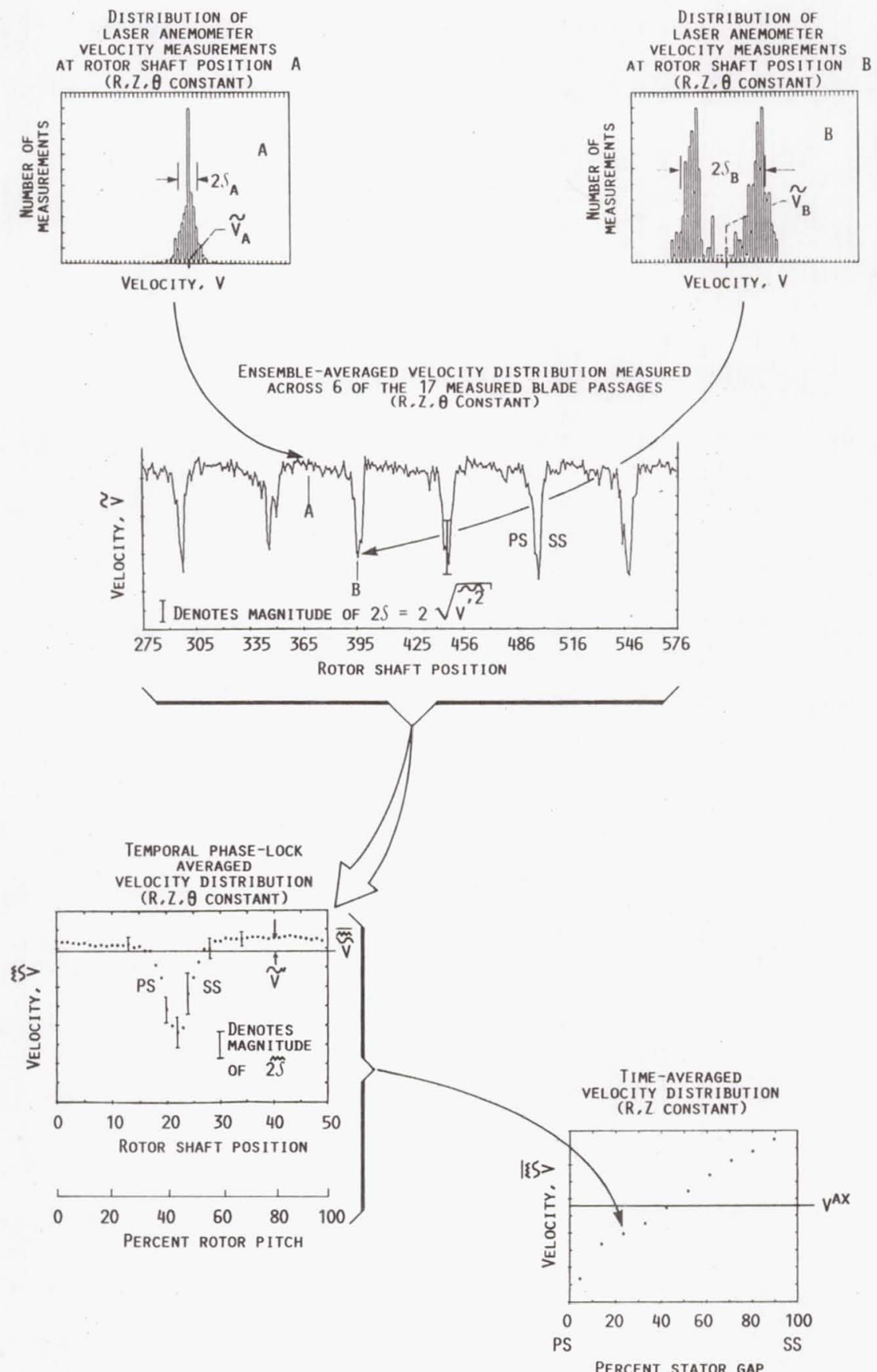

Figure 4.4 Illustration showing the relationship between the actual velocity measurements and the various averages used in the data reduction process 


\section{Velocity components}

The measured seed particle fringe crossing frequencies are converted to velocity by multiplying by the fringe spacing. The velocities are then converted to standard day conditions using the equation

$v_{c}=v \sqrt{\frac{T_{s}}{T_{p}}}$

where $V_{c}$ is the corrected velocity, $T_{p}$ is the plenum temperature, and $T_{s}$ is the standard-day temperature. In all subsequent equations $V$ will always refer to the standard-day corrected velocity and, therefore, the subscript $c$ will be eliminated henceforth.

As previously mentioned, the laser anemometer system acquires velocity measurments over many successive rotor revolutions which results in a distribution of velocity measurements at every surveyed rotor shaft position. Examples of two such velocity distributions acquired at different rotor shaft positions are provided in the upper two plots of Figure 4.4. Each measured velocity distribution contains information about both the unsteady-deterministic (i.e., rotor wake) flow-field features and the "random" unsteadiness. Because the flows in turbomachinery are nonstationary, "ensemble averaging" [78] is required in order to decouple the unsteady-deterministic flow-field features from the "random" fluctuations. For the purpose of this thesis, when ensemble averaging, an experiment is defined as all measurements acquired during a given rotor revolution. As measurements are acquired during each rotor revolution, the LFA data acquisition system automatically sums the measured 
particle fringe crossing frequency and its square at every rotor shaft position. Therefore, the ensemble average velocity and corresponding variance are readily determined at each rotor shaft position as

$\widetilde{v}=\sum_{i=1}^{n} \frac{v_{i}}{n}$

$\underset{v^{\prime}{ }^{2}}{\sim}=\frac{\left[\sum_{i=1}^{n}\left(v_{i}-\widetilde{v}^{2}\right)^{2}\right.}{(n-1)}=\frac{\left(\sum_{i=1}^{n} v_{i}^{2}-\tilde{n v^{2}}\right)}{(n-1)}=S^{2}$

where the superscript $\sim$ denotes the ensemble average, $v_{i}$ is the instantaneous velocity measured at a particular rotor shaft position during a given rotor revolution, and $n$ is the number of measurements acquired at that particular rotor shaft position. Since there were typically 30000 measurements acquired for each measured component, and assuming these measurements were equally distributed across al1 850 measured rotor shaft positions, there would be an average of $n=35$ measurements per rotor shaft position. A typical distribution of ensemble-averaged velocities across 6 of the 17 surveyed rotor blade passages is shown in the middle plot of Figure 4.4 (i.e., third plot from the top).

The ensemble-averaged velocity components in the research compressor coordinate system can be calculated, at every rotor shaft position of each survey point, using the ensemble-averaged results determined from runs made at multiple beam orientations. The research compressor coordinate system and LFA beam geometry orientation are shown in Figure 4.5. The measured velocity component $V_{m}$ lies along line $A A$, which is in the 

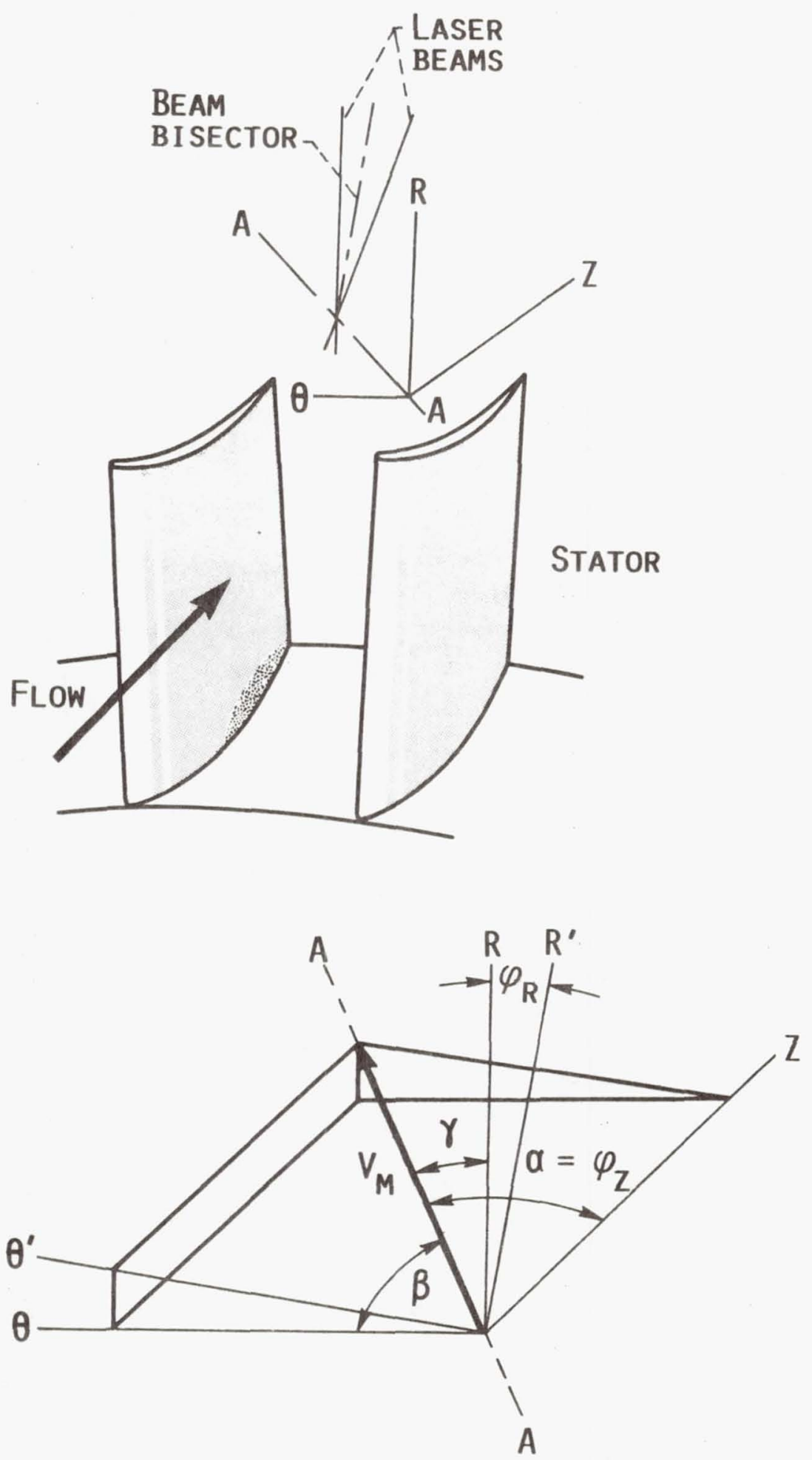

Figure 4.5 Research compressor coordinate system and laser beam geometry orientation 
plane of the beams and perpendicular to the bisector of the crossing beams. The beam bisector can be deflected in the off-radial direction by the goniometer mirror (see Fig. 3.6). The beam bisector is restricted to the $(R, \theta)$ plane, and the deflection angle is denoted by $\varphi_{R}$. The rotatable beam splitter is used to rotate the direction of the fringe normals about the $R^{\prime}$-axis (which is aligned with the beam bisector). The angle between the fringe normals and the $Z$-axis is denoted by $\varphi_{Z}$ and is measured in the $\left(Z, \theta^{\prime}\right)$ plane. The $z, \theta, r$ velocity components are related to the measured velocity components through the following three equations.

$V_{z} \cos \alpha_{m}+V_{\theta} \cos \beta_{m}+V_{R} \cos \gamma_{m}=V_{m}$

where subscript $m$ is assigned the values $1,2,3$, corresponding to each different beam orientation, and

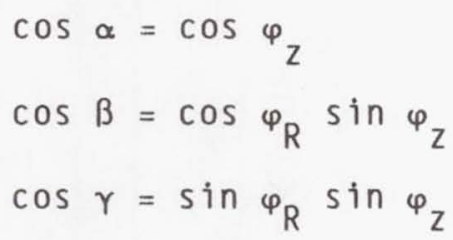

For the present investigation, there were only two runs made at different $\varphi_{Z}$ angles. Therefore, assuming $\varphi_{R}=0$, the following two equations can be used to calculate the axial and tangential components. $v_{z} \cos \alpha_{m}+v_{\theta} \cos \beta_{m}=v_{m}$

In practice $\varphi_{R}=0$ for most survey points. However, near the stator surface, the $\varphi_{R}$ angles for the two runs are equal, but are set to some nonzero value in the range $-6^{\circ}$ to $+12^{\circ}$ (pressure to suction surface, respectively) in order to eliminate beam blockage due to the window frames. Thus, the calculated tangential component of velocity actually 
lies along the $\theta^{\prime}$ direction when $\varphi_{R} \neq 0$. Although this

introduces an additional error source in the measurements, it was considered a reasonable sacrifice in order to obtain some indication of the nature of the flow field close to the stator surface, which would otherwise not be possible. Since the cosine of 12 degrees is 0.9781 , the difference between the calculated velocity in the $\theta^{\prime}$ direction and the velocity in the $\theta$ direction ( 2.2 percent) was considered acceptable.

The ensemble-averaged axial and tangential velocity components are calculated from the ensemble averages of the measured velocity components using the ensemble averaged form of Equation (4.5).

$\widetilde{v}_{z} \cos \alpha_{m}+\widetilde{v}_{\theta^{\prime}} \cos \beta_{m}=\widetilde{v}_{m}$

The total absolute ensemble-averaged velocity, therefore, is

$\widetilde{v}_{T}=\sqrt{\left(\widetilde{v}_{z}^{2}+\widetilde{v}_{\theta^{\prime}}^{2}\right)}$

Earlier investigations [79] have demonstrated the periodicity of the flow field between the rotor passages of this research compressor.

Figure 4.6 shows, at several different survey locations, ensemble-averaged axial-velocity profiles measured across each of 17 rotor blade passages, plotted to the same scale. These measurements, acquired during the scope of this research program, support the periodicity of the flow field between the rotor blade passages of this research compressor. Therefore, as standard practice, all ensemble-averaged velocity components presented herein are temporally phase-lock averaged as follows.

$$
m_{G_{j}}=\frac{\sum_{j=1}^{N_{R P}} G_{j, i}}{N_{R P}}
$$




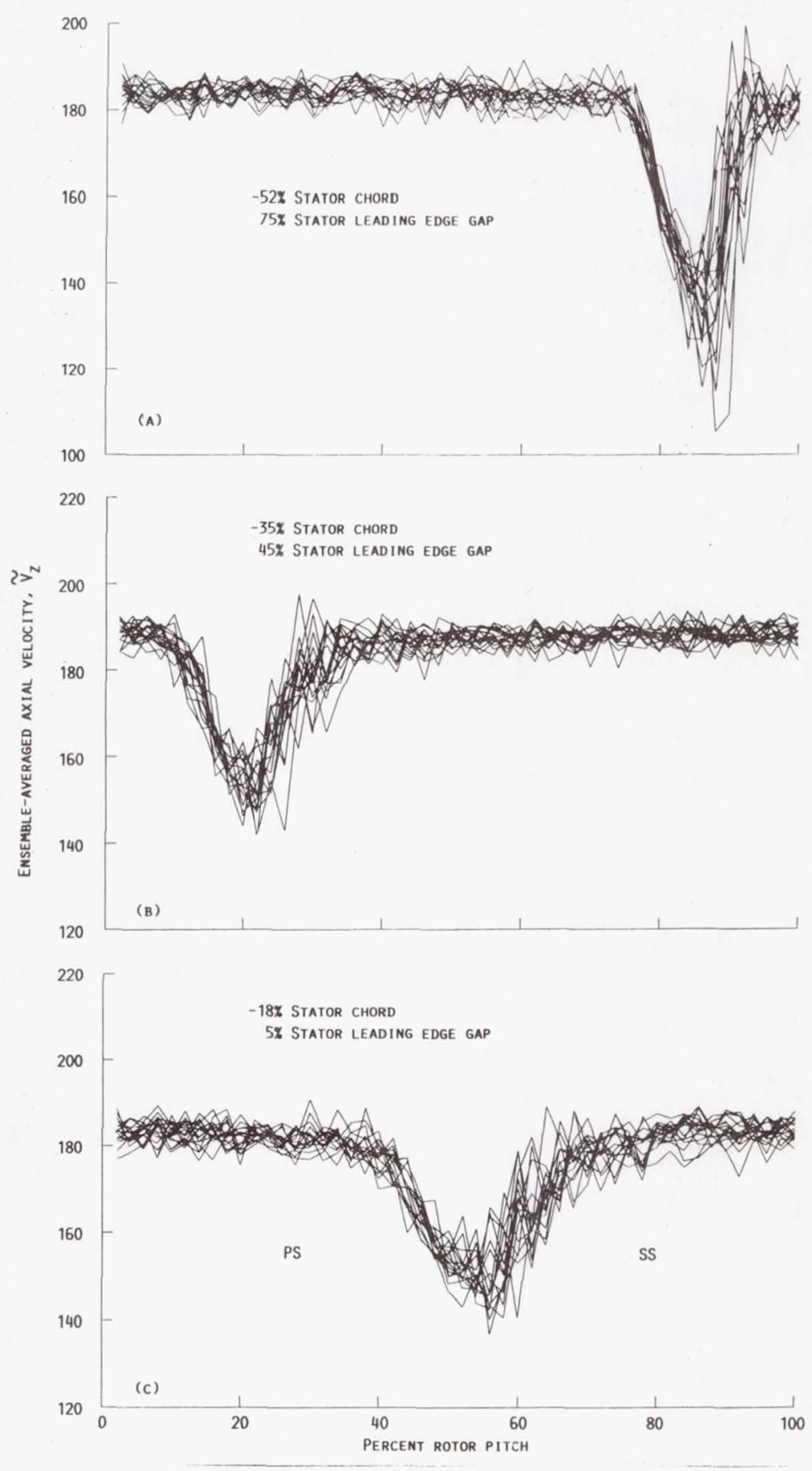

Figure 4.6 Periodicity of rotor flow field 
where $G$ represents any flow-field parameter (e.g., $\widetilde{V}$ or $\tilde{V^{\prime}}{ }^{2}$ ), the subscript $j=1$ to 50 denotes a particular shaft position measured relative to the suction surface of the $i$ 'th rotor passage, the superscript $\mathrm{m}$ denotes the temporal phase-lock average, and $\mathrm{N}_{\mathrm{RP}}$ is the total number of rotor passages surveyed (i.e., 17 passages). Since the ensemble-averaged axial and tangential velocities were determined from the measured data at 850 rotor shaft positions, equally distributed across 17 of the 22 rotor blade passages, the successive application of Equation (4.8) results in a description of the flow field in a representative rotor passage at 50 equally spaced shaft positions across the rotor passage (e.g., second plot from the bottom of Fig. 4.4). If all 30000 measurements were equally distributed across these 50 rotor shaft positions there would be an average of 600 measurements per shaft position. Note that all velocity components are temporally phase-lock averaged after the ensemble-averaged velocities and their corresponding variances are determined. This was done in an attempt to preclude any aperiodic flow-field variations, such as due to rotor passage geometry differences, from occurring in the temporally phase-lock averaged results. The temporally phase-lock averaged velocity and variance are assumed to characterize the fundamental nature of the typical unsteady-deterministic and random features, respectively, of the flow field, and therefore are used to determine all other reduced flow-field quantities, including the velocity correlations.

The lower plot of Figure 4.4 shows a typical distribution of time-averaged velocity measurements across a stator circumferential gap at one axial survey location. The temporal-phase-lock-averaged velocity 
measurements at each gap-wise location are used in determining the corresponding time-averaged velocities in the absolute (i.e., stator-relative) frame of reference (see Appendix B). The difference between the temporal-phase-lock-averaged results and the time-averaged results provides an estimate of the deterministic velocity fluctuations. The circumferential average of the gap-wise distribution of time-averaged velocities at each axial survey location provides an estimate of the corresponding axisymmetric velocity.

\section{Summary of average-passage mode 1}

In the derivation of the average-passage system of equations, Adamczyk [7] assumed that the absolute velocity field, with respect to a given blade row, could be decomposed in the following manner. First, Adamczyk assumed that the absolute velocity field could be decomposed as, in vector notation,

$\mathcal{V}=\tilde{\mathcal{V}}+\mathcal{V}^{\prime}$

where $\widetilde{q}$ is the ensemble-averaged (unsteady-deterministic) component, and $\mathcal{q}^{\prime}$ is the random fluctuating component. Next, Adamczyk assumed that the ensemble-averaged velocity field could be decomposed as

$\tilde{\mathcal{V}}=\overline{\widetilde{q}}+\tilde{\mathcal{V}}^{\prime}$

where $\overline{\widetilde{q}}$ is the time-averaged component, and $\widetilde{\mathcal{V}}^{\prime}$ is the deterministic fluctuating component. Finally, Adamczyk assumed that the time-averaged velocity field could be decomposed as

$\overline{\widetilde{q}}=\frac{\prime \prime \prime \prime \prime}{\widetilde{\mathcal{V}}}+\overline{\widetilde{q}}^{\prime}$ 
where $\frac{\frac{\prime \prime \prime \prime}{\widetilde{q}}}{\widetilde{q}}$ is the passage-to-passage averaged (periodic) component, and $\overline{\widetilde{V}}^{\prime}$ is the passage-to-passage aperiodic component. The passage-to-passage averaged component describes a steady-state flow field which is the same in each blade-to-blade passage of a specific blade row. The passage-topassage aperiodic component arises from differing rotor or stator blade counts in successive stages. In a single-stage turbomachine the aperiodic component, $\overline{\widetilde{v}}^{\prime}$, would be zero, provided passage-to-passage flow variability is not introduced by passage-to-passage geometry differences (e.g., due to manufacturing tolerances of installation). Combining all of these separate velocity decompositions together yields,

$\mathcal{V}=\frac{\prime \prime \prime \prime}{\widetilde{q}}+\frac{\tilde{q}^{\prime}}{\widetilde{\mathcal{V}}^{\prime}}+\widetilde{\mathcal{V}}^{\prime}+\mathcal{V}^{\prime}$

It should be noted that all averages in the above equation are density weighted averages, according to Adamczyk's derivation. Adamczyk then substituted the above velocity decomposition into the Navier-Stokes equations and, in a manner analogous to Reynolds averaging the Navier-Stokes equations, performed the following averages.

1. An ensemble average to decouple the unsteady-deterministic flow-field features from the random unsteadiness.

2. A time average to decouple the steady state flow-field features from the deterministic unsteadiness.

3. A phase-1ock average to decouple the passage-to-passage periodic flow-field features from the passage-to-passage aperiodic flow-field features. 
As a result, the average-passage system of equations was developed. From the derivation of the average-passage system of equations, the following second-order tensor was identified.

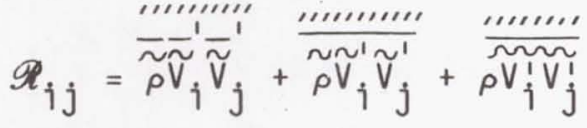

where subscripts $i$ and $j$ are assigned the values 1,2 , and 3 , which correspond to the axial, tangential, and radial coordinates, respectively. The variable $\rho$ is the fluid density, $\mathscr{x}_{i j}$ is the total apparent stress, $\underset{\rho}{\rho} \vec{v}_{i}, \widetilde{v}_{j}$ is the stress due to passage-to-passage aperiodicity, $\frac{\ldots}{\sim} \widetilde{V}_{i}^{\prime} \widetilde{V}_{j}^{\prime}$ is the stress due to deterministic unsteadiness, and $\widetilde{\rho V ! V !}$ is the stress due to random unsteadiness. This total apparent-stress tensor is generic to the average-passage system of equations, and along with body forces and energy terms, its evaluation constitutes the closure problem for this equation system.

Since the data presented herein were acquired in only one stator passage of a single-stage compressor, there is no measure of stator passage-to-passage aperiodicity. Therefore, the aperiodic stress term of Equation (4.10), $\underset{\rho}{\stackrel{\sim}{\sim} \widetilde{v}_{i}^{\prime} \widetilde{v}_{j}^{\prime}}=0$. In addition, although the measured flow field is compressible, there was no means of measuring the time-resolved density, therefore, Equation (4.10) cannot be identically calculated from the measured data. However, if the density fluctuations are negligible compared to the velocity fluctuations, we can rewrite Equation (4.10) as $\mathscr{R}_{i j}=\overline{\tilde{\rho}}\left(\overline{\widetilde{V}_{i}^{\prime} \widetilde{V}_{j}^{\prime}}+\overline{\widetilde{V_{i}^{\prime} V_{j}^{\prime}}}\right)$ 
The following sections describe the procedures and equations used to resolve the correlations of the deterministic and random velocity fluctuations (i.e., $\overline{\widetilde{v}_{i}^{\prime} \widetilde{v}_{j}^{\prime}}$ and $\overline{\widetilde{v_{i}^{\top} V_{j}^{\prime}}}$, respectively).

\section{Deterministic-velocity correlations}

A possible approach for further decomposing the deterministic-velocity correlations, $\overline{\tilde{v}_{i}^{\prime} \tilde{v}_{j}^{\prime}}$, which might be useful for developing a model of the deterministic-velocity correlations was proposed by Adamczyk et al. [69]. Drawing from an analogy to gust theory [80], Adamczyk further decomposed the absolute deterministic velocity component as

$$
\begin{aligned}
& \widetilde{\mathcal{V}}(\mathrm{R}, \theta, z, \mathrm{t})=\mathcal{V}^{\mathrm{AX}}(\mathrm{R}, \mathrm{z})+\left[\mathcal{V}^{\mathrm{S}}(\mathrm{R}, \theta, z)-\mathcal{V}^{\mathrm{AX}}(\mathrm{R}, \mathrm{z})\right] \\
& +\left[\mathcal{V}^{\mathrm{R}}(\mathrm{R}, \theta-\omega \mathrm{t}, \mathrm{z})-\mathcal{V}^{\mathrm{AX}}(\mathrm{R}, \mathrm{z})\right]+\mathcal{V}^{\mathrm{A}}(\mathrm{R}, \theta-\omega \mathrm{t}, \mathrm{z})+\mathcal{V}^{U}(\mathrm{R}, \theta, z, \mathrm{t})
\end{aligned}
$$

where, with respect to the current research compressor, $\mathscr{V}^{A X}$ is the axisymmetric velocity, $\mathcal{Q}^{R}$ is the absolute velocity field as observed in a frame of reference fixed to the rotor blade row (i.e., describes the incident gust), $\mathscr{V}^{S}$ is the corresponding velocity field observed in a frame of reference fixed to the stator blade row (i.e., the interacted velocity field), $\mathcal{Q}^{U}$ is the component of velocity which is unsteady in either frame of reference (i.e., response of the interacted field to the incident gust), $\mathcal{V}^{A}$ is the component of velocity which is unsteady in the rotor frame of reference (due to spatial aperiodicity of the stator flow field, and rotor geometry induced flow-field variations), and $t=\frac{(n-1)}{\left(N_{S P} N_{R}\right)} \frac{2 \pi}{\omega}$

where $n$ denotes a particular rotor shaft position, $N_{R}$ is the number of rotor blades, $N_{S P}$ is the number of rotor shaft positions per rotor 
blade passage ( $N_{S P}=50$ for this rotor), and $\omega$ is the angular speed of the rotor. For the test compressor used in this research program $\mathcal{Q}^{\mathrm{A}}$ is assumed negligible, and therefore was eliminated by temporally phase-lock averaging, as explained previously.

Fixed to the stator frame of reference the velocity $\mathcal{V}^{\mathrm{s}}$ will appear steady in time, while the components $\mathcal{V}^{\mathrm{R}}$ and $\mathcal{V}^{\mathrm{U}}$ will appear unsteady in time. Therefore, if we define the velocity component $\mathcal{q}^{\mathrm{I}}$ as $\mathcal{V}^{I}=\left[\mathcal{V}^{R}(R, \theta-\omega t, z)-\mathcal{V}^{\mathrm{AX}}(R, z)\right]$

then the deterministic-velocity correlations which appear in the average-passage equation system associated with the stator blade row can be obtained by forming the time average, relative to the stator blade row, of $\left(\mathcal{V}^{\mathrm{I}}+\mathcal{V}^{\mathrm{U}}\right)^{2}$, assuming density fluctuations are negligible. The result, in tensor notation, is

$\overline{\tilde{v}_{i}^{\prime} \tilde{v}_{j}^{\prime}}=\overline{v_{i}^{I} v_{j}^{I}}+\underbrace{\overline{v_{i}^{I} v_{j}^{U}}+\overline{v_{i}^{U} v_{j}^{I}}}_{\text {TDVC }}+\frac{\overline{v_{i} v_{j}^{U}}}{2 \text { ISVC }}$ SDVC

where the subscripts $i, j$ take on the values 1,2 , and 3 , corresponding to the axial, tangential, and radial velocity components, respectively. The first term on the right of the equal sign are the correlations of the deterministic-velocity fluctuations associated with the rotor-relative time-averaged rotor wake (i.e., incident gust), and may be thought of as representing the deterministic unsteadiness which might be present in the absence of rotor/stator interactions. The remaining terms on the right of the equal sign represent the stators response to the incident rotor-wake 
gust. The meaning of the acronyms below each term of Equation (4.14) are explained in a later section.

The temporally phase-lock averaged velocity field, determined using Equation (4.8), contains all information about the total deterministic unsteadiness, which is a function of $r, z, \theta, t$ (where $t$ is a function of rotor shaft position, not real time). The incident velocity field components, determined using Equation (11.1)( see Appendix B), are independent of circumferential position, $\theta$, and provide the necessary information about the incident rotor-wake gust. Therefore, the total-deterministic- and incident-velocity correlations are calculated by first determining their respective fluctuating velocity components in the research compressor coordinate system. Then, at each spatial survey point, the square of the fluctuating velocity components at every rotor shaft position are determined. Finally, these results are time averaged in the stator frame of reference (see Appendix B) to yield the corresponding total-deterministic- or incident-velocity correlations at every spatial survey point. Thus, the total-deterministic-velocity correlations are determined as

$\overline{\tilde{V}_{i}^{\prime} \tilde{V}_{j}^{\prime}}=\overline{(\tilde{\widetilde{v}}-\overline{\tilde{\widetilde{v}}})_{i}(\tilde{\tilde{V}}-\overline{\tilde{v}})_{j}}$

and the incident-velocity correlations are determined as

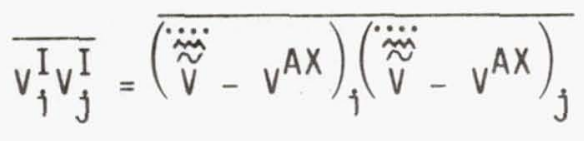

where superscripts $\sim n$, mm, $\cdots \cdots,-$, refer to ensemble average, temporal phase-lock average, rotor-relative time average, and stator-relative time average, respectively. The corresponding 
axisymmetric values of the total deterministic-velocity correlations are determined from arithmetically averaging the results determined from Equation (4.14) for all circumferential survey points at each axial survey station.

\section{Turbulent-velocity correlations}

In Equation (4.10), the term representing the turbulent-velocity correlation consists of three components (see also Eq. (4.11)). These three components are essentially the stator-relative time averages of the axial and tangential components of the Reynolds normal stresses and the Reynolds shear stress. Since a single component laser anemometer system was used during this research program to acquire the data, the Reynolds shear stress component could not be determined. Furthermore, at each survey point, velocity measurements were made at only two beam orientations, which were acquired independently of each other. Therefore, it was not possible to calculate the standard deviation of the velocities for other than the measured velocity components. However, a procedure to estimate the upper and lower bounds of the standard deviation of the velocity components in the axial and tangential directions is explained in Appendix C. Unfortunately, these bounds are extremely large and therefore they provide very little useful information. Therefore, the standard deviations of the actual measured velocity components are generally used to provide information about the nature of the turbulent-velocity correlations. 


\section{PRESENTATION AND OISCUSSION OF DATA}

The results of the LFA measurements acquired along the 10 and 50 percent axisymmetric stream surfaces are presented and discussed in this section. The results are presented in graphical form only, including contour maps which are frequently relied upon in order to help assimilate the large amounts of data involved. All measured data points are graphed with a symbol marking the actual data point and statistical error bars which represent the 95 percent confidence intervals. Contour maps are constructed to present the results across two blade passages in order to afford better visualization of the flow patterns. For contour plots of the time-resolved data which are not periodic from passage to passage, the flow field in any other passage can be determined from the results of the measured stator passage through their phase relationship with the rotor. In constructing the two-passage contour plots the contour plotting program has no knowledge of the presence of the middle stator blade of the contour plot, and therefore only the upper and lower stator blades should be used to infer conclusions about the results near the stator blade surfaces. The actual LFA measurements are stored on magnetic tape which is available for distribution.

The unsteady flows which will be discussed herein are classified into two categories; (1) deterministic unsteadiness, and (2) turbulence. Deterministic unsteadiness refers to the rotor-wake-generated unsteadiness caused by the periodic chopping and subsequent transport of rotor wakes through the stator blade row. Turbulence, in the context of this discussion, refers to any unsteady flow fluctuations which are not 
correlated with the blade passing frequency, for example; global flowfield fluctuations, vortex shedding from blades, shock induced flow oscillations, and purely random flow fluctuations.

In typical turbomachines, the unsteadiness caused by the relative motion between blade rows is normally due to both potential flow-field interactions and viscous interactions due to wake chopping. However, as previously mentioned, the data presented herein were acquired within a compressor designed for minimal acoustical interactions, which was accomplished by increasing the spacing between the blade rows. As a result, the interactions betwęen the potential flow fields of each blade row were minimized. Therefore, only viscous interactions due to deterministic (i.e., rotor-wake-generated) unsteadiness and turbulence are present in the results contained herein.

As previously mentioned (Section IV.B.4), only bounds on the minimum and maximum expected turbulence levels could be provided for turbulence components, except in the direction of the measured fringe angle orientations. To provide some indication of the turbulence variation in the flow field, the lower bound of turbulence will be used to provide qualitative indications of the axial, tangential, and total components of turbulence. However, when a quantitative measure of turbulence is required the actual measured turbulence estimates in the directions of the fringe angle orientations will be presented.

A. Uncertainty Analysis

The uncertainty analysis presented herein makes use of the terms precision and bias as defined by Kline [81], wherein precision refers to 
random components of uncertainty or repeatability and bias refers to fixed components of uncertainty or systematic errors. The uncertainties in positioning the laser probe volume and in determining the rotor shaft position are estimates of the total (precision plus bias) uncertainties, and have been previously quoted at a 95 percent confidence level in Sections III.C.3 and IV.A.3, respectively. The error in any single LFA measurement is a function of many different parameters including flow turbulence and random noise in the photomultiplier tube signal. As a result, it is difficult to make estimates of the total uncertainty in an individual LFA measurement since this noise is generated by background radiation which varies with each measurement. However, estimates of the precision uncertainty intervals of the ensemble-averaged velocities were calculated, based on the number of individual LFA measurements acquired at each rotor shaft position. The estimated precision uncertainties of the ensemble-averaged velocities were then used to estimate the precision uncertainties of all other parameters which were calculated from the ensemble-averaged velocities using the method of Kline [81] for calculating the propagation of uncertainties in calculations.

All graphed quantities include error bars to identify the estimated precision uncertainty intervals of all measured or calculated parameters. A summary of some of the other error sources associated with LFA measurements are presented below, and the estimates of the uncertainties in the measured velocities resulting from each error source are provided in Table 5.1. All uncertainties are quoted for a 95 percent confidence level. 
Table 5.1 Estimates of bias uncertainty in velocity measurements

\begin{tabular}{lll} 
Statistical bias & $\begin{array}{l}1.2 \text { percent within rotor wakes } \\
0.3 \text { percent } \\
\text { outside rotor wakes }\end{array}$ \\
$\begin{array}{l}\text { Angle bias } \\
\text { Negative velocity bias }\end{array}$ & $\begin{array}{l}1 \text { percent } \\
\text { within rotor wakes } \\
\text { outside rotor wakes } \\
\text { due to flow reversals }\end{array}$ \\
$\begin{array}{l}\text { Bias due to probe volume } \\
\text { position uncertainty }\end{array}$ & 0.2 percent \\
\hline
\end{tabular}




\section{Precision uncertainties}

A statistical measure of the uncertainty in the precision of $\widetilde{v}$ as an estimate of the true mean velocity, $\mu$, is given by

$\tilde{v}-\frac{t_{\alpha / 2 S}}{\sqrt{n}}<\mu<\tilde{v}+\frac{t_{\alpha / 2 S}}{\sqrt{n}}$

where $\widetilde{v}$ and $S$ are the ensemble-average and standard deviation (Eqs. (4.2) and (4.3)), respectively, and $t_{\alpha / 2}$ is the value of the student-t distribution at the $(1-\alpha) 100$ percent confidence level with $(n-1)$ degrees of freedom. For a 95 percent confidence level $(\alpha=0.05)$ and $n>30, t_{\alpha / 2}=2.0$.

Similarly, a statistical measure of the uncertainty in the precision of $S^{2}$ as an estimate of the true variance, $\sigma^{2}$, is given by $\frac{(n-1) S^{2}}{x_{\alpha / 2}^{2}}<\sigma^{2}<\frac{(n-1) S^{2}}{x_{1-\alpha / 2}^{2}}$

where $S^{2}$ is the variance of a random sample of size $n$ (Eq. (4.3)), and $x_{\alpha / 2}^{2}$ and $x_{1-\alpha / 2}^{2}$ are the values of a chi-square distribution at the $(1-\alpha) 100$ percent confidence level with $(n-1)$ degrees of freedom [82].

It should be noted that $S^{2}$ resulted from the sum of flow fluctuation effects such as turbulence, velocity variations due to rotor speed drift, and velocity gradients in the tangential direction across the measurement shaft position interval, plus the previously mentioned random noise in the photomultiplier tube signal. The maximum velocity gradient in the tangential direction occurs across the rotor wake and is on the order of 3 percent per rotor shaft position at the rotor trailing edge and decreases to less than 0.1 percent per rotor shaft position at the stator 
trailing edge. Observations indicate that the rotor speed drift during a run is on the order of 0.3 percent.

The axial and tangential velocity components are related to the measured velocity components and the fringe orientation angles through Equation (4.5). The 95 percent confidence level of the precision uncertainty of the fringe orientation angle, $\varphi_{z}$, is $0.03^{\circ}$, and is included along with the precision uncertainties of the measured components in determining, through the propagation of uncertainties analysis, the precision uncertainties of the axial, and tangential components.

\section{Bias uncertainties}

The uncertainties associated with LFA measurements, including methodologies for quantifying them, have been fairly comprehensively documented [83-85]. Only those sources of bias which introduce the greatest uncertainty, and for which estimates of the uncertainties can be determined will be described below. Two of the most often cited sources of LFA bias uncertainty are statistical and angle biasing. Statistical biasing [86] arises due to the variation of velocity magnitude with time. For a uniformly seeded flow, more particles cross the probe volume per unit time when the velocity is higher than when the velocity is lower than the mean. Therefore, an arithmetic average of measurements made over a given period of time yields a calculated mean velocity which is higher than the true mean. The greatest velocity variations occur in the rotor wake in which the velocity variations are as much as 15 percent of the mean, which would result in a 1.2 percent correction for velocity bias. However, these large excursions from the mean velocity are a result of the 
vortex nature of the rotor wakes [87]. Because of the vortex nature of the wake there are two equally probable velocity states which can occur during any given measurement (see Fig. 4.4), and the probability of measuring a velocity equal to the mean of the distribution can be virtually nil. All other velocity distributions outside the rotor wake are single peak distributions. The greatest standard deviation from the mean of a single peak distribution, or from either peak of the double peaked velocity distributions is about 5 percent, which would result in a 0.3 percent correction for velocity bias. Because the correction for velocity bias is typically small, and since the nature of the velocity distribution cannot be ascertained, as only the mean and standard deviation of the velocities are usually recorded, the data have not been corrected for statistical bias.

Angle biasing [88] occurs because the flow direction fluctuates with time. More measurements per unit time occur when the flow direction is parallel to the fringe normal direction, $\theta_{z}$, than when the flow direction fluctuates away from the fringe normal direction. The bias in the arithmetic average of velocity measurements acquired over a given time period is proportional to the angle between the fringe normals and the mean flow direction. For the data presented herein, the angle between the fringe normals and the mean flow direction is $20^{\circ}$, which yields an angle bias uncertainty of about 1 percent. However, based on LFA measurements the mean flow angle changes by as much as $30^{\circ}$ across the rotor wakes, and therefore there are regions in which the angle between the fringe normals and the mean flow direction are on the order of $35^{\circ}$, which could result in a 3 percent error in the measured velocity. 
Another source of velocity bias [83] occurs from the inability of the current LFA system to distinguish between seed particles traveling in the positive or negative direction. Therefore, in regions containing flow reversals, such as in the separated boundary layers, the mean velocity will be biased high. The use of Bragg shifting is one means of eliminating this source of velocity bias.

The uncertainty in positioning the probe volume within the test section is also a source of velocity bias [83]. This source of velocity bias can be calculated as the product of the estimated spatial flow gradients and the positional uncertainty in the direction of the gradient. The largest spatial gradients within the measurement grid are on the order of 1.5 percent per millimeter, and occur around the stator leading edge, near the stator suction surface, and across the stator wake. The maximum positional uncertainty of the probe volume is on the order of $0.1 \mathrm{~mm}$, which would result in less than a 0.2 percent bias uncertainty in the measured velocity.

\section{B. Description of the Measured Flow Field}

The relative motion between the rotor and stator blade rows complicates a description of the measured flow field. However, it is possible to provide a reasonably clear picture of the unsteady interactions resulting from both the deterministic unsteadiness and turbulence by presenting several descriptions of the measured flow field with respect to different viewpoints. The first viewpoint is a "time"-averaged description of the measured flow field as would be seen by an observer moving with the stator blade row. This is, of course, a view 
from the measurement frame of reference. The second viewpoint is a "time"-averaged description of the measured flow field as would be seen by an observer moving with the rotor blade row. This view provides a clear picture of the rotor wakes which eventually interact with the stator blade row. The final viewpoint is again from the measurement frame of reference, but now the "time" resolved description of the measured flow field is presented. This view shows the relative motion between the rotor and stator rows, and the actual chopping and subsequent transport of the rotor wakes as they pass through the stator blade row.

In the context of this discussion, "time" refers to the relative position of the rotor and stator rows, not real time. In the stator frame of reference, time is indicated by rotor shaft position. In the rotor frame of reference, time is indicated by circumferential position. of course, to correctly represent units of time the rotor wheel speed must be considered. However, for interpretation of the results it is not necessary to display the correct units for time.

\section{Stator-relative time-averaged description of measured flow field}

Figures 5.1 and 5.2 show the components of the stator-relative time-averaged absolute velocity field through the stator row for the 10 and 50 percent stream surfaces, respectively, which illustrates the extent of the stator potential flow field. It is apparent that the stator potential flow field extends only about 30 percent of stator chord upstream from the stator leading edge plane, whereas the rotor trailing edge is almost 100 percent of stator chord upstream of the stator leading edge. Therefore, it is obvious that potential interactions between the 


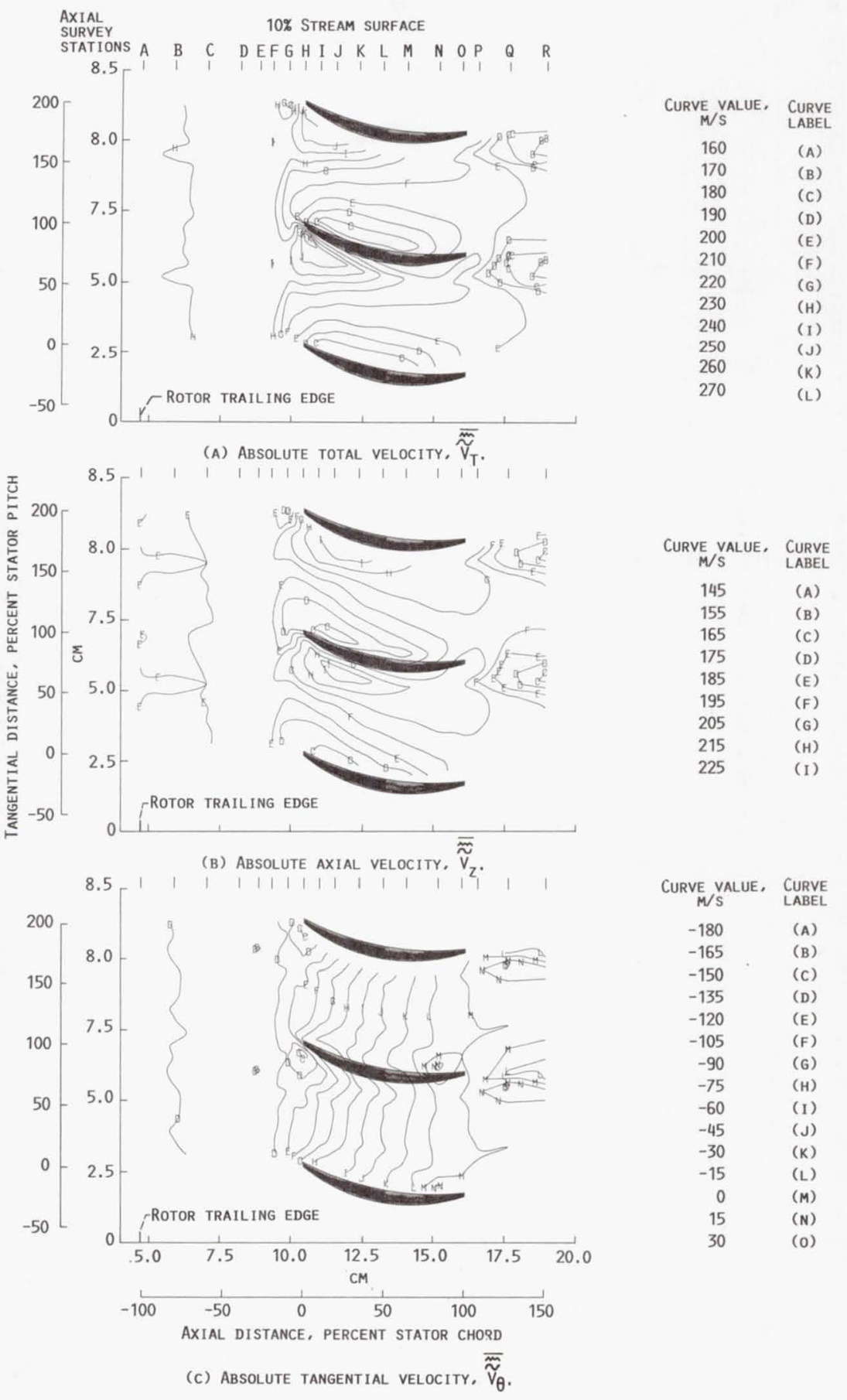

Figure 5.1 Contour maps of the stator-relative time-averaged absolute velocity field along the 10 percent stream surface 


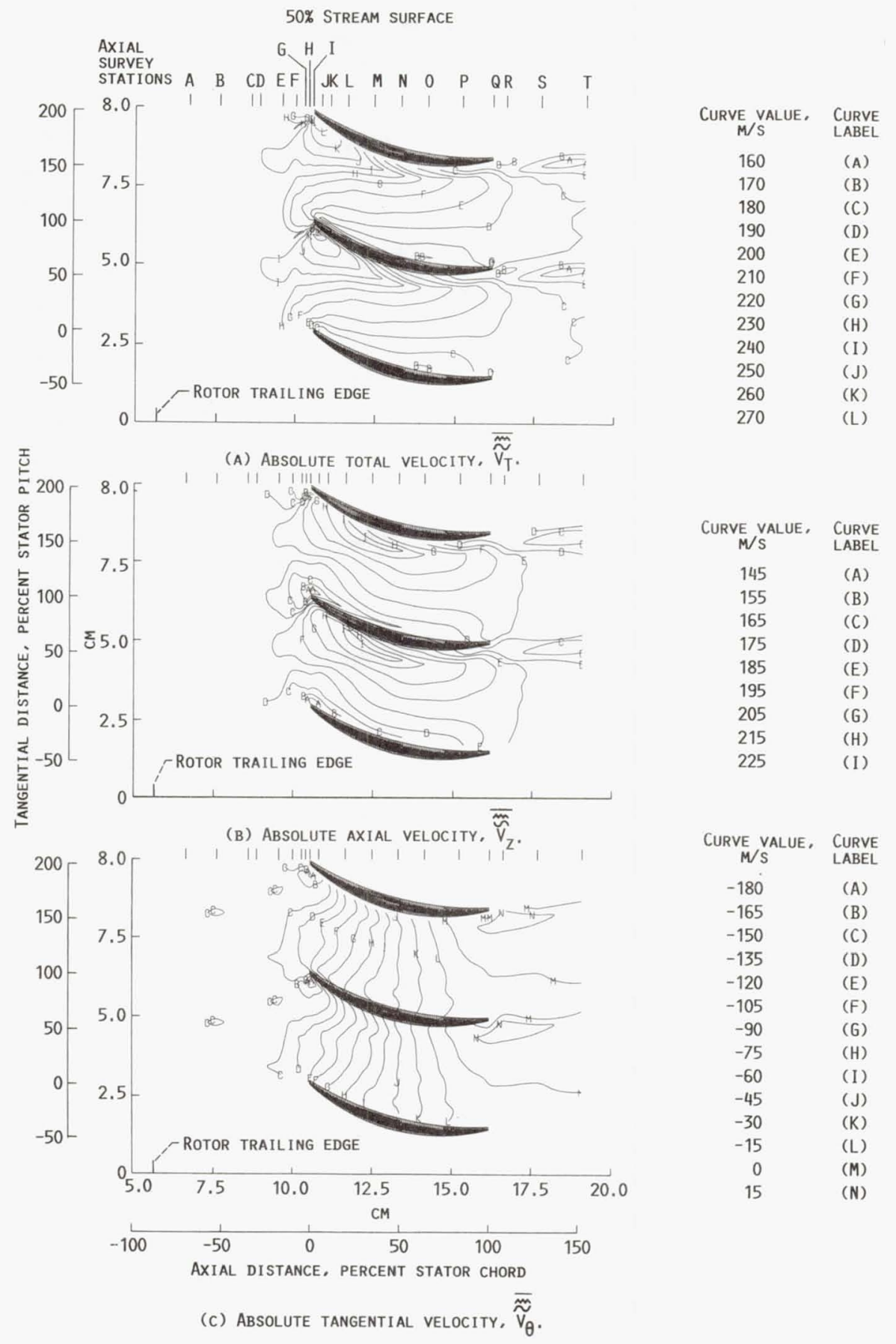

Figure 5.2 Contour maps of the stator-relative time-averagu absolute velocity field along the 50 percent stream surface 
stator and rotor are very weak (acoustic interactions, however, may still be present), and that the only significant blade row interactions are due to rotor wake generated unsteadiness and turbulence. It is also apparent from Figures 5.1 and 5.2 that a significant low velocity region exists along the stator suction surface which eventually grows to become part of the stator wake as it leaves the stator blade. From the extent of this low velocity region near the stator suction surface, it is probable that the boundary layer has separated. Figure 5.3 shows the locus of maximum velocities measured along the suction surface for both the 10 and 50 percent axisymmetric stream surfaces. These maximum velocities were determined at various chordwise locations by observing the pitchwise location at which the magnitude of the total time-averaged absolute velocity was a maximum, which occurred just prior to the laser probe volume entering the low velocity region near the stator suction surface. It is probable that reverse flows are present within this low velocity region, but this could not be ascertained with the present LFA system. A similar effort to determine the stator pressure surface boundary layer was attempted, but was unsuccessful due to the spatial resolution of the LFA probe volume compared to the thickness of the pressure surface boundary layer. Other observations of the stator-relative time-averaged flow field include the approximate location of the stagnation point and the resulting high velocity gradients around the stator leading edge.

The stator-relative time-averaged description of the stator flow field as depicted in Figures 5.1 and 5.2 is essentially the kind of picture a turbomachine designer has in mind when trying to design a blade row to match a given set of velocity triangles. If any attempt is made to 


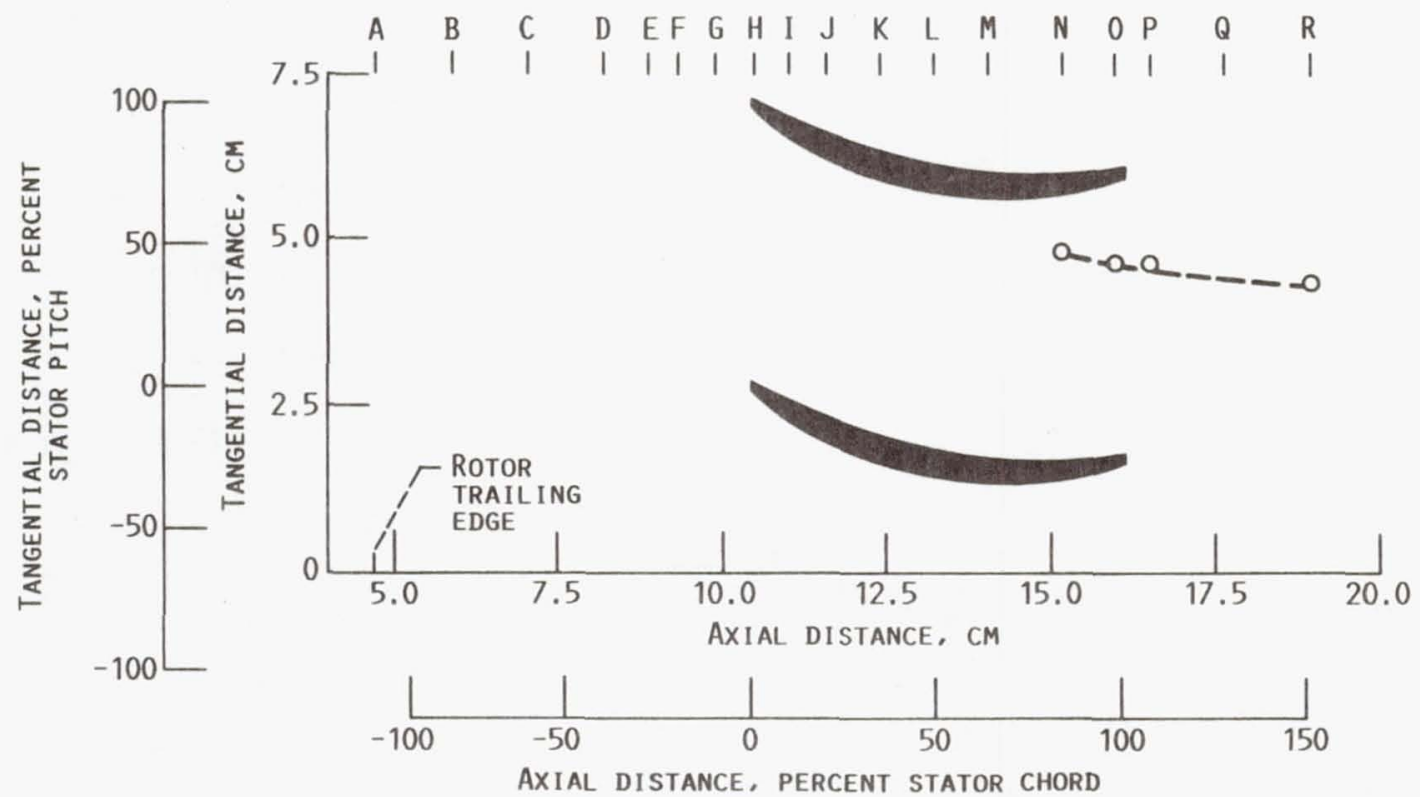

(A) 10\% Stream SURFace.

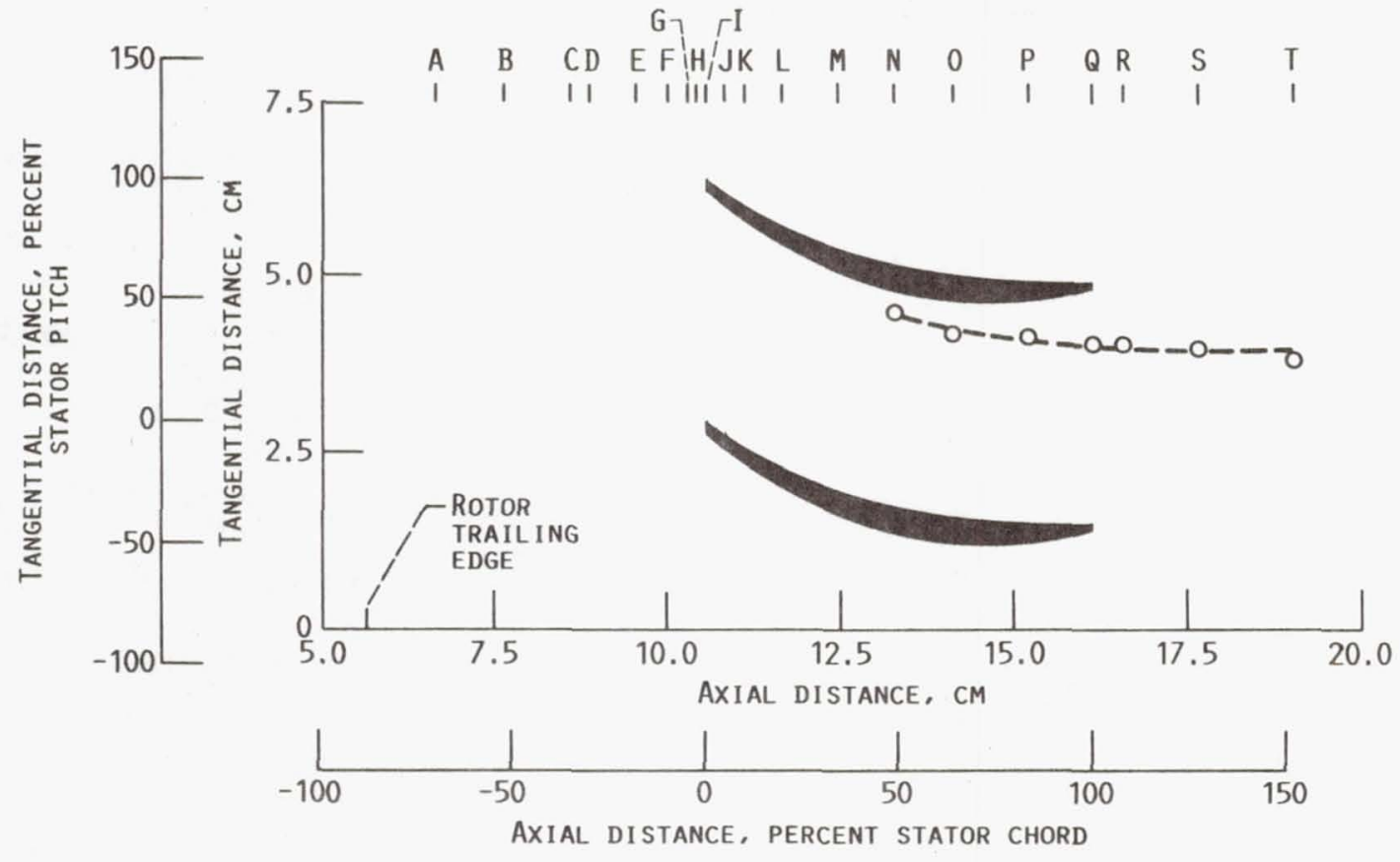

(B) $50 \%$ Stream Surface.

Figure 5.3 Measured extent of the stator suction surface low velocity region along the 10 and 50 percent stream surfaces 
account for the unsteady flow effects it is usually through "turbulence modeling." Turbulence modeling, as used in this paragraph, refers to the usual turbulence associated with external flows in which turbulence is the only unsteadiness involved. This kind of turbulence modeling is appropriate for a Reynolds averaged model of the flow field. However, in turbomachines the flow field is nonstationary, and therefore the Reynolds averaged equations of motion are time dependent. Therefore, the use of turbulence modeling of the type referred to above would require solution of the time-dependent Reynolds averaged equations of motion throughout an entire multistage turbomachine, which is currently impractical.

\section{Rotor-relative time-averaged description of measured flow field}

To provide a clearer picture of the unsteadiness a stator row sees as a result of an upstream rotor row we can recast the measured LFA data in the rotor frame of reference (see Appendix B). Contour maps of the rotor-relative time-averaged turbulence along the 10 and 50 percent stream surfaces are shown in Figure 5.4. The shaded regions of Figure 5.4 indicate the rotor wake fluid (see Appendix A). Figure 5.4, therefore, represents a time-averaged picture of the rotor wakes as they would be seen by an observer riding with the rotor blades. In this case, the stator blades appear smeared out, since they are moving relative to the rotor. Referring to Figure $5.4(B)$, the rotor wake appears to broaden more rapidly within the stator passage until eventually the adjacent rotor wakes begin to mix together by about 120 percent of stator chord. The broadening of the rotor wake within the stator passage indicates that the stator row promotes mixing. The turning of fluid by the stator row can 


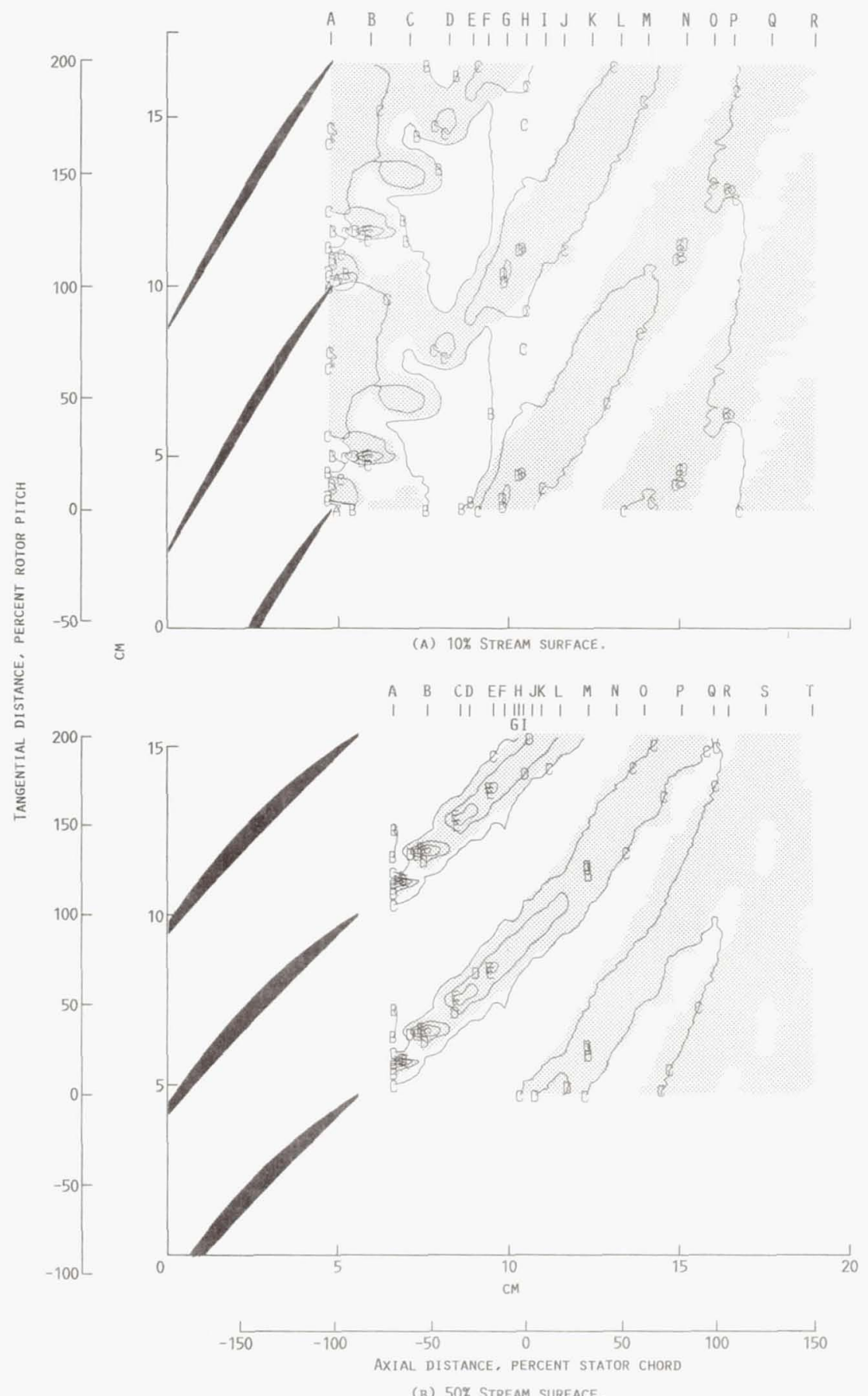

Figure 5.4 Contour maps of the rotor-relative time-averaged turbulence field showing the rotor wakes and the dissipation of turbulence 
also be observed by the upturning of the rotor wakes as they move through the stator blade row region.

Figures 5.5 and 5.6 show further details of the character of the rotor-relative time-averaged rotor wake as it moves through the stator blade row region along the 10 and 50 percent axisymmetric stream surfaces, respectively. Along the 50 percent stream surface, see Figure $5.6(A)$, the rotor-relative time-averaged axial velocity component within the rotor wake looks much like the typical gaussian model of rotor wakes which has been proposed from previous investigations of wakes in low-speed compressors [32-41]. The tangential velocity component of the time-averaged absolute total velocity, however, does not at all fit a gaussian model. At the 10 percent stream surface, see Figure 5.5 , the character of the rotor wake is much different than at the 50 percent stream surface, and the gaussian model is completely inadequate to describe this rotor wake. It is important to note that this particular rotor wake is comprised of shed vorticies from the rotor blade trailing edge [87] (see Fig. 5.7), and thus the wake has a different character than that which would occur from a simple mixing of two shear layers. Therefore, it is apparent that a gaussian model cannot, in all instances, adequately model the characteristics of the time-averaged rotor wake associated with a high-speed compressor.

The rotor-relative time-averaged picture of the measured turbulence in the directions corresponding to the fringe angle orientations (i.e., $\pm 20^{\circ}$ from the measured time-averaged absolute flow angle) are shown in Figures 5.8 and 5.9 along the 10 and 50 percent stream surfaces, respectively. From figures 5.8 and 5.9 , it is also apparent that 

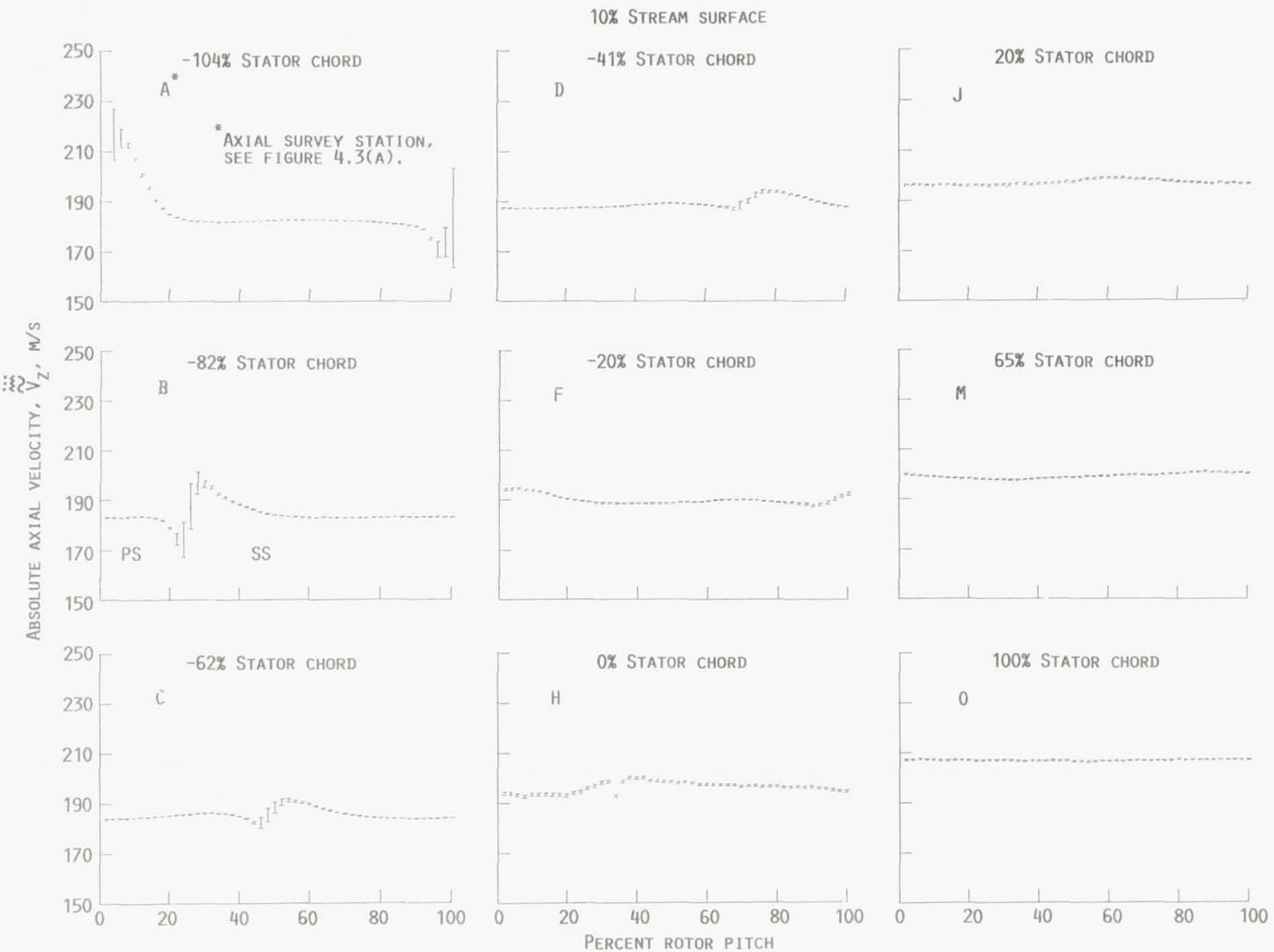

(A) ABSOLUTE AXIAL VELoCITY,

Figure 5.5 Rotor-relative time-averaged absolute velocities along the 10 percent stream surface 

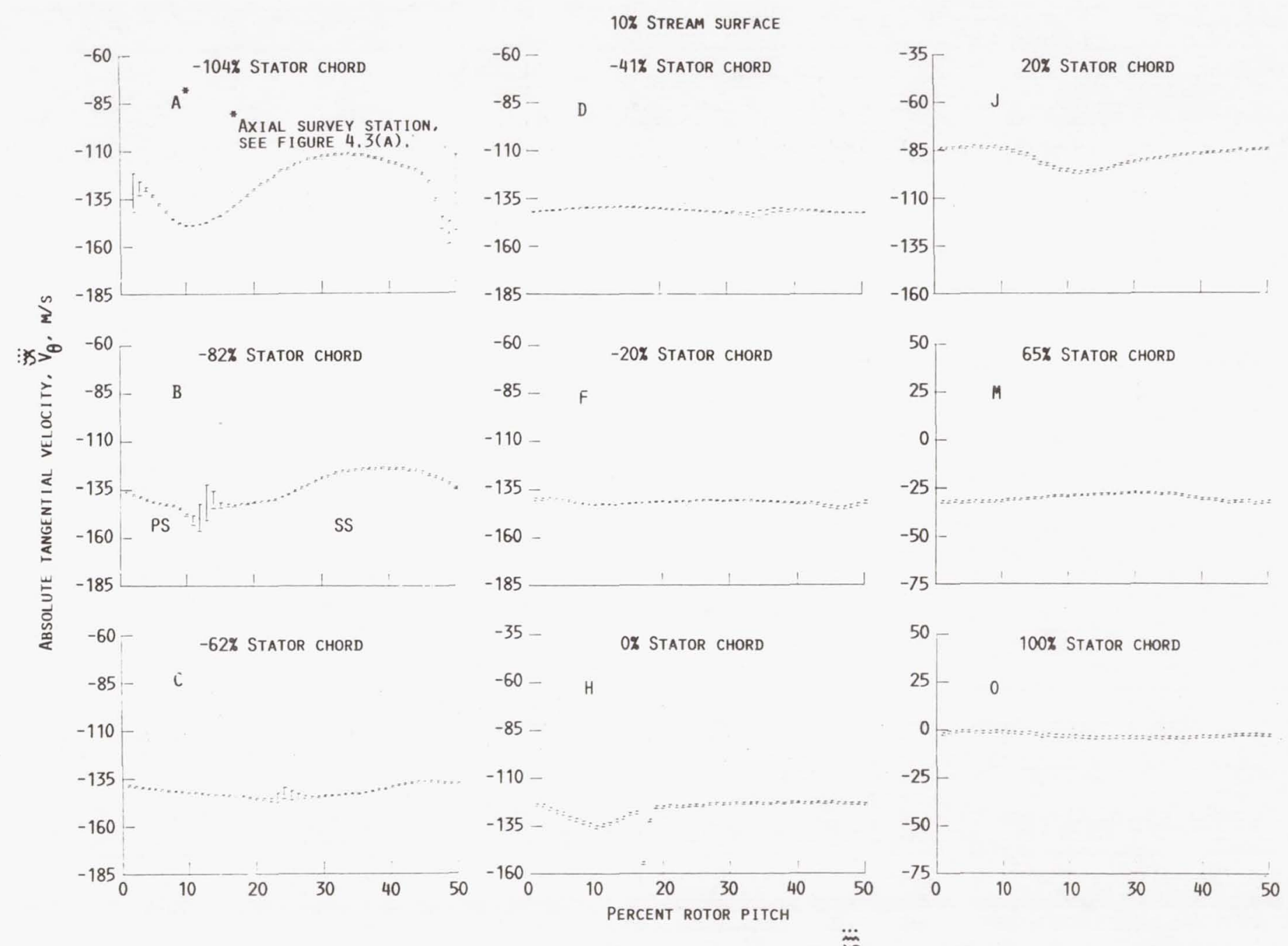

(B) ABSOLUTE TANGENTIAL VELOCITY,

Figure 5.5 Continued 

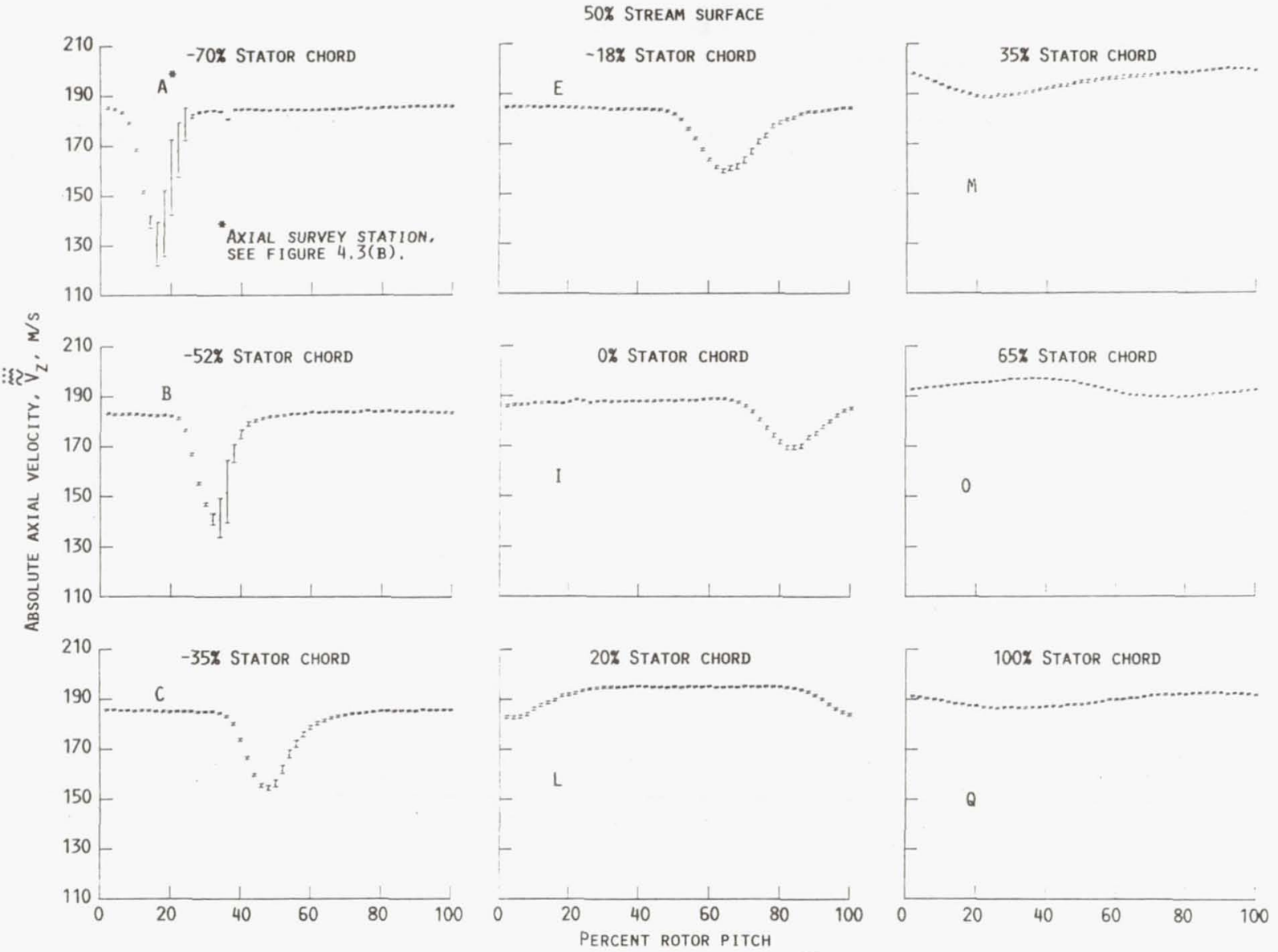

(A) Absolute axial velocity, $\dddot{\widetilde{v}}$.

Figure 5.6 Rotor-relative time-averaged absolute velocities along the 50 percent stream surface 

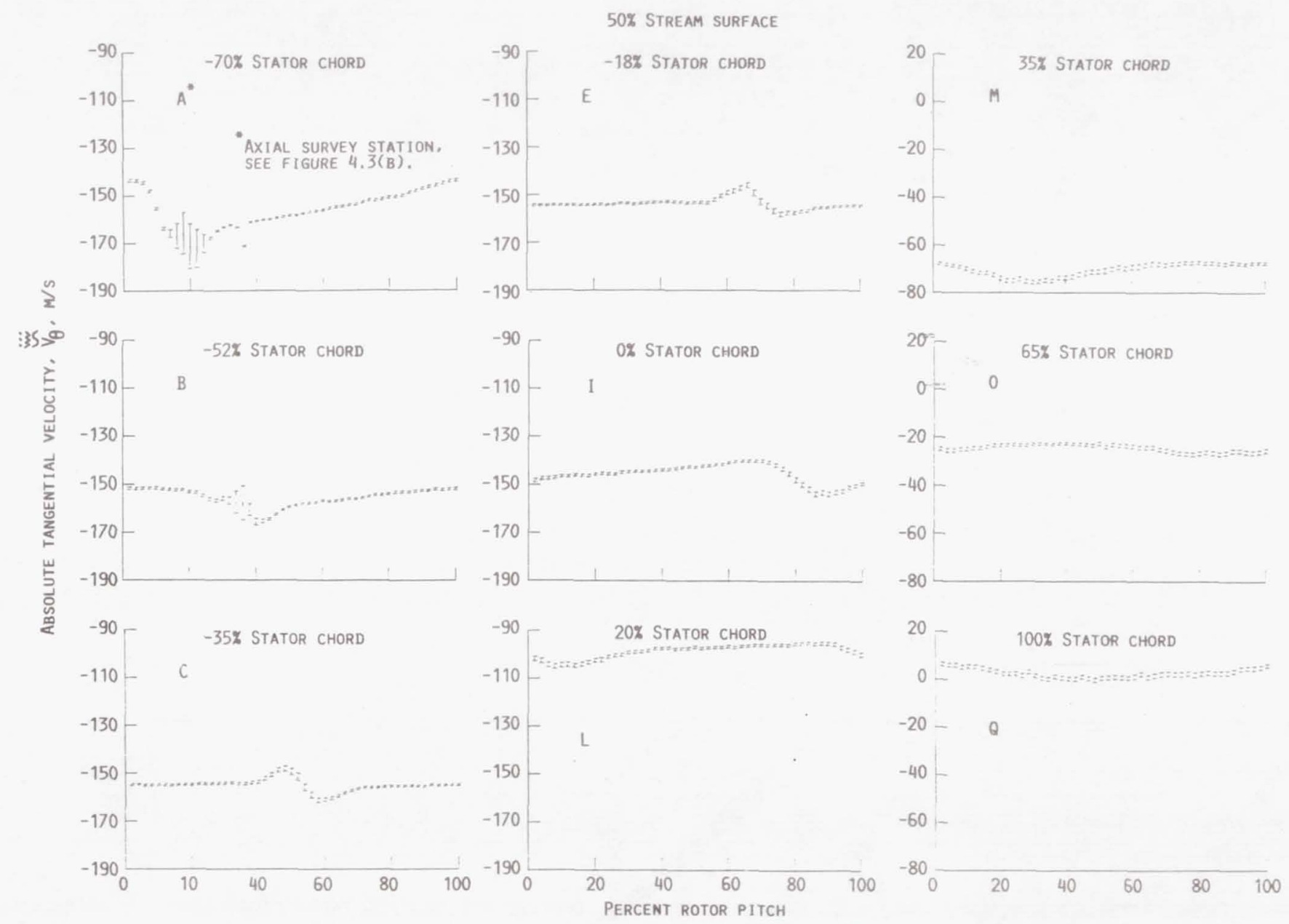

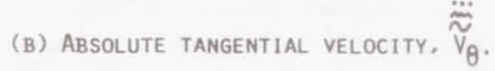

Figure 5.6 Continued 

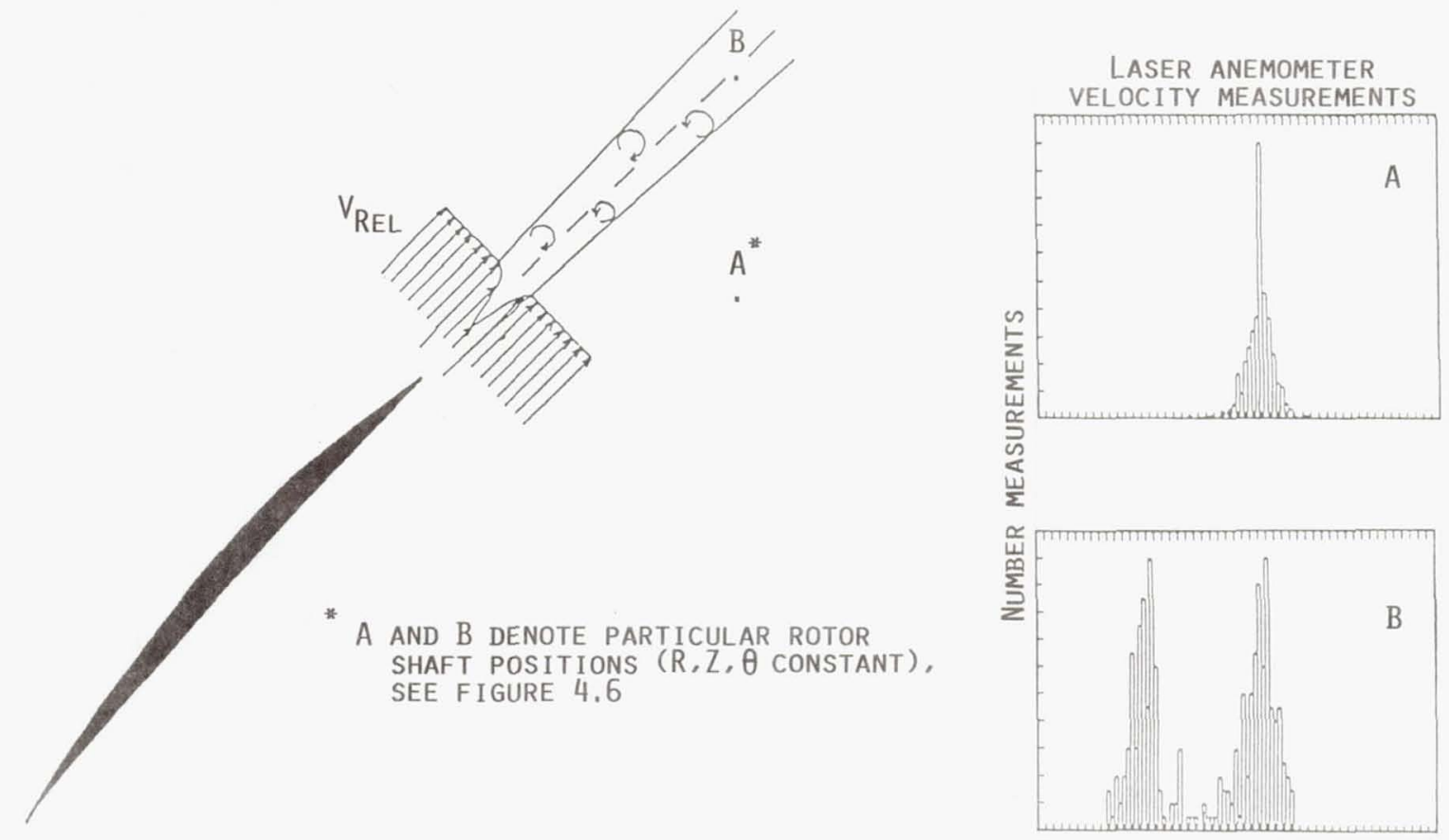

VELOCITY

Figure 5.7 Illustration showing laser anemometer measurements of the vortex street character of the rotor wake 

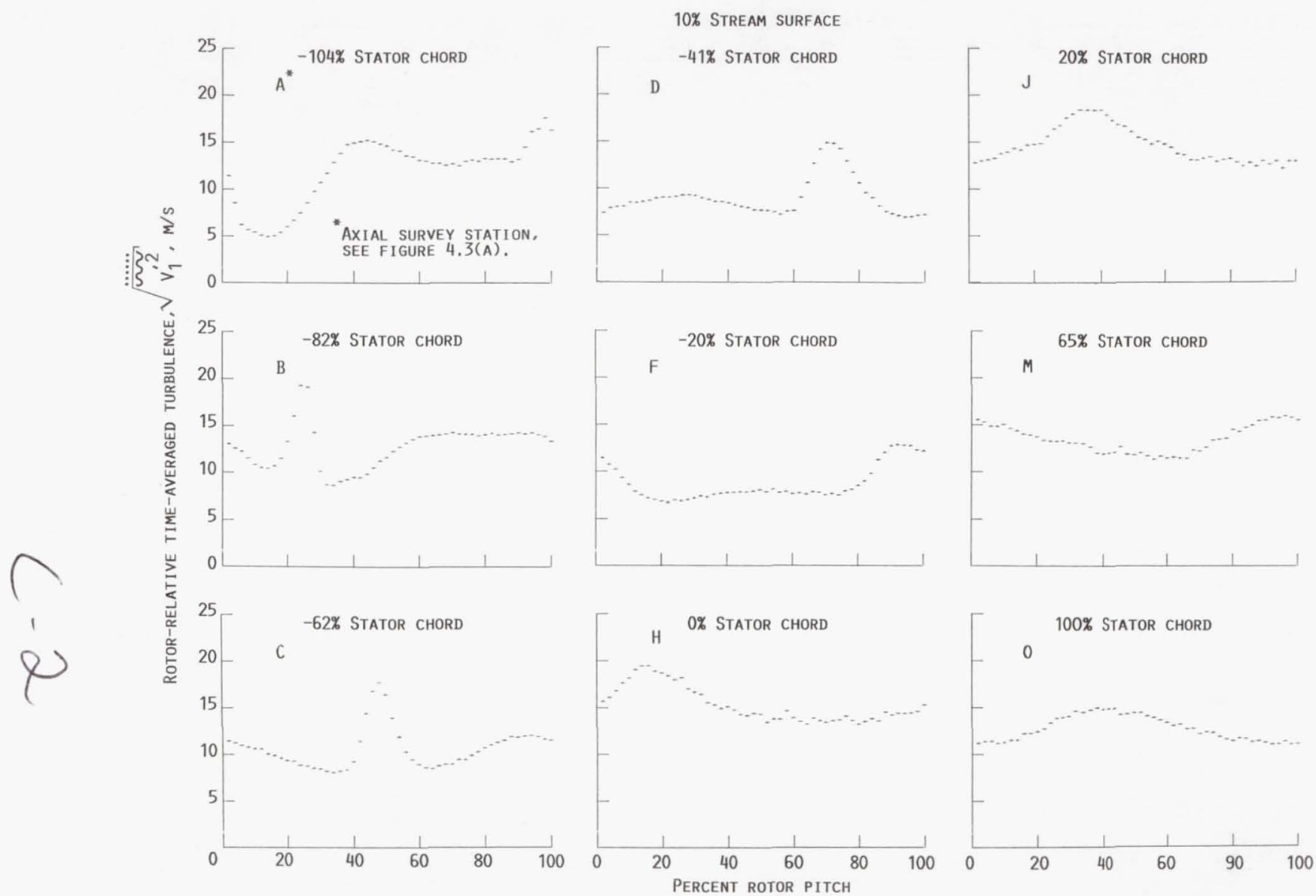

(A) FiRST MEASURED COMPONENT.

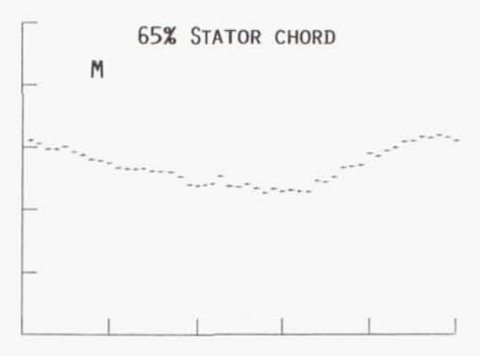

Figure 5.8 Measured components of the rotor-relative time-averaged turbulence along the 10 percent stream surface 

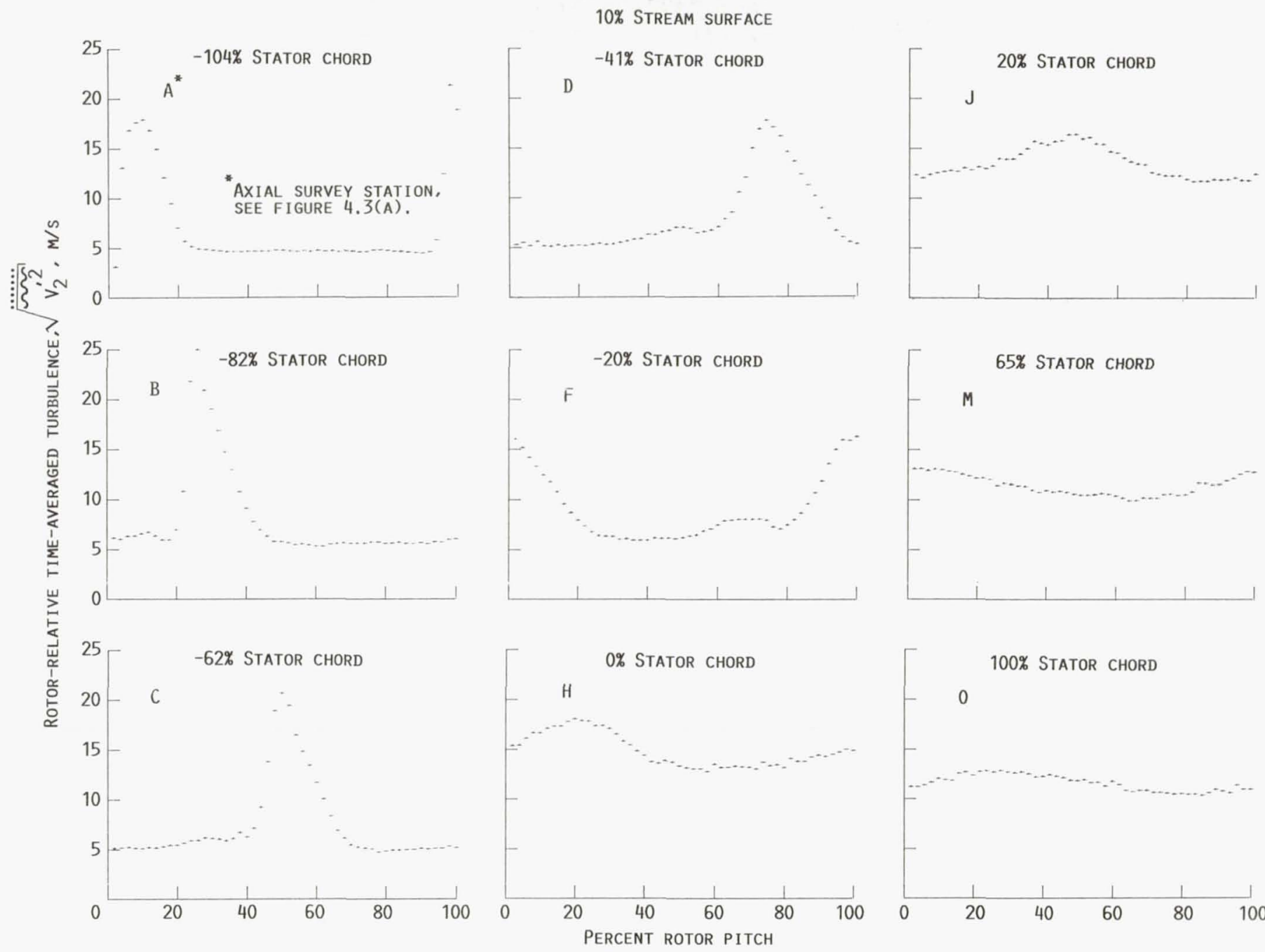

(B) SECOND MEASURED COMPONENT.

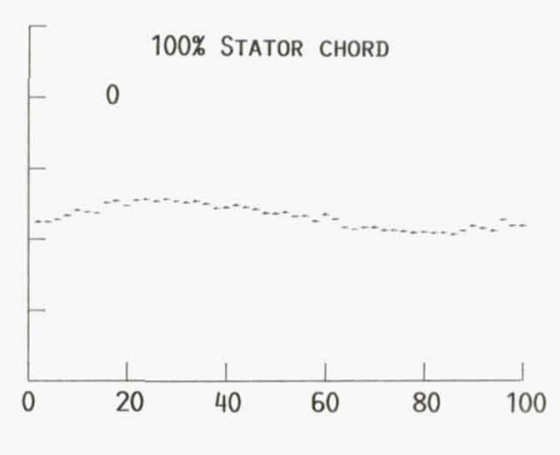

Figure 5.8 - Continued 

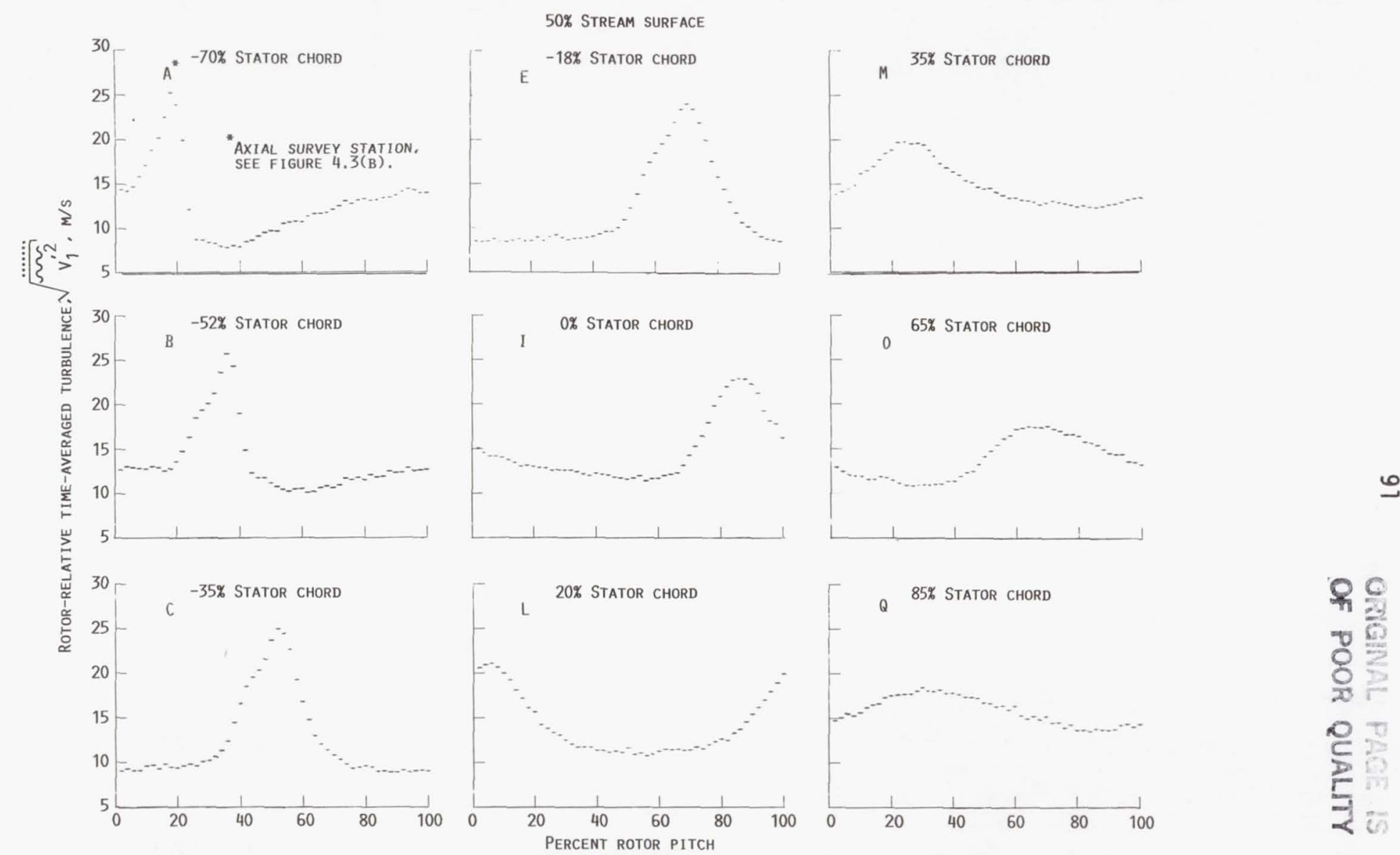

Figure 5.9 Measured components of the rotor-relative time-averaged turbulence along the 50 percent stream surface 


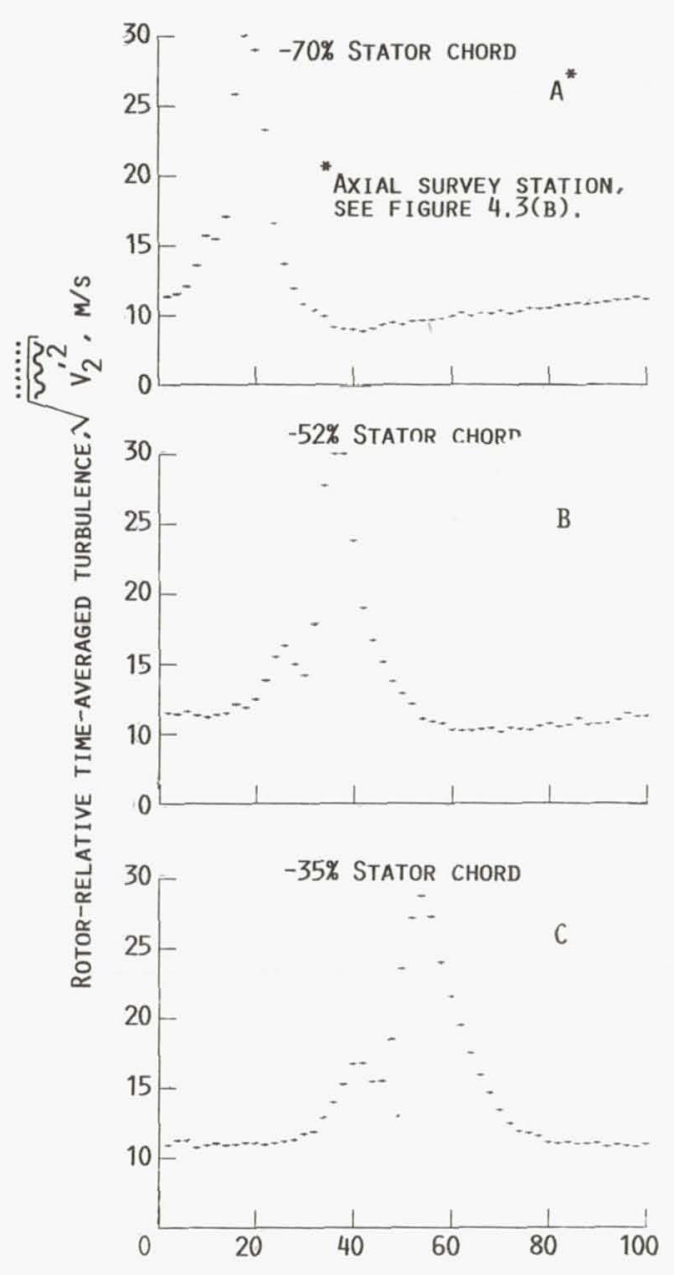

50\% StREAM SURFACE
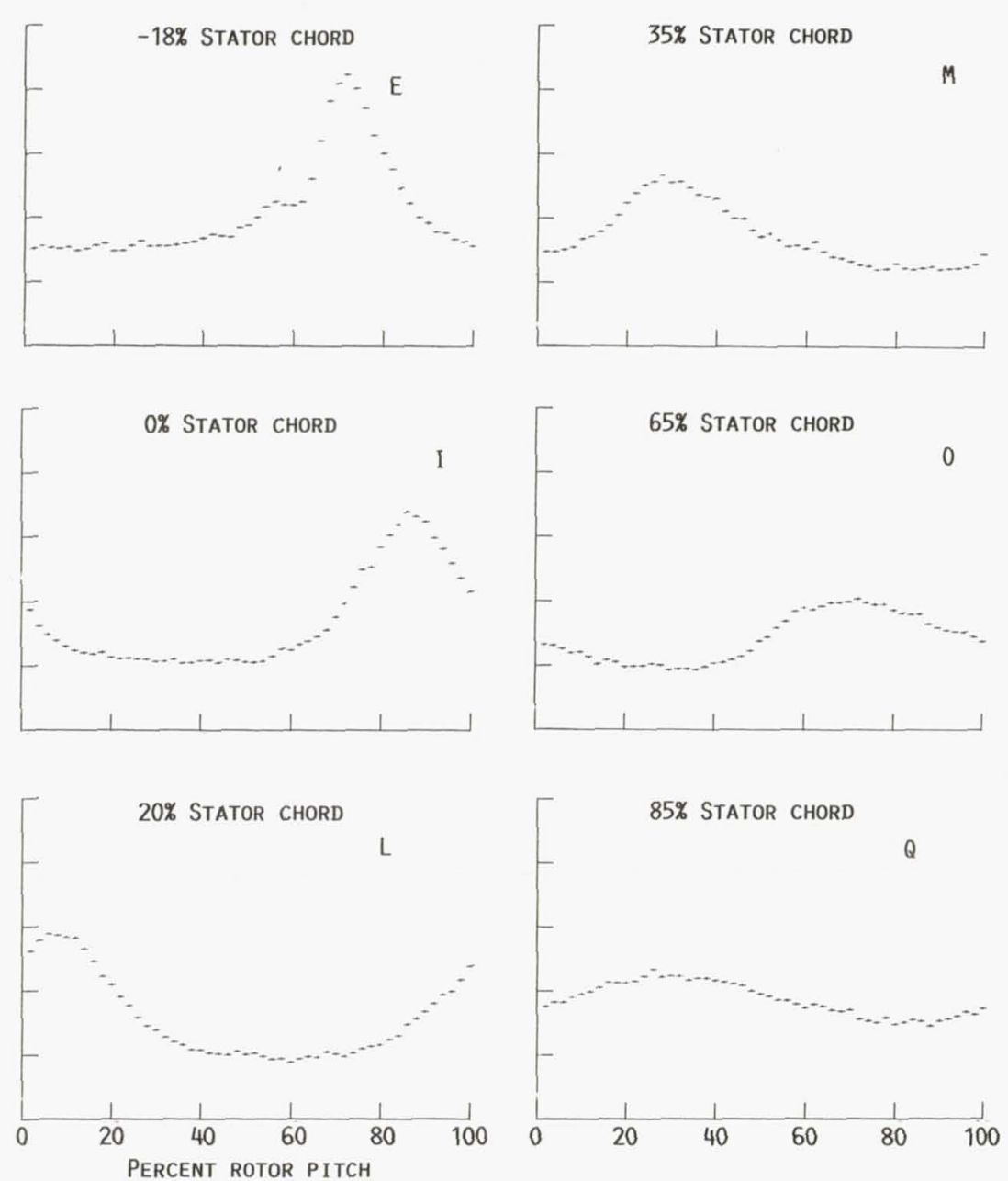

(B) SECOND MEASURED COMPONENT.

Figure 5.9 - Concluded 
turbulence increases in the rotor wake. It is obvious, therefore, that the stator is subject to both periodic fluctuations in absolute velocity and turbulence as the rotor wakes pass through the downstream stator row. Due to the vortex street character of the rotor wake, the magnitudes of turbulence within the rotor wake are higher than might be expected.

\section{Time resolved description of the measured flow field}

As previously mentioned, the dominant blade-row interactions present in the current research fan are due to viscous interactions caused by the chopping of rotor wakes by the downstream stator blade row. Figures 5.10 and 5.11 show, along the 10 and 50 percent stream surfaces respectively, a sequence of "snapshots" in time (i.e., rotor/stator orientations or rotor shaft positions) of the measured flow field as the rotor wakes are chopped and subsequently transported through the stator blade row. The shaded regions overlayed on the contour maps of turbulence are provided to indicate rotor wake fluid (see Appendix 0 ). An indication of the decay of the rotor wakes can be inferred from the contours of the lower bound of turbulence. Similar contour maps depicting the movement of wakes through adjacent blade rows have been reported by Dunker [42]; Dunker et a1. [89] for a compressor blade row, and Binder et al. [43]; Binder [44]; Binder et a1. [45] for a turbine blade row.

From Figures 5.10 and 5.11 we can see that after the stator blade chops the rotor wake, the upper and lower stator-passage wake segments begin to drift apart as they convect through the stator blade row. Thus, by the time the rotor wake segments reach the stator exit there is an appreciable mismatch between the rotor wake segments, which were 

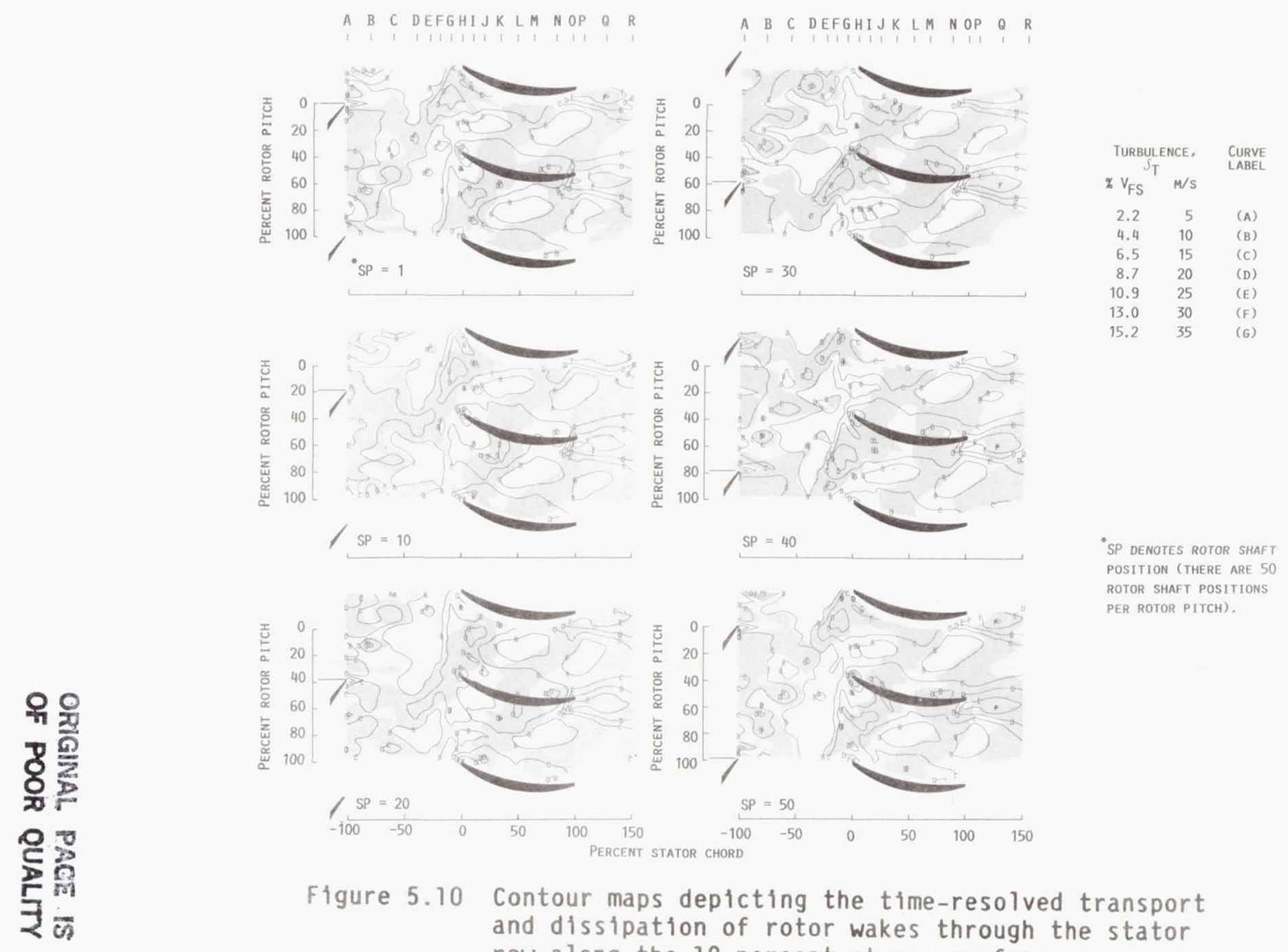

Figure 5.10 Contour maps depicting the time-resolved transport and dissipation of rotor wakes through the stator row along the 10 percent stream surface 

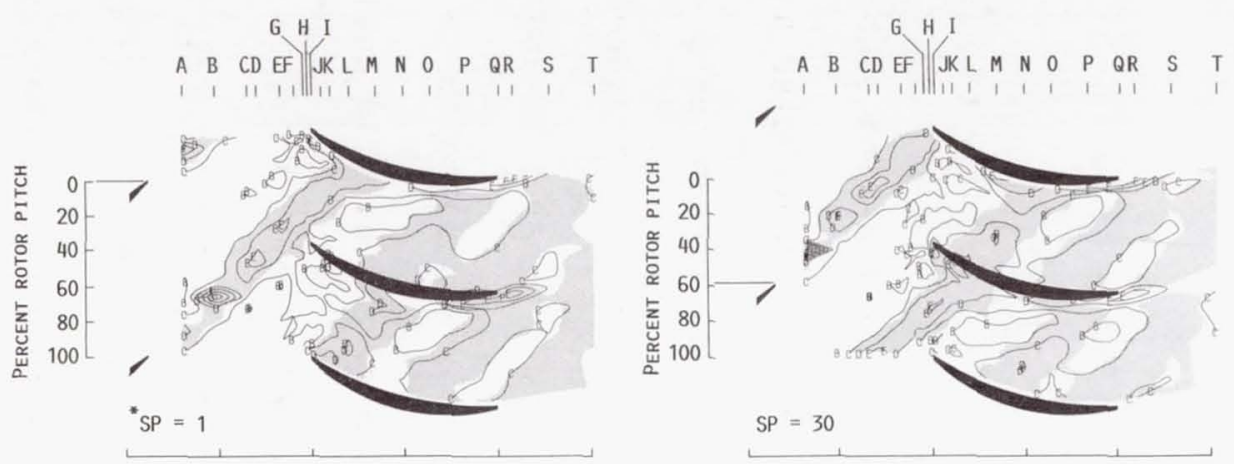

\begin{tabular}{|c|c|c|}
\hline \multicolumn{2}{|c|}{ TURBULENCE, } & \multirow[t]{2}{*}{$\begin{array}{l}\text { CURVE } \\
\text { LABEL }\end{array}$} \\
\hline $6 V_{F S}$ & M/S & \\
\hline 2.2 & 5 & (A) \\
\hline 4.4 & 10 & (B) \\
\hline 6.5 & 15 & (c) \\
\hline 8.7 & 20 & (D) \\
\hline 10.9 & 25 & (E) \\
\hline 13.0 & 30 & (F) \\
\hline 15.2 & 35 & (G) \\
\hline
\end{tabular}
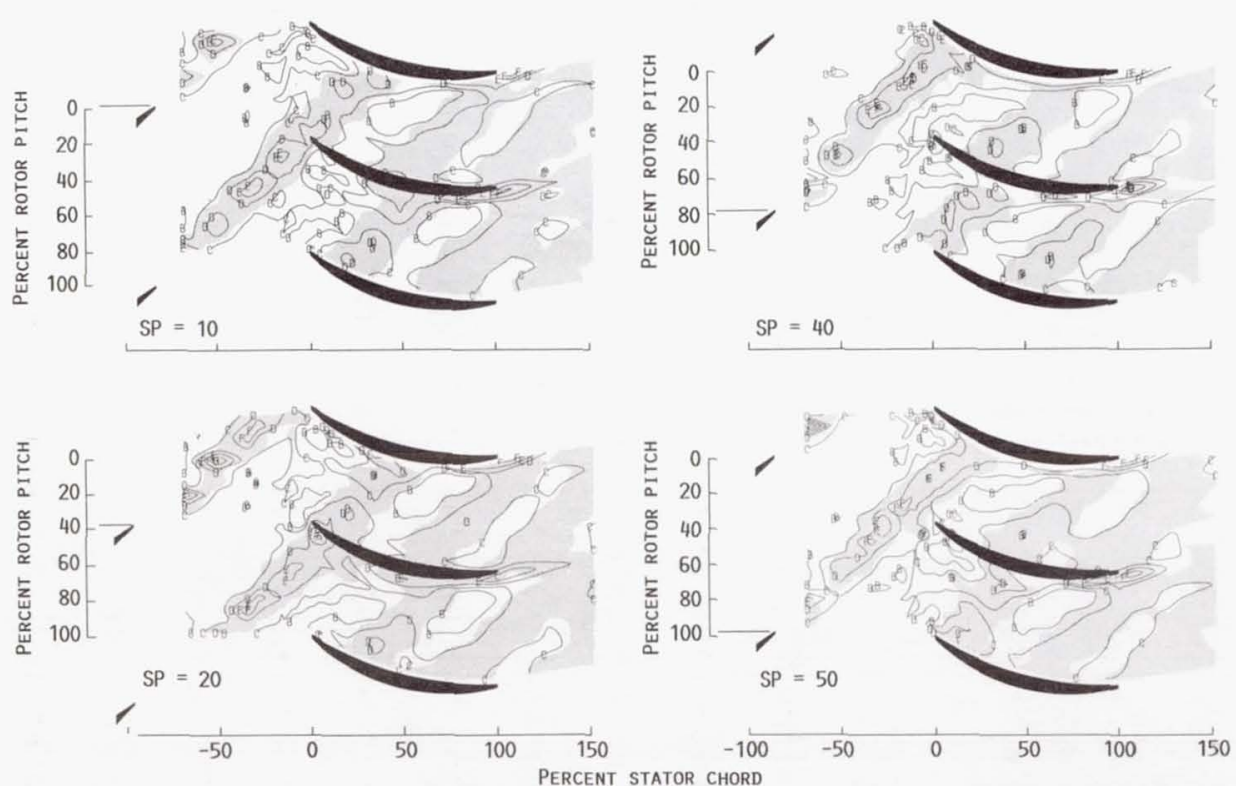

SP DENOTES ROTOR SHAFT

POSTTION (THERE ARE 50

PER ROTOR PITCH).

5.11 Contour maps depicting the time-resolved transport and dissipation of rotor wakes through the stator row along the 50 percent stream surface 
originally part of the same rotor wake. Using linear small-disturbance theory, Smith [65] showed that for thin airfoils with relatively little turning the drift distance can be related to the airfoil circulation, $\Gamma$, and the average of the inlet and exit velocities, $v_{A}$, according to the following equation.

$\Delta s=\frac{\Gamma}{v_{A}^{2}} v_{E}$

where

$\Gamma=\frac{2 \pi}{N_{S}}\left(R_{I} V_{\theta_{I}}-R_{E} V_{\theta_{E}}\right)$

$V_{A}=\frac{\left(V_{I}+V_{E}\right)}{2}$

The drift distance, $\Delta s$, is measured along the stator trailing edge streamline. Table 5.2 shows a comparison between the calculated and measured drift distances along the 10 and 50 percent stream surfaces, which have been normalized by the stator axial chord. The measured nondimensional drift distance was determined from Figures 5.10 and 5.11 based on the relative rotor/stator orientation corresponding to SP $=10$ (20 percent rotor pitch). Joslyn et al. [64] used an inviscid analysis to successfully predict the motion of a narrow smoke stream (i.e., an inviscid zero-velocity-deficit "wake") through a downstream rotating blade row by tracing isochronous lines measured relative to the initial upstream generated smoke stream. For a cusped leading edge airfoil, their approach reduces to that of Smith [65].

It is also evident from figure 5.10 and 5.11 that the rotor wakes tend to pile up at the stator exit, and that there is some spreading of 
Table 5.2 Comparison between calculated and measured rotor wake segment nondimensional drift distance

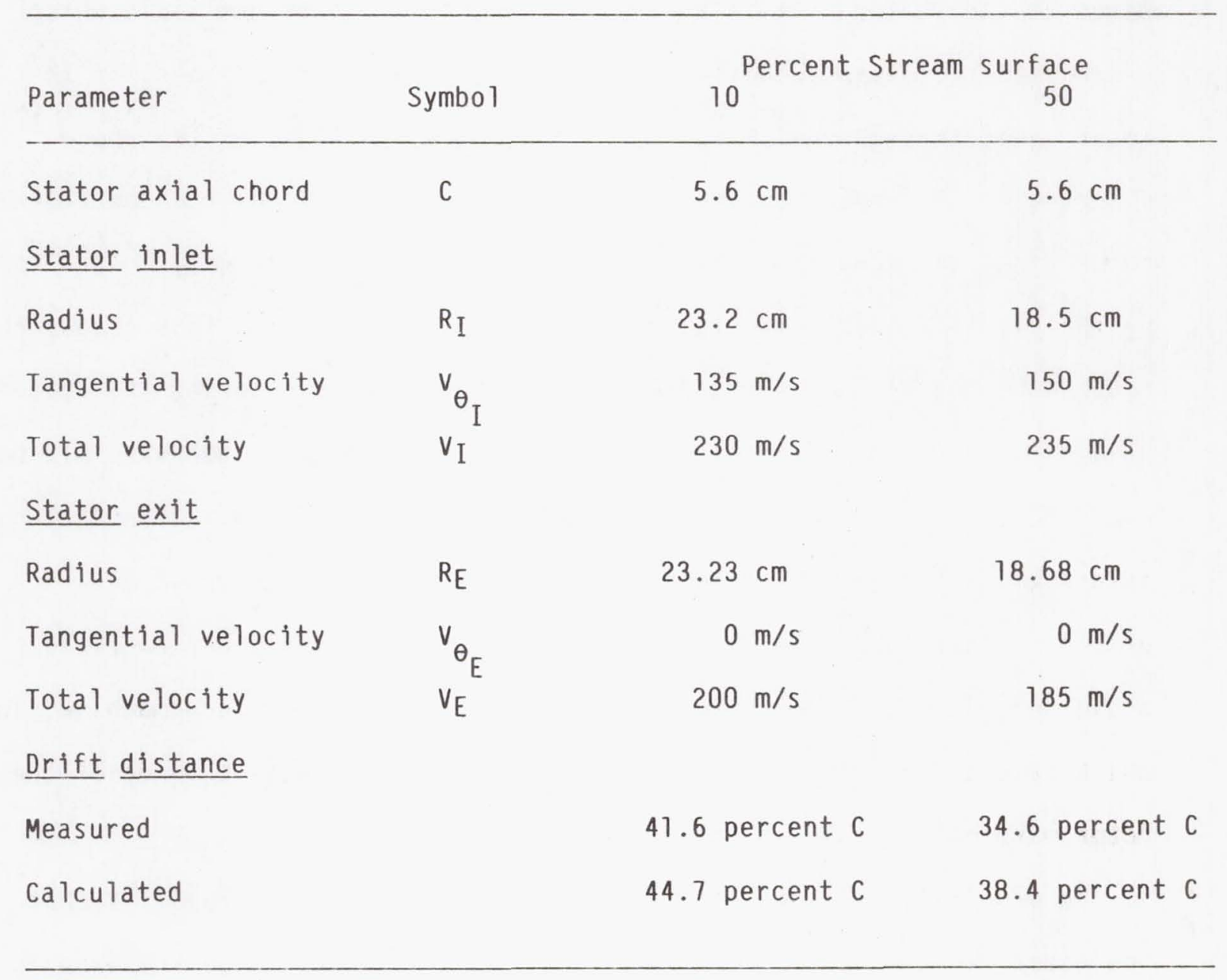


the rotor wake width, although very slight. The piling up of the rotor wakes at the stator exit is a result of the static pressure field which retards the absolute velocity, and thus slows down the transport of the rotor wakes through the stator row. Therefore, in light of the above observations, it seems apparent that the kinematics of the transport of rotor wakes through the downstream stator blade row is largely controlled by the time-averaged potential flow field. Of course, for this stage, the rotor wake has already substantially decayed prior to entering the stator blade row. In a more closely coupled stage most of the rotor wake mixing would occur while the rotor wake was within the stator row. In addition, interactions between the respective potential flow fields would be present. Therefore, the above picture of the time-resolved flow field could be quite different in a more realistically coupled turbomachine, in which case a simple inviscid analysis may not be adequate to predict the rotor wake motion through the stator blade row.

A generally accepted theory, first proposed by Meyer [52], is that the rotor wake behaves like a negative jet. Therefore, when the wake (negative jet) is cut by the stator row the width of the wake will tend to diminish on the suction surface, and increase on the pressure surface. Several investigators have since shown experimental evidence in support of this theory $[10,28,31,46]$. Most notable was an experimental investigation by Kerrebrock and Mikolaczyck [10] which indicated that the higher energy fluid of the rotor wake impinged and collected on the stator pressure surface, as evidenced by a measured increase in the stagnation temperature on the pressure side of the stator wake. However, there is no apparent evidence in Figure 5.10 or 5.11 of the rotor wake width either diminishing 
on the stator suction surface, or increasing on the pressure surface. Most likely, the manner in which the data was collected and presented, and the spatial resolution of the data have obscured this effect since, for this loosely coupled stage, it is probably quite small. However, it is apparent from Figures 5.10 and 5.11 that the rotor wakes are moving towards the pressure surface, and away from the suction surface, as expected.

Depending on where the rotor wakes are relative to the stator, the rotor wakes may be affected differently due to the influence of the stator flow field. Figures 5.12 and 5.13 show the character of the rotor wake, as measured at different points within the stator passage, along the 10 and 50 percent stream surfaces, respectively. Each picture is in the stator frame of reference, and is measured at a particular radial, axial, and tangential position. Therefore, the abscissa is a function of rotor/stator relative position (i.e., stator-relative time measured in rotor shaft positions). At a constant axial and radial position the rotor wake velocity deficit increases and decreases depending on the stator pitchwise location, therefore, it is obvious from Figures 5.12 and 5.13 that the stator flow field has a significant influence on the rotor wake. Similar behavior was found for the turbulence variation across the rotor wake, as shown in Figures $5.12(C), 5.12(D), 5.13(C)$, and 5.13(D). The stators influence on the rotor wake velocity deficit and turbulence will be discussed further, in the following sections, with respect to the velocity correlations (see Eq. (4.11)) identified from the development of the average passage equation system.

Similar blade-row interaction effects have been observed by Matsuuchi and Adachi [31] who measured the flow field inside a rotor passage of an 
10\% STREAM SURFACE
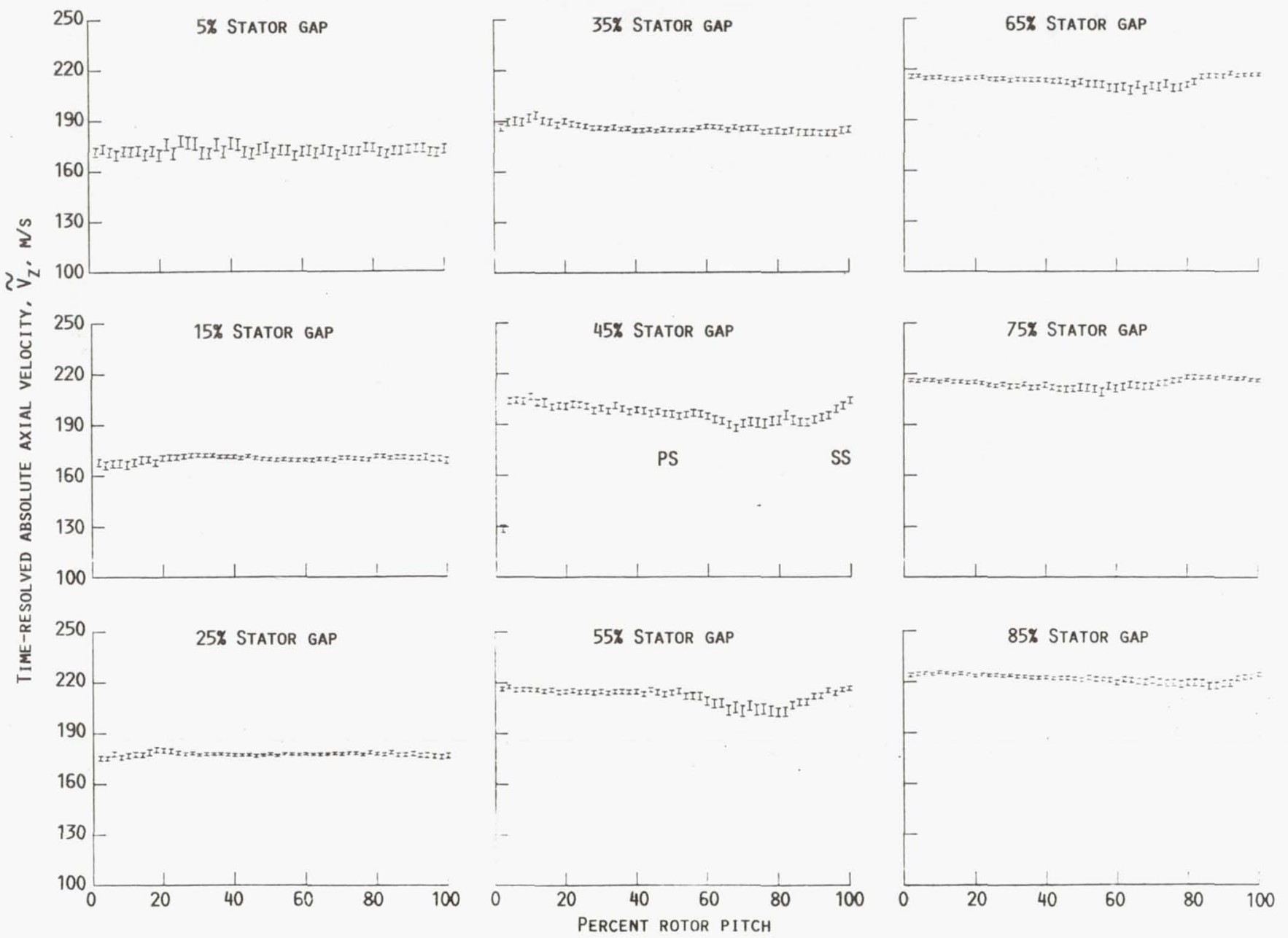

(A) AXIAL Velocity, $\widetilde{v}_{\mathrm{Z}}$.

Figure 5.12 Time-resolved character of rotor wake along the 10 percent stream surface 

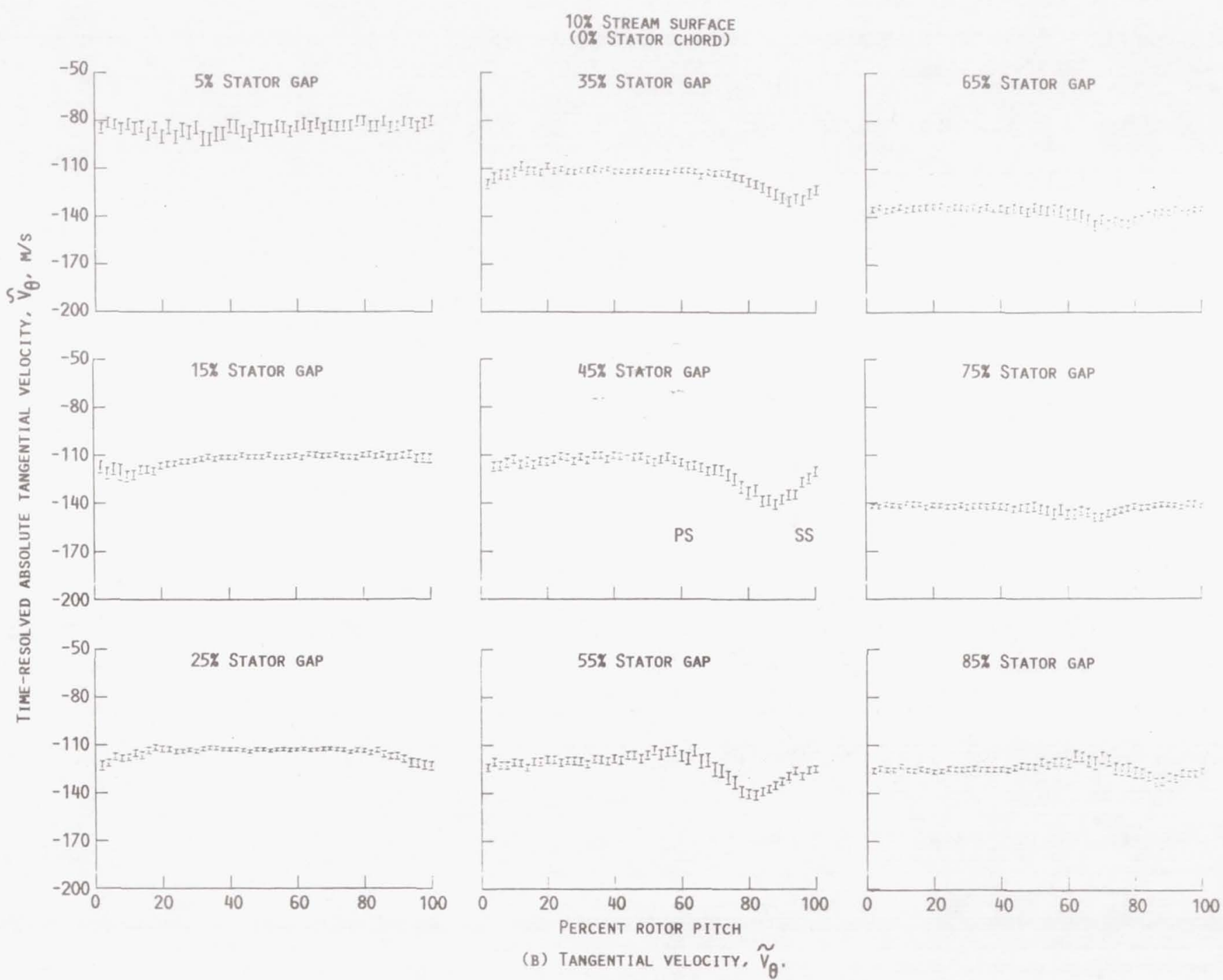

Figure 5.12 Continued 


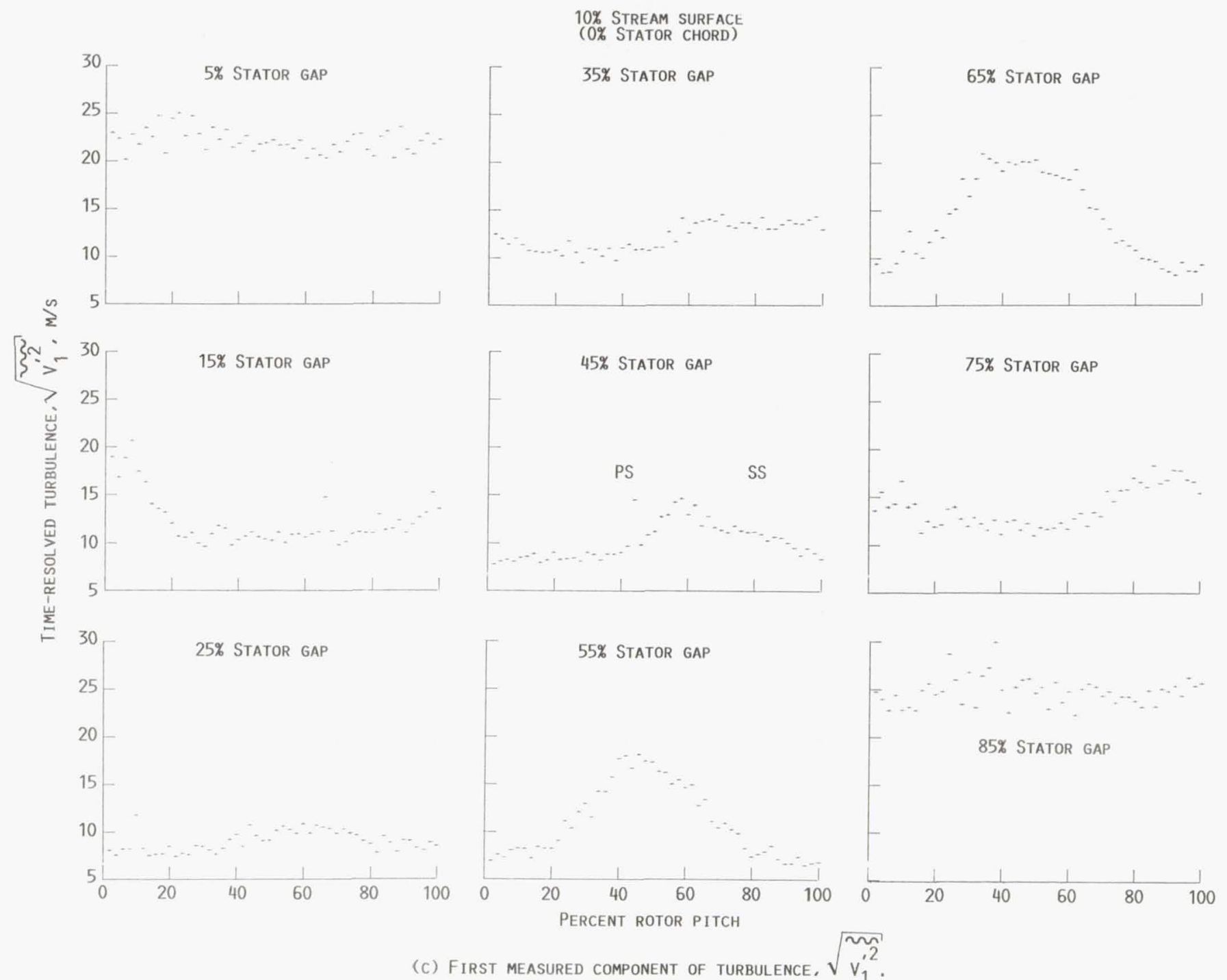

Figure 5.12 Continued 


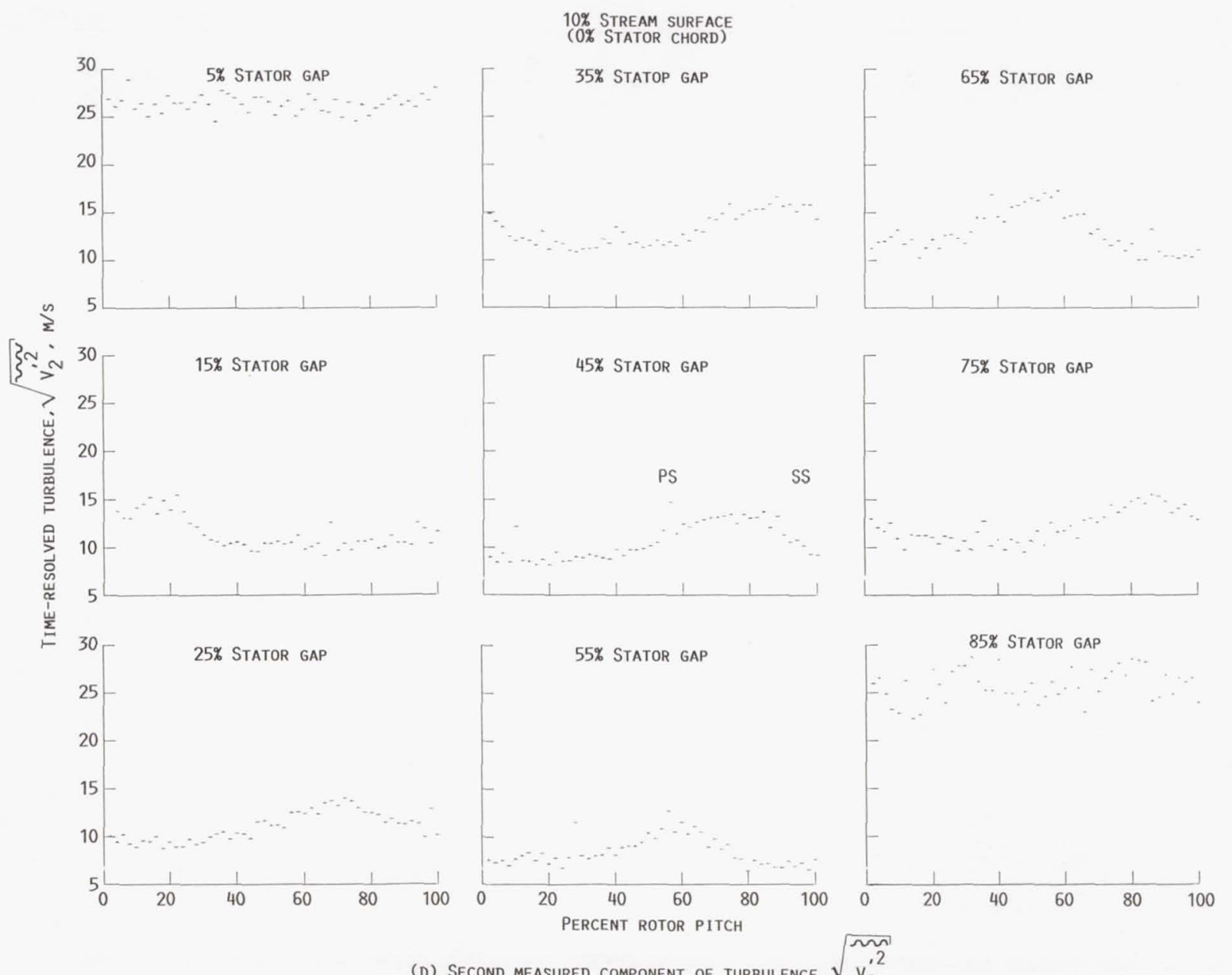

(D) Second MeAsured COMPonent OF tURBUlence, $\sqrt{v_{j}^{\prime 2}}$.

Figure 5.12 Continued 

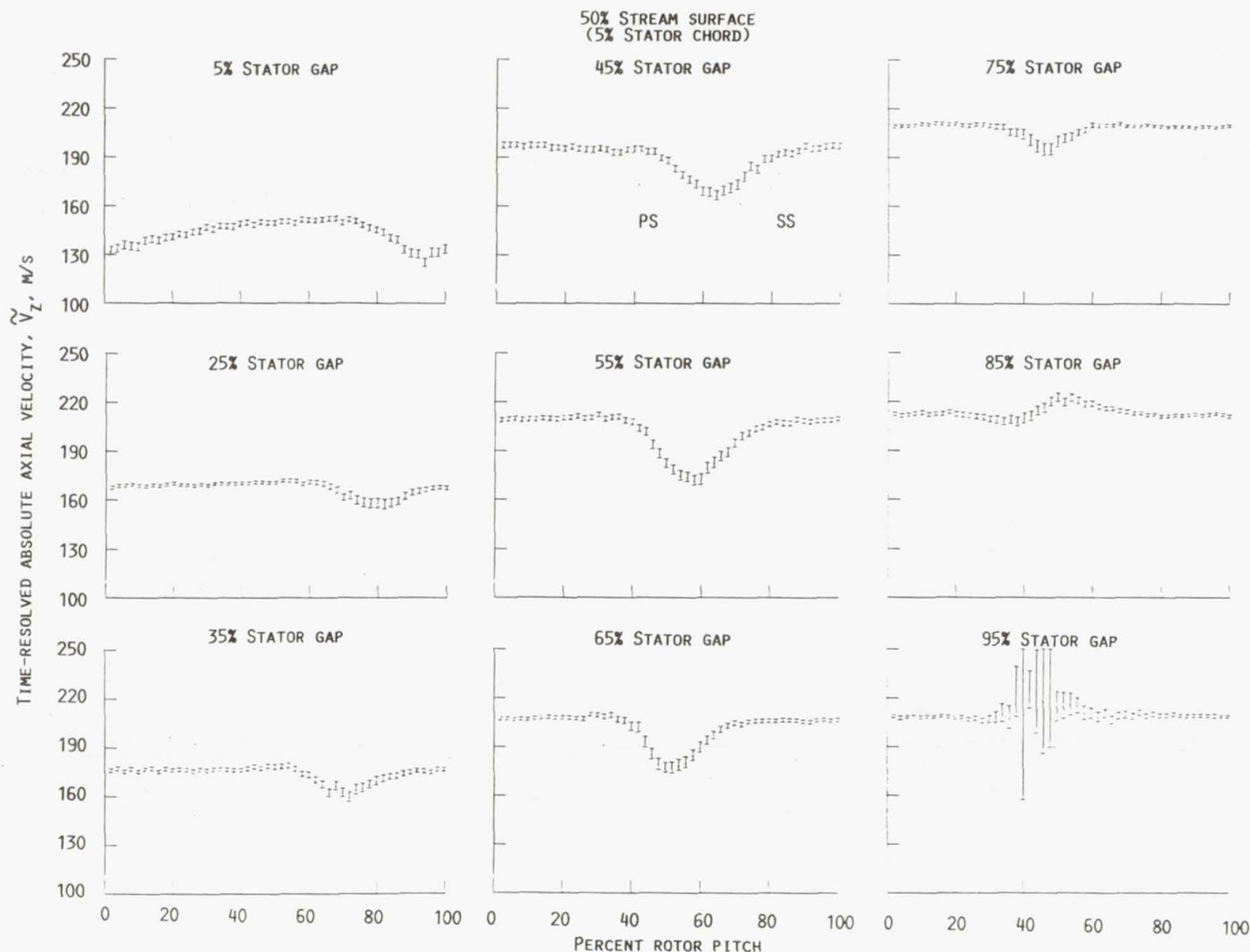

(A) AXIAL Velocity, $\tilde{v}_{Z}$

Figure 5.13 Time-resolved character of rotor wake along the 50 percent stream surface 

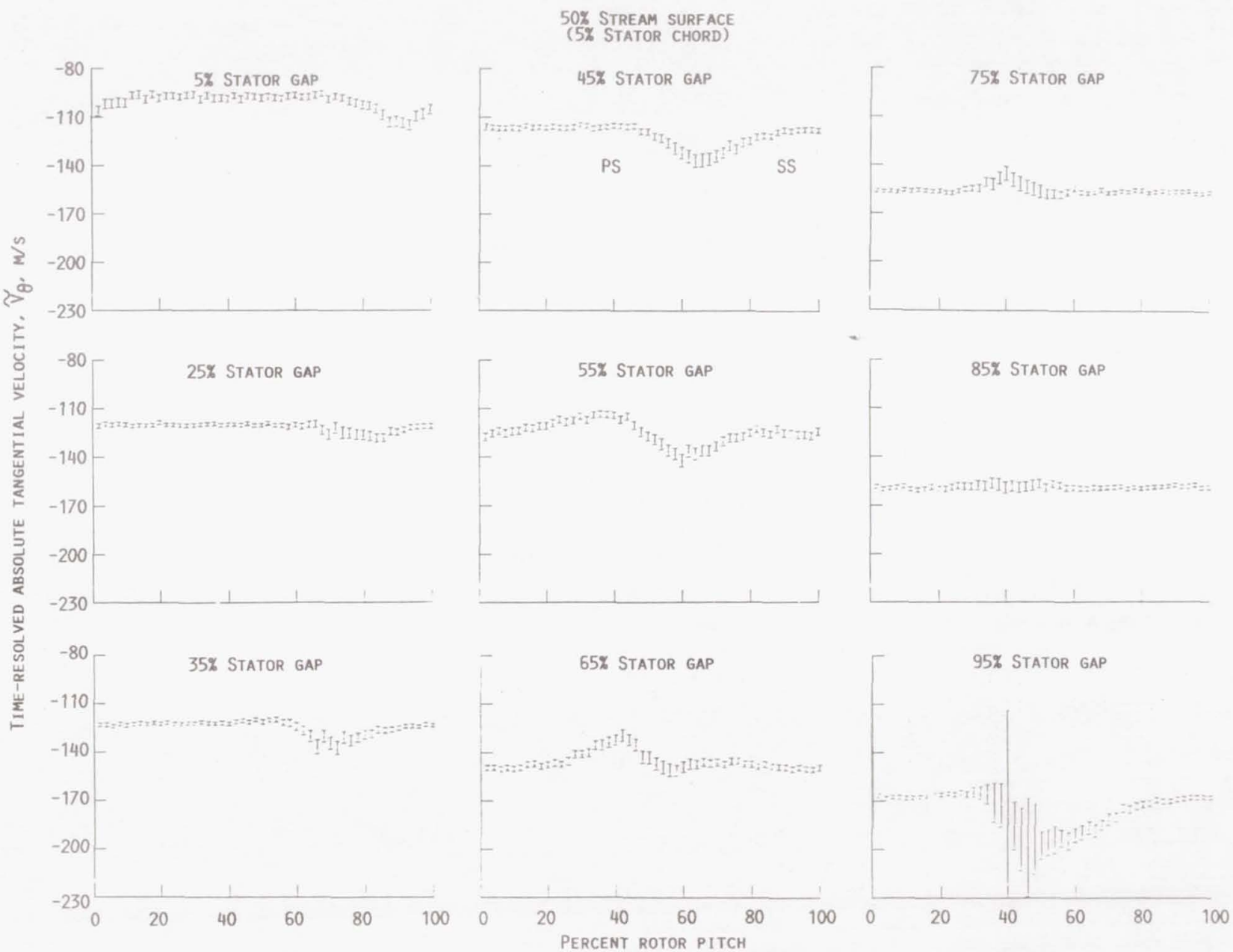

(B) TANGential velocity, $\widetilde{v}_{\theta}$

Figure 5.13 Continued 


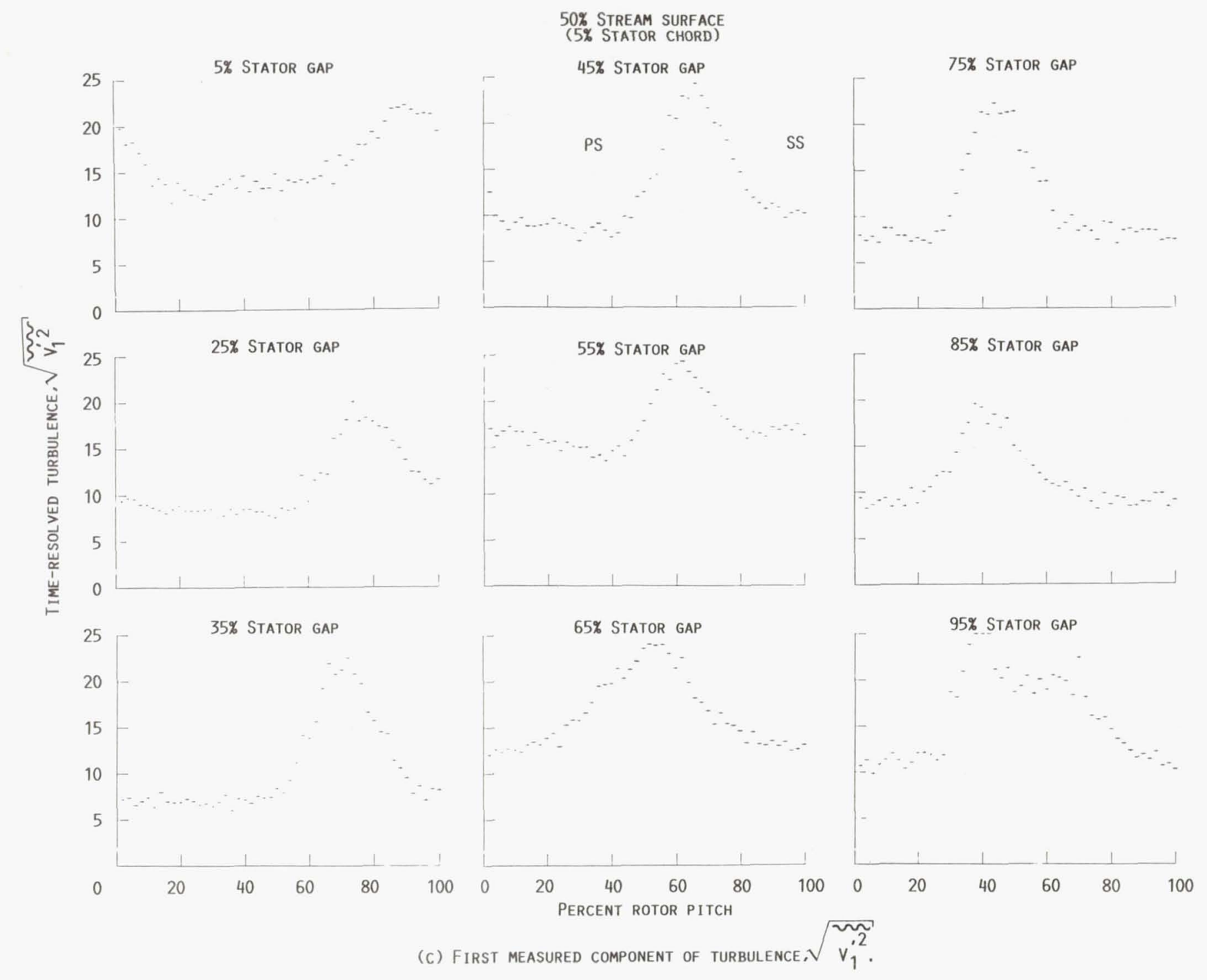

Figure 5.13 Continued 


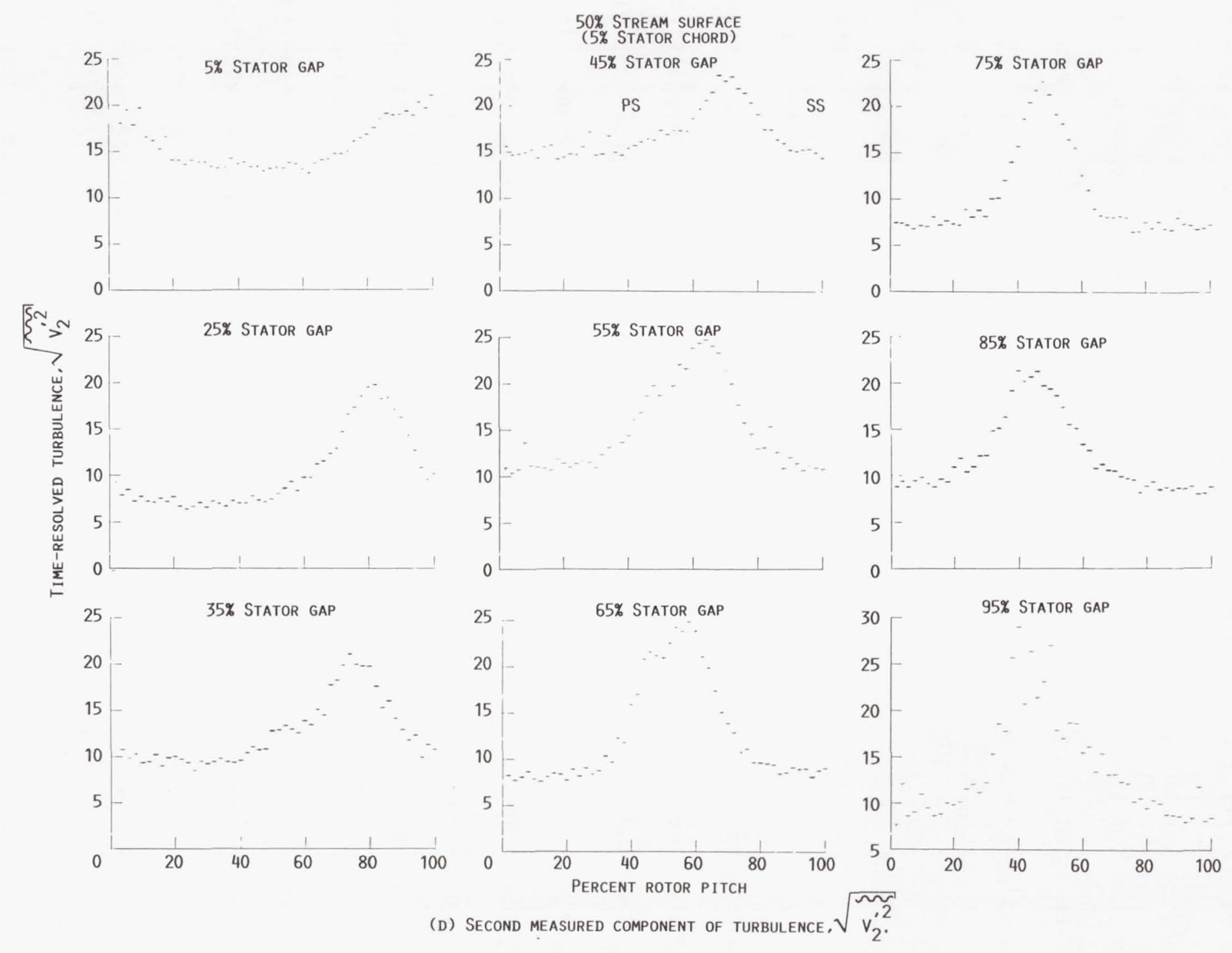

Figure 5.13 Continued 
axial flow fan using a rotating hot-wire anemometer. They observed that the wakes from the upstream inlet guide vanes became deeper and sometimes wider as the not-wire was circumferentially traversed closer to the rotor pressure surface. They attributed this behavior to the jet like character of the inlet guide vane wakes sucking fluid from the suction surface and impinging on the pressure surface.

\section{B. Unsteady-Velocity Correlations}

The average passage equation system was developed in order to provide an improved mathematical model for simulating the three-dimensional flow field in multistage turbomachines which would be consistent with current turbomachine design systems. As a result, the average passage equation system depicts a steady-state flow field in which, with respect to a given blade row, the flow is spatially periodic from passage to passage. In addition, the average passage equation system includes spatial derivatives of the aperiodic-, unsteady-deterministic-, and random-velocity correlations which were identified by Adamczyk as the major contributors to the generation of nonaxisymmetric flows in multistage turbomachines. In order to solve the average passage system of equations it is necessary to develop models to predict the behavior of these velocity correlations, and in order that modeling efforts are focused on the most significant terms, the relative importance of each of these velocity correlations should be assessed. The magnitudes and distributions of the unsteadydeterministic- and random-velocity correlations which were determined from LFA measurements of the unsteady velocity field within the stator row of the research compressor are presented in this section. All velocity 
correlations presented herein are independent of time. The totaldeterministic - and turbulent-velocity correlations are functions of $R, Z, \theta$, while the incident-velocity correlations are functions of $R, Z$ only.

\section{Deterministic-velocity correlations}

Figures 5.14 and 5.15 show contour maps of the axial, tangential, and cross components of the total-deterministic-velocity correlations (TDVC, see Eq. 4.14) along the 10 and 50 percent axisymmetric stream surfaces, respectively. As expected, see Figure 5.15(A) for example, the axial component of the TDVC decreases rapidly downstream of the rotor trailing edge as a result of the rapid decay of the rotor wake. However, instead of continuing to decrease, the axial component of the TDVC appears to increase again locally, near the stator leading edge region at about mid passage. This same behavior also occurs for the tangential and cross components of the TDVC, except less pronounced, and also along the 10 percent stream surface, see Figures 5.14 and 5.15 .

Circumferential (blade-to-blade) line plots of the axial, tangential, and cross components of the TDVC at various axial survey stations are shown in Figures 5.16 and 5.17 for the 10 and 50 percent axisymmetric stream surfaces, respectively. These line plots provide a more quantitative indication of the increase in the TDVC which occurs near the stator leading edge. The axisymmetric free stream velocity $\left(V_{F S}=235 \mathrm{~m} / \mathrm{s}\right)$ upstream of the stator potential field is used to assess the relative intensity of the total deterministic-velocity fluctuations. Referring to

Figure 5.17, the axial component of the TDVC decreases from about $190 \mathrm{~m}^{2} / \mathrm{s}^{2}$ ( 6 percent $\left.V_{F S}\right)^{2}$ at -70 percent stator chord to about $80 \mathrm{~m}^{2} / \mathrm{s}^{2}$ 

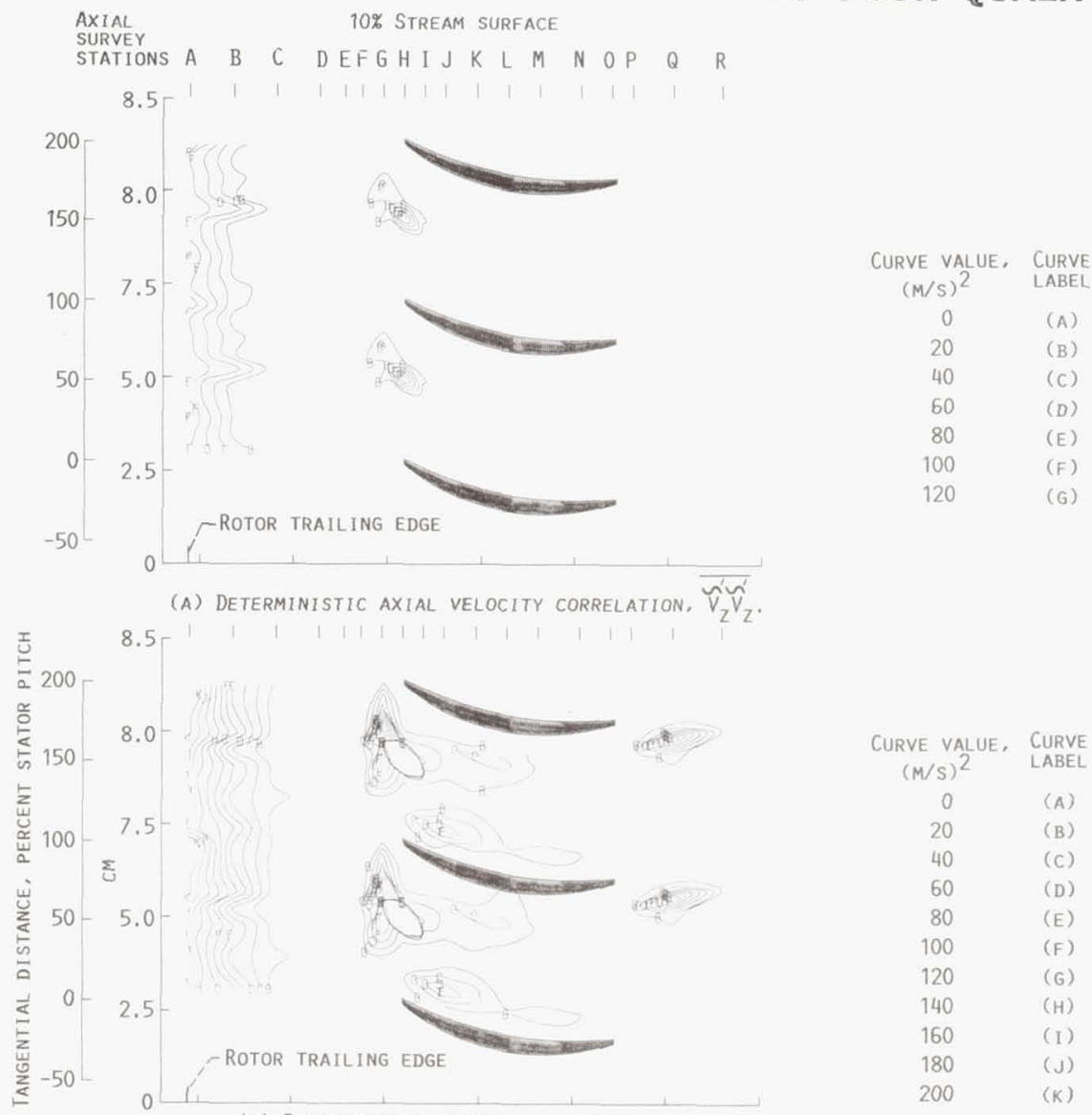

(B) Deterministic tANGENTIAL VELOCity CORRELATION, $\overline{\widetilde{V}_{\theta}^{\prime} \widetilde{V}_{\theta}^{\prime}}$

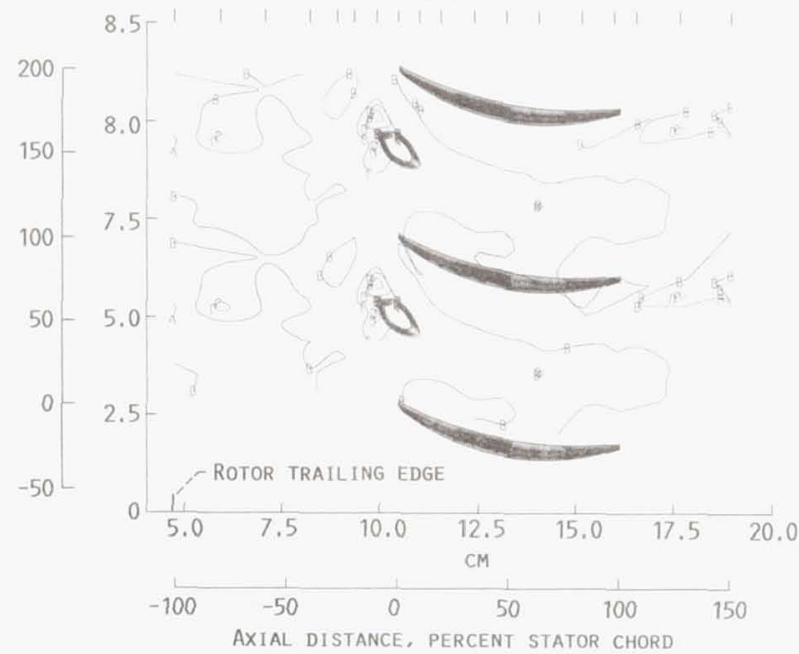

CuRVE VALUE, CURVE $(M / S)^{2}$

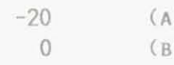

20 (C)

$40 \quad$ (D)

$60 \quad(E)$

$80 \quad(F)$

$100 \quad$ (G)

$120 \quad$ (H)

$140 \quad$ (I)

$180 \quad(\mathrm{~K})$

$200 \quad(\mathrm{~L})$

(C) DETERMINISTIC VELOCITY CROSS CORRELATION, $\overline{\widetilde{V}_{Z}^{\prime} \widetilde{V}_{\theta}^{\prime}}$.

Figure 5.14 Contour maps of the total-deterministic-velocity correlations along the 10 percent stream surface 


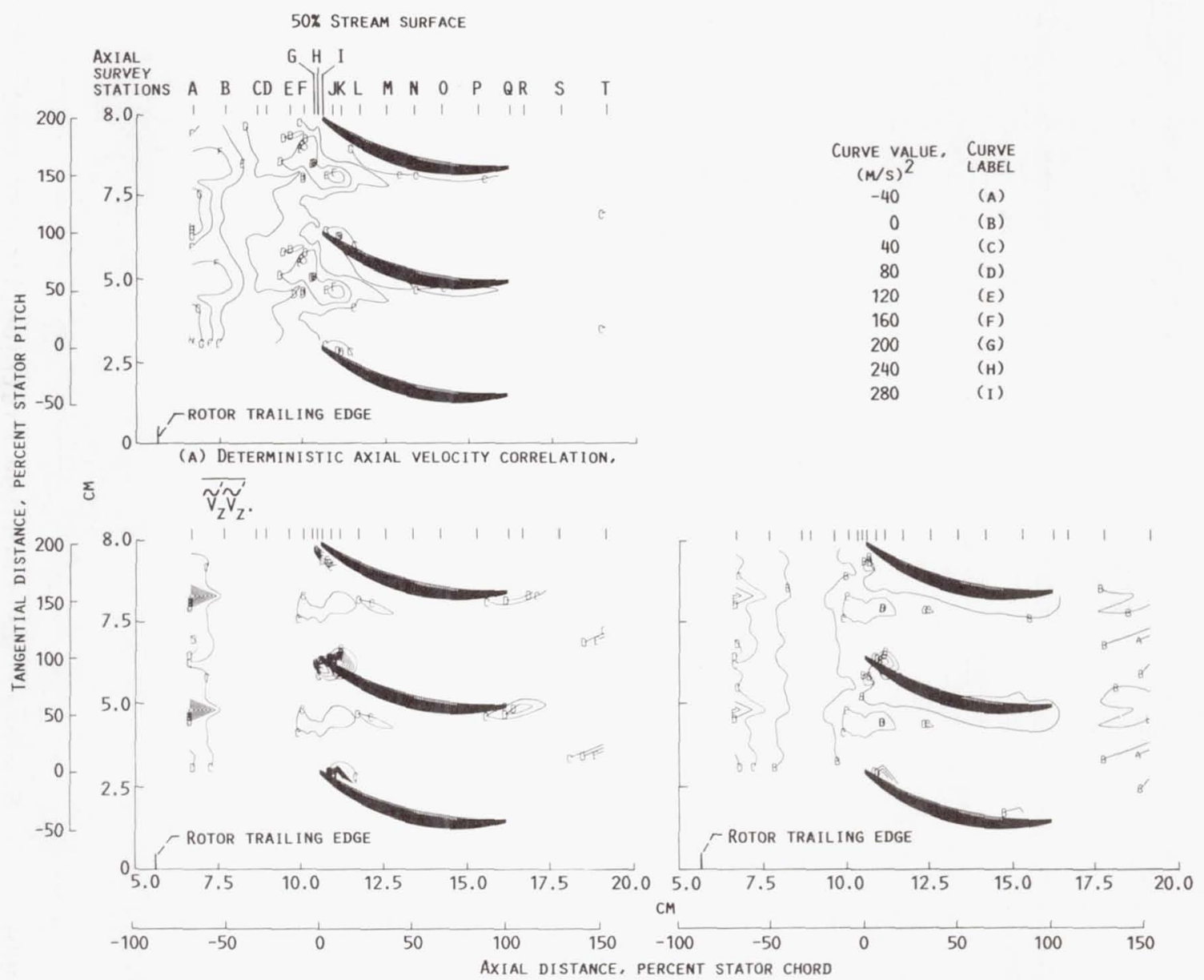

(B) Deterministic tangential Velocity CORRELAtion, $\overline{\widetilde{v}_{\theta}^{\prime} v_{\theta}^{\prime}}$.

(C) DETERMINISTIC VELOCITY CROSS CORRELATION. $\overline{v_{z}^{\prime} \hat{v}_{\theta}^{\prime}}$.

Figure 5.15 Contour maps of the total-deterministic-velocity correlations along the 50 percent stream surface 

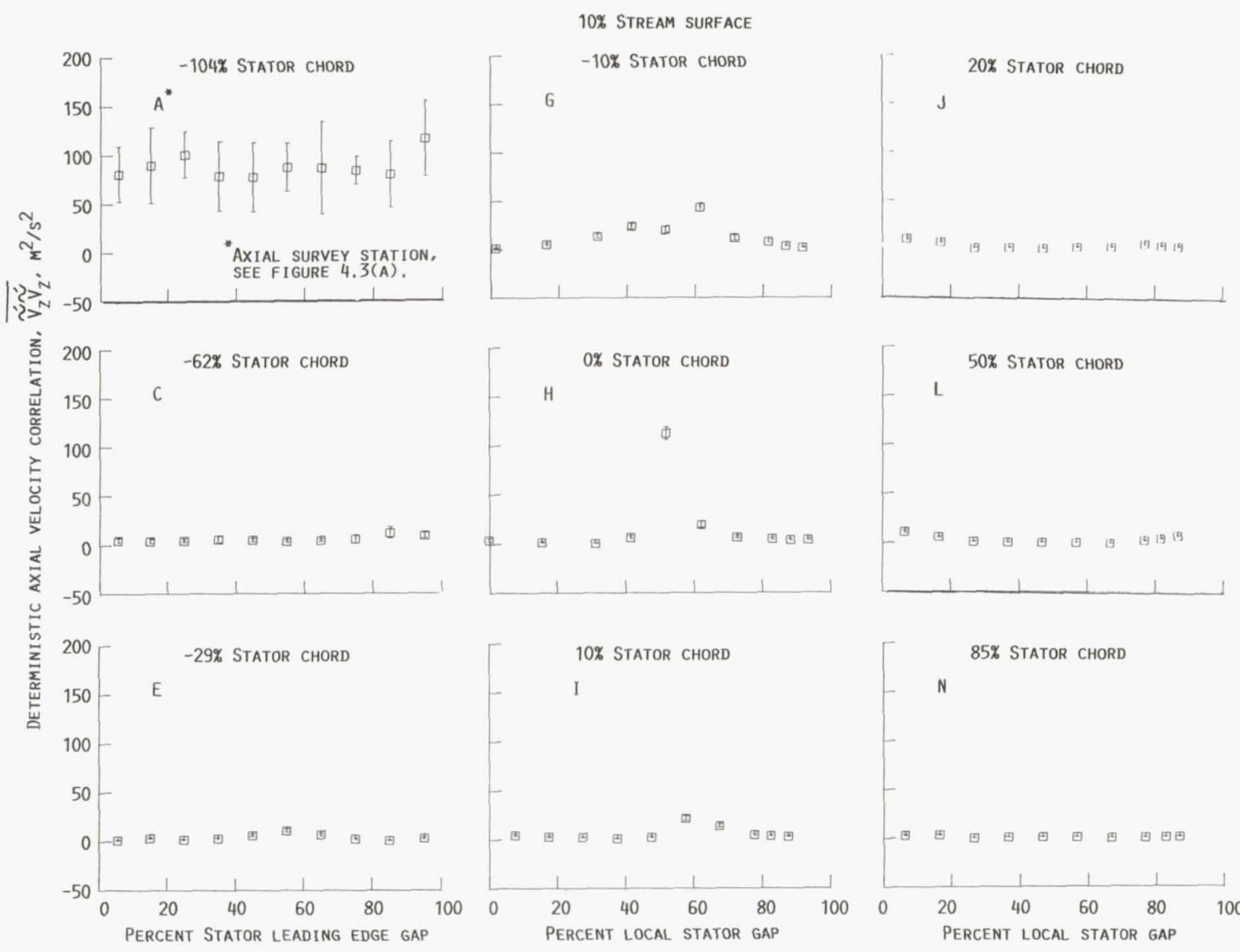

Figure 5.16 Stator blade-to-blade distributions of the total-deterministic-velocity correlations along the 10 percent stream surface 
10\% STREAM SURFACE
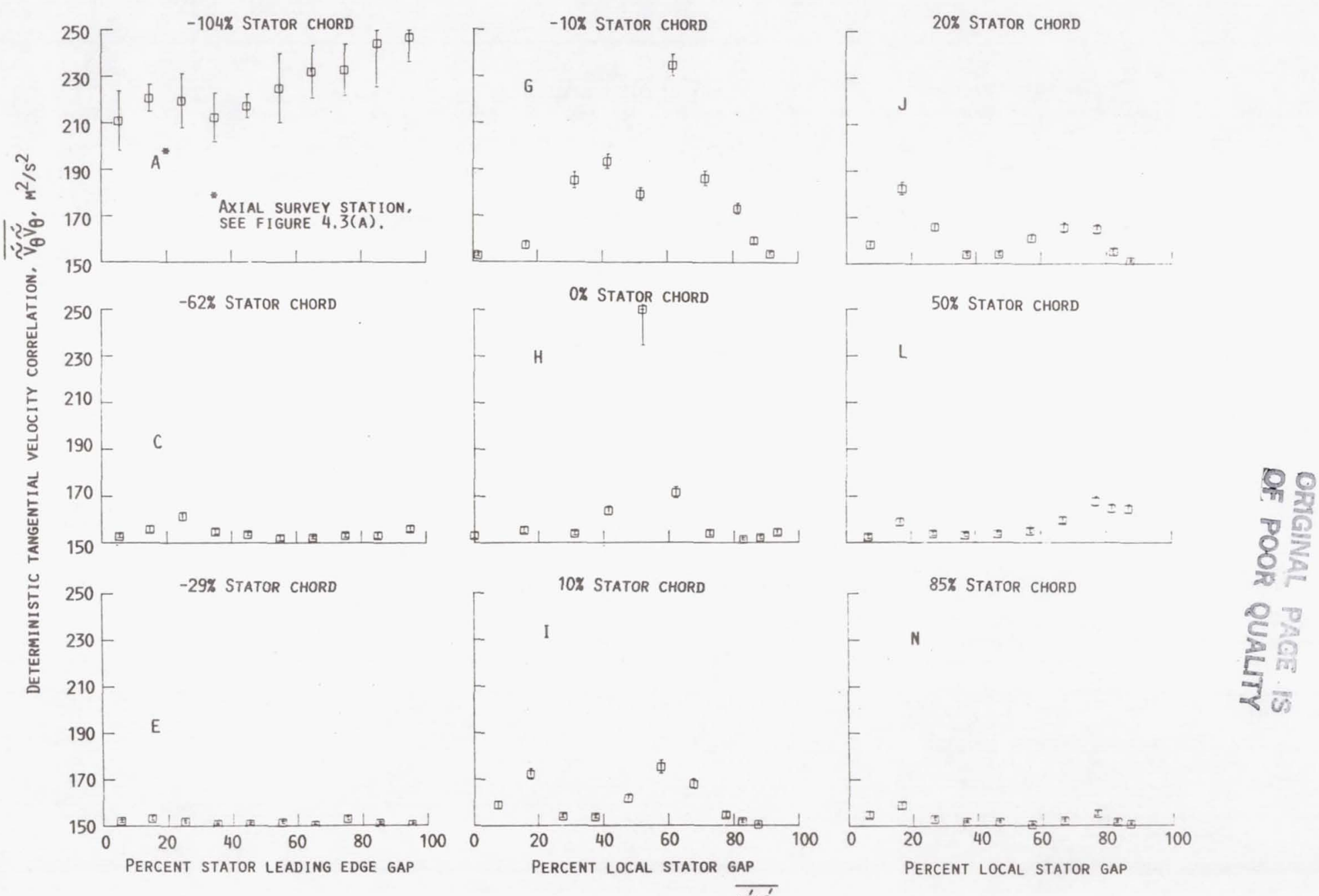

(B) TANGential COMPONENT, $\widehat{V}_{\theta}^{\prime} \widehat{V}_{\theta}^{\prime}$.

Figure 5.16 Continued 

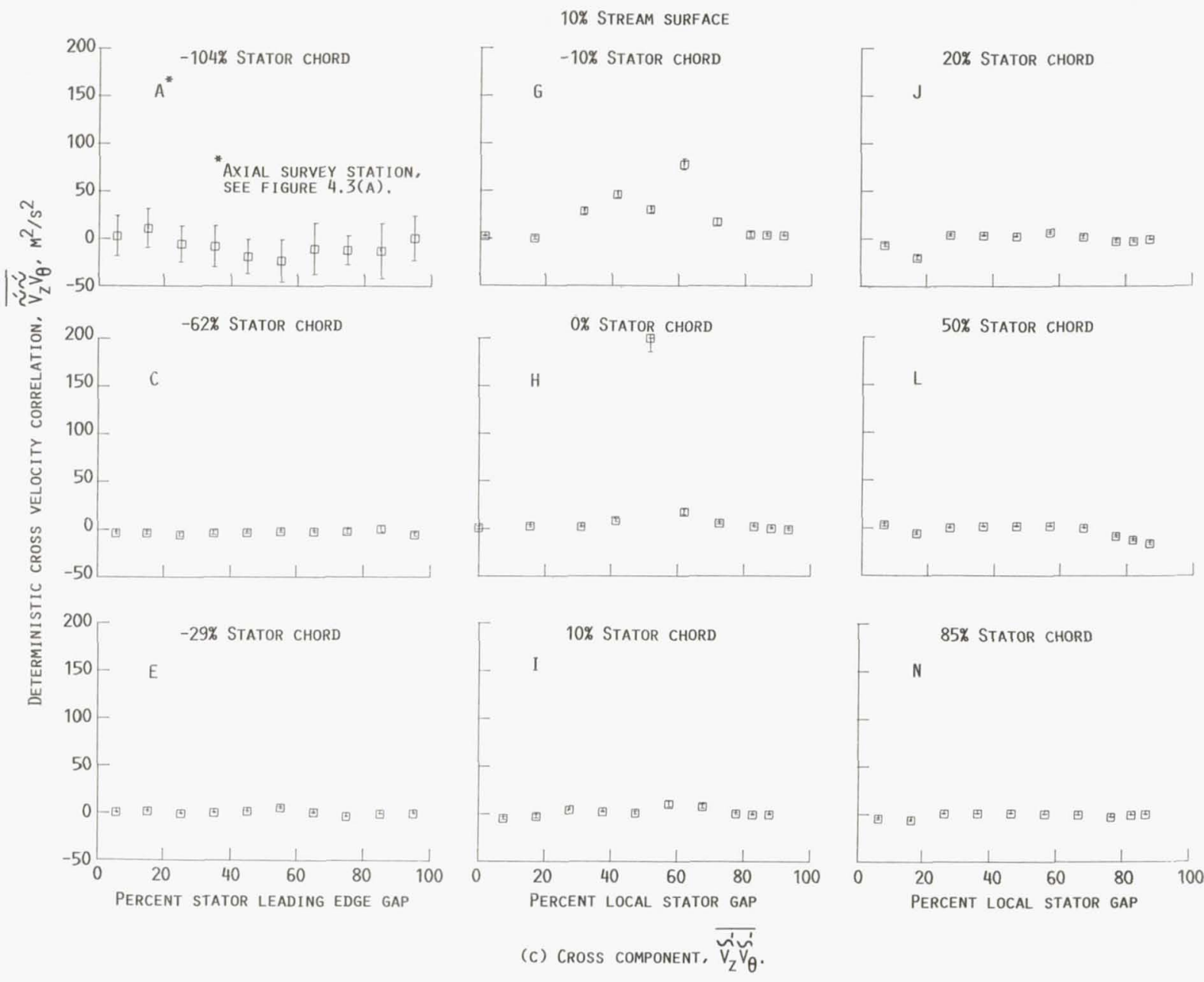

Figure 5.16 Continued 

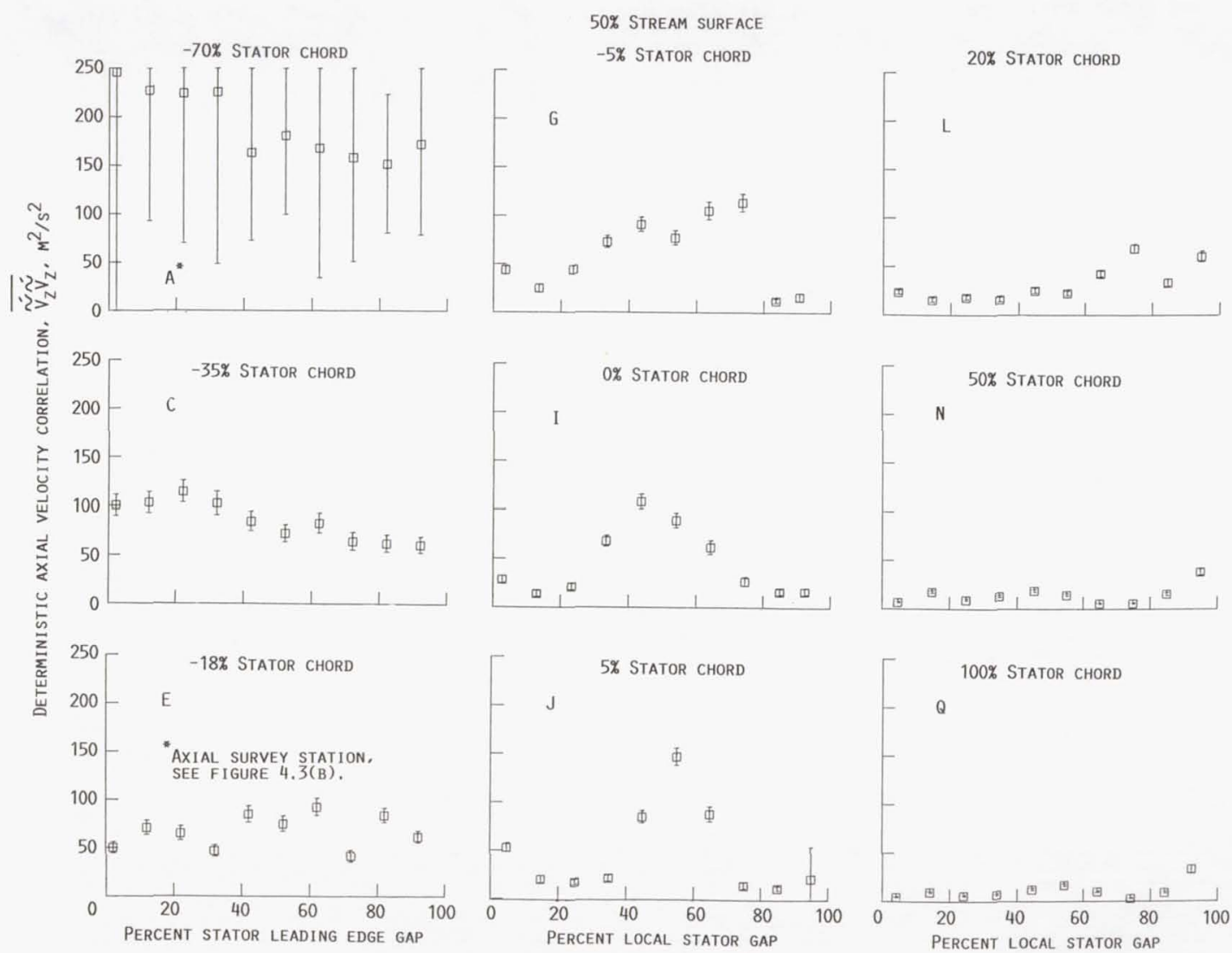

Figure 5.17 Stator blade-to-blade distributions of the total-deterministic-velocity correlations along the 50 percent stream surface 

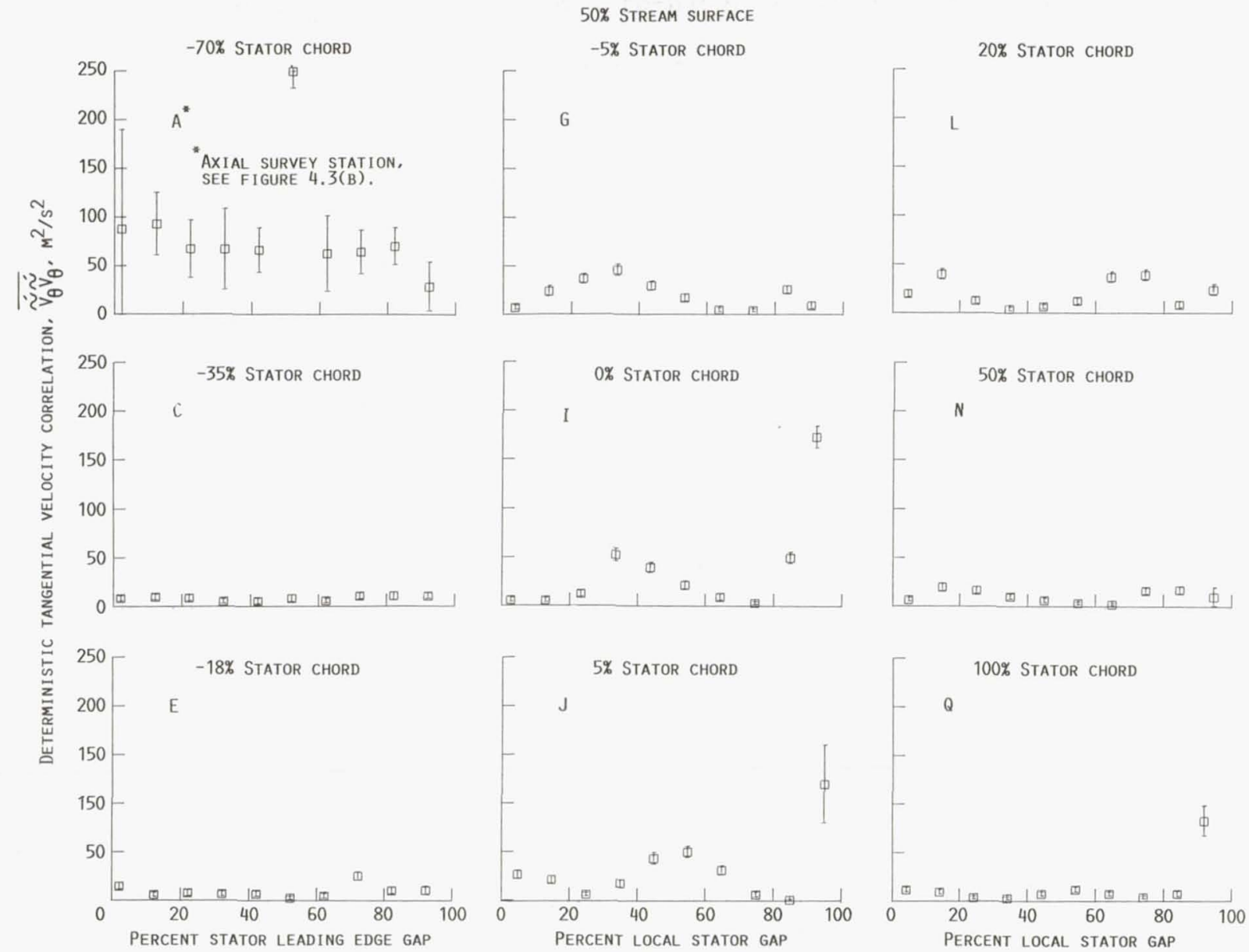

(B) TAngential Component, $\overline{\widetilde{v}_{\theta} \tilde{V}_{\theta}}$.

Figure 5.17 Continued 

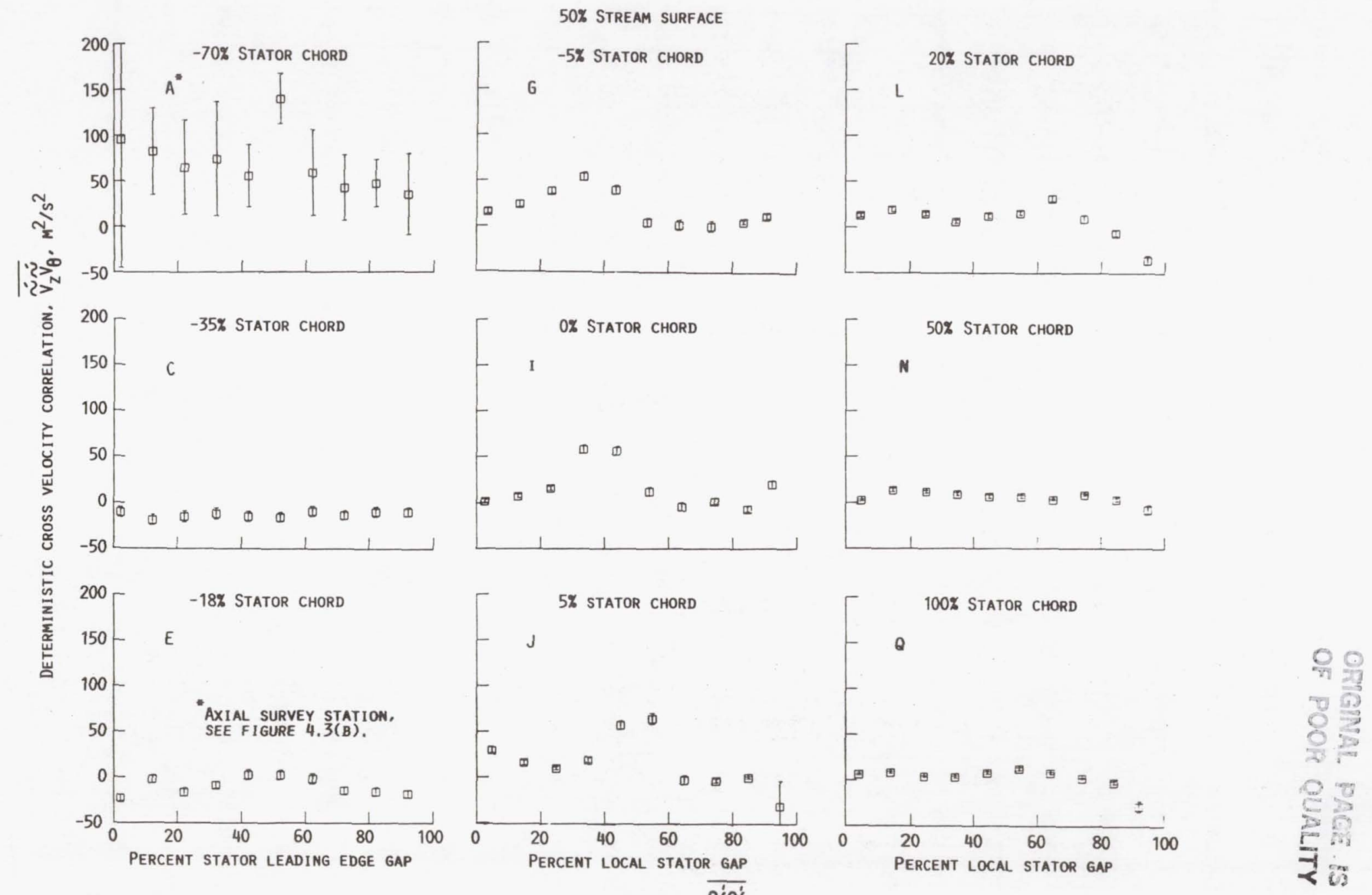

(c) CROSS COMPONENT, $\overline{\widetilde{v}_{\mathrm{Z}}^{\prime} \tilde{V}_{\theta}}$.

Figure 5.17 Continued 
(4 percent $\left.V_{F S}\right)^{2}$ at -18 percent of stator chord. From -18 percent stator chord to the stator exit the axial component of the TOVC continues to decrease to less than $25 \mathrm{~m}^{2} / \mathrm{s}^{2}$ (2 percent $\left.V_{F S}\right)^{2}$ from about 50 percent stator chord on, except in a region from about -18 to 10 percent of stator chord where the axial component of the TDVC increases near mid passage to a maximum of about $150 \mathrm{~m}^{2} / \mathrm{s}^{2}$ (5 percent $\left.V_{F S}\right)^{2}$ at 5 percent stator chord. Although considerably weaker, similar increases in the TOVC occur along the 10 percent stream surface and for the tangential and cross components of the TOVC.

In Section IV.B.3 an analogy to gust theory was used to further decompose the TDVC. In the following paragraphs this gust analogy will be used to help explain the origins of the observed increase in the TDVC. In Equation (4.12), the parameter $\mathcal{Q}^{R}$ is the rotor-relative time-averaged absolute velocity (Appendix B) which provides a description of the flow field from the perspective of an observer riding on the rotor blades, see Figures 5.4 to 5.6. The rotor-relative time-averaged velocity is used as a model of the undisturbed rotor wake which would occur in the absence of the stator blade row. The rotor-relative time-averaged velocity is, of course, independent of stator circumferential position, and only varies in time (rotor/stator relative position) and with axial distance. If the axisymmetric absolute velocity is subtracted from the rotor-relative time-averaged absolute velocity (Eq. 4.13), the result is the deterministic unsteadiness associated with the undisturbed rotor wake, and in the analogy with gust theory represents the incident gust.

Figures 5.18 and 5.19 show the axial distributions of the axial, tangential, and cross components of both the TDVC and the deterministic 


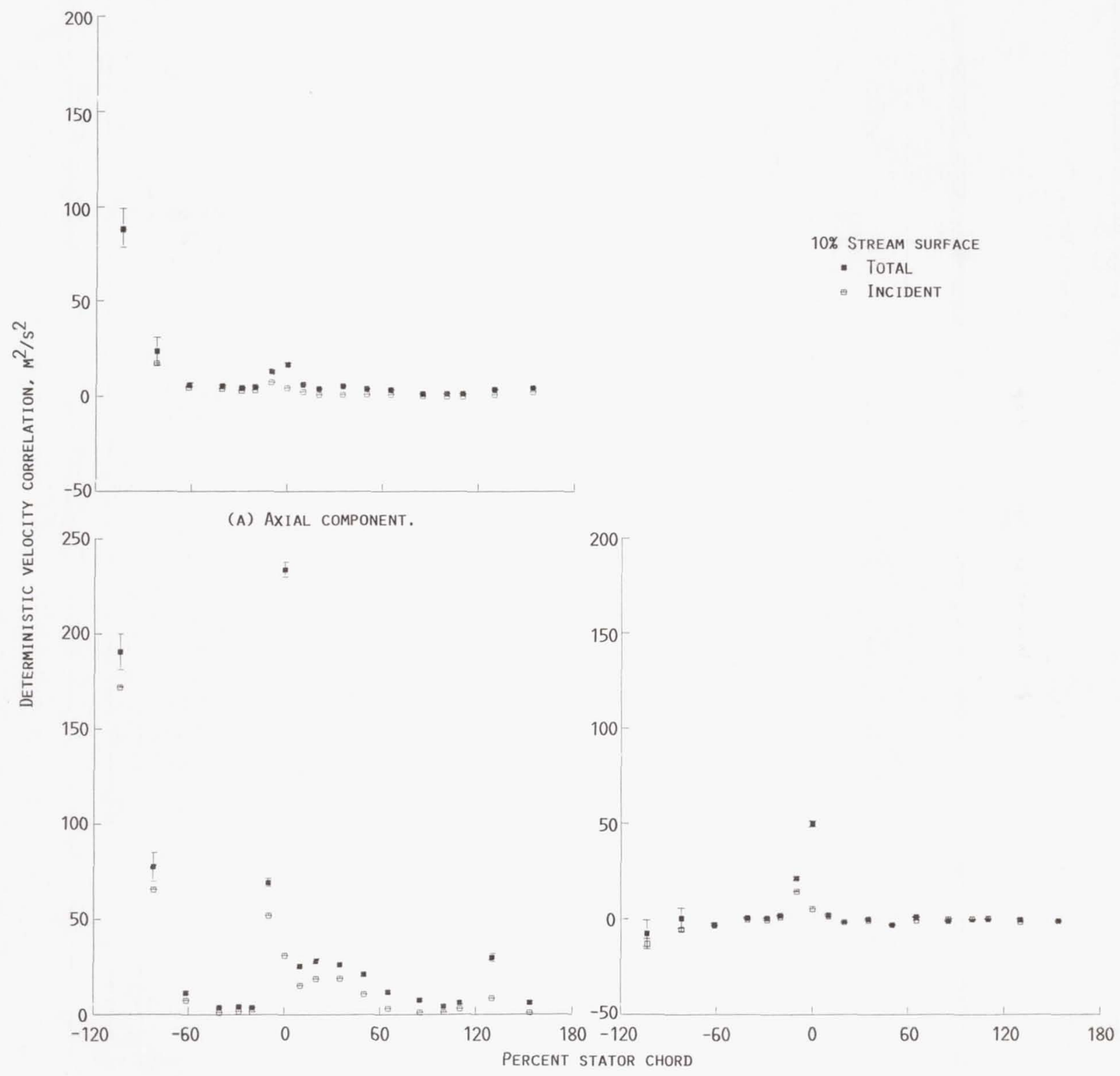

(B) TANGENTIAL COMPONENT.

(c) CROSS COMPONENT.

Figure 5.18 Axial distributions of the axisymmetric total-deterministic- and incident-velocity correlations along the 10 percent stream surface 


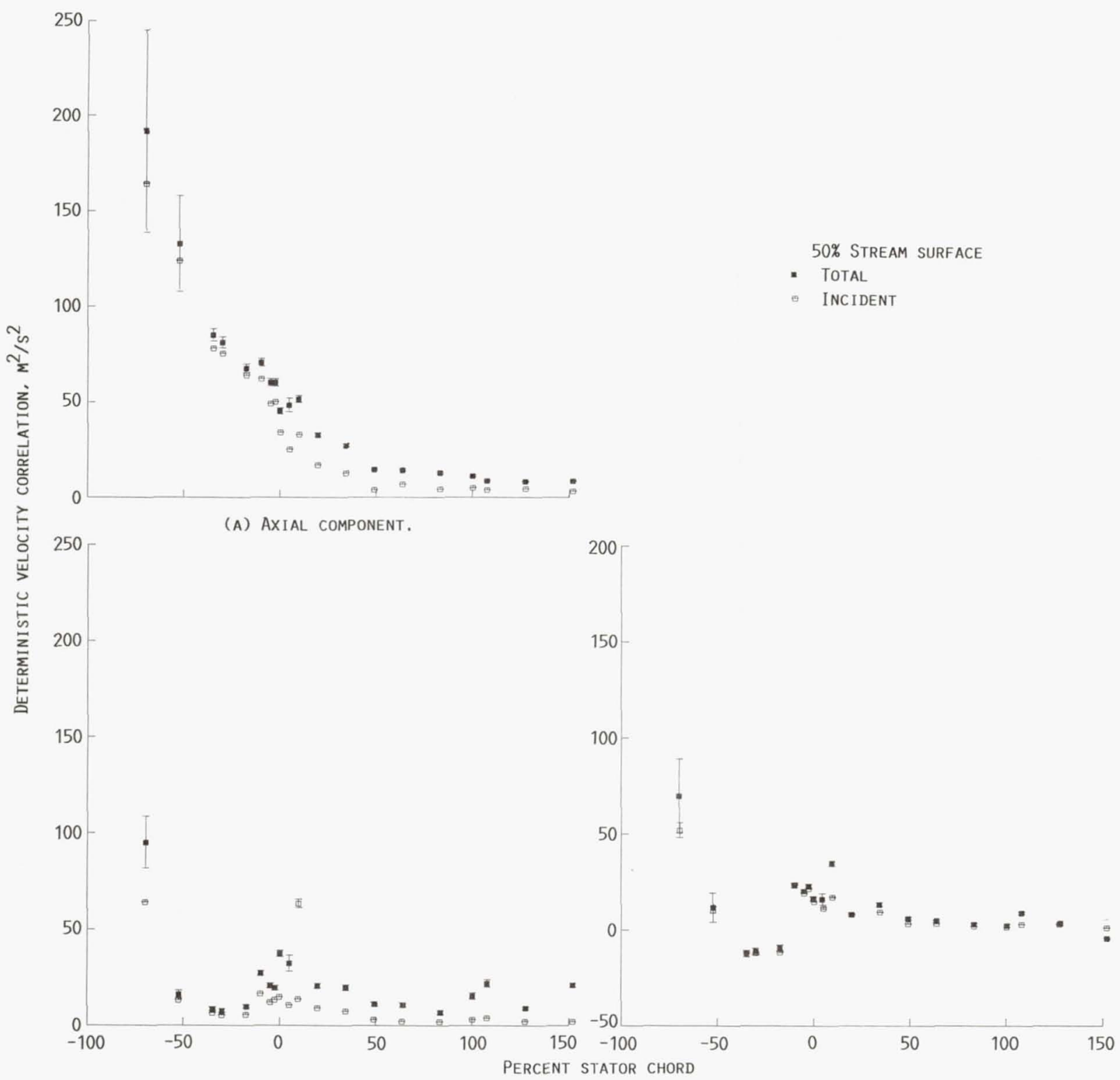

(B) TANGENTIAL COMPONENT.

(c) CROSS COMPONENT.

Figure 5.19 Axial distributions of the axisymmetric total-deterministic- and incident-velocity correlations along the 50 percent stream surface 
velocity correlations of the incident gust (IDVC, see Eq. (4.14)) along the 10 and 50 percent axisymmetric stream surfaces, respectively. The TDVC and IDVC are about the same magnitude, which indicates that the effects of blade row interactions must be small. The greatest variation between the TDVC and IDVC occurs within the stator row, see Figure 5.19(A) for example, but by this time the rotor wake has substantially decayed. A model which would predict the incident rotor wake decay could, therefore, be used to estimate the TOVC, at least for the wide axial spacing between blade rows in the present research compressor.

Also shown in Figures 5.18 and 5.19 are abrupt increases in the TDVC and IDVC which occur at the interface between the interblade- and intrablade-row surveys (which also coincides with the start of the stator potential field, see Figs. 5.1 and 5.2 ). It is unclear whether these abrupt increases in the TOVC and IDVC are real or due to a mismatch between the interblade- and intrablade-row surveys. A comparison between the interblade- and intrablade-row measurements of the TDVC and IDVC at 0 and 10 percent stator axial chord was inconclusive as the interblade-row survey at those axial locations could not be completed. During the interblade-row survey, the rotor window frame blocked the collection of data near the stator suction surface and significantly increased the data acquisition times for the remainder of the survey points at 0 and 10 percent stator axial chord, which affected the quality of the measurements.

Again referring to Equation (4.12), the parameter $\mathcal{V}^{U}$ represents the deterministic unsteadiness resulting from blade-row interactions. In other words, $\mathcal{Q}^{\mathrm{U}}$ represents the departure from $\mathcal{Q}^{\mathrm{R}}$ which results from the influence of the stator blade row, and will be subsequently referred 
to as the scattered velocity. The total deterministic velocity unsteadiness is the sum of the unsteadiness associated with the incident and scattered velocities.

Figures 5.20 and 5.21 show contour maps of the axial, tangential, and cross components of the scattered deterministic velocity correlations (SDVC, see Eq. (4.14)) along the 10 and 50 percent axisymmetric stream surfaces, respectively. Referring to Figure $5.21(\mathrm{~A})$, the axial component of the SOVC is predominately zero throughout the stator flow field, except near the stator surfaces, immediately downstream of the rotor trailing edge, and near the stator leading edge at about mid passage (i.e., where the axial component of the TDVC was also high). Similar behavior is observed for the tangential and cross components of the SDVC, along the 10 percent stream surface. The contour maps of Figures 5.20 and 5.21 illustrate the effects of blade row interactions which are a result of the stators response to the incident rotor wake.

Figure $5.21(\mathrm{~A})$ also showed an increase in the axial component of the SDVC near the stator leading edge suction surface which was not apparent in the corresponding contour map of the axial component of the TDVC (Figure 5.15(A)). In fact, the axial component of the TDVC is decreasing towards zero at the stator leading edge suction surface, which is in direct contrast to the increase in the axial component of the SDVC at the same location. Referring to Equation (4.14), there is an additional component of the TOVC to be considered, which is associated with correlations between the the incident and scattered deterministic velocity unsteadiness. 


\section{ORIGINAL RAEE IS \\ OF POOR QUALTY}
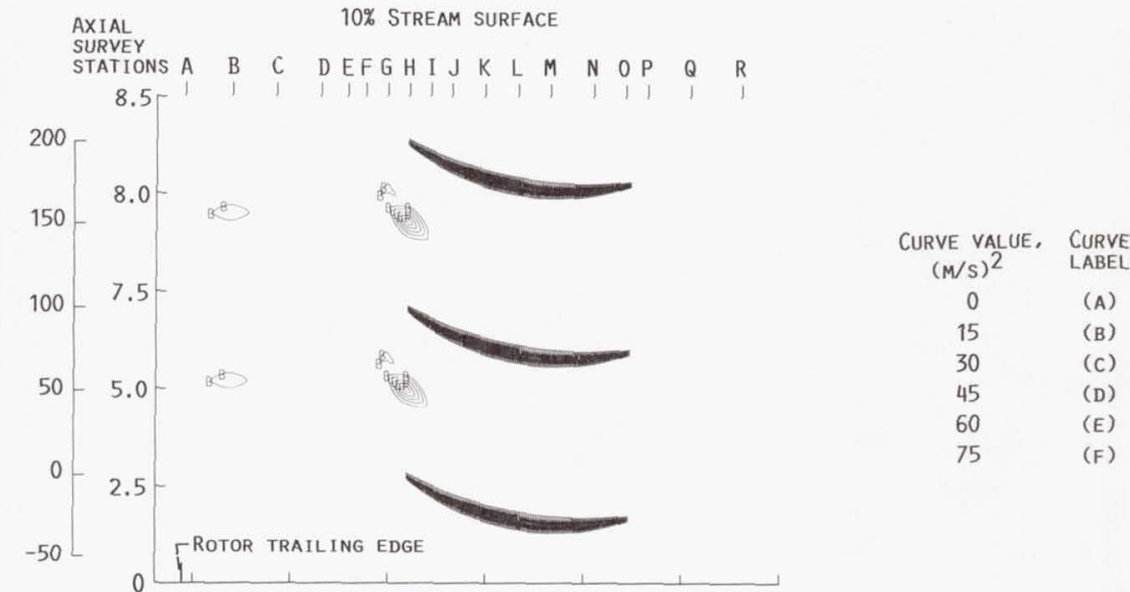

(A) AXIAL COMPONENT OF SCATTERED VELOCITY CORRELATION, $\overline{V_{Z}^{U} V_{Z}^{U}}$.

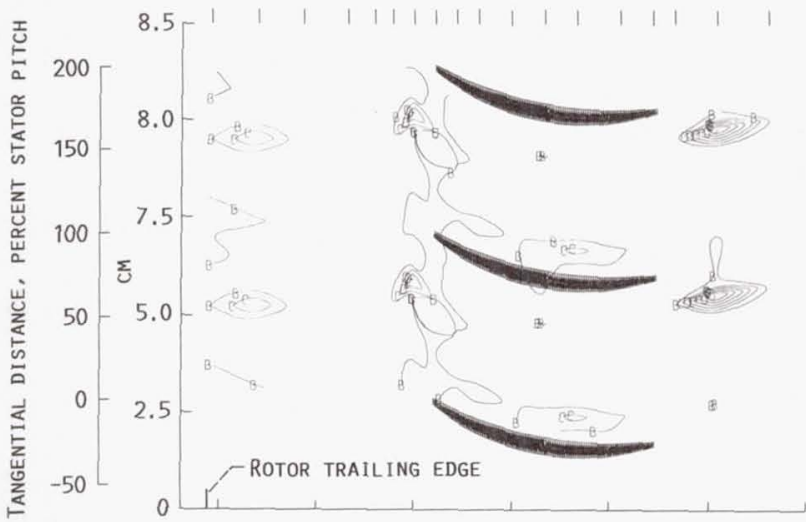

$$
\begin{array}{cc}
\begin{array}{c}
\text { Curve value, } \\
\text { (M/S })^{2}
\end{array} & \text { CuRve } \\
0 & \text { LABEL } \\
15 & \text { (A) } \\
30 & \text { (B) } \\
45 & \text { (C) } \\
60 & \text { (D) } \\
75 & \text { (E) } \\
90 & \text { (F) } \\
& \text { (G) }
\end{array}
$$

(B) TANGENTIAL COMPONENT OF SCATTERED VELOCITY CORRELATION, $\overline{V_{\theta}^{U} V_{\theta}^{U}}$.

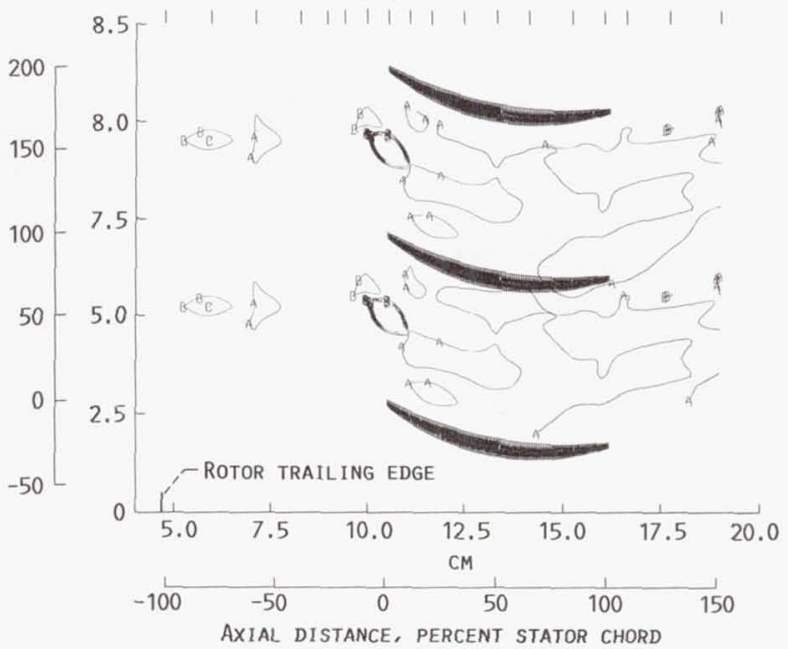

(c) CROSS COMPONENT OF SCATTERED VELOCITY CORRELATION, $\overline{V_{Z}^{U} V_{\theta}^{U}}$. 

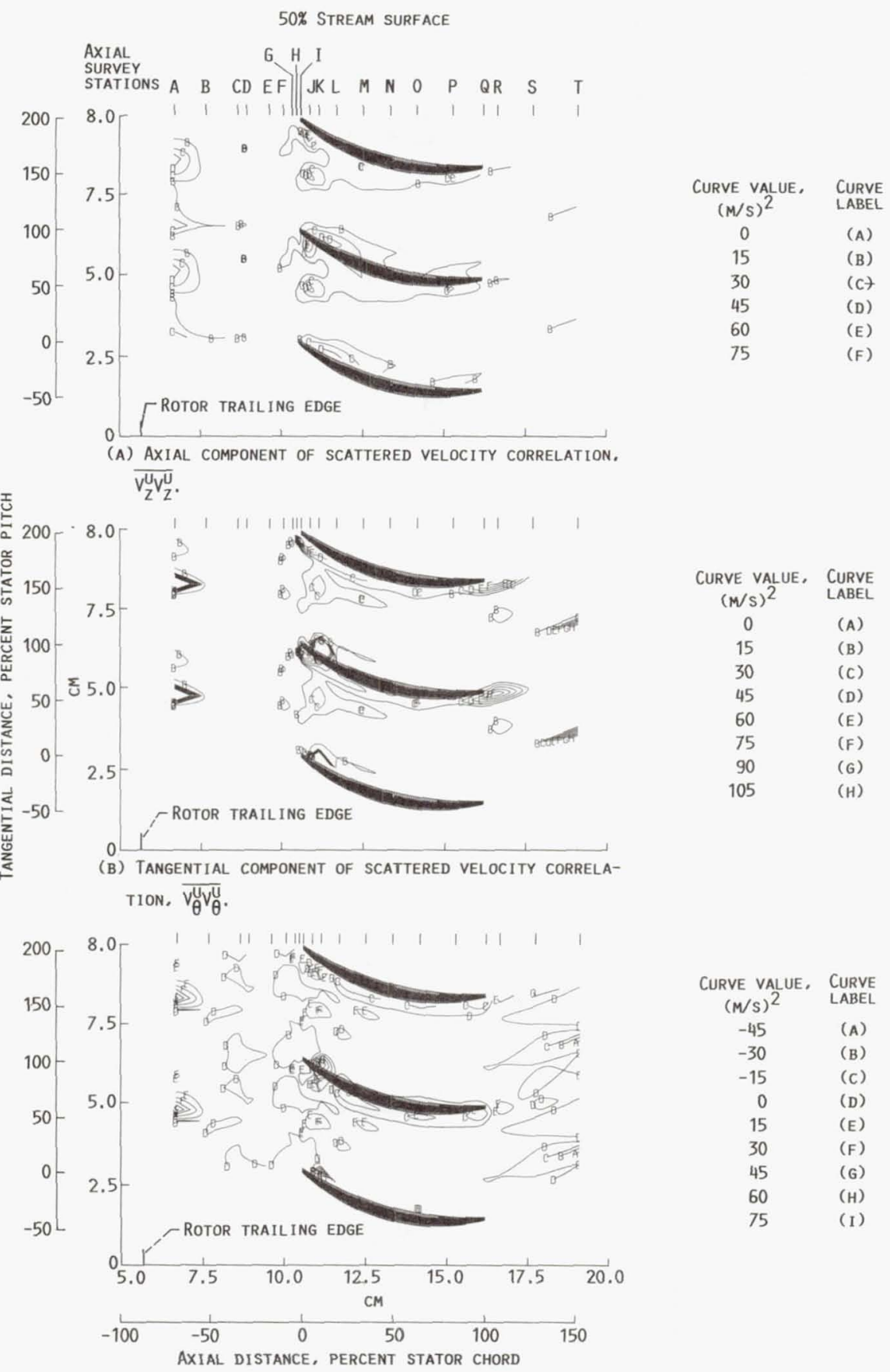

(c) CROSS COMPONENT OF SCATTERED VELOCITY CORRELATION, $\mathrm{v}_{\mathrm{z}}^{\bar{U} v_{\theta}^{\mathrm{U}}}$.

Figure 5.21 Contour maps of the scattered-velocity correlations along the 50 percent stream surface 
Figures 5.22 and 5.23 show contour maps of the axial, tangential, and cross components of the correlations between the incident and scattered unsteadiness, (ISVC, see Eq. (4.14)) along the 10 and 50 percent axisymmetric stream surfaces, respectively. Referring to Figure 5.23, the axial component of the ISVC is increasing towards greater positive values near the stator leading edge mid passage region, where the TDVC and SOVC are also increasing. However, near the stator leading edge suction surface the ISVC is decreasing towards greater negative values where the SOVC is increasing to greater positive values and the TDVC is zero. Thus, it is apparent that the deterministic velocity fluctuations associated with the incident gust are out of phase with the scattered velocity fluctuations resulting from the stators response to the incident gust. When the incident and scattered unsteadiness are out of phase they can effectively cancel the TDVC.

The physics behind this island of increased unsteadiness is still unclear. Perhaps, the straining of the rotor wakes as they enter the stator potential field results in the stretching of the vorticies within the rotor wake, which results in a greater wake deficit. This seems unlikely, however, as there is no evidence of straining of the rotor wakes near the region where the TDVC increases, see Figures 5.10 and 5.11 . Of course, the wake in actuality is three-dimensional, therefore, it is possible that the rotor wake is being strained in the radial-tangential or radial-axial plane.

A second possible scenario which deserves further investigation, and which may explain the island of increased deterministic unsteadiness, is that the fluctuations toward more positive incident angles which occur 

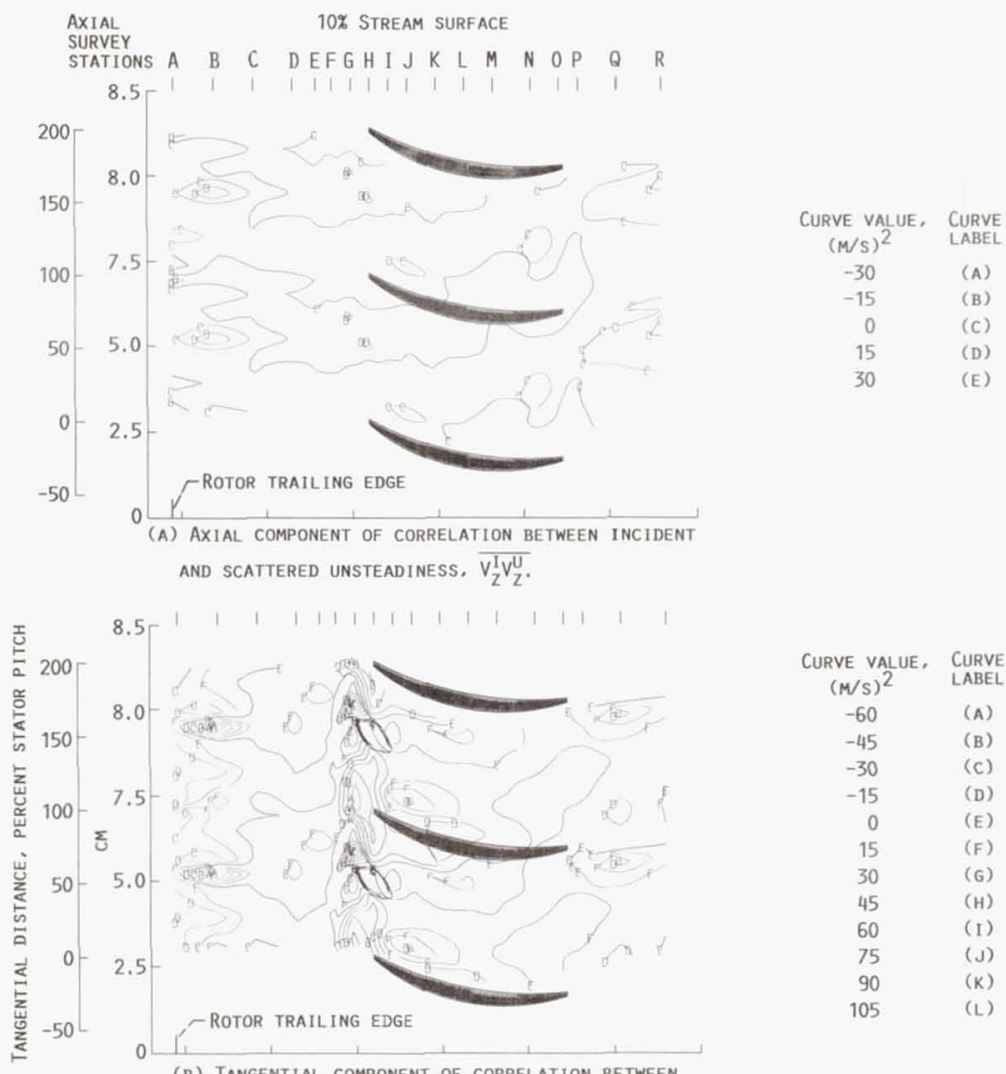

(B) TANGENTIAL COMPONENT OF CORRELATION BETWEEN INCIDENT AND SCATTERED UNSTEADINESS, $\overline{V_{\theta}^{I} V_{\theta}^{U}}$.

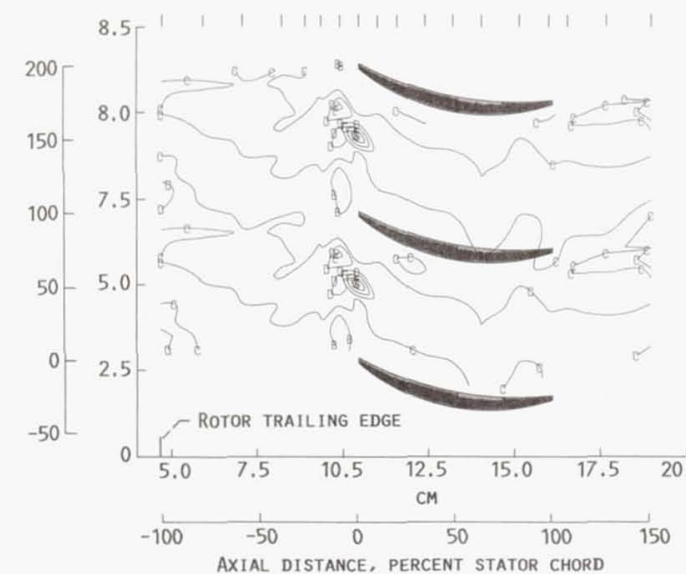

(C) CROSS COMPONENT OF CORRELATION BETWEEN INCIDENT AND SCATTERED UNSTEADINESS, $\overline{V_{Z}^{I} V_{\theta}^{\mathbb{U}}}$.

Figure 5.22 Contour maps of the cross correlations between the incident and scattered unsteady velocities along the 10 percent stream surface 


\section{ORIGINAL PAGE- IS \\ OF POOR QUALITY}

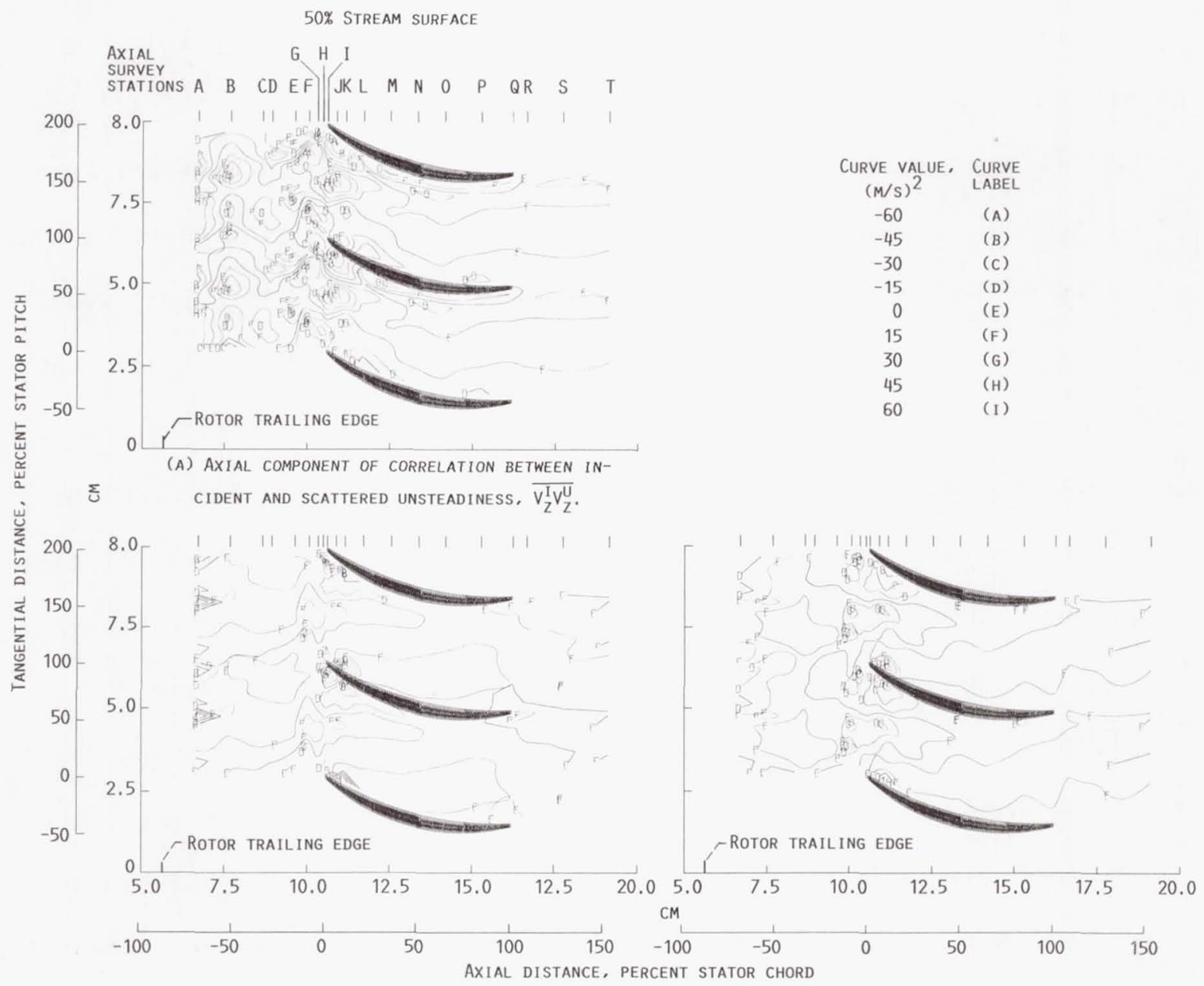

(B) TANGENTIAL COMPONENT OF CORRELATION BETWEEN IN CIDENT AND SCATTERED UNSTEADINESS, $\overline{V_{\theta}^{I} v_{\theta}^{U}}$.

(c) CROSS COMPONENT OF CORRELATION BETWEEN INCIDENT AND SCATTERED UNSTEADINESS, $\overline{V_{Z}^{I} V_{\theta}^{U}}$.

Figure 5.23 Contour maps of the cross correlations between the incident and scattered unsteady velocities along the 50 percent stream surface 
during the passage of the rotor wakes causes an intermittent separation of the stator suction surface boundary layer or perhaps a shedding of a vortex from the stator leading edge, which is then convected towards the adjacent stator-blade pressure surface as a result of the wake slip velocity. Previous experimental investigations [90-94] of isolated airfoils in oscillating flows have demonstrated the existence of significant secondary vortical structures which appear near the airfoil leading edges at higher angles of incidence. I would expect, however, that this effect would result in a "tongue" of increased deterministic unsteadiness originating from the stator leading edge and extending outward, in the streamwise direction, toward the adjacent stator-blade pressure surface. Perhaps though, another as yet unexplained competing effect suppresses or cancels any increases in the deterministic unsteadiness nearer to the stator leading edge, which results in the measured is land of increased deterministic unsteadiness out away from the stator leading edge.

A third scenario which may explain the island of increased deterministic unsteadiness is related to Binder's et al. [45] hypothesis to explain the measured increase in turbulence that he observed near the leading edge region of a turbine rotor blade, which was interacting with wakes generated from an upstream stator row. Binder concluded that stator secondary vortex cutting by the downstream rotor blades results in a breakdown in the secondary vortex and a subsequent increase in the turbulence. It seems likely that whatever phenomenon is occurring to cause the island of increased deterministic unsteadiness observed in the stator row of the present research compressor is also responsible for the 
increased turbulence observed near the leading edge of Binder's turbine rotor. However, just how a secondary vortex breakdown can result in an increase in deterministic unsteadiness, which implies an increase in the rotor wake velocity deficit, is not yet clear. Although interactions with the secondary vortex generated from the upstream blade row may be responsible for the observed increases in unsteadiness in both the present research compressor and Binder's turbine, something more than a breakdown of the secondary vortex must be occurring to cause an increase in the deterministic unsteadiness observed in the present research compressor. However, Binder's hypothesis certainly deserves further scrutiny.

A final proposed explanation for the increase in the TDVC is that as the rotor wake impinges on the stator surface a potential or acoustic perturbation emanates from the stator surface, as a result of the stators response to the incident rotor wake, and acts to destroy or induce a vortical flow near the region where the TDVC is high. For the present research compressor it may not be possible to fully explain the physics behind the increase in the TOVC, as the interactions are quite small due to the wide axial spacing between the rotor and stator rows. Further planned experiments in a more closely coupled stage may help to better explain this phenomenon.

\section{Turbulent-velocity correlations}

Figures 5.24 and 5.25 show circumferential (blade-to-blade) distributions of the measured components of the turbulent-velocity correlations at various axial survey stations along the 10 and 50 percent axisymmetric stream surfaces, respectively. Since the fringe angle 
10\% STREAM SURFACE
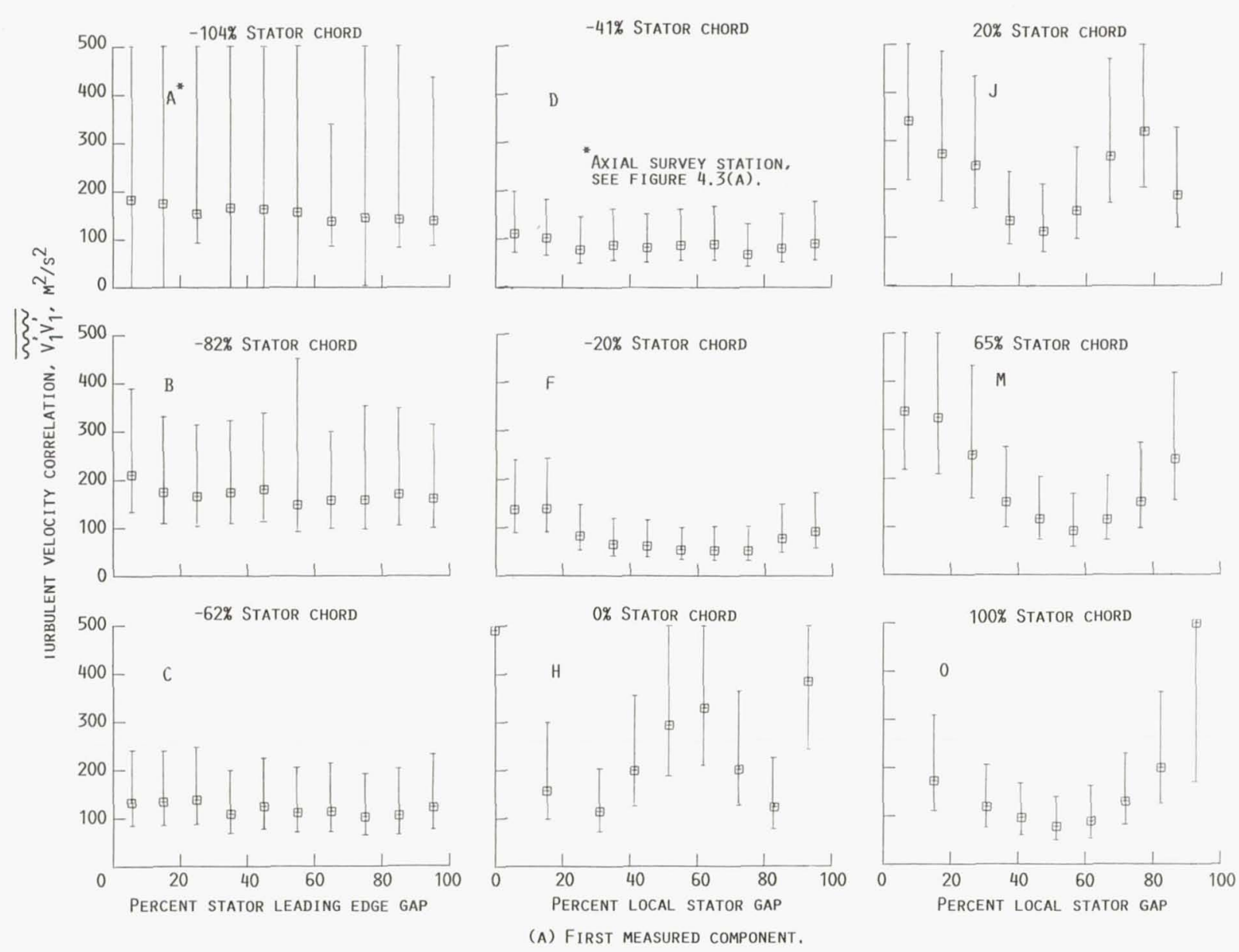

Figure 5.24 Stator blade-to-blade distributions of the turbulent-velocity correlations along the 10 percent stream surface 

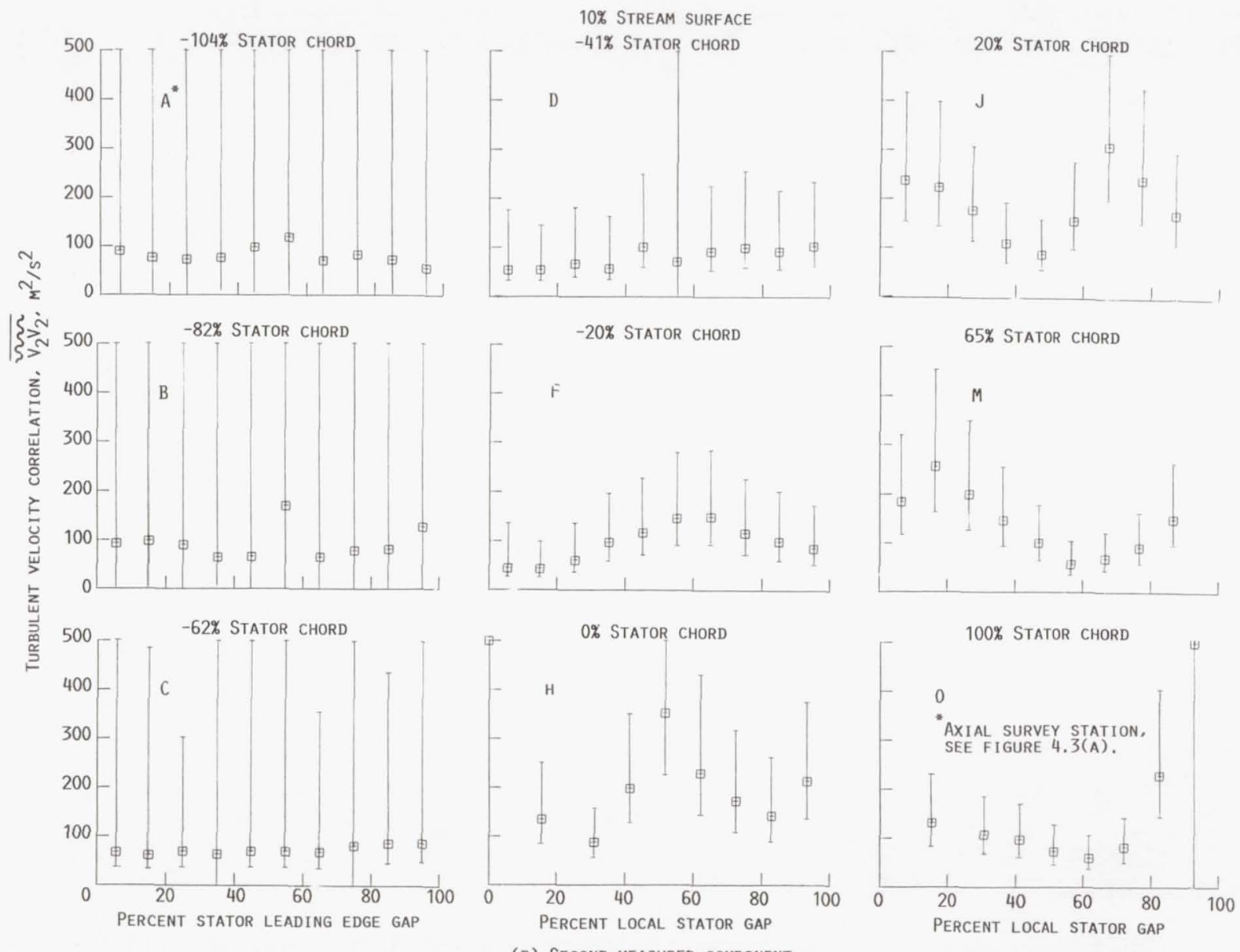

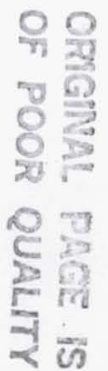
(B) SECOND MEASUREd COMPONENT.

Figure 5.24 Continued 

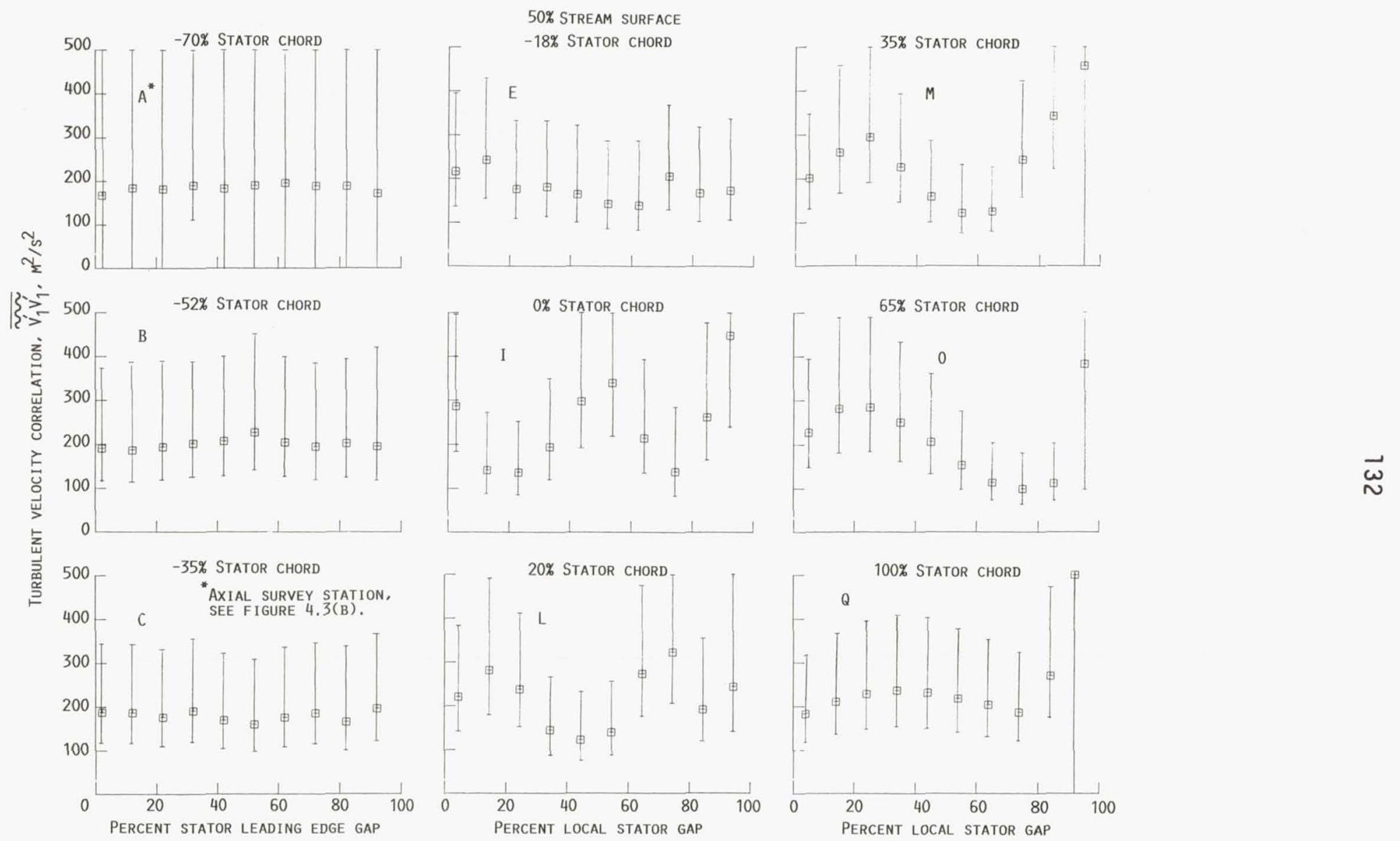

Figure 5.25 Stator blade-to-blade distributions of the turbulent-velocity correlations along the 50 percent stream surface 

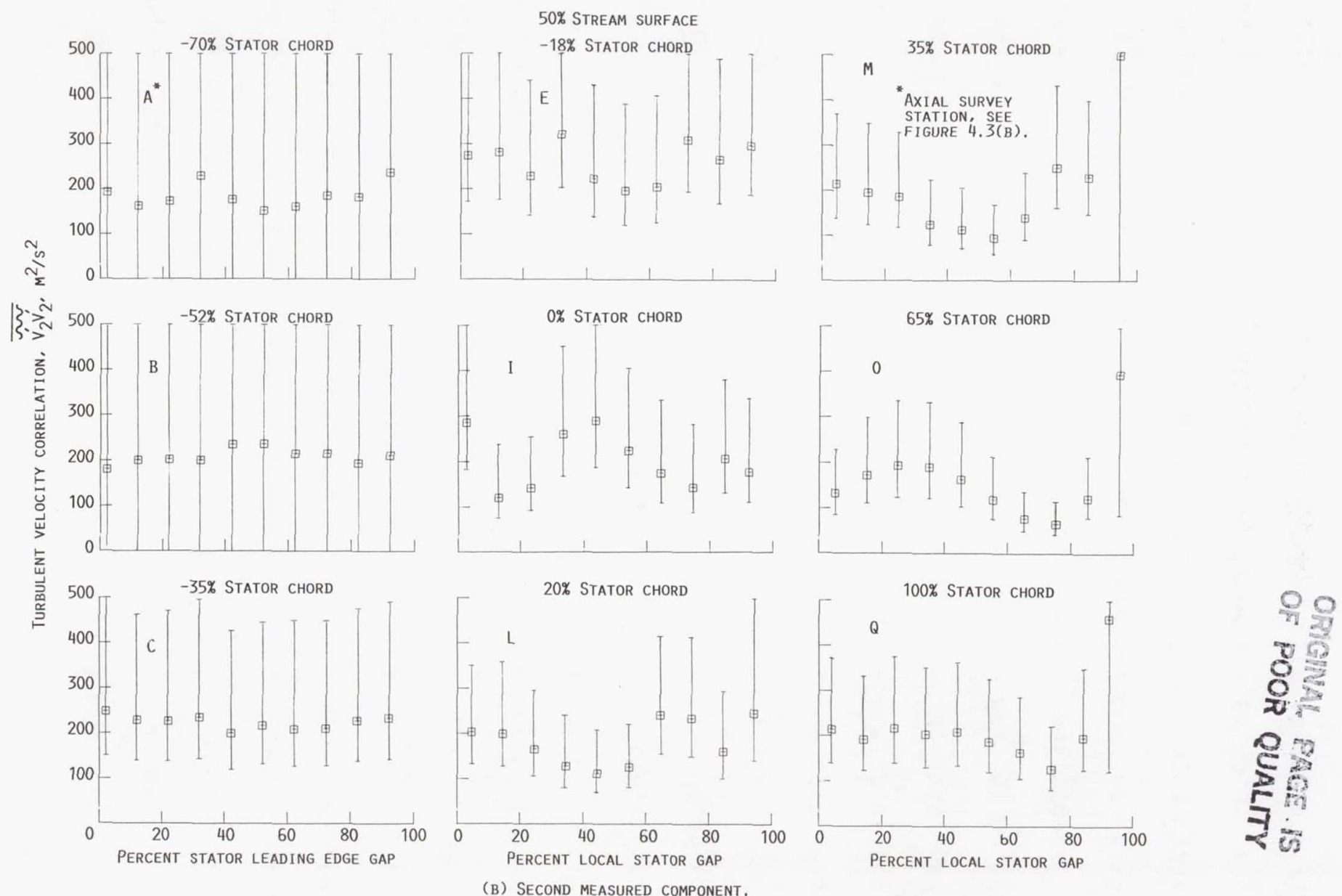

Figure 5.25 Continued 
orientation varies with the direction of the axisymmetric total-absolute velocity, which varies with axial position, the components of the turbulent-velocity correlations which are measured in the direction of the fringe angle orientations may also vary, due to the varying fringe angle orientations. Therefore, caution should be exercised when attempting to draw conclusions from apparent axial gradients in the measured turbulent-velocity correlations. However, no such caution is required in drawing conclusions from the blade-to-blade gradients of the measured turbulent-velocity correlations as the fringe angle orientation along which the turbulent-velocity correlations are measured is invariant with circumferential (blade-to-blade) position. The fringe angle orientations of the first and second measured components, $\alpha_{1}$ and $\alpha_{2}$, respectively, are shown in Figure 12.1 of Appendix $C$.

Referring to Figure 5.25(A), the first measured component of the turbulent-velocity correlation is approximately constant at a level of about $190 \mathrm{~m}^{2} / \mathrm{s}^{2}$ ( 8 percent $\left.\mathrm{V}_{\mathrm{FS}}\right)^{2}$ from -70 to -18 percent stator chord. The intensities of the turbulent-velocity correlations are quoted as percentages of the axisymmetric free-stream absolute velocity upstream of the stator potential field $\left(V_{F S}=235 \mathrm{~m} / \mathrm{s}\right)$, as was done for the deterministic-velocity correlations. At about -18 percent stator chord the first measured component of the turbulent-velocity correlation begins to increase, near midpassage, to a maximum of about $350 \mathrm{~m}^{2} / \mathrm{s}^{2}$ ( 15 percent $\left.V_{F S}\right)^{2}$ at -5 percent stator chord, and remains above $300 \mathrm{~m}^{2} / \mathrm{s}^{2}$ (13 percent $\left.V_{F S}\right)^{2}$, near midpassage, until about 20 percent stator chord, beyond which its magnitude becomes obscured by the stator suction surface boundary layer. 
Binder et a1. [43]; Binder [44]; Binder et al. [45] observed a similar increase in turbulence within the stator wake of a single stage turbine as it was transported through the downstream rotor row. Binder found that the turbulence within the stator wake increased near the rotor leading edge and attributed the increased turbulence to cutting of secondary vorticies by the rotor which caused the vorticies to breakdown, thus generating higher turbulence levels. Although this seems plausible as an explanation for the turbulence increases found by Binder, it does not seem to suffice as an explanation of the observed increases in both the deterministic- and turbulent-velocity fluctuations observed in the present research compressor. A breakdown of the secondary vortex would imply increased mixing out of the rotor wake velocity deficit, which is contrary to the increases in the rotor wake velocity deficit shown in Figures 5.12 and 5.13 .

It is interesting to note that there are two blade-to-blade regions at which the first component of the measured turbulent-velocity correlation increases, that both regions peak at about $300 \mathrm{~m}^{2} / \mathrm{s}^{2}\left(13 \text { percent } v_{F S}\right)^{2}$, and that both regions appear to move towards the stator suction surface with increasing axial distance. In reality the two regions of increasing turbulent-velocity correlation are circumferentially constant, and the changing stator camber causes the stator suction surface to move circumferentially towards the region of increased turbulent-velocity correlation. Eventually, both regions of increased turbulent-velocity correlation appear to mix out across the stator passage, except in the stator wake where the magnitude of the turbulent-velocity correlation remains high. Similar behavior occurs for both components of the 
turbulent-velocity correlation at both 10 and 50 percent span. Figures $5.12(c), 5.12(d), 5.13(c)$, and $5.13(d)$ indicate that the turbulent velocity fluctuations within the wake remain approximately constant blade-to-blade, while the turbulent velocity fluctuations within the free stream increase and decrease blade to blade. Therefore, the blade-toblade increase in the turbulent-velocity correlation occurs because of an increase in the free-stream turbulence, and is not due to an increase in the wake turbulence.

3. Comparison between deterministic- and turbulent-velocity correlations

Figures 5.26 and 5.27 show a comparison between the axial distributions of the axial and tangential components of the totaldeterministic- and turbulent-velocity correlations along the 10 and 50 percent axisymmetric stream surfaces, respectively. The axial and tangential components of the turbulent-velocity correlations are represented as the minimum and maximum bounds that the values of the turbulent-velocity correlations can attain, as the actual values could not be determined from the measured data, see Appendix $C$. The axial and tangential components of the total-deterministic-velocity correlations are denoted by symbols, and include uncertainty intervals which denote the 95 percent confidence level. The main conclusion which can be drawn from this plot is that the turbulent-velocity correlations are significantiy greater than the total-deterministic-velocity correlations. Only near the rotor trailing edge and in some instances near the stator leading edge are the total-deterministic-velocity correlations of the same order of magnitude as the turbulent-velocity correlations. Therefore, through-flow 
137

ORGNAL, PACE IS

OF POOR QUALITY

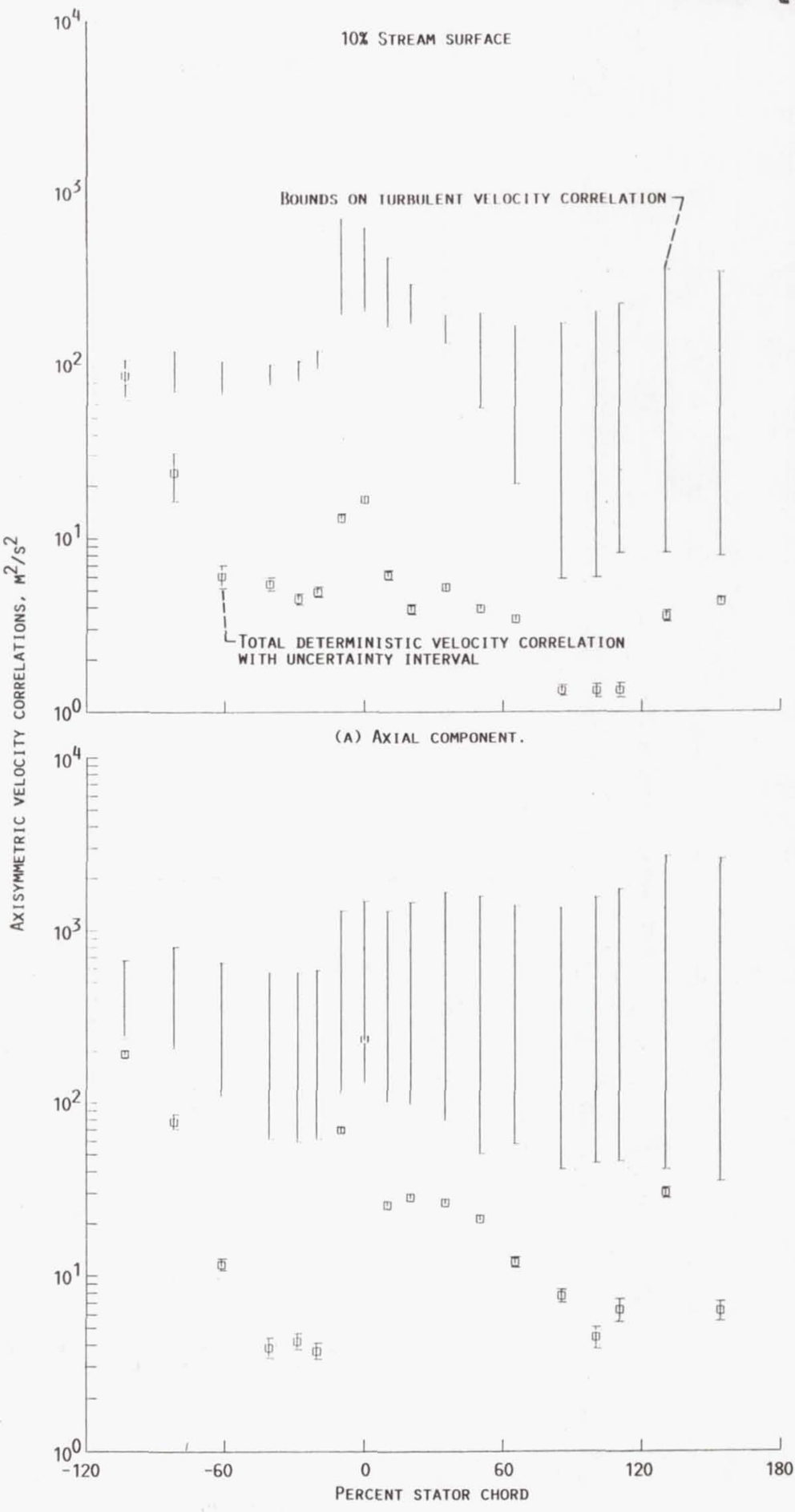

(B) TANGENTIAL COMPONENT.

Figure 5.26 Comparison between the axisymmetric values of the total-deterministic-and turbulent-velocity correlations along the 10 percent stream surface 


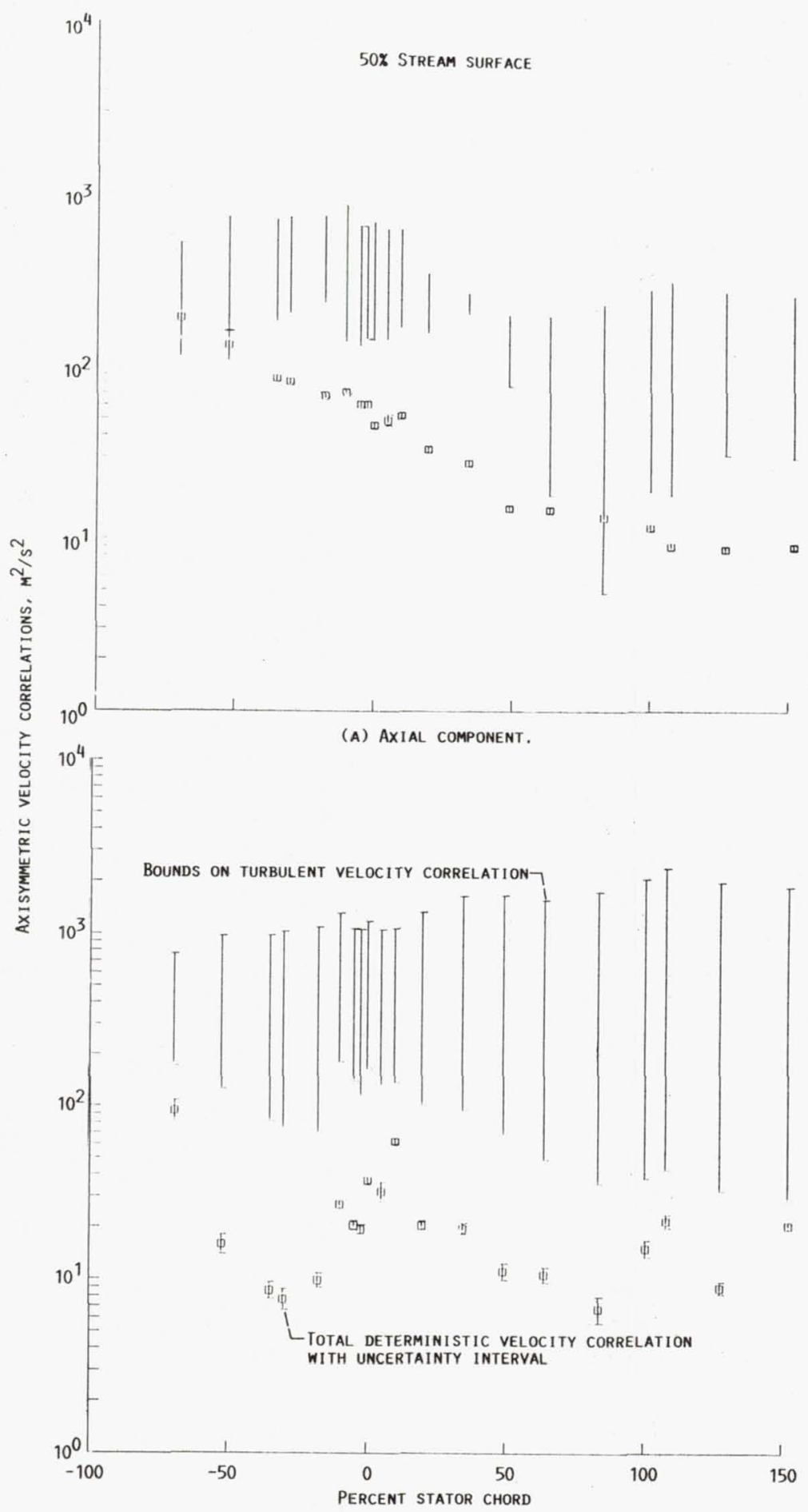

(B) TANGENTIAL COMPONENT.

Figure 5.27 Comparison between the axisymmetric values of the total-deterministic- and turbulent-velocity correlations along the 50 percent stream surface 
mixing appears to be largely controlled by the turbulence and not the deterministic unsteadiness, at least for the presently considered research fan. As previously mentioned, however, the turbulence as defined herein includes any unsteadiness not correlated with the blade passing frequency, which in the case of this research fan includes the unsteadiness due to vortex shedding from the rotor trailing edge. As a result, the large values of the turbulent-velocity correlations are to a great extent due to the increased turbulence within the rotor wake resulting from the vortex shedding. Since this increased turbulence is "frozen" with the rotor wake it may also be possible to use a gust analogy to help model the turbulentvelocity correlation, as was suggested for the total-deterministic-velocity correlation. 


\section{SUMMARY AND CONCLUSIONS}

The time-resolved unsteady velocity field along two stream surfaces in the stator row of a single-stage transonic axial-flow fan was mapped using a laser anemometer. The measured velocities were used to determine the magnitudes and distributions of the deterministic-and turbulentvelocity correlations identified from the average-passage equation system. Since the present research compressor was designed for minimal acoustical interactions, the rotor/stator axial spacing ( 0.85 percent of rotor chord) is much greater than usual in a typical compressor. As a result, the rotor wakes are considerably diminished by the time they reach the stator inlet, reducing the possibility of significant blade row interactions. However, the advantage of the wide axial spacing between the rotor and stator rows is that it allows for investigation of the rotor wake generated interactions, independently of potential flow interactions. Based on the measured data, the following conclusions can be made.

1. Rotor wakes retain their identity as they are chopped and subsequently transported through the stator row.

2. The kinematics of the transport of rotor wakes through the downstream stator row is largely controlled by the time-averaged potential flow field.

3. Simple linear disturbance theory is adequate for predicting the drift distance between wake segments convecting along the stator pressure and suction surfaces.

4. Due to the diffusing nature of the stator row the wakes tend to pile up at the stator exit. 
5. Spreading of the rotor wake segments appears to be minimal.

6. Blade row interactions can result in the amplification or attenuation of both the deterministic and turbulent unsteadiness.

7. Regions of amplified unsteadiness may occur in isolated regions away from the stator surfaces.

8. If the scattered unsteadiness is out of phase with the incident unsteadiness, the total-deterministic unsteadiness may be negligible in areas where the scattered and incident unsteadiness are significant.

9. An analogy to gust theory appears to provide a useful means for analyzing the behavior of rotor-wake-generated unsteadiness and should aid the modeling of the deterministic unsteadiness.

10. As a result of the "frozen" character of the turbulence within the rotor wakes, it may be possible to use a similar gust analogy for helping to model the turbulent unsteadiness.

11. The turbulent-velocity correlations are significantly greater than the total-deterministic-velocity correlations, which indicates that through-flow mixing is largely controlled by the turbulence and not the deterministic unsteadiness (at least for the presentiy considered research fan).

Presentiy, no satisfactory explanation of the presence of the increased deterministic and turbulent unsteadiness near the stator leading-edge plane is apparent. In a more closely coupled stage where the blade row interactions are expected to be much greater, this region of increased unsteadiness could be detrimental to the performance of the stator (e.g., induce separation of the boundary layer) particularly if the increased unsteadiness is nearer the stator suction surface. of 
course, depending on the state of the boundary layer, it is also possible that this region of increased unsteadiness could be beneficial to the performance of the stator. It is important, therefore, that further investigation of this region of increased unsteadiness be continued. An animated movie of the transport of the rotor wakes though the downstream stator row was produced from the LFA measurements. A representative sample of figures illustrating the rotor wake transport through the stator row for six of the 50 rotor shaft positions for which measurements were acquired was shown in Figures 5.10 and 5.11 . The power of movie animation in revealing details of the rotor wake transport which was not evident from viewing still figures (e.g., Figs. 5.10 and 5.11 ), was found to be invaluable. The movie animation revealed a dramatic distortion of the rotor wake occurring near the stator leading edge as it is chopped by the stator. This rotor wake distortion was not obvious from examination of the still figures. 


\section{RECOMMENDATIONS FOR FURTHER RESEARCH}

The next phase of research will be to determine the magnitudes and distributions of the unsteady-deterministic-and turbulent-velocity correlations in a more closely coupled stage, wherein the rotor trailing edge interacts strongly with the stator potential field. In a closer coupled stage the blade row interaction effects will be stronger and rapid mixing of the rotor wake will occur within the stator passage. A comparison between the unsteady-velocity correlation presented in this dissertation with the unsteady-velocity correlations of a more realistically coupled stage may provide some insight into how blade row spacing affects performance. Following the mapping of the close coupled stage will be an experimental program to determine the unsteady-velocity correlations within a transonic compressor which has an inlet guide vane row. The entire rotor and stator flow field will be mapped in order to resolve the effects of the inlet guide vane wakes and the downstream stator row on the rotor flow field, especially the effects on the rotor shock system. Another planned experimental effort is the mapping of an embedded stage of a multistage compressor to assess the importance of the aperiodic-velocity correlation, as well as the unsteady-deterministic- and turbulent-velocity correlations.

Other recommended experimental research programs are, determining the magnitudes and distributions of these unsteady-velocity correlations in the vaned diffuser of a centrifugal compressor, and in a large scale low-speed compressor or turbine where the boundary layers are thick enough to allow measurements within. The spatial gradients of the unsteady 
velocity correlations appear in the average passage equation system, and since there are large velocity gradients across boundary layers it is reasonable to expect that the effects of the unsteady-velocity correlations might also be large within the boundary layers.

In conjunction with the experimental research programs should be an on-going effort to develop instrumentation which will allow the determination of al1 components of the total apparent-stress tensor (Eq. (4.10)) of the average passage equation system. This would require the simultaneous time-resolved measurements of the axial, tangential, and radial components of the instantaneous total-absolute velocity, as well as measurement of the time-resolved density. A laser anemometer or hot wire capable of simultaneous measurement of at least two components of velocity is a necessity for measuring two-dimensional turbulence (see Appendix C). To measure three-dimensional turbulence a three component laser anemometer or hot wire is required.

Also in conjunction with the experimental research programs should be an effort at modeling the various components of the total apparent-stress tensor. As models are developed, the average passage equation system could be used for a parametric study of the effects of the aperiodic-, unsteady-deterministic- and turbulent-stress components of the total apparent-stress tensor on the performance of the turbomachines. The results of a comprehensive experimental, modeling, and computational research program should lead to a better understanding of the role of unsteady flows on turbomachinery performance. 


\section{REFERENCES}

1. Gallus, H.E., Lambertz, J., and Wallmann, Th. "Blade-Row Interaction in an Axial-Flow Subsonic Compressor Stage." ASME Paper No. 79-GT-92, March 1979.

2. Yurinskiy, V.T., and Shestachenko, I. Ya. "Losses in an Impulse Turbine Cascade in an Unsteady Flow." Fluid Mechanics Soviet Research 3, No. 1 (January-February, 1974): 22-27.

3. Doorly, D.J., and 0ldfield, M.L.G. "Simulation of Wake Passing in a Stationary Turbine Rotor Cascade." AIAA Journal of Propulsion 1, No. 4 (July-August, 1985): 316-318.

4. Gallus, H.E., Grollius, H., and Lambertz, J. "The Influence of Blade Number Ratio and Blade Spacing on Axial-Flow Compressor Stator Blade Dynamic Load and Stage Sound Pressure Level." ASME Paper No. 81-GT-165, March 1981.

5. Zierke, W.C., and Okiishi, T.H. "Measurement and Analys is of Total-Pressure Unsteadiness Data from an Axial-Flow Compressor." Transactions of the ASME, Journal of Engineering for Power 92A (1982): $\quad 479-488$.

6. Dean, R.C., Jr. "On the Necessity of Unsteady Flow in Fluid Machines." Transactions of the ASME, Journal of Basic Engineering (March, 1959): 24-28.

7. Adamczyk, J.J. "Model Equation for Simulating Flows in Multistage Turbomachinery." ASME Paper No. 85-GT-226 and NASA TM-86869, November 1984. 
8. Kofskey, M.G., and Allen, H.W. "Smoke Study of Nozzle Secondary Flows in a Low-Speed Turbine." NACA TN-3260, 1954.

9. Smith, L.H., Jr. "Wake Dispersion in Turbomachines." Transactions of the ASME, Journal of Basic Engineering 880 (1966): 688-690.

10. Kerrebrock, J.L., and Mikolajczak, A.A. "Intra-Stator Transport of Rotor Wakes and It's Effect on Compressor Performance." Transactions of the ASME, Journal of Engineering for Power 92A (October, 1970): $359-368$.

11. Hodson, H.P. "Boundary Layer and Loss Measurements on the Rotor of an Axial-Flow Turbine." ASME Paper No. 83-GT-4, March 1983.

12. Hodson, H.P. "The Development Unsteady Boundary Layers on the Rotor of an Axial-Flow Turbine." Viscous Effects in Turbomachines, AGARD-CP-351, June 1983.

13. Tanaka, S. "Influence of a Periodical Fluctuation on a Profile Loss of a Cascade (Part I, Determination of the Total Pressure Loss Coefficient)." Bulletin of JSME 27, No. 226 (April 1984): 660-674.

14. Okiishi, T.H., Hathaway, M.D., and Hansen, J.L. "A Note on Blade Wake Interaction Influence on Compressor Stator Row Aerodynamic Performance." Transactions of the ASME, Journal of Engineering for Gas Turbines and Power 107, No. 2 (Apri1, 1985): 549-551.

15. Dong, Y., Gallimore, S.J., and Hodson, H.P. "Three-Dimensional Flows and Loss Reduction in Axial Compressors." ASME Paper No. 86-GT-193, June 1986.

16. Hansen, J.L., and Okiishi, T.H. "Axial-Flow Compressor Rotor-Stator Interaction." ISU-ERI-Ames-86135, TCRL-31, December 1985. 
17. Walker, G.J. "The Unsteady Nature of Boundary Layer Transition on an Axial-Flow Compressor Blade." ASME Paper No. 74-GT-135, March 1974.

18. Evans, R.L. "Boundary-Layer Development on an Axial-Flow Compressor Stator Blade." Transactions of the ASME, Journal of Engineering for Power 100 (Apri1, 1978): 287-293.

19. Pfie1, H., and Herbst, R. "Transition Procedure of Instationary Boundary Layers." ASME Paper N0. 79-GT-128, March 1979.

20. Pfiel, H., Herbst, R., and Schroder, T. "Investigation of the Laminar-Turbulent Transition of Boundary Layers Disturbed by Wakes." Transactions of the ASME, Journal of Engineering for Power 105 (January, 1983): 130-137.

21. Fleeter, S., Jay, R.L., and Bennett, W.A. "Rotor Wake Generated Unsteady Aerodynamic Response of a Compressor Stator." Transactions of the ASME, Journal of Engineering for Power 100 (0ctober, 1978): 664-675.

22. Franke, G.F., and Henderson, R.E. "Unsteady Stator Response to Upstream Rotor Wakes." AIAA Journal of Aircraft 17 (July, 1980): 500-507.

23. Fleeter, S., Bennett, W.A., and Jay, R.L. "Time-Variant Aerodynamic Measurements in a Research Compressor." Proceedings of the Dynamic Flow Conference, 1978.

24. Adachi, T., and Murakami, Y. "Three-Dimensional Velocity Distribution Between Stator Blades and Unsteady Force on a Blade Due to Passing Wakes." Bulletin of the JSME 22, No. 170 (August, 1979): 1074-1082. 
25. Murakami, Y., Hirose, T., Adachi, T., and Kato, H. "Unsteady Force on a Cambered Blade Passing Through an Oblique Wake." Bulletin of the JSME 24, No. 195 (September, 1981): 1543-1549.

26. Capece, V.R., and Fleeter, S. "First Stage Stator Vane Unsteady Aerodynamic Response in a Multi-Stage Compressor." Paper No. AIAA-84-1209, presented at the AIAA/SAE/ASME 20th Joint Propulsion Conference, June 11-13, 1984.

27. Schmidt, D.P., and Okiishi, T.H. "Multistage Axial-Flow Turbomachinery Wake Production, Transport, and Interaction." AIAA Journal 15 (1977): 1138-1145.

28. Ng, W.F., and Epstein, A.H. "A Quasi-Three-Dimensional Model for Intra-Stator Transport of Rotor Wakes." International Symposium on Three-Dimensional Flow Phenomena in Fluid Machinery, ASME Winter Annual Meeting, November 1985.

29. Dring, R.P., Josiyn, H.D., Hardin, L.W., and Wagner, J.H. "Turbine Rotor-Stator Interaction." ASME Paper No. 82-GT-3, 1982.

30. Josiyn, H.D., Dring, R.P., and Sharma, 0.P. "Unsteady Three-Dimensional Turbine Aerodynamics." Transactions of the ASME, Journal of Engineering for Power 105 (Apri1, 1983): 322-331.

31. Matsuuchi, K., and Adachi, T. "Measurements of the Three-Dimensional Unsteady Flow Inside a Rotor Blade Passage of an Axial-Flow Fan." Tokyo International Gas Turbine Conference Proceedings 2 (October, 1983): $523-530$.

32. Raj, R., and Lakshminarayana, B. "Characteristics of the Wake Behind a Cascade of Airfoils." Journal of Fluid Mechanics 61, Part 4 (1973): $707-730$. 
33. Raj, R., and Lakshminarayana, B. "Three Dimensional Characteristics of Turbulent Wakes Behind Rotors of Axial Flow Turbomachinery." Transactions of the ASME, Journal of Engineering for Power 98A (April, 1976): $218-228$.

34. Hirsch, Ch., and Kool, P. "Measurement of the Three-Dimensional Flow Field Behind an Axial Compressor Stage." Transactions of the ASME, Journal of Engineering for Power 99A, No. 2 (Apri1, 1977): 168-179.

35. Kool, P., DeRuyck, J., and Hirsch, Ch. "The Three-Dimensioal Flow and Blade Wake in an Axial Plane Downstream of an Axial Compressor Rotor." ASME Paper No. 78-GT-66, April 1978.

36. Reynolds, B., Lakshminarayana, B., and Ravindranath, A. "Characteristics of the Near Wake of a Compressor of a Fan Rotor Blade." AIAA Journal 17, No. 9 (September, 1979): 959-967.

37. Ravindranath, A., and Lakshminarayana, B. "Mean Velocity and Decay Characteristics of the Near-and Far-Wake of a Compressor Rotor of Moderate Loading." Transactions of the ASME, Journal of Engineering for Power 102, No. 3 (Ju1y, 1980): 535-548.

38. Ravindranath, A., and Lakshminarayana, B. "Structure and Decay Characteristics of Turbulence in the Near-and Far-Wake of a Moderately Loaded Compressor Rotor-Blade." ASME Paper No. 80-GT-95, March 1980.

39. Ravindranath, A., and Lakshminarayana, B. "Rotor Wake Mixing Effects Downstream of a Compressor Rotor." ASME Paper No. 81-GT-98, March 1981. 
40. Dring, R.P., Joslyn, H.D., and Hardin, L.W. "An Investigation of Axial Compressor Rotor Aerodynamics." Transactions of the ASME, Journal of Engineering for Power 104, No. 1 (January, 1982): 84-96.

41. Inoue, M., and Kuroumaru, M. "Three-Dimensional Structure and Decay of Vortices Behind an Axial Flow Rotating Blade Row." Transactions of the ASME, Journal of Engineering for Gas Turbines and Power 106 (July, 1984): $561-569$.

42. Dunker, R.J. "Flow Measurements in the Stator Row of a Single-Stage Transonic Axial-Flow Compressor with Controlled Diffusion Stator Blades." Viscous Effects in Turbomachines, AGARD-CP-351, June 1983.

43. Binder, A., Forster, W., Kruse, H., and Rogge, H. "An Experimental Investigation into the Effect of Wakes on the Unsteady Turbine Rotor Flow." Transactions of the ASME, Journal of Engineering for Gas Turbines and Power 107 (1985): 458-466.

44. Binder, A. "Turbulence Production due to Secondary Vortex Cutting in a Turbine Rotor." ASME Paper No. 85-GT-29, 1985.

45. Binder, A., Forster, W., Mach, K., and Rogge, H. "Unsteady Flow Interaction Caused by Stator Secondary Vortices in a Turbine Rotor." ASME Paper No. 86-GT-302, June 1986.

46. Hodson, H.P. "Measurements of the Wake-Generated Unsteadiness in the Rotor Passages of Axial-flow Turbines." ASME Paper No. 84-GT-189, June 1984.

47. Wagner, J.H., Okilshi, T.H., and Holbrook, G.J. "Periodically Unsteady flow in an Imbedded Stage of a Multistage, Axial-Flow Turbomachine." ASME Paper No. 78-GT-6, April 1978. 
48. Tweedt, D.L., Hathaway, M.D., and Okiishi, T.H. "Multistage Compressor Stator/Rotor Interaction." AIAA, Journal of Propulsion and Power 1, No. 6 (November-December, 1985): 449-455.

49. Williams, M.C. "Laser Velocimetry Study of Stator/Rotor Interactions in a Multi-Stage Gas Turbine Compressor." Presented at the AGARD PEP 6th Symposium on Advanced Instrumentation for Aero Engine Components, May 1986.

50. Kemp, N.H., and Sears, W.R. "Aerodynamic Interference Between Moving Blade Rows." Journal of the Aeronautical Sciences 20 (1953): 585-598. 51. Kemp, N.H., and Sears, W.R. "The Unsteady Forces due to Viscous Wakes in Turbomachines." Journal of the Aeronautical Sciences 22 (1955): 478-483.

52. Meyer, R.X. "The Effects of Wakes on the Transient Pressure and Velocity Distributions in Turbomachines." Transactions of the ASME 80 (1958): $1544-1552$.

53. Lefcort, M.D. "An Investigation into Unsteady Blade Forces in Turbomachines." Transactions of the ASME, Journal of Engineering for Power 87A (1965): 345-354.

54. Karmen, T. von, and Sears, W.R. "Airfoil Theory for Non-Uniform Motion." Journal of the Aeronautical Sciences 5, No. 10 (1938): $379-390$.

55. Horlock, J.H. "Fluctuating Lift Forces on Airfoils Moving Through Traverse and Chordwise Gusts." Transactions of the ASME, Journal of Basic Engineering 90 (1968): 494-500. 
56. Naumann, H., and Yeh, H. "Lift and Pressure Fluctuations of a Cambered Airfoil Under Gusts and Application to Turbomachinery." ASME Paper No. 72-GT-30, 1972.

57. Goldstein, M.E., and Atassi, H. "A Complete Second-Order Theory for the Unsteady Flow About an Airfoil Due to a Periodic Gust. Journal of Fluid Mechanics 74, Part 4 (1979): 741-765.

58. Adamczyk, J.J. "The Passage of a Distorted Velocity Field Through a Cascade of Airfoils." Unsteady Phenomena in Turbomachinery, AGARD-CP-177, September 1975.

59. Erdos, J.I., and Alzner, E. "Numerical Solution of Periodic Transonic Flow Through a Fan Stage." AIAA Journal 15, No. 11 (November, 1977): $1559-1568$.

60. Krammer, P. "Computation of Unsteady Blade Forces in Turbomachines by Means of Potential Flow Theory and by Simulating Viscous wakes." ASME Paper No. 82-GT-198, 1982.

61. Hodson, H.P. "An Inviscid Blade-to-Blade Prediction of a Wake-Generated Unsteady Flow." ASME Paper No. 84-GT-43, June 1984.

62. Denton, J.D. "An Improved Time Marching Method for Turbomachinery Flow Calculation." ASME Paper No. 82-GT-239, 1982.

63. Rai, M.M. "Navier-Stokes Simulation of Rotor-Stator Interaction Using Patched and Overlaid Grids." Presented at the AIAA 7th Computational Fluid Dynamics Conference, AIAA-CP-854 (July, 1985): 282-298.

64. Josiyn, H.D., Caspar, J.R., and Dring, R.P. "Inviscid Modeling of Turbomachinery Wake Transport." Presented at the AIAA/SAE/ASME/ASEE 21 st Joint Propulsion Conference, AIAA-85-1132, June 1985. 
65. Smith, L.H., Jr. "Secondary Flow in Axial-Flow Turbomachinery." Transactions of the ASME 77, No. 7 (0ct. 1955): 1065-1076.

66. Adkins, G.G., Jr., and Smith, L.H., Jr. "Spanwise Mixing in Axial-Flow Turbomachines." ASME Paper No. 81-GT-57, March 1981.

67. Mitche11, N.A. "Non-Axisymmetric Blade Row Interaction in Axial Turbomachines." ASME Paper No. 80-GT-133, March 1980.

68. Sehra, A.K. "The Effect of Blade-to-Blade Flow Variations on the Mean Flow-Field of a Transonic Compressor." Presented at the AIAA 12th Fluid and Plasma Dynamics Conference, AIAA-79-1515, July 1979.

69. Adamczyk, J.J., Mulac, R.A., and Celestina, M.L. "A Model for Closing the Inviscid Form of the Average-Passage Equation System." ASME Paper No. 86-GT-227 and NASA TM-87199, June 1986.

70. Celestina, M.L., Mulac, J.J., and Adamczyk, J.J. "A Numerical Simulation of the Inviscid Flow Through a Counter-Rotating Propeller." NASA TM-87200, 1986.

71. Cunnan, W.S., Stevans, W., and Urasek, D.C. "Design and Performance of a 427-Meter-Per-Second-Típ-Speed Two-Stage Fan Having a 2.40 Pressure Ratio." NASA TP-1314, October 1978.

72. Urasek, D.C., Gorre11, W.T., and Cunnan, W.S. "Performance of Two-Stage Fan Having Low-Aspect-Ratio, First-Stage Rotor Blading." NASA TP-1493, August 1979.

73. Crouse, J.E., and Gorre11, W.T. "Computer Program for Aerodynamic and Blading Design of Multistage Axial-Flow Compressor." NASA TP-1946, 1981. 
74. Powe11, J.A., Strazisar, A.J., and Seasholtz, R.G. "High-Speed Laser Anemometer System for Intrarotor Flow Mapping in Turbomachinery." NASA TP-1663, February 1982.

75. Powell, J.A., Strazisar, A.J., and Seasholtz, R.G. "Efficient Laser Anemometer for Intra-Rotor Flow Mapping in Turbomachinery." Transactions of the ASME, Journal of Engineering for Power 103 (Apri1, 1981): $\quad 424-429$.

76. Stevenson, W.H., dos Santos, R., and Mettler, S.C. "Fringe Mode Fluoresence Velocimetry." Applications of Non-Intrusive Instrumentation in Fluid Flow Research, AGARD-CP-193, 1976.

77. Strazisar, A.J., and Powe11, J.A. "Laser Anemometer Measurements in a Transonic Axial Flow Compressor Rotor." Transactions of the ASME, Journal of Engineering for Power 103, No. 2 (Apri1, 1981): 430-437.

78. Bendat, J.S., and Piersol, A.G. Random Data: Analysis and Measurement Procedures. New York: Wiley-Interscience, 1971.

79. Strazisar, A.J. "Investigation of Flow Phenomena in a Transonic Fan Rotor Using Laser Anemometry." Transactions of the ASME, Journal of Engineering for Gas Turbines and Power 107 (Apri1, 1085): 427-435.

80. Goldstien, M.E. Aeroacoustics. New York: McGraw-Hill, Inc., 1976.

81. Kline, S. J. "The Purpose of Uncertainty Analysis." Transactions of the ASME, Journal of Fluids Engineering 107, No. 2 (June, 1985): 153-160.

82. Walpole, R.E., and Myers, R.H. Probability and Statistics for Engineers and Scientists. 2nd edition. New York: MacMillan Publishing Co., Inc., 1978. 
83. Patrick, W.P., and Paterson, R.W. "Error Analys is for Benchmark Fluid Dynamic Experiments, Part I: Error Analysis Methodology and the Quantification of Laser Velocimeter Error Sources." United Technologies Research Center, Report No. R85-151772, June 1985.

84. Orloff, K.L., and Snyder, P.K. "Laser Doppler Anemometer Measurements Using Nonorthogonal Velocity Components: Error Estimates." Applied Optics 21, No. 2 (January, 1982): 339-344.

85. Snyder, P.K., Orloff, K.L., and Reinath, M.S. "Reduction of Flow-Measurement Uncertainties in Laser Velocimeters with Nonorthogonal Channels." Presented at the AIAA 21 st Aerospace Sciences Meeting, AIAA-83-0051, January 1983.

86. Barnett, D.0., and Bentley, H.T. "Statistical Bias of Individual Realization Laser Velocimeters." In Second International Workshop on Laser Velocimetry, Vol. 1, pp. 428-444. H.D. Thompson and W.H. Stevenson, eds. Purdue University, 1974.

87. Hathaway, M.D., Gertz, J., Epstein, A., and Strazisar, A.J. "Rotor Wake Characteristics of a Transonic Axial Flow Fan." AIAA Journal 24, No. 11 (November 1986): 1802-1810.

88. Seasholtz, R.G. "Laser Doppler Velocimeter System for Turbine Stator Cascade Studies and Analysis of Statistical Bias Errors." NASA TN D-5427, 1977 .

89. Dunker, R., Rechter, H., Starken, H., and Weyer, H. "Redesign and Performance Analysis of a Transonic Axial Compressor Stator and Equivalent Plane Cascades with Subsonic Controlled Diffusion Blades." ASME Paper No. 83-GT-208, 1983. 
90. Miller, J.A., Pucci, P.F. "Heat Transfer to an Airfoil in Oscillating Flow." Transactions of the ASME, Journal of Engineering for Power 93A (October, 1971): 461-468.

91. McAlister, K.W., Carr, L.W. "Water Tunnel Visualizations of Dynamic Sta11." Transactions of the ASME, Journal of Fluids Engineering 101, No. 3 (September, 1979): 376-380.

92. Ericsson, L.W., and Reding, J.P. "Unsteady Flow Concepts for Dynamic Sta11 Analysis," AIAA Journal of Aircraft 21, No. 8 (August, 1984): $601-606$.

93. Walker, J.M., Helin, H.E., and Strickland, J.H. "An Experimental Investigation of an Airfoil Undergoing Large-Amplitude Pitching Motion." AIAA Journal 23, No. 8 (August, 1985): 1141-1142.

94. Francis, M.S., and Keesee, J.E. "Airfoil Dynamic Stall Performance with Large-Amplitude Motions." AIAA Journal 23, No. 11 (November, 1985): 1653-1659. 


\section{ACKNOWLEDGMENTS}

The author would like to express his appreciation to Professor Theodore H. OKiishi and Dr. Anthony J. Strazisar for their continual advice, encouragement, and patience throughout the course of this research program. In addition, the author would like to express his appreciation to $\mathrm{Dr}$. John J. Adamczyk for his advice and patience throughout many hours of helpful discussions of his development of the averaged passage equation system, and his ideas on modeling flows in multistage turbomachines. The author is also grateful to Mr. Kenneth L. Suder for his assistance in acquiring the data, and for many thoughtful questions which helped to expand the author's knowledge and understanding of many aspects of this research program. Furthermore, the author is grateful to the other members of his Doctor of Philosophy degree graduate program of study committee for their assistance, and for their patience and understanding throughout this research program. The author also extends his thanks to the members of Dennis M. Sender's Graphics and Exhibits Office, and Margaret C. Appleby's Editorial Branch for their help in preparing this dissertation, especially to Mary Eitel for being so conscientious in preparing the figures. The author is also grateful to his supervisor, Mr. Gilbert J. Weden, and to the director of the U.S. Army Propulsion Directorate, Mr. John Acurio, for providing a work environment which encourages employees to pursue advanced educational programs. Finally, the author wishes to acknowledge the National Aeronautics and Space Administrations Lewis Research Center for supporting this research program (NASA Grant NAG 3-356), and the U.S. Army Propulsion Directorate for their support of this dissertation. 


\section{APPENDIX A: NASA DESIGN CODE RESULTS}

The output from the NASA design code [73] used to design the present research compressor is presented in the following tables. Table 10.1 lists all input parameters and user defined correlations, in tabular form, required for the design code analysis. Table 10.2 lists the aerodynamic output (e.g., velocity triangle information, blade element performance) for eleven streamlines at each axial computational station. The NASA design code gives the streamline radial positions as a percentage of the flow path span measured from the hub end wall. Table 10.3 lists the stage and overall mass-averaged aerodynamic performance parameters. Tables 10.4 and 10.5 list the manufacturing coordinates at 15 spanwise locations for the rotor blade and 11 spanwise locations for the stator blade.

Figure 10.1 shows the coordinate system and nomenclature used for the manufacturing coordinates of the rotor and stator blade sections. 
*** INPUT DATA FOR COMPRESSOR DESIGN PROGAM ***

SCALE FACTOR IS 1.0000

THE COMPRESSOR ROTATIONAL SPEED IS 16042.8 RPM.

THE DESIRED COMPRESSOR PRESSURE RATIO IS 1.590 .

CALCULATIONS WILI BE PERFORMED ON 11 STREAMLINES.
THE INLET FLOW RATE IS 73.300 (LB/SEC)

THE MOLECULAR WEIGHT IS 28.97

THE COMPRESSOR HAS 2 BLADE ROWS.

CalCulations will be made at the blade edges and at is anNular stations.

THE SPECIFIC HEAT POLYNOMIAL IS IN THE FOLLOWING FORM

$\mathrm{CP}=0.23747 \mathrm{E} 00+0.21962 \mathrm{E}-04 * \mathrm{~T}+-0.87791 \mathrm{E}-07 * \mathrm{~T} * * 2+0.13991 \mathrm{E}-09 * \mathrm{~T} * * 3+-0.78056 \mathrm{E}-13 * \mathrm{~T} * * 4+0.15043 \mathrm{E}-16 * \mathrm{~T} * * 5$

INPUT DISTRIBUTIONS BY STREAMLINE OR STREAMTUBE

\begin{tabular}{|c|c|c|c|c|c|}
\hline $\begin{array}{c}\text { STREAMLINE } \\
\text { NO. }\end{array}$ & $\begin{array}{l}\text { INLET TOTAL } \\
\text { TEMPERATURE } \\
\text { (DEG R.) }\end{array}$ & $\begin{array}{l}\text { INLET TOTAL } \\
\text { PRESSURE } \\
\text { (PSIA) }\end{array}$ & $\begin{array}{l}\text { INLET WHIRL } \\
\text { VELOCITY } \\
\text { (FT/SEC) }\end{array}$ & $\begin{array}{c}\text { STREAMTUBE } \\
\text { NO. }\end{array}$ & $\begin{array}{l}\text { STPEAMTUBE } \\
\text { FIOW FRACTION }\end{array}$ \\
\hline $\begin{array}{r}1 \\
2 \\
3 \\
4 \\
5 \\
6 \\
7 \\
8 \\
9 \\
10 \\
11\end{array}$ & $\begin{array}{l}518.700 \\
518.700 \\
518.700 \\
518.700 \\
518.700 \\
518.700 \\
518.700 \\
518.700 \\
518.700 \\
518.700 \\
518.700\end{array}$ & $\begin{array}{l}14.125 \\
14.670 \\
14.700 \\
14.700 \\
14.700 \\
14.700 \\
14.700 \\
14.700 \\
14.700 \\
14.700 \\
14.660\end{array}$ & $\begin{array}{l}0.000 \\
0.000 \\
0.000 \\
0.000 \\
0.000 \\
0.000 \\
0.000 \\
0.000 \\
0.0000 \\
0.0000 \\
0.000\end{array}$ & $\begin{array}{r}1 \\
2 \\
3 \\
4 \\
5 \\
6 \\
7 \\
8 \\
9 \\
10\end{array}$ & $\begin{array}{l}0.10000 \\
0.2000 \\
0.3000 \\
0.4000 \\
0.5000 \\
0.6000 \\
0.7000 \\
0.8000 \\
0.9000 \\
1.0000\end{array}$ \\
\hline
\end{tabular}


Table 10.1 Continued

INPUT DATA POINTS FOR TIP AND HUB CONTOURS

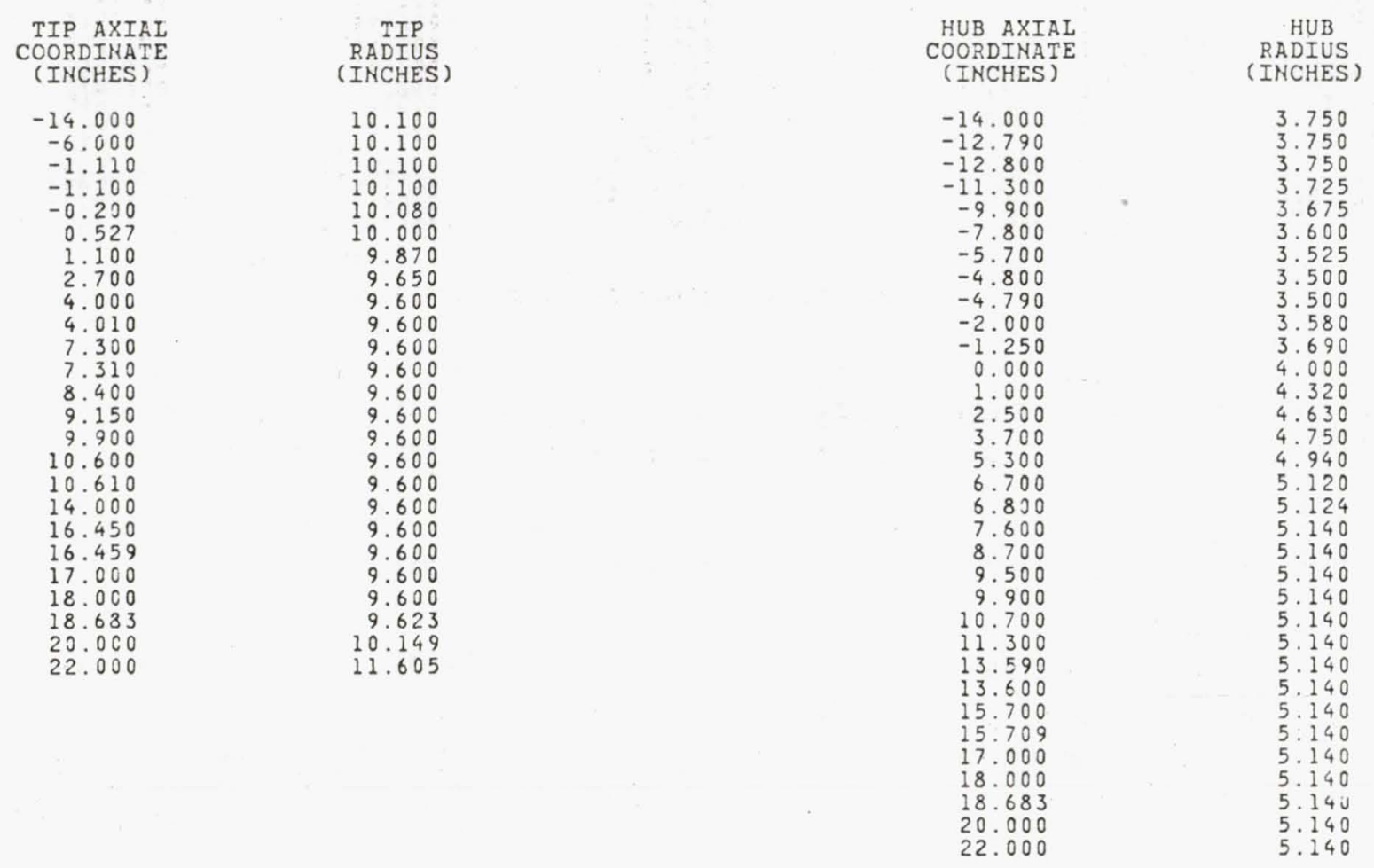

WARMING ONLY, AT IMPUT POINT, 6, THE TIP CONTOUR DATA IS NOT VERY SMOOTH.

WAPNING ONLY, AT INPUT POINT, 23, THE TIP CONTOUR DATA IS NOT VERY SMOOTH, 
Table 10.1 Continued

THE INPUT PROFILE LOSS TABLES - OMEGA(BAR)*COS(BETA)/(2.0*SIGMA)

** PROfile loss table No. 1 **

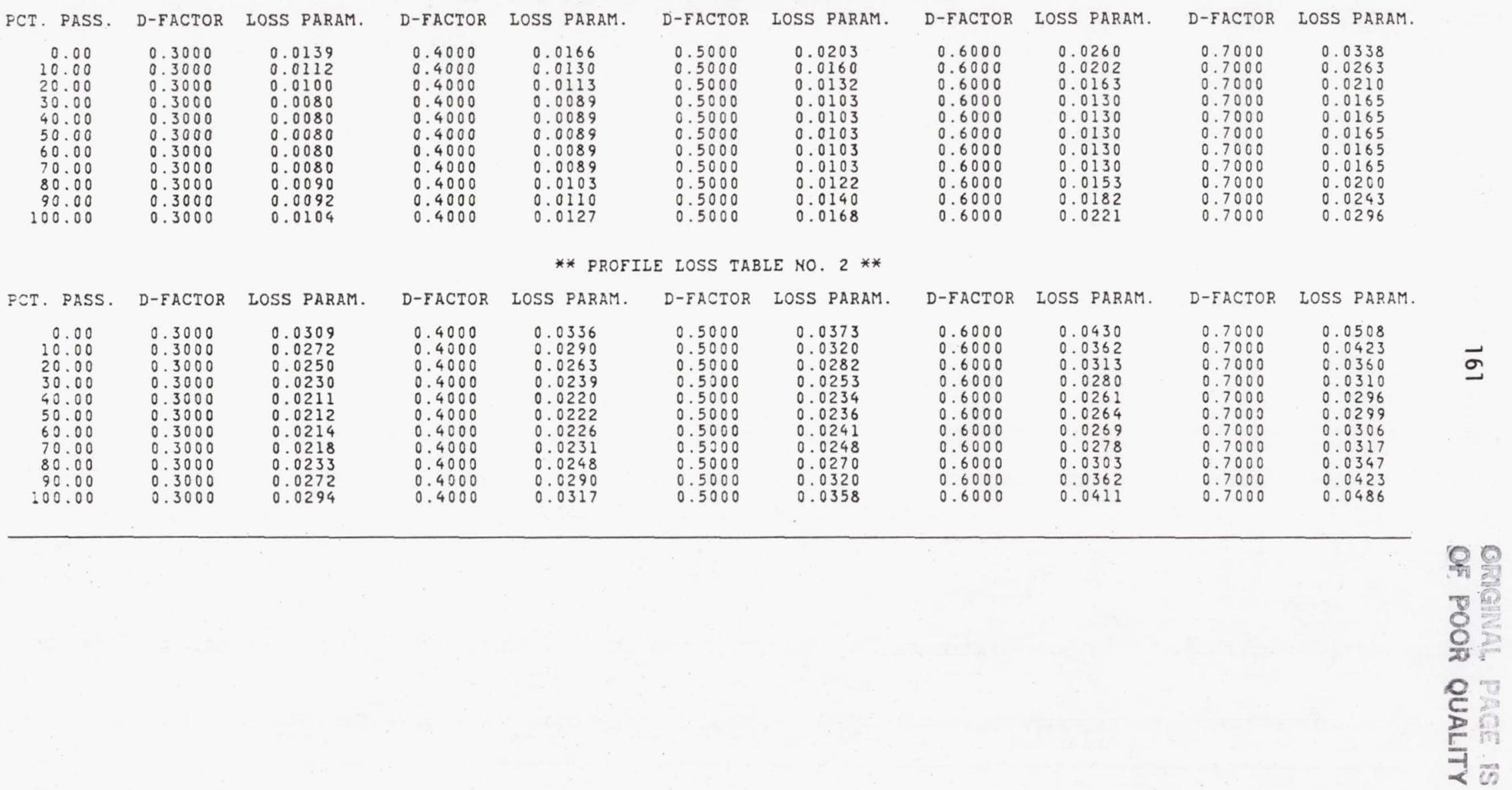


Table 10.1 Continued

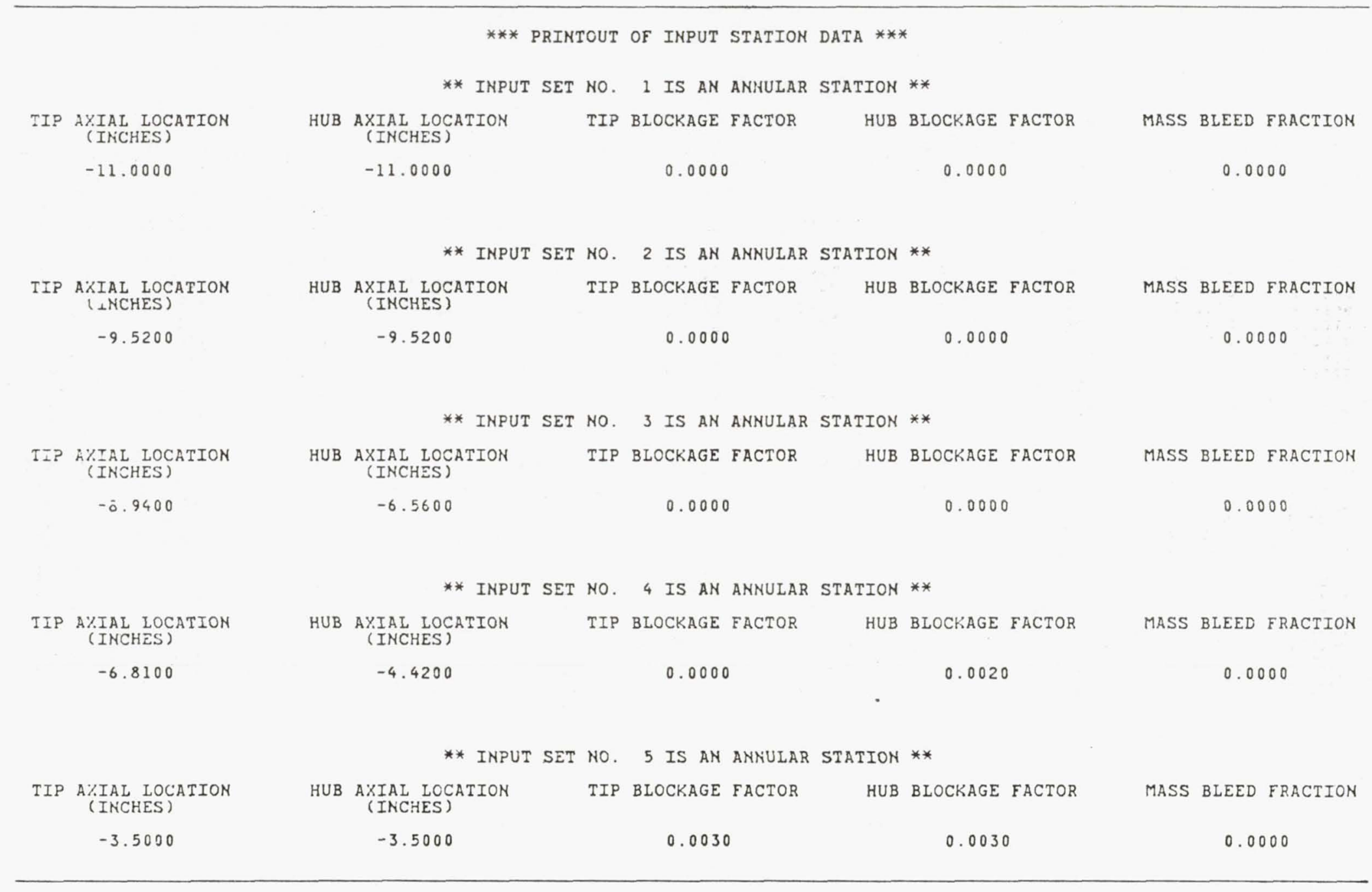


Table 10.1 Continued

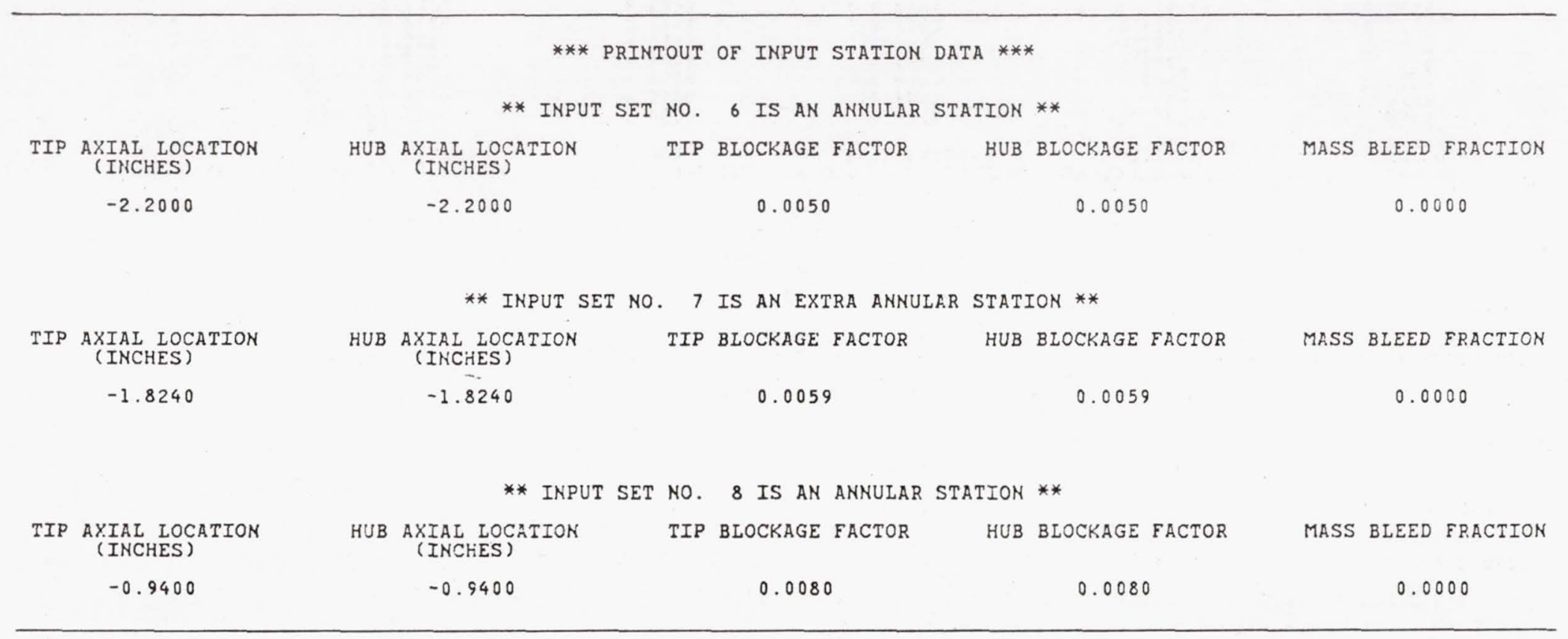




\section{*** PRINTOUT OF INPUT STATION DATA ***}

** INPUT SET NO. 9 IS ROTOR NO. 1 **

* FOR THIS BLADE ROW THE INPUT OPTIONS ARE COORD, MERIDL PUNCH *

\begin{tabular}{|c|c|c|c|c|c|}
\hline IP C & $\begin{array}{l}\text { C.G. AXIAL LOCATION } \\
\text { (INCHES) } \\
0.9410\end{array}$ & 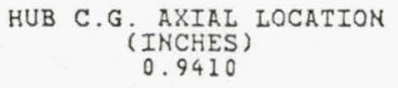 & $\begin{array}{c}\text { INLET TIP BLOCKAGE } \\
0.0100\end{array}$ & $\begin{array}{c}\text { INLET HUB BLOCKAGE } \\
0.0100\end{array}$ & $\begin{array}{c}\text { INLET MASS BLEED } \\
0.0000\end{array}$ \\
\hline & $\begin{array}{c}\text { LOSS SET USED } \\
1\end{array}$ & $\begin{array}{c}\text { BLADE TILT ANGLE } \\
\text { (DEGREES) } \\
0.0000\end{array}$ & $\begin{array}{c}\text { OUTLET TIP BLOCKAGE } \\
0.0130\end{array}$ & $\begin{array}{c}\text { OUTLET HUB BLOCKAGE } \\
0.0130\end{array}$ & $\begin{array}{c}\text { OUTLET MASS BLEED } \\
0.0000\end{array}$ \\
\hline TIP & $\begin{array}{l}\text { P D FACTOR LIMIT } \\
0.4600\end{array}$ & $\begin{array}{c}\text { HUB FLOW ANGLE LIMIT } \\
\text { (DEGREES) } \\
-20.0000\end{array}$ & $\begin{array}{c}\text { TIP SOLIDITY } \\
1.3000\end{array}$ & $\begin{array}{c}\text { NUMBER OF BLADES } \\
22\end{array}$ & $\begin{array}{c}\text { CUM ENERGY ADD FRACT } \\
1.0000\end{array}$ \\
\hline
\end{tabular}

* polynomial coefs. for radial profiles of a blade aero. parameter and basic blade element geometry parameters *

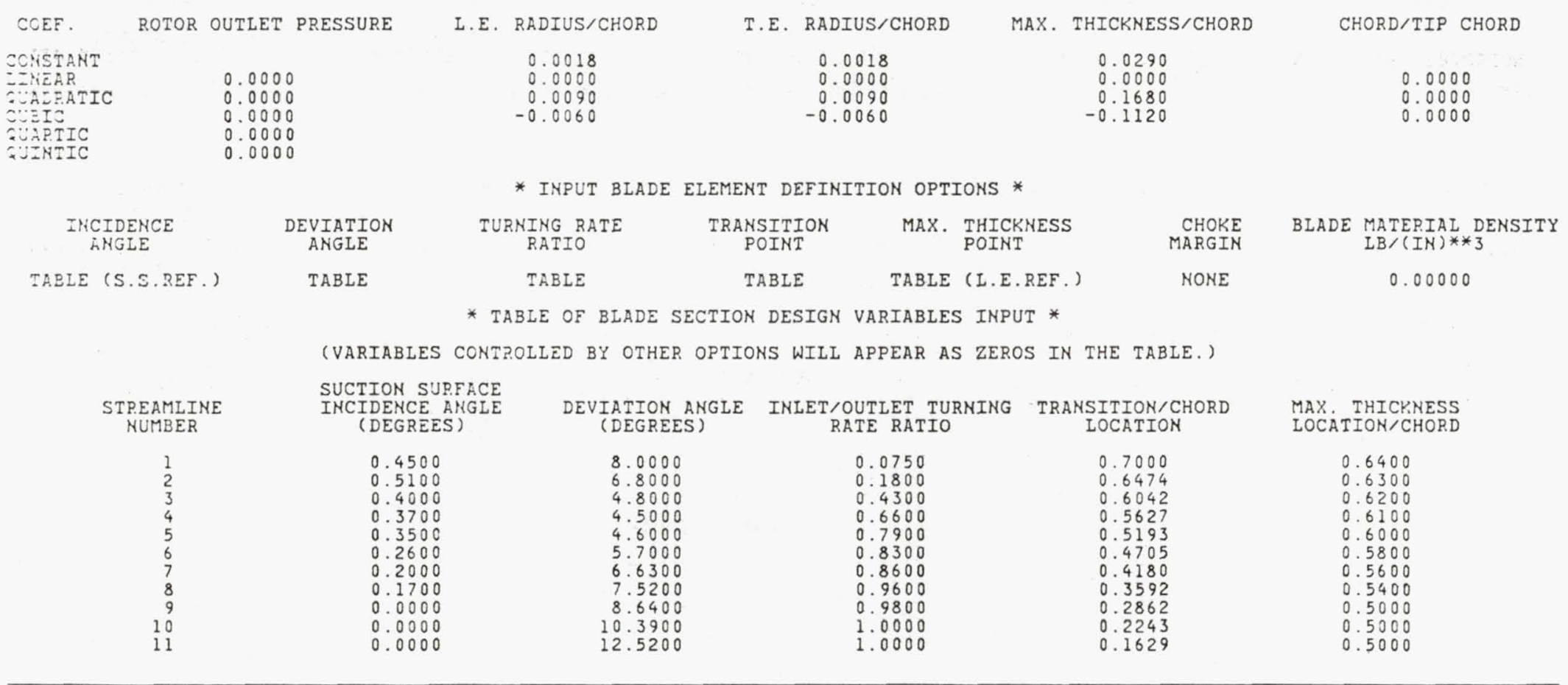


*** PRINTOUT OF INPUT Station DATa ***

* INPUT SET NO. 12 IS a GUIDE VANE OR STATOR **

* For this blade row the INPUt options are coOrd, Meridl punch *

\begin{tabular}{|c|c|c|c|c|c|c|}
\hline TIP & $\begin{array}{l}\text { C.G. AXIAL LOCATION } \\
\text { (INCHES) } \\
5.2000\end{array}$ & $\begin{array}{c}\text { HUB C.G. AXIAL LOCATION } \\
\text { (INCHES) } \\
5.2000\end{array}$ & INLET & $\begin{array}{l}\text { TIP BLOCKAGE } \\
0.0170\end{array}$ & $\begin{array}{c}\text { INLET HUB BLOCKAGE } \\
0.0170\end{array}$ & $\begin{array}{c}\text { INLET MASS BLEED } \\
0.0000\end{array}$ \\
\hline & $\begin{array}{c}\text { LOSS SET USED } \\
2\end{array}$ & $\begin{array}{c}\text { BLADE TILT ANGLE } \\
\text { (DEGREES) } \\
0.0000\end{array}$ & OUTLET & $\begin{array}{l}\text { TIP BLOCKAGE } \\
0.0200\end{array}$ & $\begin{array}{c}\text { OUTLET HUB BLOCKAGE } \\
0.0200\end{array}$ & $\begin{array}{l}\text { OUTLET MASS BLEED } \\
0.0000\end{array}$ \\
\hline $\mathrm{HU}$ & $\begin{array}{l}\text { UB D FACTOR LIMIT } \\
0.7000\end{array}$ & $\begin{array}{c}\text { INLET HUB MACH LIMIT } \\
1.0000\end{array}$ & & $\begin{array}{l}\text { P SOLIDITY } \\
1.2800\end{array}$ & NUMBER $\begin{array}{ll}\text { OF } \\
34\end{array}$ & \\
\hline
\end{tabular}

* polynomial coefs. for radial profiles of a blade aero. parameter and basic blade element geometry parameters *

COEF. STATOR OUTLET V(O) L.E. RADIUS/CHORD T.E. RADIUS/CHORD MAX. THICKNESS/CHORD CHORD/TIP CHORD

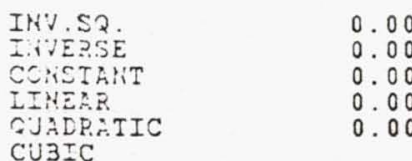

$$
\begin{aligned}
& 0.00 \\
& 0.00 \\
& 0.00 \\
& 0.00 \\
& 0.00
\end{aligned}
$$

$\begin{array}{cc}\substack{\text { INCILEHCE } \\ \text { ARIGEE }} & \begin{array}{c}\text { DEVIATION } \\ \text { ANGLE }\end{array} \\ \text { TABLE (S.S.P.EF.) } & \text { TABLE }\end{array}$

$\begin{array}{rrr}0.0130 & 0.0130 & 0.0800 \\ -0.0080 & -0.0080 & -0.0200 \\ 0.0000 & 0.0000 & 0.0000 \\ 0.0000 & 0.0000 & 0.0000\end{array}$

0.0000
0.0000

0.0000

\begin{tabular}{|c|c|c|}
\hline $\begin{array}{c}\text { TURNING RATE } \\
\text { RATIO }\end{array}$ & $\begin{array}{l}\text { TRANSITION } \\
\text { POINT }\end{array}$ & MAX. $\underset{\text { POINT }}{\text { THICKNESS }}$ \\
\hline TABLE & S.S. SHOCK & TABLE (L.E.REF.) \\
\hline
\end{tabular}

* INput blade element definition options *

* table of blade Section design Variables INPUT *

(VARIABLES CONTROLLED BY OTHER OPTIONS WILL APPEAR AS ZEROS IN THE TABLE.)

STPEAMLINE
NUIBER
1
2
3
4
5
6
7
8
9
10
11

SUCTION SURFACE

INCIDENCE ANGLE
(DEGREES)

DEVIATION ANGLE
(DEGRES)

INLET/OUTLET TURNING

T/OUTLET TUR
RATE RATIO
1.0000
1.0000
1.0000
1.0000
1.0000
1.0000
1.0000
1.0000
1.0000
1.0000
1.0000

16.2000
12.3000
10.5000
9.7000
9.1000
8.8000
8.6000
8.8000
9.00000
10.3000
14.2000

-3.00000
-3.0000
-3.0000
-3.0000
-3.00000
-3.00000
-3.00000
-3.00000
-3.00000
-3.00000
-3.00000

TRANSITION/CHORD LOCATION
LOTION/CHOR

MAX. THICYMESS

OCATION/CHORD 
Table 10.1 Continued

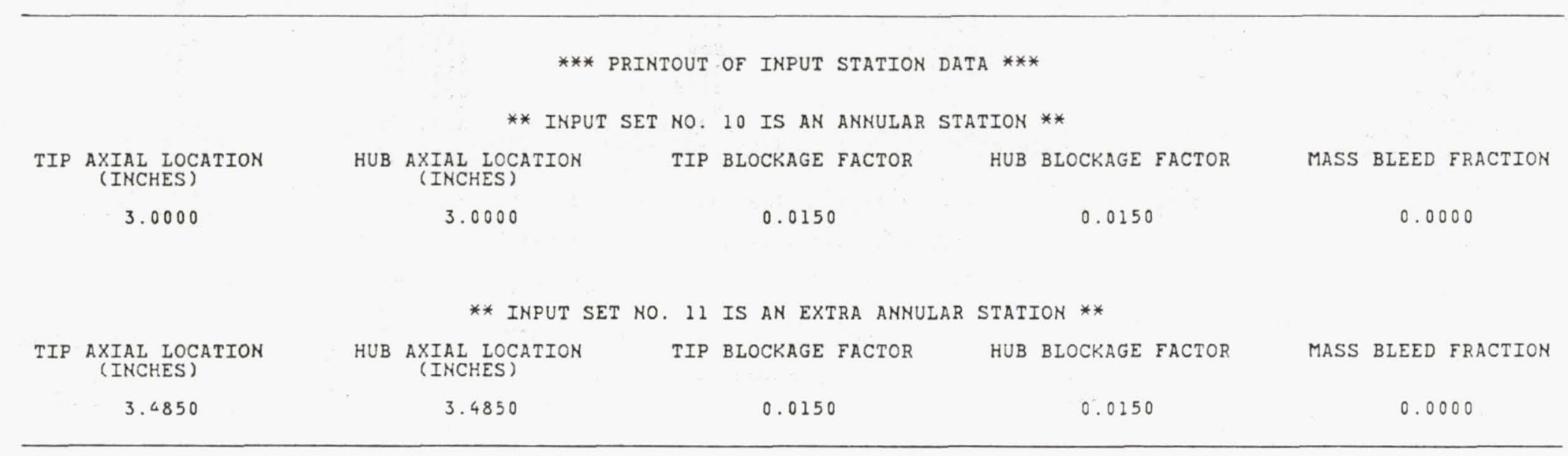


Table 10.1 Continued

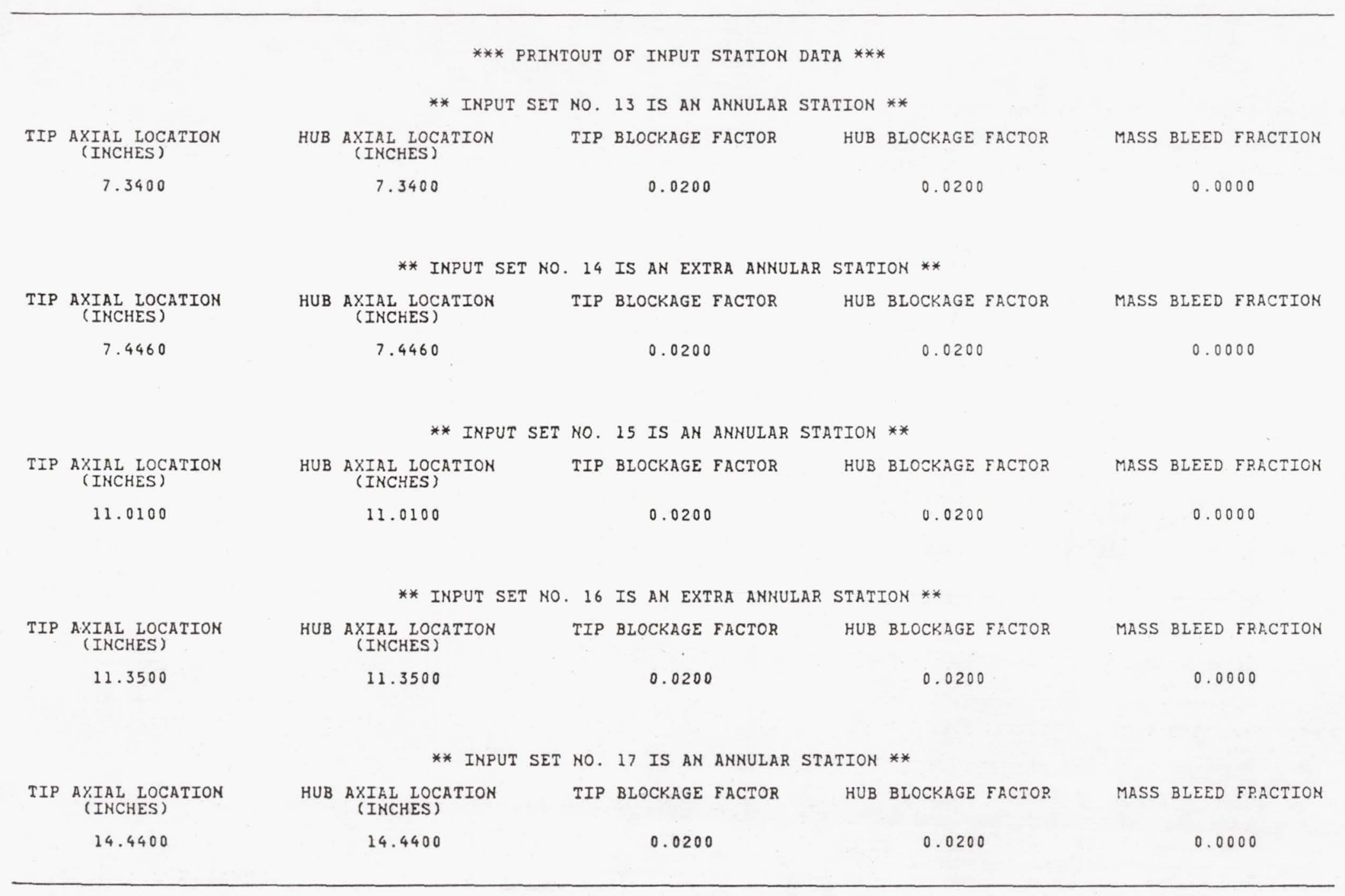




\section{-able 10.1 Continued}

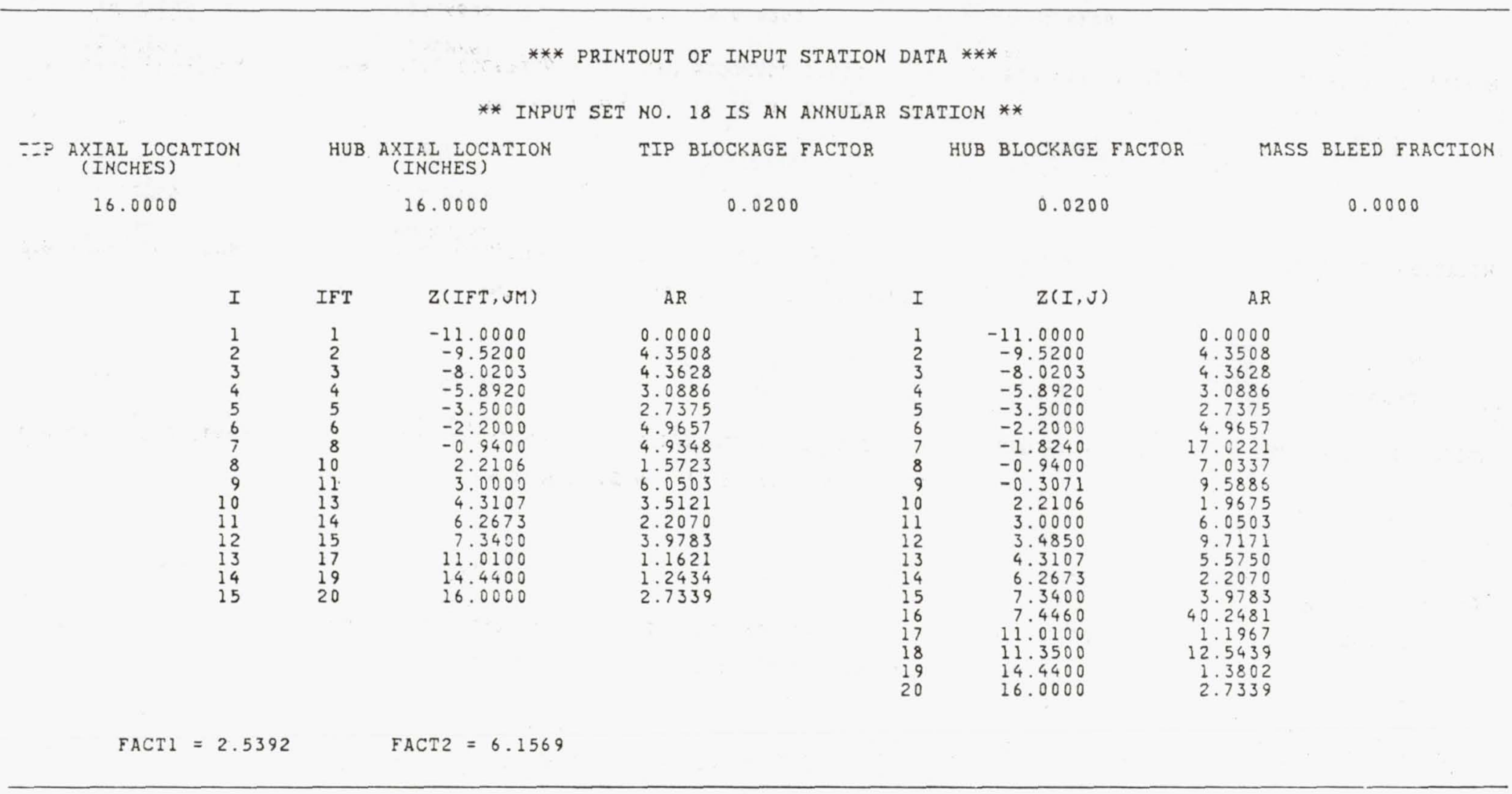

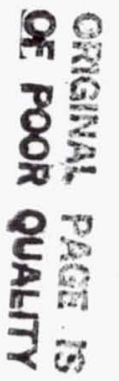


Table 10.2 Design code predictions of aerodynamic performance

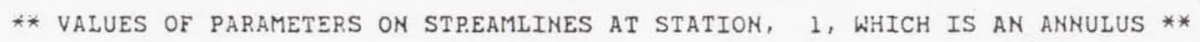

\begin{tabular}{|c|c|c|c|c|c|c|c|c|c|c|c|c|c|c|}
\hline $\begin{array}{l}\text { STR } \\
\text { No. }\end{array}$ & $\begin{array}{l}\text { REAMLINE } \\
\text { RAUIUS } \\
\text { (IN, ) }\end{array}$ & $\begin{array}{l}\text { ANTAL } \\
\text { COON.D. } \\
\text { (IN.) }\end{array}$ & $\begin{array}{l}\text { AYIAL } \\
\text { VEL } \\
\text { (FT/SEC) }\end{array}$ & $\begin{array}{c}\text { MERD. } \\
\text { VEL. } \\
\text { (FT/SEC) }\end{array}$ & $\begin{array}{c}\text { TANG. } \\
\text { VEL } \\
\text { (FT/SEC) }\end{array}$ & $\begin{array}{c}\text { ABS. } \\
\text { VEL: } \\
\text { (FT/SEC) }\end{array}$ & $\begin{array}{l}\text { ABS. } \\
\text { MACH NO. }\end{array}$ & $\begin{array}{c}\text { ABS. FLCW } \\
\text { ANGLE } \\
(D E G)\end{array}$ & $\begin{array}{l}\text { STPEAM. } \\
\text { SICPE } \\
\text { (DEG) }\end{array}$ & $\begin{array}{l}\text { STPEAM. } \\
\text { CURV. } \\
\text { (1.VIN.) }\end{array}$ & & $\begin{array}{l}\text { TOTAL } \\
\text { TEMP. } \\
\text { (DEG.R.) }\end{array}$ & $\begin{array}{l}\text { STATIC } \\
\text { PFESS } \\
\text { (PSIA) }\end{array}$ & $\begin{array}{l}\text { STATIC } \\
\text { TEMP } \\
(D E G . R .)\end{array}$ \\
\hline $\begin{array}{r}1 \\
2 \\
3 \\
4 \\
5 \\
6 \\
7 \\
8 \\
9 \\
10 \\
11\end{array}$ & $\begin{array}{r}10.100 \\
10.100 \\
9.628 \\
9.160 \\
8.668 \\
8.147 \\
7.590 \\
6.989 \\
6.331 \\
5.597 \\
4.752\end{array}$ & 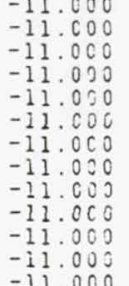 & $\begin{array}{l}506.80 \\
563.65 \\
574.17 \\
572.82 \\
573.64 \\
573.87 \\
574.29 \\
574.62 \\
575.65 \\
574.87 \\
571.25\end{array}$ & $\begin{array}{l}526.80 \\
563.66 \\
574.17 \\
572.82 \\
573.65 \\
573.88 \\
574.32 \\
574.67 \\
575.14 \\
575.04 \\
571.62\end{array}$ & $\begin{array}{l}0.00 \\
0.00 \\
0.00 \\
0.00 \\
0.00 \\
0.00 \\
0.00 \\
0.00 \\
0.00 \\
0.00\end{array}$ & $\begin{array}{l}506.80 \\
563.66 \\
574.17 \\
572.82 \\
573.65 \\
573.88 \\
574.32 \\
574.67 \\
575.14 \\
575.04 \\
571.62\end{array}$ & $\begin{array}{l}0.4635 \\
0.5181 \\
0.5283 \\
0.5270 \\
0.5278 \\
0.5280 \\
0.5284 \\
0.5288 \\
0.5292 \\
0.5292 \\
0.5258\end{array}$ & $\begin{array}{l}0.00 \\
0.00 \\
0.00 \\
0.00 \\
0.00 \\
0.00 \\
0.00 \\
0.00 \\
0.00 \\
0.00 \\
0.00\end{array}$ & $\begin{array}{l}0.00 \\
-0.05 \\
-0.10 \\
-0.17 \\
-0.26 \\
-0.38 \\
-0.52 \\
-0.72 \\
-0.99 \\
-1.39 \\
-2.08\end{array}$ & $\begin{array}{l}-0.000 \\
-0.001 \\
-0.031 \\
-0.001 \\
-0.001 \\
-0.001 \\
-0.001 \\
-0.001 \\
-0.001 \\
-0.001 \\
-0.001\end{array}$ & & $\begin{array}{l}518.70 \\
518.70 \\
518.70 \\
518.70 \\
518.70 \\
518.70 \\
518.70 \\
518.70 \\
518.70 \\
518.70 \\
518.70\end{array}$ & $\begin{array}{l}12.193 \\
12.215 \\
12.153 \\
12.165 \\
12.158 \\
12.156 \\
12.152 \\
12.149 \\
12.145 \\
12.146 \\
12.141\end{array}$ & $\begin{array}{l}497.33 \\
492.22 \\
491.22 \\
491.35 \\
491.27 \\
491.25 \\
491.21 \\
491.17 \\
491.13 \\
491.14 \\
491.46\end{array}$ \\
\hline
\end{tabular}

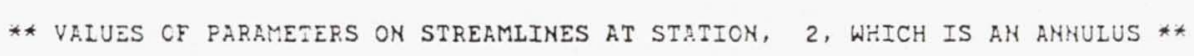

\begin{tabular}{|c|c|c|c|c|c|c|c|c|c|c|c|c|c|}
\hline $\begin{array}{l}\text { STREAMLINE } \\
\text { NO. PADIUS } \\
\text { (II.) }\end{array}$ & $\begin{array}{l}\text { AYIAL } \\
\text { COOFD. } \\
\text { (IN.) }\end{array}$ & 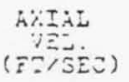 & $\begin{array}{c}\text { EDD. } \\
\text { (FT/SEC) }\end{array}$ & $\begin{array}{c}\text { TENG. } \\
\text { WEI. } \\
\text { (FT/SEC) }\end{array}$ & $\begin{array}{c}\text { ABS. } \\
\text { VEL } \\
(\text { FT/SEC) }\end{array}$ & MACH NO. & $\begin{array}{c}\text { ABS. FLON } \\
\text { ANGEE } \\
\text { (DEG) }\end{array}$ & $\begin{array}{l}\text { STPE:M } \\
\text { SEGFE } \\
(D E G)\end{array}$ & $\begin{array}{c}\text { STPEAM. } \\
\text { CUPV. } \\
\text { (1./IY, ) }\end{array}$ & $\begin{array}{l}\text { TOTAL } \\
\text { PFESS } \\
\text { (PSIA) }\end{array}$ & $\begin{array}{l}\text { TOTAL } \\
\text { TEMP. } \\
\text { (DEG.R.) }\end{array}$ & $\begin{array}{l}\text { STATIC } \\
\text { PEESS } \\
\text { (PSIA) }\end{array}$ & $\begin{array}{c}\text { STATTC } \\
\text { TEMPP. } \\
\text { (DEG.R. ) }\end{array}$ \\
\hline $\begin{array}{cc}1 & 10.100 \\
1 & 9.626 \\
3 & 9.157 \\
4 & 8.663 \\
5 & 8.139 \\
6 & 7.579 \\
7 & 6.974 \\
8 & 6.312 \\
9 & 5.571 \\
10 & 4.715 \\
11 & 3.661 \\
\text { HUB } & 3.661\end{array}$ & $\begin{array}{l}-9.520 \\
-9.520 \\
-9.520 \\
-9.520 \\
-9.520 \\
-9.520 \\
-9.520 \\
-9.520 \\
-9.520 \\
-9.520 \\
-9.520 \\
-9.520\end{array}$ & $\begin{array}{l}504.23 \\
56.34 \\
57.32 \\
570.11 \\
570.64 \\
570.52 \\
570.57 \\
570.49 \\
570.49 \\
569.86 \\
566.12\end{array}$ & $\begin{array}{l}504.23 \\
561.34 \\
571.32 \\
576.11 \\
570.64 \\
570.53 \\
570.59 \\
570.53 \\
570.57 \\
570.03 \\
556.52\end{array}$ & $\begin{array}{l}0.03 \\
0.00 \\
0.00 \\
0.00 \\
0.00 \\
0.00 \\
0.00 \\
0.00 \\
0.00 \\
0.00 \\
0.00\end{array}$ & $\begin{array}{l}504.23 \\
561.34 \\
571.72 \\
570.11 \\
570.64 \\
570.53 \\
570.59 \\
570.53 \\
570.57 \\
570.03 \\
566.52\end{array}$ & $\begin{array}{l}0.4610 \\
0.5159 \\
0.5259 \\
0.5244 \\
0.5249 \\
0.5248 \\
0.5248 \\
0.5248 \\
0.5248 \\
0.5243 \\
0.5209\end{array}$ & $\begin{array}{l}0.00 \\
0.00 \\
0.00 \\
0.00 \\
0.00 \\
0.00 \\
0.00 \\
0.00 \\
0.00 \\
0.00 \\
0.00\end{array}$ & $\begin{array}{l}-0.00 \\
-0.05 \\
-0.11 \\
-0.17 \\
-0.25 \\
-0.36 \\
-0.50 \\
-0.59 \\
-0.95 \\
-1.39 \\
-2.16\end{array}$ & $\begin{array}{r}-0.000 \\
-0.000 \\
-0.000 \\
-0.000 \\
-0.000 \\
-0.000 \\
-0.000 \\
0.000 \\
0.000 \\
0.000 \\
-0.001\end{array}$ & $\begin{array}{l}14.125 \\
14.670 \\
14.700 \\
14.700 \\
14.700 \\
14.700 \\
14.700 \\
14.700 \\
14.700 \\
14.700 \\
14.660\end{array}$ & $\begin{array}{l}518.70 \\
518.70 \\
518.70 \\
518.70 \\
518.70 \\
518.70 \\
518.70 \\
518.70 \\
518.70 \\
518.70 \\
518.70\end{array}$ & $\begin{array}{l}12.208 \\
12.234 \\
12.174 \\
12.187 \\
12.183 \\
12.183 \\
12.183 \\
12.183 \\
12.183 \\
12.188 \\
12.183\end{array}$ & $\begin{array}{l}497.50 \\
492.44 \\
491.46 \\
491.61 \\
491.56 \\
491.57 \\
491.56 \\
491.57 \\
491.56 \\
491.62 \\
491.95\end{array}$ \\
\hline
\end{tabular}


Table 10.2 Continued

** VALUES OF FARAMETERS ON STREAMLINES AT STATION, 3, WHICH IS AN ANNULUS **

\begin{tabular}{|c|c|c|c|c|c|c|c|c|c|c|c|c|c|}
\hline $\begin{array}{l}\text { STPEAMIIME } \\
\text { :O. RADIUS } \\
\text { (IN.) }\end{array}$ & $\begin{array}{l}\text { AXIAL } \\
\text { COORD. } \\
\text { (IN, ) }\end{array}$ & $\begin{array}{c}\text { AXIAL } \\
\text { VEL. } \\
\text { (FT/SEC) }\end{array}$ & $\begin{array}{c}\text { MERD. } \\
\text { VEL. } \\
\text { (ET/SEC) }\end{array}$ & $\begin{array}{c}\text { TANG. } \\
\text { VEI. } \\
(F T / S E C)\end{array}$ & $\begin{array}{c}\text { ABS. } \\
\text { VEL. } \\
\text { (FT/SEC) }\end{array}$ & $\begin{array}{l}\text { ABS. } \\
\text { MACH NO. }\end{array}$ & $\begin{array}{c}\text { ABS. FLOW } \\
\text { ANGLE } \\
\text { (DEG) }\end{array}$ & $\begin{array}{l}\text { STREAM. } \\
\text { SLOPE } \\
\text { (DEG) }\end{array}$ & $\begin{array}{c}\text { STREAM. } \\
\text { CURV. } \\
(1 . / I N .)\end{array}$ & $\begin{array}{l}\text { TOTAL } \\
\text { FRESS } \\
\text { (PSIA) }\end{array}$ & $\begin{array}{l}\text { TOTAL } \\
\text { TEMP. } \\
\text { (DEG.R.) }\end{array}$ & $\begin{array}{l}\text { STATIC } \\
\text { PP.ESS. } \\
\text { (PSIA) }\end{array}$ & $\begin{array}{l}\text { STATIC } \\
\text { TEMP. } \\
\text { (DEG.R. ) }\end{array}$ \\
\hline $\begin{array}{lr}10.100 \\
2 & 9.625 \\
3 & 9.155 \\
4 & 8.660 \\
5 & 8.134 \\
6 & 7.571 \\
7 & 6.961 \\
8 & 6.291 \\
3 & 5.538 \\
0 & 4.660 \\
1 & 3.557 \\
& 3.557\end{array}$ & $\begin{array}{l}-8.940 \\
-8.767 \\
-8.596 \\
-8.416 \\
-8.225 \\
-8.020 \\
-7.798 \\
-7.554 \\
-7.281 \\
-6.961 \\
-6.560 \\
-6.560\end{array}$ & $\begin{array}{l}503.17 \\
560.16 \\
570.28 \\
568.31 \\
568.34 \\
567.53 \\
566.60 \\
565.08 \\
562.94 \\
558.86 \\
548.52\end{array}$ & $\begin{array}{l}503.17 \\
560.16 \\
570.28 \\
568.31 \\
568.34 \\
567.54 \\
565.61 \\
565.10 \\
552.97 \\
558.94 \\
548.73\end{array}$ & $\begin{array}{l}0.00 \\
0.00 \\
0.00 \\
0.00 \\
0.00 \\
0.00 \\
0.00 \\
0.00 \\
0.00 \\
0.00 \\
0.00\end{array}$ & $\begin{array}{l}503.17 \\
550.16 \\
570.28 \\
568.31 \\
568.34 \\
567.54 \\
566.61 \\
565.10 \\
552.97 \\
558.94 \\
548.73\end{array}$ & $\begin{array}{l}0.4600 \\
0.5147 \\
0.5245 \\
0.5226 \\
0.5227 \\
0.5219 \\
0.5210 \\
0.5195 \\
0.5174 \\
0.5135 \\
0.5037\end{array}$ & $\begin{array}{l}0.00 \\
0.00 \\
0.00 \\
0.00 \\
0.00 \\
0.00 \\
0.00 \\
0.00 \\
0.00 \\
0.00 \\
0.00\end{array}$ & $\begin{array}{l}0.00 \\
-0.05 \\
-0.09 \\
-0.14 \\
-0.20 \\
-0.27 \\
-0.35 \\
-0.48 \\
-0.66 \\
-0.25 \\
-1.57\end{array}$ & $\begin{array}{l}0.000 \\
0.000 \\
0.000 \\
0.000 \\
0.001 \\
0.001 \\
0.002 \\
0.003 \\
0.004 \\
0.006 \\
0.008\end{array}$ & $\begin{array}{l}14.125 \\
14.670 \\
14.700 \\
14.700 \\
14.700 \\
14.700 \\
14.700 \\
14.700 \\
14.700 \\
14.700 \\
14.660\end{array}$ & $\begin{array}{l}518.70 \\
518.770 \\
518.70 \\
518.70 \\
518.70 \\
518.70 \\
518.70 \\
518.70 \\
518.70 \\
518.70 \\
518.70\end{array}$ & $\begin{array}{l}12.216 \\
12.243 \\
12.186 \\
12.202 \\
12.201 \\
12.208 \\
12.216 \\
12.228 \\
12.245 \\
12.278 \\
12.327\end{array}$ & $\begin{array}{l}497.59 \\
492.55 \\
491.59 \\
491.78 \\
491.78 \\
491.85 \\
491.94 \\
492.08 \\
432.28 \\
492.66 \\
493.60\end{array}$ \\
\hline
\end{tabular}

* VAZUES OF PAPAMETERS CN STREAMLINES AT STATION, 4, WHICH IS AN AHHULUS **

\begin{tabular}{|c|c|c|c|c|c|c|c|c|c|c|c|c|c|c|}
\hline $\begin{array}{l}\text { ST? } \\
\text { Hic. }\end{array}$ & $\begin{array}{l}\text { ELMLINE } \\
\text { PADIUS } \\
\text { (IN.) }\end{array}$ & $\begin{array}{l}\text { AXIAL } \\
\text { CCOR.D. } \\
\text { (IN.) }\end{array}$ & $\begin{array}{c}\text { AYIAL } \\
\text { VEL. } \\
\text { (FT/SEC) }\end{array}$ & $\begin{array}{c}\text { MERD. } \\
\text { VEZLAC) } \\
\text { (ET/SEC) }\end{array}$ & $\begin{array}{c}\text { TANG. } \\
\text { VEL } \\
\text { (ET/SEC) }\end{array}$ & $\begin{array}{c}\text { ABS. } \\
\text { (FEL } \\
\text { (FISEC) }\end{array}$ & $\begin{array}{l}\text { ABS. } \\
\text { MACH NO. }\end{array}$ & $\begin{array}{c}\text { ABS. FLOW } \\
\text { A.NGLE } \\
\text { (DEG) }\end{array}$ & $\begin{array}{l}\text { STPEAM. } \\
\text { SLCPE } \\
\text { (DEG) }\end{array}$ & $\begin{array}{c}\text { STPEAM. } \\
\text { CUPV. } \\
\text { (1./IN.) }\end{array}$ & $\begin{array}{l}\text { TOTAL } \\
\text { FPESS } \\
\text { (PSIA) }\end{array}$ & $\begin{array}{l}\text { TOTAL } \\
\text { TEMP. } \\
\text { (DEG.R.) }\end{array}$ & $\begin{array}{l}\text { STAIIC } \\
\text { PPESS } \\
\text { (PSIA) }\end{array}$ & $\begin{array}{c}\text { STATIC } \\
\text { TEMP } \\
\text { (DEG.P.) }\end{array}$ \\
\hline $\begin{array}{r}2 \\
3 \\
4 \\
5 \\
6 \\
7 \\
8 \\
9 \\
10\end{array}$ & $\begin{array}{r}10.100 \\
9.623 \\
7.152 \\
8.656 \\
8.129 \\
7.565 \\
6.954 \\
6.233 \\
5.527 \\
4.644 \\
3.526\end{array}$ & $\begin{array}{l}-6.810 \\
-6.637 \\
-6.467 \\
-6.287 \\
-6.096 \\
-5.892 \\
-5.671 \\
-5.428 \\
-5.154 \\
-4.835 \\
-4.430\end{array}$ & $\begin{array}{l}500.72 \\
558.23 \\
568.63 \\
566.72 \\
566.62 \\
565.43 \\
563.80 \\
561.14 \\
557.03 \\
549.46 \\
532.69\end{array}$ & $\begin{array}{l}500.72 \\
558.23 \\
568.63 \\
566.72 \\
566.62 \\
555.43 \\
553.80 \\
561.14 \\
557.03 \\
549.46 \\
532.69\end{array}$ & $\begin{array}{l}0.00 \\
0.00 \\
0.00 \\
0.00 \\
0.00 \\
0.00 \\
0.00 \\
0.00 \\
0.00 \\
0.00 \\
0.00\end{array}$ & $\begin{array}{l}500.72 \\
558.23 \\
558.63 \\
566.72 \\
556.62 \\
565.43 \\
563.80 \\
551.14 \\
557.03 \\
549.46 \\
532.69\end{array}$ & $\begin{array}{l}0.4577 \\
0.5129 \\
0.5229 \\
0.5211 \\
0.5210 \\
0.5198 \\
0.5182 \\
0.5157 \\
0.5117 \\
0.5044 \\
0.4832\end{array}$ & $\begin{array}{l}0.00 \\
0.00 \\
0.00 \\
0.00 \\
0.00 \\
0.00 \\
0.00 \\
0.00 \\
0.00 \\
0.00 \\
0.00\end{array}$ & $\begin{array}{l}-0.02 \\
-0.06 \\
-0.06 \\
-0.04 \\
-0.01 \\
0.03 \\
0.08 \\
0.15 \\
0.22 \\
0.27 \\
0.12\end{array}$ & $\begin{array}{l}-0.001 \\
-0.000 \\
0.001 \\
0.002 \\
0.003 \\
0.004 \\
0.005 \\
0.008 \\
0.010 \\
0.014 \\
0.019\end{array}$ & $\begin{array}{l}14.125 \\
14.670 \\
14.700 \\
14.700 \\
14.700 \\
14.700 \\
14.700 \\
14.700 \\
14.700 \\
14.700 \\
14.650\end{array}$ & $\begin{array}{l}518.70 \\
518.70 \\
518.70 \\
518.70 \\
518.70 \\
518.70 \\
518.70 \\
518.70 \\
518.70 \\
518.70 \\
518.70\end{array}$ & $\begin{array}{l}12.233 \\
12.259 \\
12.199 \\
12.215 \\
12.216 \\
12.225 \\
12.239 \\
12.250 \\
12.294 \\
12.355 \\
12.454\end{array}$ & $\begin{array}{l}497.80 \\
492.73 \\
491.75 \\
491.93 \\
491.74 \\
492.05 \\
492.20 \\
492.45 \\
492.84 \\
493.54 \\
495.05\end{array}$ \\
\hline
\end{tabular}

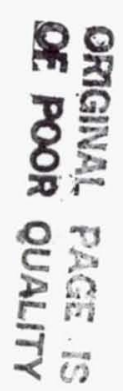


* Values of parameters on streamlimes at station, 5, Which is an ammulus **

\begin{tabular}{|c|c|c|c|c|c|c|c|c|c|c|c|c|c|}
\hline 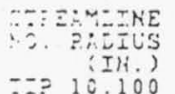 & $\begin{array}{l}\text { AXIAL } \\
\text { COORD } \\
\text { (IN.) } \\
-3.500\end{array}$ & $\begin{array}{c}\text { AXIAL } \\
\text { VEL } \\
(\text { FT/SEC) }\end{array}$ & $\begin{array}{c}\text { MEFD. } \\
\text { VEL. } \\
(\text { FT/SEC })\end{array}$ & $\begin{array}{c}\text { TANG. } \\
\text { VEL . } \\
\text { (FT/SEC) }\end{array}$ & $\begin{array}{c}\text { AES. } \\
\text { VEI. } \\
(F T / S E C)\end{array}$ & MACS NO. & $\begin{array}{c}\text { ABS. FLOW } \\
\text { AYGLE } \\
\text { (DEG) }\end{array}$ & $\begin{array}{c}\text { STREAM. } \\
\text { SLOPE } \\
\text { (DEG) }\end{array}$ & $\begin{array}{c}\text { STREAM. } \\
\text { CURV } \\
\text { (1./IM.) }\end{array}$ & $\begin{array}{l}\text { TOTAL } \\
\text { PPESS } \\
\text { (FSIA) }\end{array}$ & 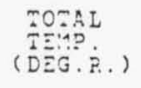 & $\begin{array}{l}\text { STATIC } \\
\text { FRESS } \\
\text { (PSIA) }\end{array}$ & $\begin{array}{c}\text { STLIIC } \\
\text { TETP. } \\
\text { (DEG.P.) }\end{array}$ \\
\hline $\begin{array}{l}0.037 \\
9.515 \\
9.148 \\
2.656\end{array}$ & $\begin{array}{l}-3.500 \\
-3.500 \\
-3.500 \\
-3.500 \\
-3.500 \\
-3.500 \\
-3.500 \\
-3.500 \\
-3.500 \\
-3.500 \\
-3.500 \\
-3.500 \\
-3.500\end{array}$ & $\begin{array}{l}508.58 \\
565.85 \\
575.93 \\
573.77 \\
573.29 \\
571.52 \\
568.84 \\
564.31 \\
556.99 \\
544.04 \\
521.16\end{array}$ & $\begin{array}{l}503.61 \\
555.85 \\
575.93 \\
573.77 \\
573.30 \\
571.54 \\
568.90 \\
554.44 \\
557.21 \\
544.36 \\
521.35\end{array}$ & $\begin{array}{l}0.00 \\
0.00 \\
0.00 \\
0.00 \\
0.00 \\
0.00 \\
0.00 \\
0.00 \\
0.00 \\
0.00 \\
0.00\end{array}$ & $\begin{array}{l}508.61 \\
565.85 \\
575.93 \\
573.77 \\
573.30 \\
571.54 \\
568.90 \\
564.44 \\
557.21 \\
544.36 \\
521.35\end{array}$ & $\begin{array}{l}0.4652 \\
0.5202 \\
0.5300 \\
0.5279 \\
0.5275 \\
0.5258 \\
0.5232 \\
0.5189 \\
0.5119 \\
0.4995 \\
0.4774\end{array}$ & $\begin{array}{l}0.00 \\
0.00 \\
0.00 \\
0.00 \\
0.00 \\
0.00 \\
0.00 \\
0.00 \\
0.00 \\
0.00 \\
0.00\end{array}$ & $\begin{array}{l}-0.58 \\
-0.25 \\
-0.09 \\
0.07 \\
0.27 \\
0.52 \\
0.83 \\
1.20 \\
1.61 \\
1.96 \\
1.53\end{array}$ & $\begin{array}{r}-0.005 \\
0.000 \\
0.061 \\
0.002 \\
0.004 \\
0.006 \\
0.009 \\
0.014 \\
0.020 \\
0.031 \\
0.033\end{array}$ & $\begin{array}{l}14.125 \\
14.6700 \\
14.7000 \\
14.700 \\
14.700 \\
14.700 \\
14.700 \\
14.700 \\
14.7000 \\
14.700 \\
14.660\end{array}$ & $\begin{array}{l}513.70 \\
518.70 \\
518.70 \\
518.70 \\
518.70 \\
518.70 \\
518.70 \\
518.70 \\
513.70 \\
518.70 \\
518.70\end{array}$ & $\begin{array}{l}12.177 \\
12.197 \\
12.139 \\
12.157 \\
12.161 \\
12.175 \\
12.197 \\
12.234 \\
12.292 \\
12.396 \\
12.541\end{array}$ & $\begin{array}{l}497.13 \\
492.01 \\
491.05 \\
491.25 \\
491.30 \\
491.47 \\
491.72 \\
492.15 \\
492.82 \\
494.00 \\
496.05\end{array}$ \\
\hline
\end{tabular}

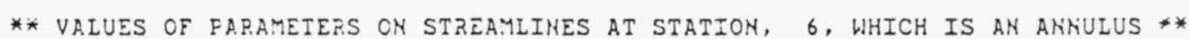

\begin{tabular}{|c|c|c|c|c|c|c|c|c|c|c|c|c|c|}
\hline $\begin{array}{c}\text { SEEMIIUE } \\
\text { FAEIUS } \\
\text { (IN.) }\end{array}$ & $\begin{array}{l}\text { AXIRL } \\
\text { COORD. } \\
\text { (IN.) }\end{array}$ & $\begin{array}{c}\text { AXIAL } \\
\text { VEL } \\
(F T / S E C)\end{array}$ & $\begin{array}{c}\text { MESD. } \\
V E D . \\
(E T / S E C)\end{array}$ & $\begin{array}{c}\text { TANG. } \\
\text { VEI. } \\
(\text { TISEC) }\end{array}$ & $\begin{array}{c}\text { AES. } \\
\text { VEL } \\
\text { (FT/SEC) }\end{array}$ & $\begin{array}{l}\text { ABS. } \\
M A C H\end{array}$ & $\begin{array}{c}\text { ABS. FLOW } \\
\text { ANGLE } \\
\text { (DEG) }\end{array}$ & $\begin{array}{c}\text { STPEAM. } \\
\text { SIOPE } \\
\text { (DEG) }\end{array}$ & $\begin{array}{l}\text { STPEAM. } \\
\text { CURV. } \\
\text { (1.IIN.) }\end{array}$ & $\begin{array}{l}\text { TOTAL } \\
\text { FPESS } \\
\text { (PSIA) }\end{array}$ & 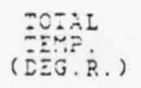 & $\begin{array}{l}\text { STETIC } \\
\text { FESSS } \\
\text { (FSIA) }\end{array}$ & 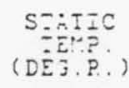 \\
\hline $\begin{array}{rr} & 0.078 \\
\vdots & 9.607 \\
3 & 9.143 \\
4 & 8.653 \\
5 & 8.138 \\
5 & 7.587 \\
7 & 6.973 \\
3 & 6.340 \\
3 & 5.606 \\
0 & 4.742 \\
\vdots & 3.622 \\
3 & 3.560\end{array}$ & $\begin{array}{l}-2.200 \\
-2.200 \\
-2.200 \\
-2.200 \\
-2.200 \\
-2.200 \\
-2.200 \\
-2.200 \\
-2.200 \\
-2.200 \\
-2.200 \\
-2.200\end{array}$ & $\begin{array}{l}516.06 \\
569.02 \\
580.41 \\
580.65 \\
582.84 \\
583.39 \\
582.13 \\
577.53 \\
567.73 \\
548.02 \\
497.21\end{array}$ & $\begin{array}{l}516.05 \\
569.02 \\
580.42 \\
580.66 \\
582.84 \\
583.42 \\
582.27 \\
577.93 \\
568.67 \\
549.92 \\
500.67\end{array}$ & $\begin{array}{l}0.00 \\
0.000 \\
0.00 \\
0.00 \\
0.00 \\
0.00 \\
0.00 \\
0.00 \\
0.00 \\
0.00 \\
0.00\end{array}$ & $\begin{array}{l}516.06 \\
559.02 \\
580.42 \\
580.66 \\
582.84 \\
583.42 \\
582.27 \\
577.93 \\
558.67 \\
549.92 \\
560.67\end{array}$ & $\begin{array}{l}0.4723 \\
0.5233 \\
0.5344 \\
0.5346 \\
0.5367 \\
0.5373 \\
0.5362 \\
0.5320 \\
0.5230 \\
0.5048 \\
0.4576\end{array}$ & $\begin{array}{l}0.00 \\
0.00 \\
0.00 \\
0.00 \\
0.00 \\
0.00 \\
0.00 \\
0.00 \\
0.00 \\
0.00 \\
0.00\end{array}$ & $\begin{array}{r}0.20 \\
-0.24 \\
-0.32 \\
-0.21 \\
0.09 \\
0.58 \\
1.26 \\
2.15 \\
3.29 \\
4.77 \\
6.74\end{array}$ & $\begin{array}{r}0.026 \\
-0.003 \\
-0.006 \\
-0.007 \\
-0.005 \\
-0.000 \\
0.006 \\
0.015 \\
0.027 \\
0.046 \\
0.105\end{array}$ & $\begin{array}{l}14.125 \\
14.670 \\
14.700 \\
14.700 \\
14.700 \\
14.700 \\
14.700 \\
14.700 \\
14.700 \\
14.700 \\
14.660\end{array}$ & $\begin{array}{l}518.70 \\
518.70 \\
518.70 \\
518.70 \\
518.70 \\
518.70 \\
518.70 \\
518.70 \\
5: 8.70 \\
518.70 \\
518.70\end{array}$ & $\begin{array}{l}12.123 \\
12.171 \\
12.102 \\
12.160 \\
12.081 \\
12.075 \\
12.086 \\
12.122 \\
12.199 \\
12.351 \\
12.697\end{array}$ & $\begin{array}{l}495.50 \\
471.71 \\
490.62 \\
496.50 \\
499.38 \\
490.33 \\
490.44 \\
493.86 \\
491.75 \\
493.49 \\
497.80\end{array}$ \\
\hline
\end{tabular}


Table 10.2 Continued

** Values of parameters on Streamlimes at station, 7 , whICH is an anmUlus **

\begin{tabular}{|c|c|c|c|c|c|c|c|c|c|c|c|c|c|}
\hline $\begin{array}{l}\text { STEEAMLINE } \\
\text { NO. RP.DIUS } \\
\text { (IN.) }\end{array}$ & $\begin{array}{l}\text { AYIAL } \\
\text { COOR.D. } \\
\text { (IN.) }\end{array}$ & $\begin{array}{c}\text { A:IAL } \\
\text { VEL. } \\
\text { (FT/SEC) }\end{array}$ & $\begin{array}{c}\text { MERD. } \\
\text { VEL. } \\
\text { (FT/SEC) }\end{array}$ & $\begin{array}{l}\text { TAMG. } \\
\text { VEL. } \\
\text { (FT/SEC) }\end{array}$ & $\begin{array}{c}\text { ABS. } \\
\text { VEL } \\
\text { (FT/SEC) }\end{array}$ & MACH $N$ NO. & $\begin{array}{c}\text { ABS. FLOW } \\
\text { ANGLE } \\
\text { (DEG) }\end{array}$ & $\begin{array}{l}\text { STPEAM. } \\
\text { SLOPE } \\
\text { (DEG) }\end{array}$ & $\begin{array}{l}\text { STREAM. } \\
\text { CURY. } \\
\text { (1.,IN.) }\end{array}$ & $\begin{array}{l}\text { TOTAL } \\
\text { PPESS } \\
\text { (PSIA) }\end{array}$ & $\begin{array}{l}\text { TOTAL } \\
\text { TEMP } \\
\text { (DEG.P.) }\end{array}$ & $\begin{array}{l}\text { STATIC } \\
\text { PRESS } \\
\text { (PSIA) }\end{array}$ & $\begin{array}{c}\text { STATIC } \\
\text { TEEMP. } \\
\text { (DEG.R. }\end{array}$ \\
\hline $\begin{array}{cc}\text { TIP } & 10.100 \\
1 & 10.074 \\
2 & 9.600 \\
3 & 9.135 \\
4 & 8.648 \\
5 & 8.135 \\
6 & 7.589 \\
7 & 7.001 \\
8 & 6.357 \\
9 & 5.631 \\
10 & 4.778 \\
11 & 3.674\end{array}$ & $\begin{array}{l}-1.824 \\
-1.824 \\
-1.824 \\
-1.824 \\
-1.824 \\
-1.824 \\
-1.824 \\
-1.824 \\
-1.824 \\
-1.824 \\
-1.824 \\
-1.824\end{array}$ & $\begin{array}{l}504.89 \\
566.70 \\
582.48 \\
585.94 \\
590.18 \\
591.86 \\
590.87 \\
585.69 \\
574.36 \\
551.73 \\
500.07\end{array}$ & $\begin{array}{l}504.90 \\
566.72 \\
582.51 \\
585.96 \\
590.18 \\
591.88 \\
591.03 \\
536.21 \\
575.66 \\
554.51 \\
506.16\end{array}$ & $\begin{array}{l}0.00 \\
0.00 \\
0.00 \\
0.00 \\
0.00 \\
0.00 \\
0.00 \\
0.00 \\
0.00 \\
0.00 \\
0.00\end{array}$ & $\begin{array}{l}504.90 \\
566.72 \\
582.51 \\
585.96 \\
590.18 \\
591.88 \\
591.03 \\
586.21 \\
575.66 \\
554.51 \\
506.16\end{array}$ & $\begin{array}{l}0.4617 \\
0.5211 \\
0.5364 \\
0.5398 \\
0.5439 \\
0.5456 \\
0.5447 \\
0.5400 \\
0.5298 \\
0.5093 \\
0.4529\end{array}$ & $\begin{array}{l}0.00 \\
0.00 \\
0.00 \\
0.00 \\
0.00 \\
0.00 \\
0.00 \\
0.00 \\
0.00 \\
0.00 \\
0.00\end{array}$ & $\begin{array}{r}0.30 \\
-0.46 \\
-0.61 \\
-0.49 \\
-0.10 \\
0.51 \\
1.35 \\
2.43 \\
3.85 \\
5.74 \\
8.90\end{array}$ & $\begin{array}{r}-0.017 \\
-0.023 \\
-0.020 \\
-0.015 \\
-0.009 \\
-0.002 \\
0.006 \\
0.017 \\
0.030 \\
0.050 \\
0.093\end{array}$ & $\begin{array}{l}14.125 \\
14.670 \\
14.700 \\
14.700 \\
14.700 \\
14.700 \\
14.700 \\
14.700 \\
14.700 \\
14.700 \\
14.660\end{array}$ & $\begin{array}{l}518.70 \\
518.70 \\
518.70 \\
518.70 \\
518.70 \\
518.70 \\
518.70 \\
518.70 \\
518.70 \\
518.70 \\
518.70\end{array}$ & $\begin{array}{l}12.204 \\
12.190 \\
12.084 \\
12.055 \\
12.020 \\
12.005 \\
12.012 \\
12.053 \\
12.14 \\
12.314 \\
12.656\end{array}$ & $\begin{array}{l}497.45 \\
491.93 \\
690.42 \\
690.68 \\
489.67 \\
689.50 \\
489.58 \\
690.05 \\
691.03 \\
493.07 \\
69.34\end{array}$ \\
\hline
\end{tabular}

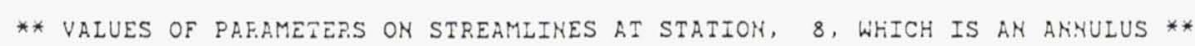

\begin{tabular}{|c|c|c|c|c|c|c|c|c|c|c|c|c|c|c|}
\hline \multirow{2}{*}{\multicolumn{2}{|c|}{ 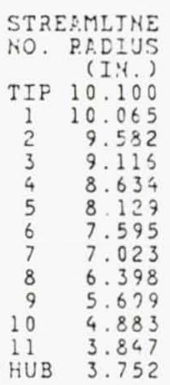 }} & \multirow{2}{*}{$\begin{array}{l}\text { DXILL } \\
\text { COS?D } \\
(I N,) \\
-0.940 \\
-0.940 \\
-0.940 \\
-0.940 \\
-0.940 \\
-0.940 \\
-0.940 \\
-0.940 \\
-0.940 \\
-0.940 \\
-0.940 \\
-0.940 \\
-0.940\end{array}$} & $\begin{array}{c}\text { RKIAL } \\
\forall E L . \\
(F T / S E C)\end{array}$ & $\begin{array}{c}\text { MEPD. } \\
\text { (FISIEC) }\end{array}$ & $\begin{array}{c}\text { TANG. } \\
\text { VEL. } \\
\text { (FT/SEC) }\end{array}$ & $\begin{array}{c}\text { ABS. } \\
\text { VEL } \\
\text { (FT/SEC) }\end{array}$ & MACBS. NO. & $\begin{array}{c}\text { ABS.FLOW } \\
\text { ANGIEE } \\
(D E G)\end{array}$ & $\begin{array}{l}\text { STEEAM } \\
\text { SLOPE } \\
\text { ( } D E G)\end{array}$ & $\begin{array}{c}\text { STDEA.M. } \\
\text { CUEV. } \\
\text { (1.YK. }\end{array}$ & $\begin{array}{l}\text { TOTAL } \\
\text { FPESS } \\
\text { (PSIA) }\end{array}$ & $\begin{array}{l}\text { TOTAL } \\
\text { TEMP. } \\
\text { (DEG.R.) }\end{array}$ & $\begin{array}{l}\text { STAZIC } \\
\text { PEESS } \\
\text { (FSIA) }\end{array}$ & 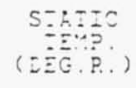 \\
\hline & & & $\begin{array}{l}481.80 \\
563.17 \\
588.17 \\
598.59 \\
607.48 \\
612.19 \\
613.01 \\
608.85 \\
598.10 \\
575.35 \\
525.75\end{array}$ & $\begin{array}{l}482.52 \\
563.53 \\
588.75 \\
598.91 \\
607.57 \\
512.19 \\
613.21 \\
609.72 \\
600.48 \\
581.00 \\
539.52\end{array}$ & $\begin{array}{l}0.00 \\
0.00 \\
0.00 \\
0.00 \\
0.00 \\
0.00 \\
0.00 \\
0.00 \\
0.00 \\
0.00 \\
0.00\end{array}$ & $\begin{array}{l}482.52 \\
563.93 \\
588.75 \\
598.91 \\
607.57 \\
612.19 \\
613.21 \\
609.72 \\
600.48 \\
581.00 \\
539.52\end{array}$ & $\begin{array}{l}0.4404 \\
0.5134 \\
0.5425 \\
0.5524 \\
0.5609 \\
0.5654 \\
0.5654 \\
0.5530 \\
0.5540 \\
0.5350 \\
0.4948\end{array}$ & $\begin{array}{l}0.00 \\
0.00 \\
0.00 \\
0.00 \\
0.00 \\
0.00 \\
0.00 \\
0.00 \\
0.00 \\
0.00 \\
0.00\end{array}$ & $\begin{array}{r}-3.14 \\
-2.99 \\
-2.55 \\
-1.87 \\
-0.97 \\
0.14 \\
1.46 \\
3.07 \\
5.10 \\
8.00 \\
12.97\end{array}$ & $\begin{array}{l}-0.118 \\
-0.062 \\
-0.046 \\
-0.032 \\
-0.020 \\
-0.009 \\
0.001 \\
0.012 \\
0.024 \\
0.041 \\
0.065\end{array}$ & $\begin{array}{l}14.125 \\
14.670 \\
14.700 \\
14.700 \\
14.700 \\
14.700 \\
14.700 \\
14.700 \\
14.700 \\
14.700 \\
14.660\end{array}$ & $\begin{array}{l}518.70 \\
518.70 \\
518.70 \\
518.70 \\
518.70 \\
518.70 \\
518.70 \\
518.70 \\
518.70 \\
518.70 \\
518.70\end{array}$ & $\begin{array}{l}12.352 \\
12.213 \\
12.032 \\
11.946 \\
11.871 \\
11.831 \\
11.823 \\
11.853 \\
11.932 \\
12.057 \\
12.400\end{array}$ & $\begin{array}{l}499.29 \\
492.19 \\
489.81 \\
688.80 \\
687.93 \\
687.46 \\
487.35 \\
487.71 \\
683.64 \\
49.56 \\
694.44\end{array}$ \\
\hline
\end{tabular}




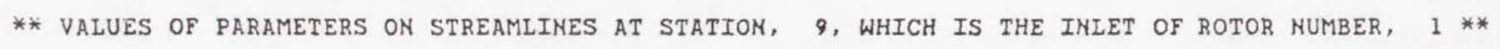

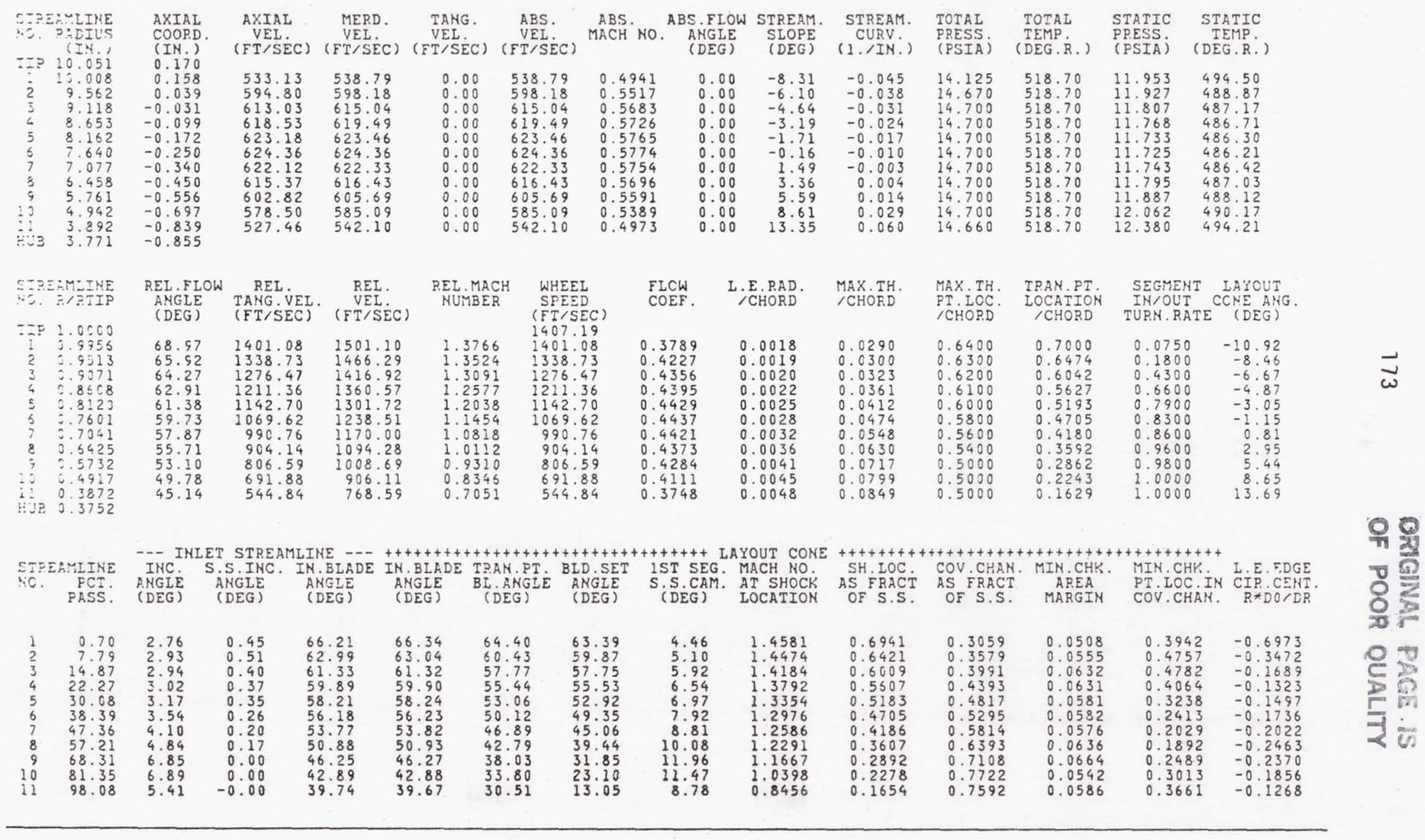


Table 10.2 Continued

** Values of parameters on Streamlimes at Station, 10, whICh IS THE OUtLet of rotor nUmber, 1 **

\begin{tabular}{|c|c|c|c|c|c|c|c|c|c|c|c|c|c|c|c|}
\hline \multirow{2}{*}{\multicolumn{2}{|c|}{ 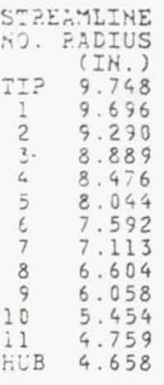 }} & \multirow{2}{*}{$\begin{array}{l}\text { AXIAL } \\
\text { COORD. } \\
\text { (IN.) } \\
1.765 \\
1.777 \\
1.870 \\
1.920 \\
1.976 \\
2.042 \\
2.143 \\
2.254 \\
2.383 \\
2.555 \\
2.666 \\
2.720 \\
2.728\end{array}$} & \multirow{2}{*}{$\begin{array}{c}\text { AXIAL } \\
\text { VEL } \\
\text { (FT/SEC) } \\
479.17 \\
510.40 \\
519.52 \\
523.93 \\
529.35 \\
533.87 \\
539.32 \\
547.62 \\
559.88 \\
576.64 \\
608.61\end{array}$} & $\begin{array}{l}\text { MERD. } \\
\text { VEL. } \\
\text { (FT/SEC) }\end{array}$ & $\begin{array}{c}\text { TANG. } \\
\text { VEL. } \\
\text { (FT/SEC) }\end{array}$ & $\begin{array}{c}\text { ABS. } \\
\text { VEL: } \\
(\text { FT/SEC })\end{array}$ & MACH. NO. & $\begin{array}{l}\text { ABS. FLOW } \\
\text { ANGLE } \\
\text { (DEG) }\end{array}$ & $\begin{array}{l}\text { STREAM. } \\
\text { SLOPE } \\
\text { (DEG) }\end{array}$ & \multicolumn{2}{|c|}{$\begin{array}{l}\text { STREAM. } \\
\text { CURV. } \\
\text { (1./IN.) }\end{array}$} & $\begin{array}{l}\text { TOTAL } \\
\text { PRESS } \\
\text { (PSIA) }\end{array}$ & $\begin{array}{l}\text { TOTAL } \\
\text { TEMP. } \\
\text { (DEG.R.) }\end{array}$ & $\begin{array}{l}\text { STATIC } \\
\text { PRESS } \\
\text { (PSIA) }\end{array}$ & $\begin{array}{l}\text { STATIC } \\
\text { TEMP. } \\
\text { (DEG.R.) }\end{array}$ \\
\hline & & & & $\begin{array}{l}483.59 \\
512.86 \\
520.83 \\
524.48 \\
529.47 \\
533.88 \\
539.59 \\
548.57 \\
562.15 \\
580.68 \\
616.14\end{array}$ & $\begin{array}{l}449.83 \\
423.31 \\
430.62 \\
440.03 \\
453.73 \\
475.68 \\
502.43 \\
536.41 \\
578.34 \\
638.47 \\
729.02\end{array}$ & $\begin{array}{l}660.46 \\
664.99 \\
675.80 \\
684.62 \\
697.29 \\
715.05 \\
737.28 \\
767.25 \\
806.53 \\
863.04 \\
954.51\end{array}$ & $\begin{array}{l}0.5576 \\
0.5665 \\
0.5775 \\
0.5868 \\
0.5993 \\
0.6162 \\
0.6374 \\
0.6660 \\
0.7039 \\
0.7590 \\
0.8507\end{array}$ & $\begin{array}{l}42.93 \\
39.54 \\
39.58 \\
40.00 \\
40.60 \\
41.70 \\
42.96 \\
44.36 \\
45.81 \\
47.71 \\
49.80\end{array}$ & $\begin{array}{r}-7.76 \\
-5.61 \\
-4.07 \\
-2.63 \\
-1.20 \\
0.26 \\
1.80 \\
3.38 \\
5.15 \\
6.76 \\
8.96\end{array}$ & $\begin{array}{r}0 . \\
0 . \\
0 . \\
0 . \\
0 . \\
0 . \\
0 . \\
-0 . \\
-0 . \\
-0 . \\
-0 .\end{array}$ & $\begin{array}{l}.057 \\
0339 \\
033 \\
026 \\
018 \\
0110 \\
002 \\
010 \\
024 \\
052 \\
0106\end{array}$ & $\begin{array}{l}23.896 \\
23.896 \\
23.896 \\
23.896 \\
23.896 \\
23.896 \\
23.896 \\
23.896 \\
23.896 \\
23.896 \\
23.896\end{array}$ & $\begin{array}{l}620.30 \\
610.33 \\
607.89 \\
605.60 \\
603.75 \\
602.85 \\
601.99 \\
601.26 \\
600.35 \\
599.85 \\
599.55\end{array}$ & $\begin{array}{l}19.348 \\
19.221 \\
19.062 \\
18.928 \\
18.744 \\
18.495 \\
18.178 \\
17.747 \\
17.166 \\
16.312 \\
14.886\end{array}$ & $\begin{array}{l}84.05 \\
73.56 \\
69.92 \\
66.63 \\
63.32 \\
60.33 \\
56.77 \\
52.29 \\
46.23 \\
37.88 \\
23.72\end{array}$ \\
\hline & $\begin{array}{l}\text { DMINE } \\
\text { R.PTIP }\end{array}$ & $\begin{array}{l}\text { REL. FLOW } \\
\text { ANGLE } \\
\text { (DEG) }\end{array}$ & $\begin{array}{c}\text { REL } \\
\text { TANG.VEL. } \\
\text { (FT/SEC) }\end{array}$ & $\begin{array}{c}\text { PEL. } \\
\text { VEL: } \\
\text { (FT/SEC) }\end{array}$ & $\begin{array}{l}\text { REL.MACH } \\
\text { NUMBER }\end{array}$ & $\begin{array}{l}\text { WHEEL } \\
\text { SFEED } \\
\text { (FT/SEC) }\end{array}$ & $\begin{array}{l}\text { FLOW } \\
\text { COEF. }\end{array}$ & $\begin{array}{l}\text { HEAD } \\
\text { COEF. }\end{array}$ & $\begin{array}{l}\text { IDEAL HA } \\
\text { COEF }\end{array}$ & $\begin{array}{l}\text { HEAD } \\
\text {. }\end{array}$ & $\begin{array}{l}\text { ADIAB. } \\
\text { EFF. }\end{array}$ & $\begin{array}{l}\text { DIFFUSI } \\
\text { FACTOR }\end{array}$ & $\begin{array}{l}\text { LOSS } \\
\text { COEF. }\end{array}$ & $\begin{array}{l}\text { SHOCK } \\
\text { IOSS } \\
\text { COEF. }\end{array}$ & $\begin{array}{c}\text { DEGREE } \\
\text { REACIION }\end{array}$ \\
\hline $\begin{array}{c}7 \\
2 \\
2 \\
3 \\
4 \\
5 \\
6 \\
7 \\
8 \\
9 \\
90 \\
12 \\
103\end{array}$ & $\begin{array}{l}0.9946 \\
0.9530 \\
0.9119 \\
0.8695 \\
0.8252 \\
0.7783 \\
0.7297 \\
0.6775 \\
0.6214 \\
0.5594 \\
0.4282 \\
0.4778\end{array}$ & $\begin{array}{l}61.95 \\
59.69 \\
57.38 \\
54.91 \\
51.79 \\
47.72 \\
42.44 \\
35.28 \\
25.63 \\
12.15 \\
-5.82\end{array}$ & $\begin{array}{l}907.54 \\
877.31 \\
813.89 \\
746.56 \\
672.47 \\
587.19 \\
493.44 \\
388.17 \\
269.71 \\
125.02 \\
-62.78\end{array}$ & $\begin{array}{r}1028.35 \\
1016.21 \\
966.28 \\
912.38 \\
855.89 \\
793.61 \\
731.19 \\
672.02 \\
623.50 \\
593.99 \\
619.33\end{array}$ & $\begin{array}{l}0.8682 \\
0.8657 \\
0.8258 \\
0.7820 \\
0.7357 \\
0.6839 \\
0.6321 \\
0.5833 \\
0.5442 \\
0.5224 \\
0.5520\end{array}$ & $\begin{array}{r}1357.38 \\
1300.62 \\
1244.52 \\
1186.59 \\
1126.21 \\
1062.87 \\
995.87 \\
924.59 \\
848.05 \\
763.49 \\
666.24\end{array}$ & $\begin{array}{l}0.3405 \\
0.3627 \\
0.3692 \\
0.3723 \\
0.3762 \\
0.3794 \\
0.3833 \\
0.3892 \\
0.3979 \\
0.4098 \\
0.4325\end{array}$ & $\begin{array}{l}0.2551 \\
0.2354 \\
0.2343 \\
0.2343 \\
0.2343 \\
0.2343 \\
0.2343 \\
0.2343 \\
0.2343 \\
0.2343 \\
0.2357\end{array}$ & $\begin{array}{l}0.3086 \\
0.278 \\
0.2706 \\
0.263 \\
0.258 \\
0.255 \\
0.252 \\
0.250 \\
0.247 \\
0.246 \\
0.245\end{array}$ & & $\begin{array}{l}0.8271 \\
0.8466 \\
0.8658 \\
0.8887 \\
0.9080 \\
0.9177 \\
0.9273 \\
0.9355 \\
0.9460 \\
0.9517 \\
0.9611\end{array}$ & $\begin{array}{l}0.4282 \\
0.4112 \\
0.4232 \\
0.4361 \\
0.4517 \\
0.4729 \\
0.4941 \\
0.5120 \\
0.5169 \\
0.4930 \\
0.3657\end{array}$ & $\begin{array}{l}0.1341 \\
0.1128 \\
0.1007 \\
0.0863 \\
0.0743 \\
0.0705 \\
0.0670 \\
0.0652 \\
0.0615 \\
0.0652 \\
0.0698\end{array}$ & $\begin{array}{l}0.0500 \\
0.0391 \\
0.0359 \\
0.0313 \\
0.0259 \\
0.0215 \\
0.0171 \\
0.0142 \\
0.0076 \\
0.0002 \\
0.0000\end{array}$ & $\begin{array}{l}0.7569 \\
0.7906 \\
0.7890 \\
0.7787 \\
0.7624 \\
0.7361 \\
0.6998 \\
0.6473 \\
0.5740 \\
0.4621 \\
0.2714\end{array}$ \\
\hline $\begin{array}{l}\text { STPE } \\
\text { NO. }\end{array}$ & $\begin{array}{l}\text { EAMLINE } \\
\text { PCT' } \\
\text { SPAN }\end{array}$ & $\begin{array}{l}\text { PRESS. } \\
\text { RATIO }\end{array}$ & $\begin{array}{l}\text { TEMP. } \\
\text { RATIO }\end{array}$ & $\begin{array}{l}\text { AERO. } \\
\text { CHORD } \\
\text { (IN.) }\end{array}$ & $\begin{array}{l}\text { ELEMENT } \\
\text { SOLIDITY }\end{array}$ & $\begin{array}{l}\text { LOCAL } \\
\text { RADIUS FS } \\
\text { (IN.) }\end{array}$ & $\begin{array}{l}\text { L BLADE FO } \\
\text { FOR.AXIAL } \\
\text { (LBS } / I N)\end{array}$ & $\begin{array}{l}\text { ORCES } \\
\text { TANG } \\
\text { (LBS/IN) }\end{array}$ & $\begin{array}{l}-- \text { OU } \\
\text { T.E.RAI } \\
\text { /CHORI }\end{array}$ & $\begin{array}{l}\text { UTLET } \\
\text { AD. }\end{array}$ & $\begin{array}{l}\text { STREA } \\
\text { DEV } \\
\text { ARGLE } \\
(D E G)\end{array}$ & $\begin{array}{l}\text { AMLINE - } \\
\text { OUT BLADE } \\
\text { ANGGE } \\
\text { (DEG) }\end{array}$ & $\begin{array}{c}-++ \text { LAYOUT } \\
\text { E OUT, BLADDE } \\
\text { ANGLE } \\
\text { (DEG) }\end{array}$ & $\begin{array}{l}\text { CONE +++ } \\
\text { MAX.CAMB . } \\
\text { PT. IOC. } \\
\text { /CHOR.D }\end{array}$ & $\begin{array}{l}\text { T.E.EDGE } \\
\text { CIR.CEYHT } \\
R * D O / D R\end{array}$ \\
\hline $\begin{array}{l}1 \\
2 \\
3 \\
4 \\
5 \\
6 \\
7 \\
8 \\
9 \\
90 \\
11\end{array}$ & $\begin{array}{r}1.03 \\
9.00 \\
16.87 \\
25.00 \\
33.47 \\
42.36 \\
51.76 \\
61.76 \\
72.50 \\
84.36 \\
98.01\end{array}$ & $\begin{array}{l}1.6917 \\
1.6289 \\
1.6255 \\
1.6255 \\
1.6255 \\
1.6255 \\
1.6255 \\
1.6255 \\
1.6255 \\
1.6255 \\
1.6300\end{array}$ & $\begin{array}{l}1.1959 \\
1.1766 \\
1.1720 \\
1.1675 \\
1.1640 \\
1.1622 \\
1.1606 \\
1.1592 \\
1.1574 \\
1.1565 \\
1.1559\end{array}$ & $\begin{array}{l}3.6642 \\
3.6725 \\
3.6701 \\
3.6677 \\
3.6658 \\
3.6645 \\
3.6644 \\
3.6686 \\
3.6741 \\
3.6951 \\
3.7588\end{array}$ & $\begin{array}{l}1.3023 \\
1.3642 \\
1.4273 \\
1.4995 \\
1.5840 \\
1.6847 \\
1.8083 \\
1.9557 \\
2.1769 \\
2.4891 \\
3.0428\end{array}$ & $\begin{array}{l}9.852 \\
9.426 \\
9.004 \\
8.564 \\
8.103 \\
7.616 \\
7.095 \\
5.531 \\
5.909 \\
5.198 \\
4.325\end{array}$ & $\begin{array}{r}19.6015 \\
17.7714 \\
16.5638 \\
15.4306 \\
14.2440 \\
12.8940 \\
11.4312 \\
9.7984 \\
7.9601 \\
5.6774 \\
2.8398\end{array}$ & $\begin{array}{l}-10.9508 \\
-10.3378 \\
-10.3487 \\
-10.1285 \\
-9.9200 \\
-9.7834 \\
-9.6067 \\
-9.3923 \\
-9.0242 \\
-8.4343 \\
-8.6529\end{array}$ & $\begin{array}{l}0.0018 \\
0.0019 \\
0.0028 \\
0.0023 \\
0.0026 \\
0.0033 \\
0.0034 \\
0.0038 \\
0.0042 \\
0.0046 \\
0.0048\end{array}$ & & $\begin{array}{r}8.00 \\
6.80 \\
4.80 \\
4.50 \\
4.60 \\
5.70 \\
6.63 \\
7.52 \\
8.64 \\
10.39 \\
12.52\end{array}$ & $\begin{array}{r}53.95 \\
52.89 \\
52.58 \\
50.41 \\
47.19 \\
42.02 \\
35.81 \\
27.76 \\
16.99 \\
1.76 \\
-18.34\end{array}$ & $\begin{array}{r}53.32 \\
52.55 \\
52.36 \\
50.21 \\
46.99 \\
41.84 \\
35.85 \\
27.67 \\
17.08 \\
2.66 \\
-15.47\end{array}$ & $\begin{array}{l}0.7273 \\
0.6727 \\
0.6052 \\
0.5511 \\
0.5292 \\
0.5192 \\
0.5117 \\
0.5006 \\
0.4964 \\
0.4914 \\
0.4833\end{array}$ & $\begin{array}{l}0.3422 \\
0.1640 \\
0.1109 \\
0.1417 \\
0.1910 \\
0.2285 \\
0.2617 \\
0.3191 \\
0.3865 \\
0.4775 \\
0.5900\end{array}$ \\
\hline
\end{tabular}


Table 10.2 Continued

** Values of parameters on streamlines at station, 11 , Which is an annulus **

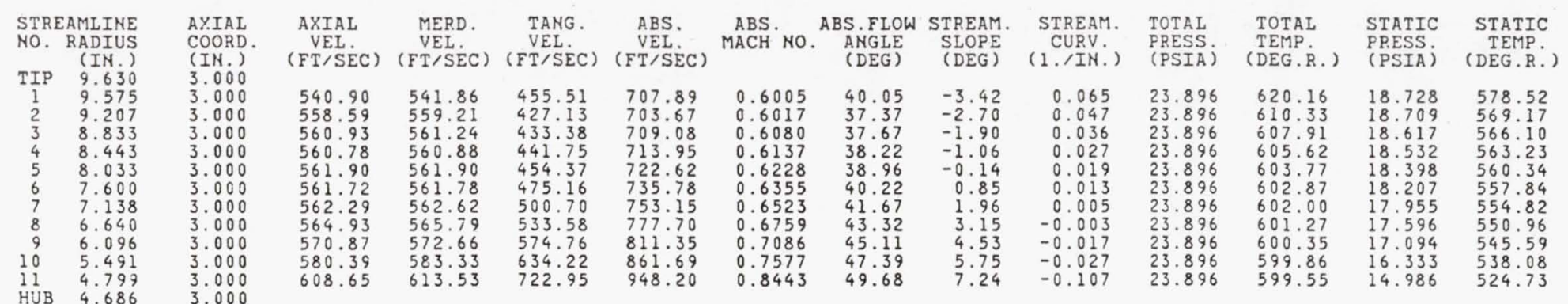

* VAlUes of parameters on Streamlimes at Station, 12, WhICH IS an anNulus **

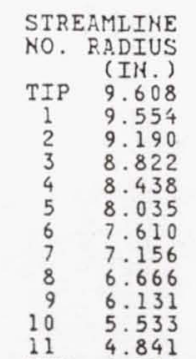

AXIAL
COORD.
(IN.)
3.485
3.485
3.485
3.485
3.485
3.485
3.485
3.485
3.485
3.485
3.485
3.485
3.485

$\begin{array}{ccc}\begin{array}{c}\text { AXIAL } \\ \text { VEL } \\ \text { (FT/SEC) }\end{array} & \begin{array}{c}\text { MERD. } \\ \text { VEL. }\end{array} & \begin{array}{c}\text { TANG. } \\ \text { VET/SEC) }\end{array} \\ \text { (FT/SEC) } \\ 550.45 & 550.76 & 456.52 \\ 570.20 & 570.40 & 427.90 \\ 573.48 & 573.57 & 433.92 \\ 573.75 & 573.76 & 442.00 \\ 574.81 & 574.83 & 454.24 \\ 574.22 & 574.35 & 474.54 \\ 573.78 & 574.17 & 499.42 \\ 574.41 & 575.27 & 531.41 \\ 576.44 & 577.97 & 571.41 \\ 578.62 & 580.98 & 629.34 \\ 587.21 & 589.80 & 716.69\end{array}$

ABS.
VEL.
FT/SEC)
715.36
713.06
719.21
724.27
732.64
745.02
750.98
783.16
812.75
856.50
928.17

ABS.
MACH NO.
0.6073
0.6104
0.6173
0.6233
0.6321
0.6441
0.6596
0.6810
0.7099
0.7526
0.8240

ABS. FLOW
ANGLE
(DEGY
39.66
36.88
37.11
37.61
38.32
39.56
41.02
42.73
44.67
47.29
50.55

STPEAM.
SLOPE
(DEG)
-1.90
-1.52
-1.01
-0.37
0.36
1.19
2.11
3.13
4.17
5.16
5.37

STPEAM
CUPV
$(1 . I N$
0.044
0.037
0.030
0.022
0.01
0.014
0.01
0.00
0.00
0.00
-0.02

HUB 4.731

$T O$
$F P$
$F$
$F$
23
23
23.8
23.
23.8
23.8
23.8
23.8
23.8
23.8
23.8

TOTAL
FPESS
(FSIA)
23.896
23.896
23.896
23.896
23.896
23.896
23.896
23.896
23.896
23.896
23.896

TOTAL

STATIC STATIC
PP.ESS. TTEP.

$\begin{array}{llll}620.15 & 18.628 & 577.63\end{array}$

$\begin{array}{lll}610.33 & 18.522 & 568.06 \\ 607.91 & 18.479 & 564.90\end{array}$

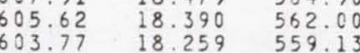

$\begin{array}{llll}602.87 & 18.077 & 555.70 \\ 602.00 & 17.843 & 553.83\end{array}$

601.27

$\begin{array}{ll}17.843 & 553.83 \\ 17.517 & 550.25 \\ 17 & 54.274\end{array}$

$\begin{array}{lll}559.86 & 16.411 & 535.40 \\ 599.55 & 15.301 & 527.82\end{array}$

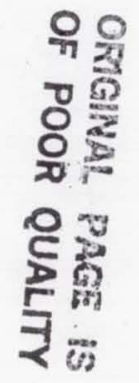


Table 10.2 Continued

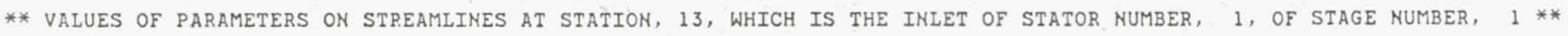

\begin{tabular}{|c|c|c|c|c|c|c|c|c|c|c|c|c|c|c|c|c|c|c|c|}
\hline \multirow{2}{*}{\multicolumn{2}{|c|}{$\begin{array}{cr}\text { NELAILINL } \\
\text { NO. RADIUS } \\
\text { (IN.) } \\
\text { TIP } & 9.600 \\
1 & 9.539 \\
2 & 9.179 \\
3 & 8.815 \\
4 & 8.436 \\
5 & 8.041 \\
6 & 7.625 \\
7 & 7.182 \\
8 & 6.705 \\
9 & 6.184 \\
10 & 5.603 \\
11 & 4.920 \\
\text { HUB } & 4.799\end{array}$}} & \multirow{2}{*}{$\begin{array}{l}\text { AXIAL } \\
\text { COORD. } \\
\text { (IH.) } \\
4.116 \\
4.116 \\
4.114 \\
4.120 \\
4.124 \\
4.129 \\
4.135 \\
4.143 \\
4.151 \\
4.162 \\
4.175 \\
4.190 \\
4.192\end{array}$} & \multicolumn{2}{|c|}{$\begin{array}{c}\text { AXIAL } \\
\text { VEL } \\
(F T / S E C)\end{array}$} & \multicolumn{2}{|c|}{$\begin{array}{c}\text { MERD. } \\
\text { VEL. } \\
\text { (FT/SEC) }\end{array}$} & \multicolumn{2}{|c|}{$\begin{array}{c}\text { TANG. } \\
\text { VEL. } \\
\text { (FT/SEC) }\end{array}$} & $\begin{array}{c}\text { ABS. } \\
\text { VEL: } \\
(\text { FT/SEC) }\end{array}$ & \multicolumn{2}{|c|}{$\begin{array}{l}\text { ABS. } \\
\text { MACH NO. }\end{array}$} & $\begin{array}{c}\text { ABS.FLOW } \\
\text { ANGLE } \\
(\mathrm{DEG})\end{array}$ & $\begin{array}{l}\text { STREAM. } \\
\text { SLOPE } \\
\text { (DEG) }\end{array}$ & $\begin{array}{c}\text { STREAM. } \\
\text { CURV. } \\
\text { (1./IN.) }\end{array}$ & $\begin{array}{l}\text { TOTAL } \\
\text { PRESS } \\
\text { (PSIA) }\end{array}$ & $\begin{array}{l}\text { TOTAL } \\
\text { TEMP. } \\
\text { (DEG.R.) }\end{array}$ & $\begin{array}{l}\text { STATIC } \\
\text { PRESS } \\
\text { (PSIA) }\end{array}$ & \multicolumn{2}{|c|}{$\begin{array}{c}\text { STATIC } \\
\text { TEMP. } \\
\text { (DEG.R.) }\end{array}$} \\
\hline & & & $\begin{array}{l}555 . \\
579 . \\
585 \\
587 . \\
589 \\
589 \\
589 \\
589 \\
588 . \\
584 . \\
563 .\end{array}$ & & $\begin{array}{l}555.7 \\
579.5 \\
585.1 \\
587.0 \\
589.2 \\
589.7 \\
589.9 \\
590.6 \\
590.7 \\
587.0 \\
567.0\end{array}$ & & $\begin{array}{l}457.2 \\
428.4 \\
434.2 \\
442.0 \\
453.9 \\
473.6 \\
497.6 \\
528.3 \\
566.5 \\
621.5 \\
705.1\end{array}$ & $\begin{array}{l}24 \\
.45 \\
28 \\
.07 \\
90 \\
.62 \\
65 \\
39 \\
52 \\
54 \\
13\end{array}$ & $\begin{array}{l}719.70 \\
720.72 \\
728.73 \\
734.89 \\
743.84 \\
756.37 \\
771.84 \\
792.49 \\
818.46 \\
854.97 \\
904.84\end{array}$ & $\begin{array}{l}0.6 \\
0.6 \\
0.6 \\
0.6 \\
0.6 \\
0.6 \\
0.6 \\
0.6 \\
0.7 \\
0.7 \\
0.8\end{array}$ & $\begin{array}{l}113 \\
174 \\
261 \\
331 \\
425 \\
548 \\
699 \\
899 \\
154 \\
511 \\
006\end{array}$ & $\begin{array}{l}39.44 \\
36.48 \\
36.58 \\
36.98 \\
37.61 \\
38.77 \\
40.15 \\
41.82 \\
43.80 \\
46.63 \\
51.19\end{array}$ & $\begin{array}{r}-0.83 \\
-0.47 \\
-0.10 \\
0.37 \\
0.94 \\
1.61 \\
2.42 \\
3.36 \\
4.43 \\
5.70 \\
6.67\end{array}$ & $\begin{array}{l}0.016 \\
0.020 \\
0.020 \\
0.017 \\
0.014 \\
0.011 \\
0.010 \\
0.010 \\
0.014 \\
0.024 \\
0.090\end{array}$ & $\begin{array}{l}23.896 \\
23.896 \\
23.896 \\
23.896 \\
23.896 \\
23.896 \\
23.896 \\
23.896 \\
23.896 \\
23.896 \\
23.896\end{array}$ & $\begin{array}{l}620.11 \\
610.34 \\
607.92 \\
605.63 \\
603.78 \\
602.88 \\
602.00 \\
601.27 \\
600.36 \\
599.86 \\
599.55\end{array}$ & $\begin{array}{l}18.569 \\
18.478 \\
18.348 \\
18.243 \\
18.102 \\
17.917 \\
17.687 \\
17.381 \\
16.989 \\
16.435 \\
15.665\end{array}$ & $\begin{array}{l}577 \\
567 \\
563 \\
560 \\
557 \\
555 \\
552 \\
549 \\
544 \\
539 \\
531\end{array}$ & $\begin{array}{l}7.06 \\
7.16 \\
3.77 \\
0.72 \\
7.76 \\
5.29 \\
2.45 \\
9.03 \\
4.63 \\
9.04 \\
1.43\end{array}$ \\
\hline \multicolumn{2}{|c|}{$\begin{array}{l}\text { STREAMLINE } \\
\text { NO. R/RTIP }\end{array}$} & $\begin{array}{l}\text { FLOW } \\
\text { COEF. }\end{array}$ & \multicolumn{2}{|c|}{$\begin{array}{l}\text { REL, FLOW } \\
\text { ANGLE } \\
\text { (DEG) }\end{array}$} & \multicolumn{2}{|c|}{$\begin{array}{l}\text { L.E.RAJ. } \\
\text { /CHORD }\end{array}$} & \multicolumn{3}{|c|}{$\begin{array}{l}\text { MAKTH. } \\
\text { /CHORD }\end{array}$} & $\begin{array}{l}\text { MAX.TH. } \\
\text { PT.LOC. } \\
\text { /CHORD }\end{array}$ & \multicolumn{2}{|c|}{$\begin{array}{l}\text { TRAN.PT. } \\
\text { LOCATION } \\
\text { /CHORD }\end{array}$} & $\begin{array}{l}\text { SEGMENT } \\
\text { IN NOUT } \\
\text { CURN.RATE }\end{array}$ & $\begin{array}{l}\text { LAYOUT } \\
\text { CONE ANG . } \\
\text { (DEG) }\end{array}$ & & & & & \\
\hline $\begin{array}{l}71 \text { P } \\
1 \\
2 \\
3 \\
4 \\
5 \\
6 \\
7 \\
8 \\
9 \\
10 \\
11 \\
\text { HUB }\end{array}$ & $\begin{array}{l}1.0000 \\
0.9936 \\
0.9561 \\
0.9182 \\
0.8788 \\
0.8377 \\
0.7943 \\
0.7481 \\
0.6984 \\
0.6442 \\
0.5836 \\
0.5125 \\
0.4999\end{array}$ & $\begin{array}{l}0.3949 \\
0.4118 \\
0.4159 \\
0.4172 \\
0.4187 \\
0.4189 \\
0.4189 \\
0.4190 \\
0.4185 \\
0.4151 \\
0.4002\end{array}$ & $\begin{array}{l}57 . \\
55 . \\
53 . \\
51 . \\
48 . \\
45 . \\
40 . \\
34 . \\
26 . \\
15 . \\
-1 .\end{array}$ & & $\begin{array}{l}0.0 \\
0.0 \\
0.0 \\
0.0 \\
0.0 \\
0.0 \\
0.0 \\
0.0 \\
0.0 \\
0.0 \\
0.0\end{array}$ & $\begin{array}{l}0129 \\
0123 \\
0117 \\
0111 \\
0104 \\
01097 \\
0090 \\
0082 \\
0073 \\
0063 \\
0053\end{array}$ & & $\begin{array}{l}.0797 \\
0787 \\
0767 \\
0752 \\
0739 \\
0718 \\
.059 \\
.0579 \\
0658 \\
0633 \\
050\end{array}$ & $\begin{array}{l}0 . \\
0 . \\
0 . \\
0 . \\
0 . \\
0 . \\
0 . \\
0 . \\
0 . \\
0 . \\
0 .\end{array}$ & 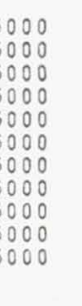 & & $\begin{array}{l}3310 \\
3088 \\
3035 \\
2975 \\
2917 \\
2877 \\
2821 \\
2754 \\
2670 \\
2562 \\
2406\end{array}$ & $\begin{array}{l}1.0000 \\
1.0000 \\
1.0000 \\
1.0000 \\
1.0000 \\
1.0000 \\
1.0000 \\
1.0000 \\
1.0000 \\
1.0000 \\
1.0000\end{array}$ & $\begin{array}{r}-0.20 \\
0.27 \\
0.58 \\
0.92 \\
1.33 \\
1.82 \\
2.46 \\
3.27 \\
4.34 \\
5.78 \\
7.95\end{array}$ & & & & & \\
\hline $\begin{array}{l}\text { STP. } \\
\text { Rio. }\end{array}$ & $\begin{array}{l}\text { EAMLINE } \\
\text { PCT. } \\
\text { PASS. }\end{array}$ & $\begin{array}{l}\text { INC. INLE } \\
\text { AN:GLE } \\
\text { (DEG) }\end{array}$ & $\begin{array}{l}\text { T STREAT } \\
\text { S. . . INC. } \\
\text { AMGLE } \\
\text { (DEG) }\end{array}$ & $\begin{array}{l}\text { MLIN } \\
\text { IN } \\
\text { AN } \\
\text { (D. }\end{array}$ & 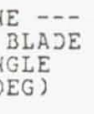 & $\begin{array}{r}++++ \\
\text { IN.B } \\
\text { ARIG } \\
\text { (DD }\end{array}$ & $\begin{array}{l}++++++ \\
\text { BLADE } \\
\text { GLE } \\
\text { EG) }\end{array}$ & $\begin{array}{l}+++++ \\
\text { TRA) } \\
\text { BE. } \\
\text { CDE }\end{array}$ & $\begin{array}{l}+++++++++ \\
\text { AN.PT. BI } \\
\text { ANGLE } \\
\text { DEG) }\end{array}$ & $\begin{array}{l}\text { l+++++ } \\
\text { D. SET } \\
\text { INGEE } \\
\text { DEG }\end{array}$ & $\begin{array}{r}++++ \\
\text { is } \\
\mathrm{S}_{i}\end{array}$ & $\begin{array}{l}++++ \text { LAY } \\
\text { T SEG. M } \\
\text { S.CAM. } \\
\text { DEG) }\end{array}$ & $\begin{array}{l}\text { OUT CONE } \\
\text { AACH NO. } \\
\text { TT SHOCK } \\
\text { OCATION }\end{array}$ & $\begin{array}{l}+++++++++ \\
\text { SH. LCC. } \\
\text { AS FRACT } \\
\text { OF S.S. }\end{array}$ & $\begin{array}{l}+++++++++++ \\
\text { COV.CHAN } \\
\text { AS FR.CT } \\
\text { OF S.S. }\end{array}$ & $\begin{array}{c}\text { MIN.CHK. } \\
\text { AREA } \\
\text { MAPGIN }\end{array}$ & $\begin{array}{r}++++++++ \\
\text { MIN. Ch } \\
\text { PT. IOC } \\
\text { COV. CH }\end{array}$ & HAN. & $\begin{array}{l}\text { L.E.EDGE } \\
\text { CIR.CENT. } \\
R * D O / D R\end{array}$ \\
\hline $\begin{array}{r}1 \\
2 \\
3 \\
4 \\
5 \\
5 \\
6 \\
7 \\
8 \\
9 \\
10 \\
11\end{array}$ & $\begin{array}{r}1.28 \\
8.78 \\
16.36 \\
24.23 \\
32.46 \\
41.13 \\
50.36 \\
60.30 \\
71.14 \\
83.25 \\
97.47\end{array}$ & $\begin{array}{l}2.94 \\
2.97 \\
2.94 \\
2.89 \\
2.82 \\
2.75 \\
2.66 \\
2.55 \\
2.42 \\
2.23 \\
1.95\end{array}$ & $\begin{array}{l}-3.00 \\
-3.00 \\
-3.00 \\
-3.00 \\
-3.00 \\
-3.00 \\
-3.00 \\
-3.00 \\
-3.00 \\
-3.00 \\
-3.00\end{array}$ & $\begin{array}{l}36 \\
33 \\
33 \\
34 \\
34 \\
36 \\
37 \\
39 \\
41 \\
44 \\
49\end{array}$ & $\begin{array}{l}.50 \\
.50 \\
.64 \\
.09 \\
.78 \\
.02 \\
.49 \\
.27 \\
.39 \\
.40 \\
.25\end{array}$ & $\begin{array}{l}36 . \\
33 \\
33 \\
34 . \\
34 . \\
36 . \\
37 . \\
39 \\
41 . \\
44 . \\
49 .\end{array}$ & & & $\begin{array}{l}9.01 \\
9.39 \\
0.29 \\
1.10 \\
2.00 \\
3.14 \\
4.45 \\
5.95 \\
7.80 \\
.18 \\
3.62\end{array}$ & $\begin{array}{l}10.15 \\
0.62 \\
1.60 \\
1.23 \\
2.23 \\
2.88 \\
3.65 \\
4.49 \\
15.30 \\
16.29 \\
7.24 \\
7.24\end{array}$ & & $\begin{array}{l}1.38 \\
7.78 \\
6.95 \\
6.47 \\
6.13 \\
6.12 \\
6.15 \\
6.26 \\
6.33 \\
6.72 \\
6.79\end{array}$ & $\begin{array}{l}0.8314 \\
0.8016 \\
0.8039 \\
0.8079 \\
0.8163 \\
0.8319 \\
0.8514 \\
0.8783 \\
0.9116 \\
0.9620 \\
1.0395\end{array}$ & $\begin{array}{l}0.3314 \\
0.3080 \\
0.3026 \\
0.2967 \\
0.2910 \\
0.2870 \\
0.2823 \\
0.2762 \\
0.2685 \\
0.2590 \\
0.2460\end{array}$ & $\begin{array}{l}0.5198 \\
0.5775 \\
0.6016 \\
0.6174 \\
0.6312 \\
0.6410 \\
0.6508 \\
0.6593 \\
0.6699 \\
0.6769 \\
0.6771\end{array}$ & $\begin{array}{l}0.2368 \\
0.1991 \\
0.1865 \\
0.1775 \\
0.1673 \\
0.1580 \\
0.1475 \\
0.1356 \\
0.1219 \\
0.1091 \\
0.1097\end{array}$ & $\begin{array}{l}0.000 \\
0.000 \\
0.000 \\
0.000 \\
0.000 \\
0.000 \\
0.0000 \\
0.000 \\
0.000 \\
0.000 \\
0.000\end{array}$ & & $\begin{array}{r}-0.0584 \\
0.0383 \\
0.0813 \\
0.0826 \\
0.0961 \\
0.1106 \\
0.1201 \\
0.1332 \\
0.1518 \\
0.1766 \\
0.2039\end{array}$ \\
\hline
\end{tabular}


Table 10.2 Continued

** Values of parametefs on Streamlines at Station, 15, Which is an anNulus **

\begin{tabular}{|c|c|c|c|c|c|c|c|c|c|c|c|c|c|}
\hline $\begin{array}{l}\text { STPEAMLINE } \\
\text { Wo. RADIUS } \\
\text { (IN.) }\end{array}$ & $\begin{array}{l}\text { AXIAL } \\
\text { COOPD. } \\
\text { (IH,) }\end{array}$ & $\begin{array}{c}\text { AXIAL } \\
\text { VEL. } \\
\text { (FT/SEC) }\end{array}$ & $\begin{array}{c}\text { MERD. } \\
\text { VEL. } \\
\text { (FT/SEC) }\end{array}$ & $\begin{array}{c}\text { TANG. } \\
\text { VEL. } \\
\text { (FT/SEC) }\end{array}$ & $\begin{array}{c}\text { ABS. } \\
\text { VEL. } \\
\text { (FT/SEC) }\end{array}$ & MACH No. & $\begin{array}{c}\text { ABS. FLOW } \\
\text { AHGLE } \\
(D E G)\end{array}$ & $\begin{array}{l}\text { STREAM. } \\
\text { SLOPE } \\
\text { (DEG) }\end{array}$ & $\begin{array}{l}\text { STREAM. } \\
\text { CUPV. } \\
\text { (1./IN.) }\end{array}$ & $\begin{array}{l}\text { TOTAL } \\
\text { PRESS } \\
\text { (PSIA) }\end{array}$ & $\begin{array}{l}\text { TOTAL } \\
\text { TEMP. } \\
\text { (DEG.R.) }\end{array}$ & $\begin{array}{l}\text { STATIC } \\
\text { PRESS } \\
\text { (PSIA) }\end{array}$ & $\begin{array}{c}\text { STATIC } \\
\text { TEMP. } \\
\text { (DEG.R.) }\end{array}$ \\
\hline $\begin{array}{l}9.600 \\
9.531 \\
9.194 \\
8.846 \\
8.486 \\
8.110 \\
7.718 \\
7.305 \\
6.865 \\
6.391 \\
5.869\end{array}$ & $\begin{array}{l}7.340 \\
7.340 \\
7.340 \\
7.340 \\
7.340 \\
7.340 \\
7.340 \\
7.340 \\
7.340 \\
7.340 \\
7.340 \\
7.340\end{array}$ & $\begin{array}{l}580.30 \\
579.12 \\
579.07 \\
579.57 \\
580.24 \\
580.45 \\
579.27 \\
577.01 \\
572.13 \\
557.50 \\
520.82\end{array}$ & $\begin{array}{l}580.30 \\
579.13 \\
579.08 \\
579.59 \\
580.29 \\
580.53 \\
579.39 \\
577.18 \\
572.35 \\
557.72 \\
520.89\end{array}$ & $\begin{array}{l}0.00 \\
0.00 \\
0.00 \\
0.00 \\
0.00 \\
0.00 \\
0.00 \\
0.00 \\
0.00 \\
0.00 \\
0.00\end{array}$ & $\begin{array}{l}580.30 \\
579.13 \\
579.08 \\
579.59 \\
580.29 \\
580.53 \\
579.39 \\
577.18 \\
572.35 \\
557.72 \\
520.89\end{array}$ & $\begin{array}{l}0.4871 \\
0.4896 \\
0.4906 \\
0.4920 \\
0.4934 \\
0.4940 \\
0.4933 \\
0.4916 \\
0.4877 \\
0.4749 \\
0.4424\end{array}$ & $\begin{array}{l}0.00 \\
0.00 \\
0.00 \\
0.00 \\
0.00 \\
0.00 \\
0.00 \\
0.00 \\
0.00 \\
0.00 \\
0.00\end{array}$ & $\begin{array}{l}0.01 \\
0.16 \\
0.35 \\
0.55 \\
0.75 \\
0.97 \\
1.18 \\
1.39 \\
1.56 \\
1.61 \\
0.99\end{array}$ & $\begin{array}{l}-0.000 \\
-0.001 \\
-0.003 \\
-0.005 \\
-0.008 \\
-0.010 \\
-0.013 \\
-0.016 \\
-0.020 \\
-0.023 \\
-0.016\end{array}$ & $\begin{array}{l}23.421 \\
23.458 \\
23.468 \\
23.478 \\
23.480 \\
23.466 \\
23.415 \\
23.340 \\
23.223 \\
22.954 \\
22.407\end{array}$ & $\begin{array}{l}618.99 \\
610.26 \\
607.94 \\
605.69 \\
603.87 \\
602.97 \\
602.10 \\
601.37 \\
600.46 \\
599.96 \\
599.66\end{array}$ & $\begin{array}{l}19.915 \\
19.912 \\
19.909 \\
19.898 \\
19.882 \\
19.862 \\
19.828 \\
19.786 \\
19.737 \\
19.670 \\
19.588\end{array}$ & $\begin{array}{l}591.01 \\
582.38 \\
580.07 \\
577.76 \\
575.87 \\
574.95 \\
574.19 \\
573.67 \\
573.22 \\
574.10 \\
577.08\end{array}$ \\
\hline
\end{tabular}

** VALUES OF PARAMEZERS OM STREAMLINES AT STATION, 16, WHICH IS AN ANNULUS **

\begin{tabular}{|c|c|c|c|c|c|c|c|c|c|c|c|c|c|}
\hline $\begin{array}{l}\text { STREAMLIME } \\
\text { :O. RADIUS } \\
\text { (IN.) }\end{array}$ & $\begin{array}{l}\text { AXIAL } \\
\text { CCORD. } \\
\text { (IN.) }\end{array}$ & $\begin{array}{c}\text { AXIAL } \\
\text { VEL. } \\
\text { (FT/SEC) }\end{array}$ & $\begin{array}{c}\text { MERD. } \\
\text { VEL } \\
\text { (FT/SEC) }\end{array}$ & $\begin{array}{c}\text { TANG. } \\
\text { WEL } \\
\text { (FT/SEC) }\end{array}$ & $\begin{array}{c}\text { ABS. } \\
\text { VEEL: } \\
\text { (FT/SEC) }\end{array}$ & MBCH & $\begin{array}{c}\text { ABS. FLOW } \\
\text { ANGLE } \\
(D E G)\end{array}$ & $\begin{array}{l}\text { STREAM. } \\
\text { SLOPE } \\
\text { (DEG) }\end{array}$ & $\begin{array}{c}\text { STREAI1. } \\
\text { CURV. } \\
\text { (1./IN.) }\end{array}$ & $\begin{array}{l}\text { TOIAL } \\
\text { PEESS } \\
\text { (PSIA) }\end{array}$ & $\begin{array}{l}\text { TOTAL } \\
\text { TEMP. } \\
\text { (DEG.R.) }\end{array}$ & $\begin{array}{l}\text { SIATIC } \\
\text { PFESS } \\
\text { (FSIA) }\end{array}$ & $\begin{array}{c}\text { SIATIC } \\
\text { OERP } \\
\text { (DEG.R.) }\end{array}$ \\
\hline $\begin{array}{r}9.531 \\
9.195 \\
8.848 \\
8.489 \\
8.115 \\
7.724 \\
7.311 \\
6.871 \\
6.397 \\
5.874 \\
5.255 \\
5\end{array}$ & $\begin{array}{l}7.446 \\
7.446 \\
7.446 \\
7.446 \\
7.446 \\
7.446 \\
7.446 \\
7.446 \\
7.446 \\
7.446 \\
7.446\end{array}$ & $\begin{array}{l}582.82 \\
581.58 \\
581.41 \\
581.70 \\
582.02 \\
581.73 \\
579.84 \\
576.60 \\
570.38 \\
553.84 \\
515.48\end{array}$ & $\begin{array}{l}582.82 \\
581.58 \\
581.42 \\
581.72 \\
582.07 \\
581.80 \\
579.95 \\
576.75 \\
570.56 \\
554.03 \\
515.55\end{array}$ & $\begin{array}{l}0.00 \\
0.00 \\
0.00 \\
0.00 \\
0.00 \\
0.00 \\
0.00 \\
0.00 \\
0.00 \\
0.00 \\
0.00\end{array}$ & $\begin{array}{l}582.82 \\
581.58 \\
581.42 \\
581.72 \\
582.07 \\
581.80 \\
579.95 \\
576.75 \\
570.56 \\
554.03 \\
515.55\end{array}$ & $\begin{array}{l}0.4893 \\
0.4918 \\
0.4926 \\
0.4939 \\
0.4949 \\
0.4951 \\
0.4938 \\
0.4913 \\
0.4861 \\
0.4716 \\
0.4377\end{array}$ & $\begin{array}{l}0.00 \\
0.00 \\
0.00 \\
0.00 \\
0.00 \\
0.00 \\
0.00 \\
0.00 \\
0.00 \\
0.00 \\
0.00\end{array}$ & $\begin{array}{l}0.01 \\
0.15 \\
0.33 \\
0.52 \\
0.71 \\
0.91 \\
1.11 \\
1.30 \\
1.45 \\
1.48 \\
0.90\end{array}$ & $\begin{array}{l}-0.000 \\
-0.001 \\
-0.003 \\
-0.004 \\
-0.006 \\
-0.007 \\
-0.009 \\
-0.012 \\
-0.014 \\
-0.016 \\
-0.015\end{array}$ & $\begin{array}{l}23.421 \\
23.458 \\
23.468 \\
23.478 \\
23.480 \\
23.465 \\
23.415 \\
23.340 \\
23.223 \\
22.954 \\
22.407\end{array}$ & $\begin{array}{l}618.99 \\
610.26 \\
607.94 \\
60.5 .69 \\
603.87 \\
602.97 \\
602.10 \\
601.37 \\
500.46 \\
599.96 \\
599.66\end{array}$ & $\begin{array}{l}19.888 \\
19.884 \\
19.881 \\
19.873 \\
19.851 \\
19.847 \\
19.821 \\
19.791 \\
19.757 \\
19.712 \\
19.643\end{array}$ & $\begin{array}{l}570.77 \\
582.14 \\
579.84 \\
577.55 \\
575.70 \\
574.83 \\
574.14 \\
573.71 \\
573.39 \\
574.44 \\
577.55\end{array}$ \\
\hline
\end{tabular}

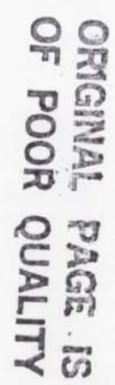


Table 10.2 Continued

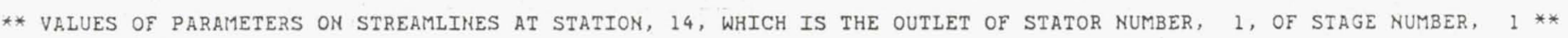

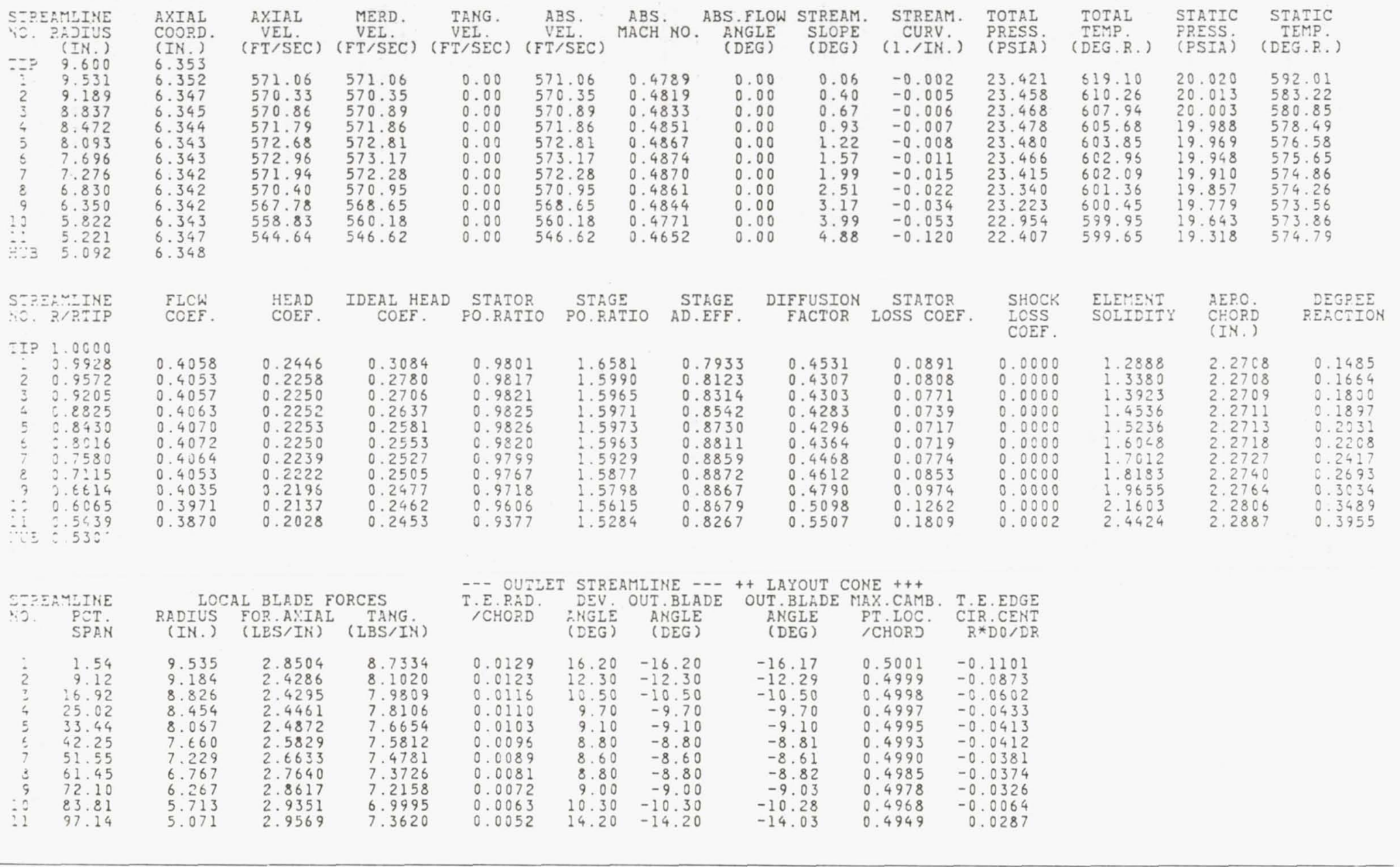


Table 10.2 Continued

** values of parameters on Streamlines at Station, 17, which is an anNulus **

\begin{tabular}{|c|c|c|c|c|c|c|c|c|c|c|c|c|c|}
\hline $\begin{array}{l}\text { STPEAMIINE } \\
\text { NO. ROEIUS } \\
\text { (IN.) }\end{array}$ & $\begin{array}{l}\text { AXIAL } \\
\text { COORD. } \\
\text { (IN.) }\end{array}$ & $\begin{array}{c}\text { AXIAL } \\
\text { VEL } \\
\text { (FT/SEC) }\end{array}$ & $\begin{array}{c}\text { MERD. } \\
\text { VEL } \\
\text { (FT/SEC) }\end{array}$ & $\begin{array}{c}\text { TANG. } \\
\text { VEL. } \\
\text { (FT/SEC) }\end{array}$ & $\begin{array}{c}\text { ABS. } \\
\text { VEL: } \\
\text { (FT/SEC) }\end{array}$ & $\begin{array}{l}\text { ABS. } \\
\text { MACH No. }\end{array}$ & $\begin{array}{c}\text { ABS. FLOW } \\
\text { ANGLE } \\
(D E G)\end{array}$ & $\begin{array}{l}\text { STPEAM. } \\
\text { SIOPE } \\
\text { (DEG) }\end{array}$ & $\begin{array}{c}\text { SIREAM. } \\
\text { CUR. } \\
\text { (1./IN.) }\end{array}$ & $\begin{array}{l}\text { TOTAL } \\
\text { PPESS } \\
\text { (PSIA) }\end{array}$ & $\begin{array}{l}\text { TOTAL } \\
\text { TEMP. } \\
\text { (DEG.R.) }\end{array}$ & $\begin{array}{l}\text { STATIC } \\
\text { PRESS } \\
\text { (PSIA) }\end{array}$ & $\begin{array}{l}\text { STATIC } \\
\text { TEMP. } \\
\text { (DEG.R.) }\end{array}$ \\
\hline $\begin{array}{r}9.531 \\
9.198 \\
8.854 \\
8.498 \\
8.127 \\
7.738 \\
7.328 \\
6.889 \\
6.415 \\
5.887\end{array}$ & $\begin{array}{r}010 \\
010 \\
010 \\
010 \\
010 \\
010 \\
010 \\
010 \\
010 \\
010\end{array}$ & $\begin{array}{l}589.27 \\
588.04 \\
587.58 \\
587.26 \\
586.64 \\
584.97 \\
581.18 \\
575.29 \\
555.40 \\
543.72 \\
497.78\end{array}$ & $\begin{array}{l}589.27 \\
588.04 \\
587.58 \\
587.26 \\
586.64 \\
584.97 \\
581.18 \\
575.29 \\
565.40 \\
543.72 \\
457.78\end{array}$ & $\begin{array}{l}0.00 \\
0.00 \\
0.00 \\
0.00 \\
0.00 \\
0.00 \\
0.00 \\
0.00 \\
0.00 \\
0.00 \\
0.00\end{array}$ & $\begin{array}{l}589.27 \\
588.04 \\
587.58 \\
587.26 \\
586.64 \\
584.97 \\
581.18 \\
575.29 \\
565.40 \\
543.72 \\
497.78\end{array}$ & $\begin{array}{l}0.4951 \\
0.4976 \\
0.4981 \\
0.4988 \\
0.4990 \\
0.4979 \\
0.4949 \\
0.4899 \\
0.4815 \\
0.4625 \\
0.4220\end{array}$ & $\begin{array}{l}0.00 \\
0.00 \\
0.00 \\
0.00 \\
0.00 \\
0.00 \\
0.00 \\
0.00 \\
0.00 \\
0.00 \\
0.00\end{array}$ & $\begin{array}{r}-0.00 \\
0.01 \\
0.01 \\
0.00 \\
-0.00 \\
-0.01 \\
-0.04 \\
-0.07 \\
-0.13 \\
-0.20 \\
-0.22\end{array}$ & $\begin{array}{r}0.000 \\
-0.000 \\
-0.000 \\
-0.000 \\
-0.000 \\
-0.000 \\
-0.000 \\
0.0000 \\
0.001 \\
0.002 \\
0.004\end{array}$ & $\begin{array}{l}23.421 \\
23.458 \\
23.468 \\
23.478 \\
23.480 \\
23.466 \\
23.415 \\
23.340 \\
23.223 \\
22.954 \\
22.407\end{array}$ & $\begin{array}{l}618.53 \\
610.21 \\
607.94 \\
605.71 \\
603.90 \\
603.01 \\
602.14 \\
601.41 \\
600.50 \\
600.01 \\
599.70\end{array}$ & $\begin{array}{l}19.809 \\
19.808 \\
19.810 \\
19.809 \\
19.808 \\
19.810 \\
19.807 \\
19.808 \\
19.817 \\
19.824 \\
19.822\end{array}$ & $\begin{array}{l}589.68 \\
581.47 \\
579.24 \\
577.04 \\
575.29 \\
574.56 \\
574.06 \\
573.90 \\
573.92 \\
575.42 \\
579.09\end{array}$ \\
\hline
\end{tabular}

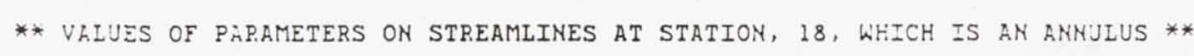

\begin{tabular}{|c|c|c|c|c|c|c|c|c|c|c|c|c|c|c|}
\hline $\begin{array}{l}\text { STR } \\
\text { YO. }\end{array}$ & $\begin{array}{l}\text { AMLINE } \\
\text { FADIUS } \\
\text { (IN.) }\end{array}$ & $\begin{array}{l}\text { AXIP.L } \\
\text { COOP.D. } \\
\text { (IN.) }\end{array}$ & $\begin{array}{c}\text { AXIAL } \\
\text { VET. } \\
\text { (FT/SEC) }\end{array}$ & $\begin{array}{c}\text { MESD. } \\
\text { (FTISEC) }\end{array}$ & $\begin{array}{c}\text { TANG. } \\
\text { VEI. } \\
\text { (FT/SEC) }\end{array}$ & $\begin{array}{c}\text { ABS. } \\
\text { VEI } \\
(\text { FT/SEC) }\end{array}$ & $\begin{array}{l}\text { ABS. } \\
\text { MACH NO. }\end{array}$ & $\begin{array}{c}\text { ABS.FLOW } \\
\text { ANGLE } \\
\text { (DEG) }\end{array}$ & $\begin{array}{l}\text { STPEAM. } \\
\text { SLCPE } \\
\text { (DEG) }\end{array}$ & $\begin{array}{c}\text { STEEAM. } \\
\text { CLPV. } \\
\text { (1./IN.) }\end{array}$ & $\begin{array}{l}\text { TOTAL } \\
\text { PPESS } \\
\text { (PSIA) }\end{array}$ & $\begin{array}{l}\text { TOTAL } \\
\text { IEMP. } \\
\text { (LEG.R.) }\end{array}$ & $\begin{array}{l}\text { STATIC } \\
\text { PPESS } \\
\text { (PSIA) }\end{array}$ & $\begin{array}{l}\text { STATIC } \\
\text { FEMP. } \\
\text { (DEG.P.) }\end{array}$ \\
\hline $\begin{array}{c}1 \\
1 \\
2 \\
3 \\
4 \\
5 \\
5 \\
7 \\
8 \\
9 \\
10 \\
11 \\
\text { HUB }\end{array}$ & $\begin{array}{l}9.000 \\
9.531 \\
9.198 \\
8.855 \\
8.499 \\
8.128 \\
7.740 \\
7.329 \\
6.891 \\
6.416 \\
5.828 \\
5.266 \\
5.140\end{array}$ & $\begin{array}{l}11.350 \\
11.350 \\
11.350 \\
11.350 \\
11.350 \\
11.350 \\
11.350 \\
11.350 \\
11.350 \\
11.350 \\
11.350 \\
11.350\end{array}$ & $\begin{array}{l}589.87 \\
588.51 \\
588.10 \\
537.70 \\
585.98 \\
585.18 \\
581.21 \\
575.11 \\
564.97 \\
542.96 \\
495.84\end{array}$ & $\begin{array}{l}589.87 \\
588.61 \\
588.10 \\
587.70 \\
586.98 \\
533.18 \\
531.21 \\
575.11 \\
564.97 \\
542.95 \\
496.84\end{array}$ & $\begin{array}{l}0.00 \\
0.00 \\
0.00 \\
0.00 \\
0.00 \\
0.00 \\
0.00 \\
0.00 \\
0.00 \\
0.00 \\
0.00\end{array}$ & $\begin{array}{l}589.87 \\
588.61 \\
588.10 \\
587.70 \\
586.98 \\
585.18 \\
581.21 \\
575.11 \\
564.97 \\
542.96 \\
496.84\end{array}$ & $\begin{array}{l}0.4957 \\
0.4981 \\
0.4986 \\
0.4992 \\
0.4993 \\
0.4981 \\
0.4949 \\
0.4898 \\
0.4811 \\
0.4618 \\
0.4212\end{array}$ & $\begin{array}{l}0.00 \\
0.00 \\
0.00 \\
0.00 \\
0.00 \\
0.00 \\
0.00 \\
0.00 \\
0.00 \\
0.00 \\
0.00\end{array}$ & $\begin{array}{r}-0.00 \\
0.01 \\
0.01 \\
0.00 \\
0.00 \\
-0.01 \\
-0.02 \\
-0.05 \\
-0.09 \\
-0.014 \\
-0.15\end{array}$ & $\begin{array}{l}0.000 \\
0.000 \\
0.000 \\
0.000 \\
0.000 \\
0.000 \\
0.001 \\
0.001 \\
0.002 \\
0.00=3 \\
0.003\end{array}$ & $\begin{array}{l}23.421 \\
23.458 \\
23.468 \\
23.478 \\
23.480 \\
23.466 \\
23.415 \\
23.340 \\
23.223 \\
22.954 \\
22.407\end{array}$ & $\begin{array}{l}618.53 \\
610.21 \\
607.94 \\
605.71 \\
603.90 \\
603.01 \\
602.14 \\
601.41 \\
500.50 \\
600.01 \\
599.70\end{array}$ & $\begin{array}{l}19.803 \\
19.802 \\
19.803 \\
19.804 \\
19.804 \\
19.808 \\
19.807 \\
19.810 \\
19.821 \\
19.832 \\
19.832\end{array}$ & $\begin{array}{l}589.62 \\
581.41 \\
579.19 \\
576.99 \\
575.25 \\
574.54 \\
574.05 \\
573.91 \\
573.96 \\
575.48 \\
579.17\end{array}$ \\
\hline
\end{tabular}


* Values of parameters on Streamlines at Station, 19, Which is an anNulus **

\begin{tabular}{|c|c|c|c|c|c|c|c|c|c|c|c|c|c|}
\hline $\begin{array}{l}\text { SZREAMLINE } \\
\text { :0. PADIUS } \\
\text { (IM, }\end{array}$ & $\begin{array}{l}\text { AXIAL } \\
\text { CCORD. } \\
\text { (IH.) }\end{array}$ & $\begin{array}{c}\text { AXIAL } \\
\text { VEL } \\
\text { (FT/SEC) }\end{array}$ & $\begin{array}{c}\text { MERD. } \\
\text { VEL. } \\
\text { (FT/SEC) }\end{array}$ & $\begin{array}{c}\text { TANG. } \\
\text { VEL } \\
\text { (FT/S } E C)\end{array}$ & $\begin{array}{c}\text { A.BS. } \\
\text { (FTISEC) }\end{array}$ & MACH NO. & $\begin{array}{l}\text { ABS. FLOW } \\
\text { ANGLE } \\
\text { (DEG) }\end{array}$ & $\begin{array}{c}\text { STREAM. } \\
\text { SLOPE } \\
\text { (DEG) }\end{array}$ & $\begin{array}{l}\text { STREAM. } \\
\text { CURV } \\
\text { (1./IN.) }\end{array}$ & $\begin{array}{l}\text { TONAL } \\
\text { PRESS. } \\
\text { (PSIA) }\end{array}$ & $\begin{array}{l}\text { TOTAL } \\
\text { TEMP. } \\
\text { (DEG.R.) }\end{array}$ & $\begin{array}{l}\text { STATIC } \\
\text { PPESS } \\
\text { (PSIA) }\end{array}$ & $\begin{array}{c}\text { STATIC } \\
\text { TEMPP. } \\
\text { (DEG.R.) }\end{array}$ \\
\hline $\begin{array}{r}9.531 \\
9.198 \\
8.854 \\
8.498 \\
8.127 \\
7.738 \\
7.327 \\
6.888 \\
6.414 \\
5.886 \\
5.266\end{array}$ & $\begin{array}{l}14.440 \\
14.440 \\
14.440 \\
14.440 \\
14.440 \\
14.440 \\
14.440 \\
14.440 \\
14.440 \\
14.440 \\
14.440\end{array}$ & $\begin{array}{l}588.97 \\
587.87 \\
587.41 \\
587.04 \\
586.39 \\
584.68 \\
580.90 \\
575.08 \\
565.44 \\
544.29 \\
499.70\end{array}$ & $\begin{array}{l}588.97 \\
587.87 \\
587.41 \\
587.04 \\
586.39 \\
584.68 \\
580.90 \\
575.08 \\
555.44 \\
544.29 \\
499.70\end{array}$ & $\begin{array}{l}0.00 \\
0.00 \\
0.00 \\
0.00 \\
0.00 \\
0.00 \\
0.00 \\
0.00 \\
0.00 \\
0.00 \\
0.00\end{array}$ & $\begin{array}{l}588.97 \\
587.87 \\
587.41 \\
587.04 \\
586.39 \\
584.68 \\
580.90 \\
575.08 \\
565.44 \\
544.29 \\
499.70\end{array}$ & $\begin{array}{l}0.4950 \\
0.4974 \\
0.4980 \\
0.4986 \\
0.4938 \\
0.4976 \\
0.4946 \\
0.4897 \\
0.4815 \\
0.4629 \\
0.4237\end{array}$ & $\begin{array}{l}0.00 \\
0.00 \\
0.00 \\
0.00 \\
0.00 \\
0.00 \\
0.00 \\
0.00 \\
0.00 \\
0.00 \\
0.00\end{array}$ & $\begin{array}{r}0.00 \\
-0.00 \\
-0.00 \\
-0.00 \\
-0.00 \\
0.00 \\
0.00 \\
0.01 \\
0.02 \\
0.04 \\
0.05\end{array}$ & $\begin{array}{r}-0.000 \\
0.000 \\
-0.000 \\
-0.000 \\
-0.000 \\
-0.000 \\
-0.000 \\
-0.000 \\
-0.000 \\
-0.001 \\
-0.001\end{array}$ & $\begin{array}{l}23.421 \\
23.458 \\
23.468 \\
23.478 \\
23.430 \\
23.466 \\
23.415 \\
23.340 \\
23.223\end{array}$ & $\begin{array}{l}618.17 \\
610.17 \\
607.94 \\
605.72 \\
603.93 \\
603.04 \\
602.17 \\
601.45 \\
600.54 \\
600.05 \\
599.74\end{array}$ & $\begin{array}{l}19.811 \\
19.810 \\
19.812 \\
19.811 \\
19.811 \\
19.814 \\
19.810 \\
19.810 \\
19.816 \\
19.817 \\
19.803\end{array}$ & $\begin{array}{l}589.35 \\
581.45 \\
579.26 \\
577.07 \\
575.34 \\
574.62 \\
574.12 \\
573.95 \\
573.95 \\
575.40 \\
578.97\end{array}$ \\
\hline
\end{tabular}

** Values ce parametzrs CN Streamitmes at Station, 20, which is an anNulus **

\begin{tabular}{|c|c|c|c|c|c|c|c|c|c|c|c|c|c|c|}
\hline $\begin{array}{l}8.0 \\
\therefore 0\end{array}$ & $\begin{array}{l}\text { OLINF } \\
\text { 2AIUS } \\
\text { (IP.) }\end{array}$ & $\begin{array}{l}\text { AUIAI } \\
\text { COOND } \\
\text { (IN.) }\end{array}$ & $\begin{array}{c}\text { AXIAL } \\
\text { VEL. } \\
\text { (FT/SEC) }\end{array}$ & $\begin{array}{c}\text { ME?D. } \\
\text { VEU } \\
(\text { FT/SEC })\end{array}$ & $\begin{array}{c}\text { TANG. } \\
\text { VEL. } \\
\text { (FISSEC) }\end{array}$ & $\begin{array}{c}43 S . \\
y=L \\
(E T / S E C)\end{array}$ & MACH NO. & $\begin{array}{l}\text { ABS. FLOW } \\
\text { ANGLE } \\
\text { (DEG) }\end{array}$ & $\begin{array}{l}\text { STREAM. } \\
\text { SLOPE } \\
\text { (DEG) }\end{array}$ & $\begin{array}{c}\text { STPEAM. } \\
\text { CURV. } \\
(1 . / \text { IN. })\end{array}$ & $\begin{array}{l}\text { TOTAL } \\
\text { PPESS } \\
\text { (PSIA) }\end{array}$ & $\begin{array}{l}\text { TOTAL } \\
\text { TEM? } \\
(D E G, ?)\end{array}$ & $\begin{array}{l}\text { STATIC } \\
\text { FPESS } \\
\text { (FSIA) }\end{array}$ & $\begin{array}{l}\text { STATIC } \\
\text { TEMP. } \\
\text { (DEG.R.) }\end{array}$ \\
\hline $\begin{array}{r}7 \\
8 \\
3 \\
\vdots ? \\
13 \\
3 ?\end{array}$ & $\begin{array}{l}9.531 \\
9.198 \\
8.854 \\
8.498 \\
8.127 \\
7.738 \\
7.327 \\
6.888 \\
6.414 \\
5.836 \\
5.266 \\
5.140\end{array}$ & $\begin{array}{l}16.000 \\
16.000 \\
16.000 \\
16.000 \\
16.000 \\
16.000 \\
16.000 \\
16.000 \\
16.000 \\
16.000 \\
16.000 \\
16.000\end{array}$ & $\begin{array}{l}588.85 \\
587.82 \\
587.39 \\
587.03 \\
586.38 \\
584.71 \\
580.94 \\
575.14 \\
565.49 \\
544.32 \\
499.62\end{array}$ & $\begin{array}{l}588.85 \\
537.82 \\
587.39 \\
587.03 \\
586.38 \\
584.71 \\
580.94 \\
575.14 \\
565.49 \\
544.32 \\
499.62\end{array}$ & $\begin{array}{l}0.00 \\
c .000 \\
3.00 \\
. .00 \\
0.00 \\
0.00 \\
0.00 \\
0.00 \\
0.00 \\
0.00 \\
0.00 \\
0.00\end{array}$ & $\begin{array}{l}588.85 \\
587.82 \\
587.39 \\
587.63 \\
585.38 \\
584.71 \\
580.94 \\
575.14 \\
565.49 \\
544.32 \\
499.62\end{array}$ & $\begin{array}{l}0.4950 \\
0.4974 \\
0.4979 \\
0.4986 \\
0.4988 \\
0.4977 \\
0.4947 \\
0.4898 \\
0.4816 \\
0.4630 \\
0.4236\end{array}$ & $\begin{array}{l}0.00 \\
0.00 \\
0.00 \\
0.00 \\
0.00 \\
0.00 \\
0.00 \\
0.00 \\
0.00 \\
0.00 \\
0.00\end{array}$ & $\begin{array}{l}-0.00 \\
-0.00 \\
-0.00 \\
-0.01 \\
-0.01 \\
-0.01 \\
-0.01 \\
-0.02 \\
-0.02 \\
-0.03 \\
-0.04\end{array}$ & $\begin{array}{l}-0.0000 \\
-0.0000 \\
-0.000 \\
-0.000 \\
-0.000 \\
-0.000 \\
-0.000 \\
-0.000 \\
-0.000 \\
-0.000 \\
-0.000 \\
-0.001\end{array}$ & $\begin{array}{l}23.421 \\
23.458 \\
23.458 \\
23.478 \\
23.480 \\
23.465 \\
23.415 \\
23.340 \\
23.223 \\
22.954 \\
22.407\end{array}$ & $\begin{array}{l}618.01 \\
610.16 \\
507 \cdot 95 \\
505.73 \\
603.94 \\
503.95 \\
602.19 \\
601.46 \\
600.56 \\
500.05 \\
599.75\end{array}$ & $\begin{array}{l}19.811 \\
19.811 \\
19.812 \\
19.812 \\
19.811 \\
19.814 \\
19.810 \\
19.810 \\
19.816 \\
19.817 \\
19.804\end{array}$ & $\begin{array}{l}589.20 \\
581.44 \\
579.26 \\
577.08 \\
575.36 \\
574.63 \\
574.13 \\
573.96 \\
573.97 \\
575.41 \\
578.99\end{array}$ \\
\hline
\end{tabular}


Table 10.3 Design code stage and overall performance predictions

*** COH?UTED CCMPRESSOR DESIGN PARAMETERS FOR A ROTRTIONAL SPEED OF, 16042.8 , RPM ***

** THE CORRECTED WEIGHTFLOW PER UNIT OF CASIMG AMNULAR AREA AT THE INLET FACE CF THE FIRST BLADE ROW IS 38.78 LBS/SEC/FT SQ **

** MaSS AVERAgEd ROTOR AND STAGE aERODZMAMIC PAERMEIE?S **

\begin{tabular}{|c|c|c|c|c|c|c|c|c|c|c|c|c|c|c|}
\hline $\begin{array}{l}\text { STAGE } \\
\text { NO. }\end{array}$ & $\begin{array}{l}\text { BLADE } \\
\text { TYPE }\end{array}$ & $\begin{array}{l}\text { FLOW } \\
\text { COEF. }\end{array}$ & $\begin{array}{l}\text { HEAD } \\
\text { CUER. }\end{array}$ & ID. $\frac{H E A D}{C C E \bar{F}}$. & $\begin{array}{l}\text { TOTAL } \\
\text { PEESS. } \\
\text { FATIO }\end{array}$ & $\begin{array}{l}\text { TOTAL } \\
\text { TEMP. } \\
\text { RATIO }\end{array}$ & ADIA. & $\begin{array}{l}\text { POIY. } \\
\text { EFF. }\end{array}$ & $\begin{array}{l}\text { ASPECT } \\
\text { RATIO }\end{array}$ & 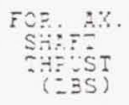 & \multicolumn{2}{|c|}{$\begin{array}{l}\text { GAS BENDING MOHENTS } \\
\text { FOR EACH BLEDE } \\
\text { FOR. AX. TARE. } \\
\text { (FT-LBS; (FT-LBS) }\end{array}$} & $\begin{array}{l}\text { TORQUE } \\
\text { (FT-LBS) }\end{array}$ & $\begin{array}{l}\text { PCAE? } \\
\text { (HP) }\end{array}$ \\
\hline $\begin{array}{l}1 \\
1\end{array}$ & $\begin{array}{r}\text { ROTOR } \\
\text { STATOR }\end{array}$ & $\begin{array}{l}0.4280 \\
0.4152\end{array}$ & $\begin{array}{l}0.2355 \\
0.2229\end{array}$ & $\begin{array}{l}0.2600 \\
0.2600\end{array}$ & $\begin{array}{l}1.6293 \\
1.5900\end{array}$ & $\begin{array}{l}1.1652 \\
1.1652\end{array}$ & $\begin{array}{l}0.9060 \\
0.8575\end{array}$ & $\begin{array}{l}0.9122 \\
0.8565\end{array}$ & $\begin{array}{l}1.55 \\
2.05\end{array}$ & $\begin{array}{l}=048.80 \\
=242.80\end{array}$ & $\begin{array}{r}17.698 \\
2.310\end{array}$ & $\begin{array}{r}-12.650 \\
6.067\end{array}$ & 698.10 & 2132.37 \\
\hline \multicolumn{14}{|c|}{ SS AVERAGED ROTOR AND STAGE } & \multirow[b]{2}{*}{$\begin{array}{l}\text { FPACT } \\
\text { ERE?G? }\end{array}$} \\
\hline $\begin{array}{l}\text { STAGE } \\
\text { No. }\end{array}$ & $\begin{array}{l}\text { BLADE } \\
\text { TYPE }\end{array}$ & $\begin{array}{c}\text { WEIGHT } \\
\text { FLO } \\
\text { (IBS/SEC) }\end{array}$ & $\begin{array}{l}\text { TOTAL } \\
\text { FFESS } \\
\text { (PSIA) }\end{array}$ & 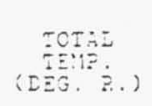 & $\begin{array}{l}\text { TETAL } \\
\text { FESS } \\
\text { RATOO }\end{array}$ & $\begin{array}{l}\text { TOTAL } \\
\text { TEMPF } \\
\text { RATIO }\end{array}$ & $\begin{array}{l}\text { HEAD } \\
\text { CCEF. }\end{array}$ & $\begin{array}{c}\text { IDEAL UEAD } \\
\text { COEF. }\end{array}$ & $\begin{array}{l}\text { EDIA. } \\
\text { E:F. }\end{array}$ & 影。 & $\begin{array}{l}\text { FOR A\%. } \\
\text { SHEFT } \\
\text { THFUST } \\
\text { (LES) }\end{array}$ & $\begin{array}{c}\text { TOPQUE } \\
\text { (FT-LBS) }\end{array}$ & $\begin{array}{l}\text { POAER } \\
\text { (HP) }\end{array}$ & \\
\hline $\begin{array}{l}1 \\
1\end{array}$ & $\begin{array}{r}\text { INIET } \\
\text { POTOR } \\
\text { STATOR }\end{array}$ & $\begin{array}{l}73.30 \\
73.30 \\
73.30\end{array}$ & $\begin{array}{l}14.665 \\
23.876 \\
23.318\end{array}$ & $\begin{array}{l}518.76 \\
664.38 \\
604.38\end{array}$ & $\begin{array}{l}1.6293 \\
1.5900\end{array}$ & $\begin{array}{l}1.1652 \\
1.1652\end{array}$ & $\begin{array}{l}0.2355 \\
0.2229\end{array}$ & $\begin{array}{l}0.2600 \\
0.2600\end{array}$ & $\begin{array}{l}0.90 \leqslant 0 \\
0.85\end{array}$ & $\begin{array}{l}3.3: 22 \\
0.85 \leq 5\end{array}$ & $\begin{array}{r}: 043.80 \\
806.00\end{array}$ & 698.10 & 2132.37 & 1.0000 \\
\hline
\end{tabular}


Table 10.4 Rotor blade manufacturing coordinates generated by NASA design code

** BLADE SECtion PROPERTIES OF ROTOR NO. 1 **

NUMBER OF BLADES $=22.0$ AXIAL LOCATION OF STACKING LIME IN COMPRESSOR $=0.941$ IN.

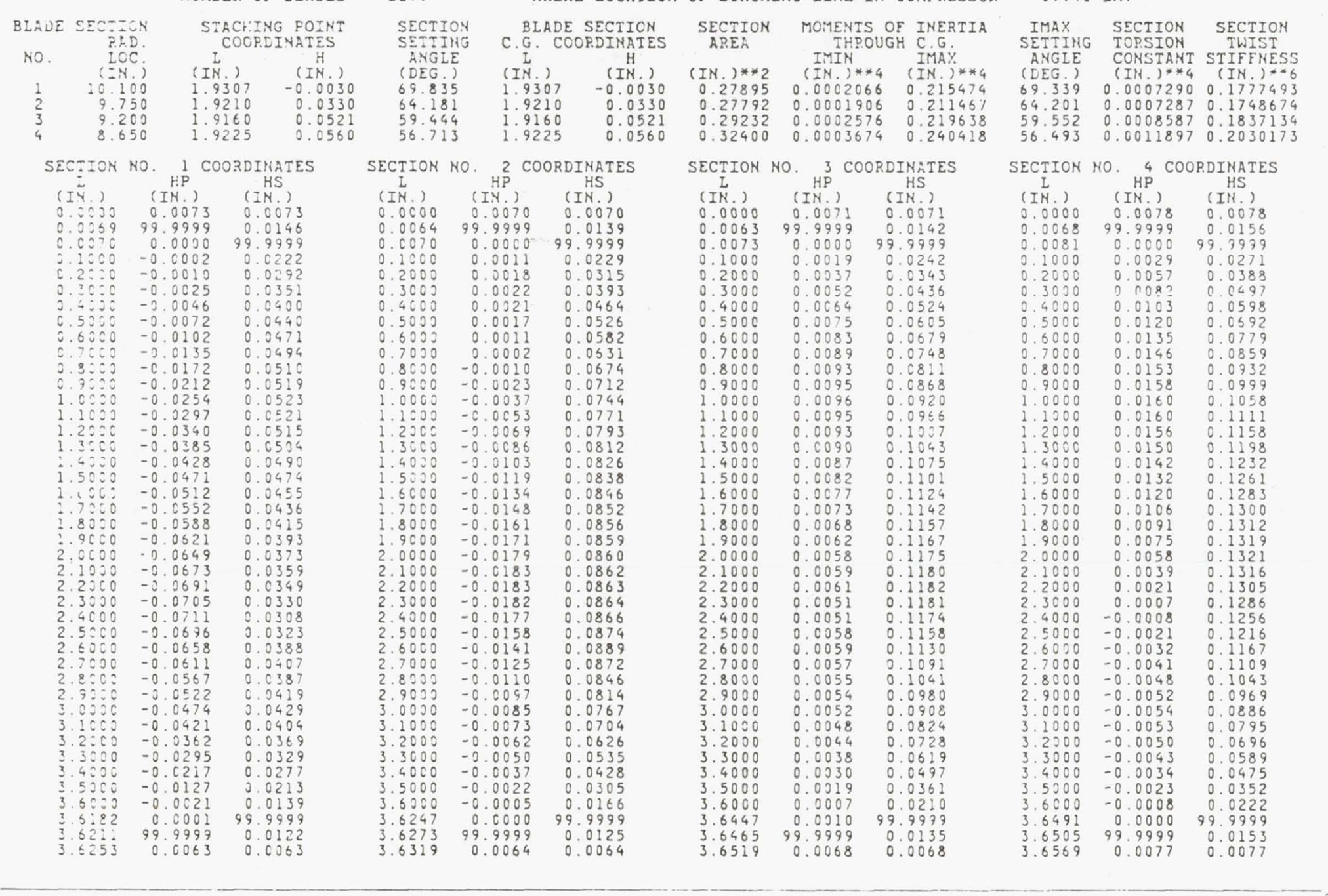


Table 10.4 Continued

* Blade section properties of rotor no. 1 **

NUMBER OF BLADES $=22.0$

AXIAL LOCATION OF STACKING LINE IN COMPRESSOR $=0.941 \mathrm{IN}$.

\begin{tabular}{|c|c|c|c|c|c|c|c|c|c|c|c|c|c|c|c|}
\hline $\begin{array}{cc}\text { BLADE } & \text { SECTION } \\
\text { P.AD. } \\
\text { NO. } & \text { IOC } \\
& \text { (IN.j } \\
9 & 6.150 \\
10 & 5.650 \\
11 & 5.150 \\
12 & 4.450\end{array}$ & $\begin{array}{l}\text { ON } \\
\text { D. } \\
\text { C. } \\
50 \\
50 \\
50 \\
50\end{array}$ & $\begin{array}{l}\text { TACK.I } \\
\text { COOR. } \\
\text { L } \\
\text { CN.) } \\
8849 \\
8439 \\
8368 \\
8388\end{array}$ & $\begin{array}{l}\text { POINT } \\
\text { PATES } \\
\text { H } \\
\text { (IN ) } \\
0.2149 \\
0.2731 \\
0.3554 \\
0.4473\end{array}$ & $\begin{array}{l}\text { SECTI } \\
\text { SETTI } \\
\text { ANGI } \\
\text { CDEG. } \\
35.52 \\
28.55 \\
21.41 \\
14.48\end{array}$ & $\begin{array}{ll}\text { ION } & \text { ING } \\
\text { IEE } & \text { C.C } \\
\text { ) } & (I) \\
22 & 1.8 \\
53 & 1.8 \\
17 & 1.8 \\
87 & 1.8\end{array}$ & $\begin{array}{l}\text { BLADE } \\
\text { G. COOO } \\
\text { IN.) } \\
.8849 \\
.8439 \\
8368 \\
.8388\end{array}$ & $\begin{array}{l}\text { ECTION } \\
\text { DINATES } \\
\text { H } \\
(\text { IN }) \\
0.2149 \\
0.2731 \\
0.3554 \\
0.4473\end{array}$ & $\begin{array}{l}\text { SECTION } \\
\text { AREA } \\
\text { (IN.)**2 } \\
0.64225 \\
0.71637 \\
0.77157 \\
0.81317\end{array}$ & \multicolumn{3}{|c|}{ 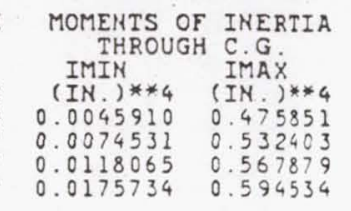 } & $\begin{array}{l}\text { IMAX } \\
\text { SETTING } \\
\text { ANGLE } \\
\text { (DEG) } \\
35.118 \\
28.683 \\
22.015 \\
15.523\end{array}$ & $\begin{array}{l}\text { SECTION } \\
\text { TORSION } \\
\text { CONSTANT } \\
\text { (IN ) **4 } \\
0.0090665 \\
0.0123591 \\
0.0153858 \\
0.0178553\end{array}$ & $\begin{array}{c}\text { SECTION } \\
\text { TWIST } \\
\text { STIFFNESS } \\
\text { (IN.)**6 } \\
0.4015445 \\
0.4387047 \\
0.4638299 \\
0.4912950\end{array}$ & \\
\hline $\begin{array}{l}\text { SECTION } \\
\text { L } \\
(I N .) \\
0.0000 \\
0.0095 \\
0.0161 \\
0.1000 \\
0.2000 \\
0.3000 \\
0.4000 \\
0.5000 \\
0.6000 \\
0.7000 \\
0.8000 \\
0.9000 \\
1.0000 \\
1.1000 \\
1.2000 \\
1.3000 \\
1.4000 \\
1.5000 \\
1.6000 \\
1.7000 \\
1.8000 \\
1.9000 \\
2.0000 \\
2.1000 \\
2.2000 \\
2.3000 \\
2.4000 \\
2.5000 \\
2.6000 \\
2.7000 \\
2.8000 \\
2.9000 \\
3.0000 \\
3.1000 \\
3.2000 \\
3.3000 \\
3.4000 \\
3.5000 \\
3.6000 \\
3.6490 \\
3.6566 \\
3.6669\end{array}$ & $\begin{array}{l}\text { NO CO } \\
\text { HP } \\
(I N .) \\
0.0140 \\
99999 \\
0.0001 \\
0.0164 \\
0.0344 \\
0.0508 \\
0.05557 \\
0.0792 \\
0.0913 \\
0.1021 \\
0.1115 \\
0.1197 \\
0.1268 \\
0.1326 \\
0.1372 \\
0.1408 \\
0.1434 \\
0.1452 \\
0.1461 \\
0.1453 \\
0.1456 \\
0.1441 \\
0.1418 \\
0.1387 \\
0.1349 \\
0.1303 \\
0.1249 \\
0.1188 \\
0.1120 \\
0.1045 \\
0.0952 \\
0.0873 \\
0.0777 \\
0.0575 \\
0.0556 \\
0.0451 \\
0.0329 \\
0.0202 \\
0.0068 \\
0.0001 \\
99.9999 \\
0.0162\end{array}$ & 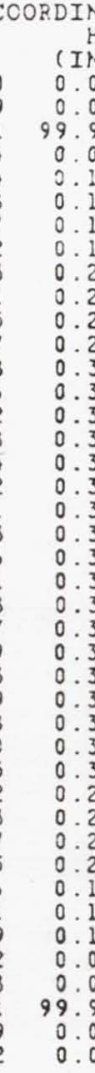 & & $\begin{array}{l}\text { SECTION } \\
\text { I } \\
(I N .) \\
0.0000 \\
0.0090 \\
0.0180 \\
0.1003 \\
0.2060 \\
0.3000 \\
0.3000 \\
0.4000 \\
0.5060 \\
0.6000 \\
0.7000 \\
0.8000 \\
0.9000 \\
1.0000 \\
1.1000 \\
1.2000 \\
1.3000 \\
1.4000 \\
1.5000 \\
1.6000 \\
1.7000 \\
1.8000 \\
1.9060 \\
2.0000 \\
2.1000 \\
2.2000 \\
2.3000 \\
2.4300 \\
2.5000 \\
2.6000 \\
2.7000 \\
2.8000 \\
2.9000 \\
3.0000 \\
3.1000 \\
3.2030 \\
3.3000 \\
3.4000 \\
3.5000 \\
3.6000 \\
3.6068 \\
3.6184 \\
3.6278\end{array}$ & 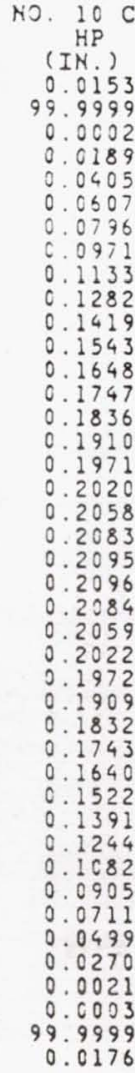 & 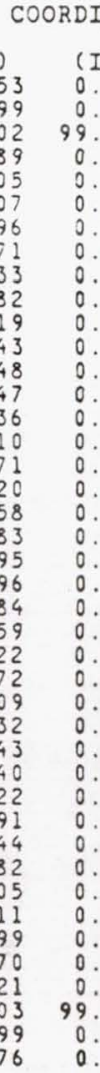 & $\begin{array}{l}\text { ATES } \\
15 \\
19 \\
153 \\
292 \\
999 \\
748 \\
218 \\
655 \\
061 \\
436 \\
781 \\
101 \\
396 \\
656 \\
880 \\
096 \\
284 \\
439 \\
566 \\
671 \\
750 \\
805 \\
833 \\
837 \\
816 \\
769 \\
696 \\
598 \\
4972 \\
320 \\
139 \\
930 \\
699 \\
418 \\
114 \\
774 \\
396 \\
978 \\
516 \\
005 \\
442 \\
999 \\
9331 \\
176 \\
176\end{array}$ & $\begin{array}{l}\text { SECTION } \\
\text { I } \\
(I N .) \\
0.0000 \\
0.0083 \\
0.0205 \\
0.1000 \\
0.2000 \\
0.3000 \\
0.4000 \\
0.5000 \\
0.6000 \\
0.7000 \\
0.8000 \\
0.9000 \\
1.0000 \\
1.1000 \\
1.2000 \\
1.3000 \\
1.4000 \\
1.5000 \\
1.6000 \\
1.7000 \\
1.8000 \\
1.9000 \\
2.0000 \\
2.1000 \\
2.2000 \\
2.3000 \\
2.4000 \\
2.5000 \\
2.6000 \\
2.7000 \\
2.8000 \\
2.9000 \\
3.0000 \\
3.1000 \\
3.2000 \\
3.3000 \\
3.4000 \\
3.5000 \\
3.5659 \\
3.5814 \\
3.5892\end{array}$ & $\begin{array}{l}\text { NO. } 11 \text { COC } \\
\text { HP } \\
\text { (IN.) } \\
0.0164 \\
99.9999 \\
0.0005 \\
0.0254 \\
0.0551 \\
0.0332 \\
0.1096 \\
0.1343 \\
0.1573 \\
0.1784 \\
0.1974 \\
0.2151 \\
0.2313 \\
0.2456 \\
0.2584 \\
0.2696 \\
0.2792 \\
0.2871 \\
0.2933 \\
0.2979 \\
0.3007 \\
0.3019 \\
0.301 .2 \\
0.2988 \\
0.2944 \\
0.2882 \\
0.2800 \\
0.2697 \\
0.2573 \\
0.2427 \\
0.2257 \\
0.2063 \\
0.1843 \\
0.1594 \\
0.1317 \\
0.1007 \\
0.0663 \\
0.0281 \\
0.0008 \\
99.9999 \\
0.0181\end{array}$ & $\begin{array}{r}\text { ORDIM } \\
\text { H } \\
\text { IIN } \\
0.0 \\
0.0 \\
99.9 \\
0.0 \\
0.1 \\
0.1 \\
0.2 \\
0.2 \\
0.3 \\
0.3 \\
0.4 \\
0.4 \\
0.4 \\
0.4 \\
0.5 \\
0.5 \\
0.5 \\
0.5 \\
0.5 \\
0.5 \\
0.5 \\
0.5 \\
0.5 \\
0.5 \\
0.5 \\
0.5 \\
0.5 \\
0.5 \\
0.5 \\
0.4 \\
0.4 \\
0.4 \\
0.3 \\
0.3 \\
0.2 \\
0.2 \\
0.1 \\
0.0 \\
99.9 \\
0.0 \\
0.0\end{array}$ & $\begin{array}{l}\text { HATES } \\
\text { HS } \\
\text { H. } \\
0164 \\
0306 \\
9999 \\
0871 \\
1445 \\
1979 \\
2475 \\
2935 \\
3360 \\
3748 \\
4103 \\
4434 \\
4729 \\
4988 \\
5216 \\
5415 \\
5584 \\
5721 \\
5829 \\
5907 \\
5954 \\
5972 \\
5958 \\
5913 \\
5835 \\
5725 \\
5580 \\
5399 \\
5181 \\
4923 \\
4623 \\
4278 \\
3885 \\
3438 \\
2932 \\
2362 \\
1718 \\
0992 \\
9999 \\
0330 \\
0181\end{array}$ & $\begin{array}{l}\text { SECTION } \\
\text { I } \\
\text { (IN.) } \\
0.0000 \\
0.0076 \\
0.0231 \\
0.1000 \\
0.2000 \\
0.3000 \\
0.4000 \\
0.5000 \\
0.6000 \\
0.7000 \\
0.8000 \\
0.9000 \\
1.0000 \\
1.1000 \\
1.2000 \\
1.3000 \\
1.4000 \\
1.5000 \\
1.6000 \\
1.7000 \\
1.8000 \\
1.9000 \\
2.0000 \\
2.1000 \\
2.2000 \\
2.3000 \\
2.4000 \\
2.5000 \\
2.6000 \\
2.7000 \\
2.8000 \\
2.9000 \\
3.0060 \\
3.1000 \\
3.2000 \\
3.3000 \\
3.4000 \\
3.5000 \\
3.5428 \\
3.5613 \\
3.5671\end{array}$ & 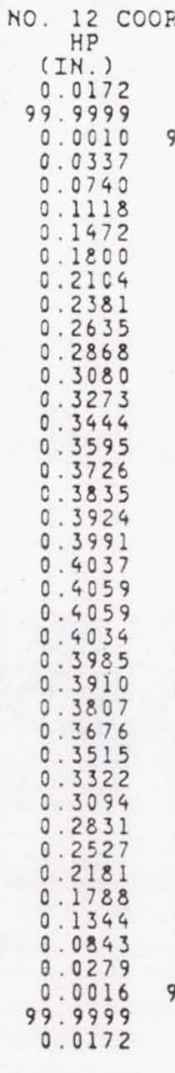 & $\begin{array}{l}\text { ORDINATES } \\
\text { HS } \\
\text { (IN }) \\
0.0172 \\
0.0315 \\
99.9999 \\
0.0994 \\
0.1678 \\
0.2314 \\
0.2906 \\
0.3456 \\
0.3956 \\
0.4436 \\
0.4868 \\
0.5261 \\
0.5614 \\
0.5930 \\
0.6210 \\
0.6454 \\
0.6663 \\
0.6836 \\
0.6974 \\
0.7077 \\
0.7144 \\
0.7175 \\
0.7170 \\
0.7127 \\
0.7045 \\
0.6923 \\
0.6758 \\
0.6549 \\
0.6293 \\
0.5986 \\
0.5625 \\
0.5204 \\
0.4718 \\
0.4159 \\
0.3517 \\
0.2783 \\
0.1940 \\
0.0969 \\
99.9999 \\
0.0300 \\
0.0172\end{array}$ & 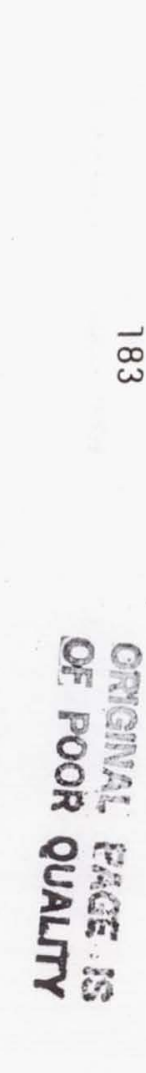 \\
\hline
\end{tabular}


Table 10.4 Continued

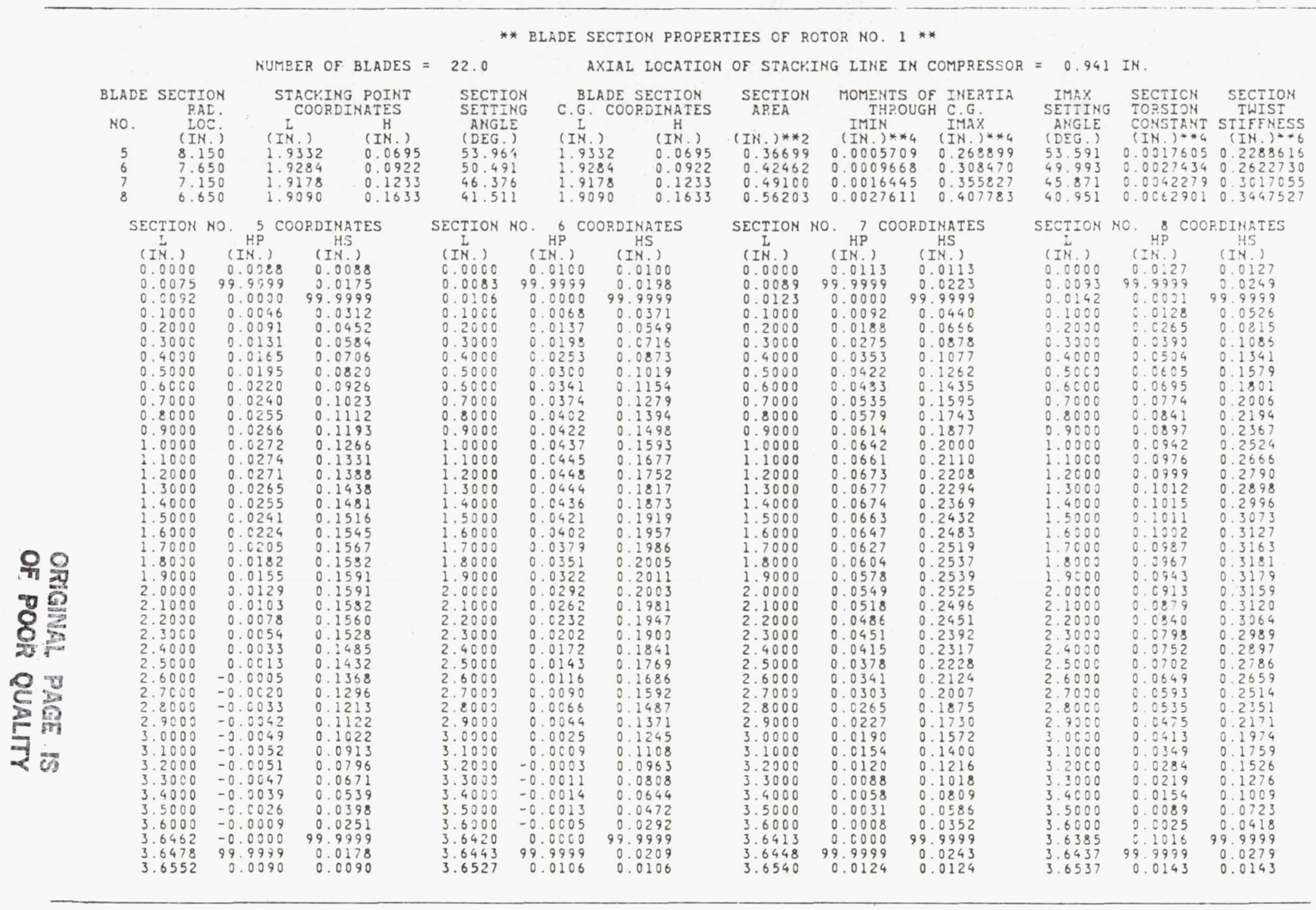


Table 10.4 Continued

* BLADE SECTION PROPERTIES OF ROTOR NO. 1 **

NUMBER OF BLADES $=22.0$

AXIAL LOCATION OF STACKING LINE IN COMPPESSOR $=0.941 \mathrm{IN}$.

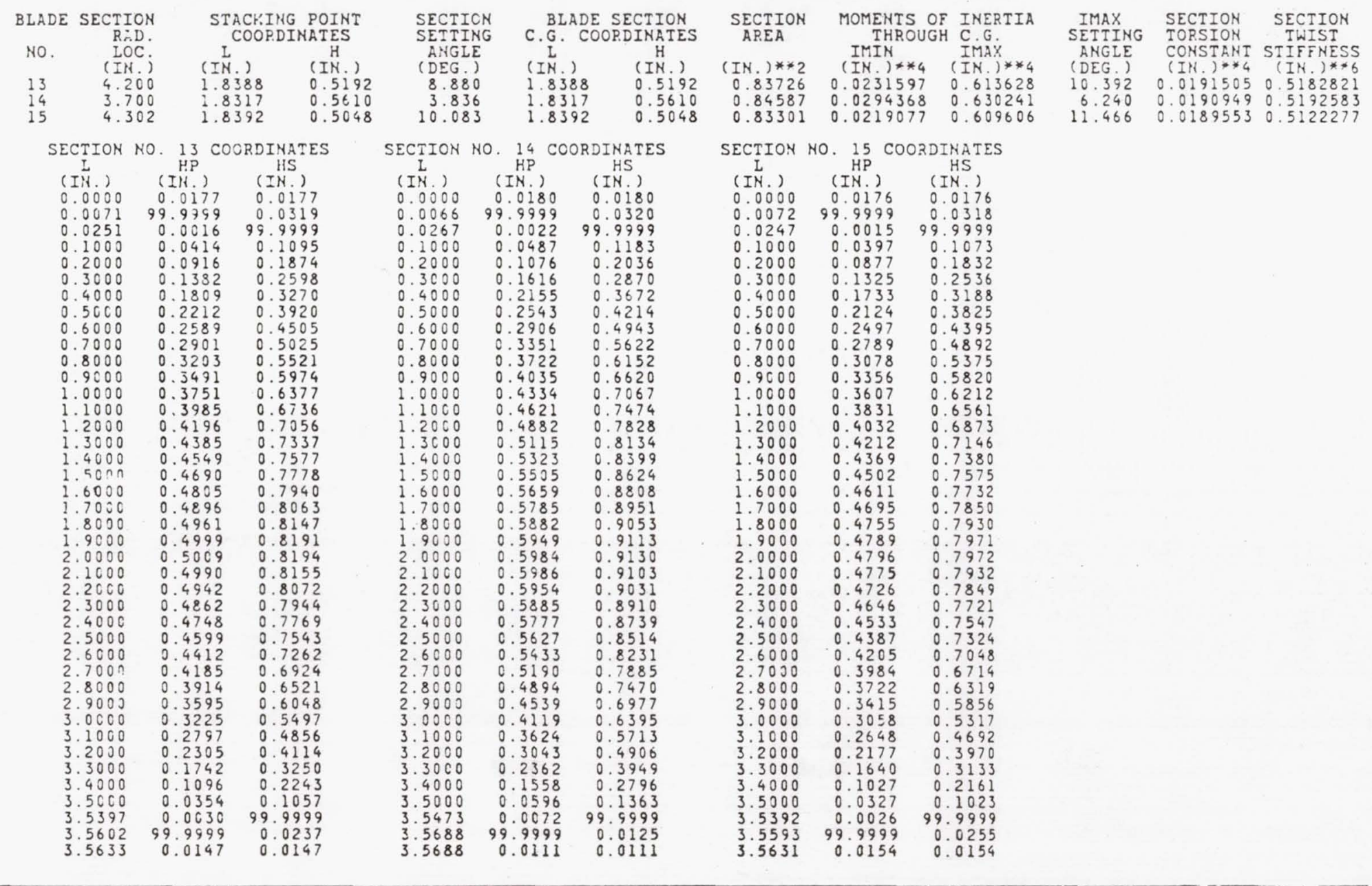


Table 10.5 Stator blade manufacturing coordinates generated by NASA design code

** BLAde Section properties of Stator no. 1 following potor nO. 1 **

NUMBER OF BLADES $=34.0$ AXIAL LOCATION OF STACKING LINE IN COMPRESSOR $=5.200$ IN.

\begin{tabular}{|c|c|c|c|c|c|c|c|c|c|c|c|c|c|c|}
\hline \multirow{2}{*}{\multicolumn{2}{|c|}{$\begin{array}{rr}\text { BLADE } & \text { SECTION } \\
\text { HO. } & \text { IOD. } \\
\text { HOC } & \text { (IN. } \\
9 & 5.075 \\
10 & 4.750 \\
11 & 9.600\end{array}$}} & \multicolumn{3}{|c|}{$\begin{array}{c}\text { STRCK.ING POINT } \\
\text { COORDINATES }\end{array}$} & $\begin{array}{l}\text { SECTION } \\
\text { SEITIRG }\end{array}$ & \multicolumn{3}{|c|}{$\begin{array}{l}\text { BLADE SECTION } \\
\text { C.G. COOPDINATES }\end{array}$} & $\begin{array}{l}\text { SECTION } \\
\text { AREA }\end{array}$ & \multicolumn{2}{|c|}{$\begin{array}{c}\text { MOMEMTS OF IHERTIA } \\
\text { THROUGH C.G. }\end{array}$} & \multirow{2}{*}{$\begin{array}{l}\text { IMAX } \\
\text { SEITING } \\
\text { ANGLE } \\
(\text { DEG.) } \\
17.569 \\
17.521 \\
10.189\end{array}$} & \multirow{2}{*}{ 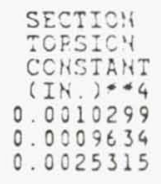 } & \multirow{2}{*}{$\begin{array}{c}\text { SECTIOH } \\
\text { TNIST } \\
\text { STYFFESS } \\
\text { (IN. \$ } 6 \\
0.0241935 \\
0.0236715 \\
0.0372960\end{array}$} \\
\hline & & $\begin{array}{l}\text { II } \\
\text { (IN } \\
1.1 \\
1.1 \\
1.1\end{array}$ & $\begin{array}{l}3) \\
349 \\
341 \\
352\end{array}$ & $\begin{array}{l}H \\
(I N .) \\
0.2522 \\
0.2791 \\
0.2291\end{array}$ & $\begin{array}{l}\text { A:GLLE } \\
(D E G \text {. } \\
17.152 \\
16.929 \\
10.180\end{array}$ & $\begin{array}{l}\text { L } \\
\text { IN } \\
1.13 \\
1.13 \\
1.13\end{array}$ & & $\begin{array}{c}H \\
(I N .) \\
0.2522 \\
0.2791 \\
0.2291\end{array}$ & $\begin{array}{l}(I N .) * * 2 \\
0.23510 \\
0.23051 \\
0.32621\end{array}$ & $\begin{array}{l}\text { IMIN } \\
(I N .) * * \\
0.001657 \\
0.001912 \\
0.002369\end{array}$ & $\begin{array}{ll}* 4 & \text { IMAX } \\
77 & 0.07213 * 4 \\
27 & 0.070614 \\
91 & 0.108565\end{array}$ & & & \\
\hline $\begin{array}{c}\text { SEC } \\
(1 \\
0 \\
0 \\
0 \\
0 \\
0 \\
0 \\
0 \\
0 \\
0 \\
0 \\
0 \\
1 \\
1 \\
1 \\
1\end{array}$ & $\begin{array}{l}\text { TION } \\
\text { L } \\
C N .) \\
0000 \\
0053 \\
0179 \\
1030 \\
2000 \\
3000 \\
4000 \\
5000 \\
6000 \\
7000 \\
8000 \\
9000 \\
0000 \\
1000 \\
2000 \\
3000 \\
4000 \\
5060 \\
6000 \\
7000 \\
8000 \\
9000 \\
0000 \\
1000 \\
2000 \\
2460 \\
2582 \\
2626\end{array}$ & $\begin{array}{l}\text { 9O CO } \\
(I P \text { P } \\
0.0126 \\
0.0126 \\
99.9999 \\
0.0012 \\
0.0372 \\
0.0771 \\
0.1127 \\
0.1443 \\
0.1717 \\
0.1952 \\
0.2148 \\
0.2306 \\
0.2426 \\
0.2509 \\
0.2553 \\
0.2559 \\
0.2527 \\
0.2454 \\
0.2341 \\
0.2186 \\
0.1987 \\
0.1742 \\
0.1449 \\
0.1105 \\
0.0705 \\
0.0246 \\
0.0012 \\
99.9999 \\
0.0114\end{array}$ & $\begin{array}{l}\text { ORDI } \\
\text { (I I } \\
0 . \\
0 . \\
99 . \\
0 . \\
0 . \\
0 . \\
0 . \\
0 . \\
0 . \\
0 . \\
0 . \\
0 . \\
0 . \\
0 . \\
0 . \\
0 . \\
0 . \\
0 . \\
0 . \\
0 . \\
0 . \\
0 . \\
0 . \\
9 . \\
0 . \\
0 .\end{array}$ & $\begin{array}{l}26 \\
29 \\
99 \\
53 \\
38 \\
52 \\
01 \\
89 \\
18 \\
90 \\
06 \\
69 \\
79 \\
35 \\
40 \\
91 \\
89 \\
30 \\
15 \\
38 \\
96 \\
85 \\
96 \\
21 \\
47\end{array}$ & $\begin{array}{l}\text { SECTION M } \\
I \\
(I N .) \\
0.0000 \\
0.0044 \\
0.0167 \\
0.1000 \\
0.2000 \\
0.3000 \\
0.4000 \\
0.5000 \\
0.6000 \\
0.7000 \\
0.8000 \\
0.9300 \\
1.0000 \\
1.1000 \\
1.2000 \\
1.3000 \\
1.4000 \\
1.5000 \\
1.6000 \\
1.7000 \\
1.8000 \\
1.9000 \\
2.0000 \\
2.1000 \\
2.2000 \\
2.2426 \\
2.2546 \\
2.2580\end{array}$ & $\begin{array}{l}\text { NO. } 100 \mathrm{COC} \\
\mathrm{HP} \\
\text { (IN ) } \\
0.0114 \\
99.9999 \\
0.0013 \\
0.0428 \\
0.0880 \\
0.1285 \\
0.1641 \\
0.1954 \\
0.2218 \\
0.2441 \\
0.2622 \\
3.2760 \\
0.2856 \\
0.2910 \\
0.2920 \\
0.2887 \\
0.2808 \\
0.2684 \\
0.2511 \\
0.2288 \\
0.2610 \\
0.1676 \\
0.1279 \\
0.0813 \\
0.0271 \\
0.0015 \\
99.9999 \\
0.0102\end{array}$ & 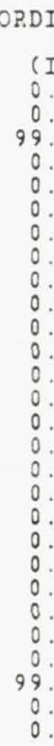 & 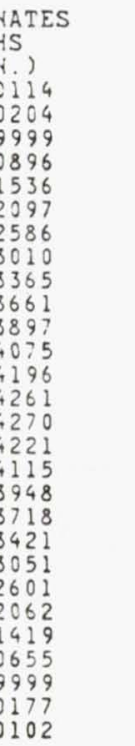 & $\begin{array}{c}\text { SECTION N } \\
\text { L } \\
(I N .) \\
0.0000 \\
0.0134 \\
0.0405 \\
0.1000 \\
0.2000 \\
0.3000 \\
0.4000 \\
0.5000 \\
0.6000 \\
0.7000 \\
0.8000 \\
0.9000 \\
1.0000 \\
1.1000 \\
1.2000 \\
1.3000 \\
1.4000 \\
1.5000 \\
1.6000 \\
1.7000 \\
1.8000 \\
1.9000 \\
2.0000 \\
2.1000 \\
2.2000 \\
2.2305 \\
2.2576 \\
2.2709\end{array}$ & $\begin{array}{l}\text { No. } 11 \mathrm{COO} \\
\text { HP } \\
\text { (IN.) } \\
0.0297 \\
99.9999 \\
0.0020 \\
0.0247 \\
0.0596 \\
0.0905 \\
0.1176 \\
0.1409 \\
0.1608 \\
0.1773 \\
0.1897 \\
0.1997 \\
0.2058 \\
0.2087 \\
0.2082 \\
0.2045 \\
0.1973 \\
0.1869 \\
0.1729 \\
0.1556 \\
0.1347 \\
0.1102 \\
0.0819 \\
0.0499 \\
0.0139 \\
0.0020 \\
99.9999 \\
0.0296\end{array}$ & $\begin{array}{l}\text { ORDINATES } \\
\text { HS } \\
(\text { IN.) } \\
0.0297 \\
0.0545 \\
99.9999 \\
0.1086 \\
0.1638 \\
0.2120 \\
0.2536 \\
0.2892 \\
0.3191 \\
0.3436 \\
0.3626 \\
0.3770 \\
0.3861 \\
0.3903 \\
0.3897 \\
0.3841 \\
0.3736 \\
0.3580 \\
0.3372 \\
0.3111 \\
0.2795 \\
0.2421 \\
0.1985 \\
0.1483 \\
0.0908 \\
99.9999 \\
0.0542 \\
0.0296\end{array}$ & & & \\
\hline
\end{tabular}


Table 10.5 Continued

** BLADE SECTION PROPERTIES OF STATOR NO. 1 FOLLOWING ROTOR NO. 1 **

NUMBER OF BLADES $=34.0 \quad$ AXIAL LOCATION OF STACRING IINE IN COMPRESSOR $=5.200$ IN.

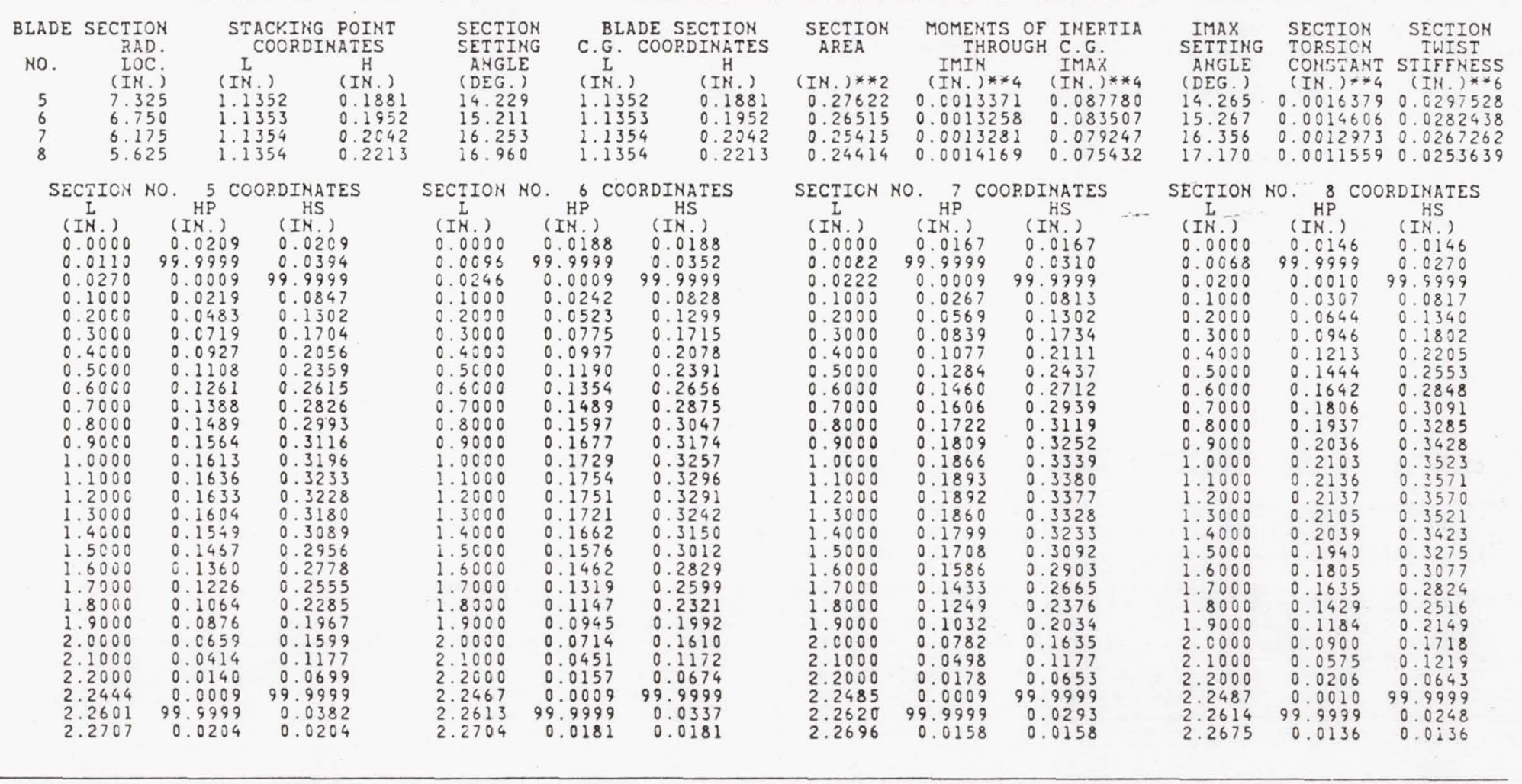


Table 10.5 Continued

* blade Section properties of stator no. 1 following potor no. 1 **

NUMBER OF BLADES $=34.0 \quad$ AXIAL LOCATION OF STACKING LINE IN COMPRESSOR $=5.200$ IN.

\begin{tabular}{|c|c|c|c|c|c|c|c|c|c|c|c|c|c|c|}
\hline $\begin{array}{cc}\text { BLADE } & \text { SECTION } \\
& \text { PAD. } \\
\text { NO. } & \text { LOC } \\
& \text { (IN.) } \\
1 & 9.625 \\
2 & 9.050 \\
3 & 8.475 \\
4 & 7.900\end{array}$ & $\begin{array}{l}\text { ION } \\
D \text { C. } \\
25 \\
50 \\
75 \\
70 \\
90\end{array}$ & $\begin{array}{l}\text { ACK.I } \\
\text { CCOR } \\
\text {. } \\
352 \\
353 \\
352 \\
352\end{array}$ & $\begin{array}{l}\text { POINT } \\
\text { NATES } \\
\text { H } \\
\text { (IN.) } \\
0.2326 \\
0.1894 \\
0.1845 \\
0.1841\end{array}$ & \multicolumn{2}{|c|}{$\begin{array}{l}\text { SECTION } \\
\text { SETTING } \\
\text { ANGLE } \\
\text { (DEG.) } \\
10.202 \\
10.969 \\
12.177 \\
13.138\end{array}$} & $\begin{array}{l}A D E \\
C O O \\
\\
52 \\
52 \\
52 \\
52\end{array}$ & $\begin{array}{l}\text { ECTION } \\
\text { DINATES } \\
\text { H } \\
\text { (IN.) } \\
0.2326 \\
0.1894 \\
0.1845 \\
0.1841\end{array}$ & $\begin{array}{l}(I N .) * * 2 \\
0.32714 \\
0.31091 \\
0.29901 \\
0.28745\end{array}$ & \multicolumn{3}{|c|}{$\begin{array}{cl}\text { MOMENTS OF } & \text { INERTIA } \\
\text { THROUGH } & \text { C.G. } \\
\text { IMIN } & \text { IMAX } \\
\text { (IN.)***4 } & (\text { IN.)***4 } \\
0.0024336 & 0.109044 \\
0.0016324 & 0.101485 \\
0.0014738 & 0.096707 \\
0.0013794 & 0.092145\end{array}$} & $\begin{array}{l}\text { IMAX } \\
\text { SETTING } \\
\text { AHGLE } \\
\text { (DEG ) } \\
10.215 \\
10.969 \\
12.185 \\
13.159\end{array}$ & $\begin{array}{l}\text { SECTION } \\
\text { TOPSION } \\
\text { CONSTANT } \\
\text { (IN.)**4 } \\
0.0025458 \\
0.0022673 \\
0.0020401 \\
0.0018305\end{array}$ & $\begin{array}{l}\text { SECTION } \\
\text { TWIST } \\
\text { STIFFNESS } \\
\text { (IN )** } \\
0.0374229 \\
0.0346121 \\
0.0329079 \\
0.0312922\end{array}$ \\
\hline $\begin{array}{c}\text { SECTION } \\
L \\
(I N .) \\
0.0000 \\
0.0133 \\
0.0408 \\
0.1000 \\
0.2000 \\
0.3000 \\
0.4000 \\
0.5000 \\
0.6000 \\
0.7000 \\
0.8000 \\
0.9000 \\
1.0000 \\
1.1000 \\
1.2000 \\
1.3000 \\
1.4000 \\
1.5000 \\
1.6000 \\
1.7000 \\
1.8000 \\
1.9000 \\
2.0000 \\
2.1000 \\
2.2000 \\
2.2301 \\
2.2577 \\
2.2709\end{array}$ & 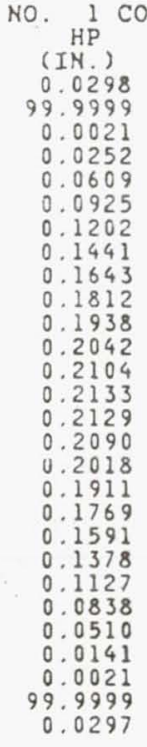 & 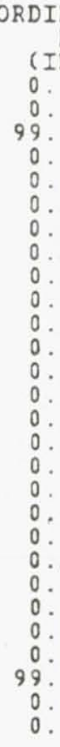 & & $\begin{array}{c}\text { SECTION } \\
\text { I } \\
\text { (IN.) } \\
0.0000 \\
0.0144 \\
0.0351 \\
0.1000 \\
0.2000 \\
0.3000 \\
0.4000 \\
0.5000 \\
0.6000 \\
0.7000 \\
0.8000 \\
0.9000 \\
1.0000 \\
1.1000 \\
1.2000 \\
1.3000 \\
1.4000 \\
1.5000 \\
1.6000 \\
1.7000 \\
1.8000 \\
1.9000 \\
2.0000 \\
2.1000 \\
2.2000 \\
2.2359 \\
2.2565 \\
2.2708\end{array}$ & $\begin{array}{l}\text { NO. CO } \\
\text { HP } \\
(\mathrm{IN} .) \\
0.0274 \\
99.9999 \\
0.0011 \\
0.0194 \\
0.0452 \\
0.0683 \\
0.0886 \\
0.1063 \\
0.1213 \\
0.1337 \\
0.1436 \\
0.1508 \\
0.1555 \\
0.1576 \\
0.1573 \\
0.1544 \\
0.1489 \\
0.1409 \\
0.1303 \\
0.1171 \\
0.1013 \\
0.0829 \\
0.0618 \\
0.0379 \\
0.0113 \\
0.0011 \\
99.9999 \\
0.0273\end{array}$ & $\begin{array}{r}\text { ORDI } \\
(I \\
0 . \\
0 . \\
99 \\
0 . \\
0 . \\
0 . \\
0 . \\
0 . \\
0 . \\
0 . \\
0 . \\
0 . \\
0 . \\
0 . \\
0 . \\
0 . \\
0 . \\
0 . \\
0 . \\
0 . \\
0 . \\
0 . \\
0 . \\
0 . \\
0 . \\
99 \\
0 .\end{array}$ & $\begin{array}{l}4 \\
6 \\
9 \\
4 \\
2 \\
6 \\
8 \\
1 \\
7 \\
7 \\
3 \\
4 \\
3 \\
9 \\
3 \\
4 \\
3 \\
9 \\
0 \\
7\end{array}$ & $\begin{array}{c}\text { SECTION } \\
\text { L } \\
\text { (IN.) } \\
0.0000 \\
0.0135 \\
0.0322 \\
0.1000 \\
0.2000 \\
0.3000 \\
0.4000 \\
0.5000 \\
0.6000 \\
0.7000 \\
0.8000 \\
0.9000 \\
1.0000 \\
1.1000 \\
1.2000 \\
1.3000 \\
1.4000 \\
1.5000 \\
1.6000 \\
1.7000 \\
1.8000 \\
1.9000 \\
2.0000 \\
2.1000 \\
2.2000 \\
2.2390 \\
2.2575 \\
2.2708\end{array}$ & $\begin{array}{l}\text { NO. } \begin{array}{c}\text { HP } \\
\text { (IN. }\end{array} \\
0.0253 \\
99.999 \\
0.00100 \\
0.0195 \\
0.0445 \\
0.0668 \\
0.0865 \\
0.1037 \\
0.1182 \\
0.1303 \\
0.1398 \\
0.1469 \\
0.1514 \\
0.1535 \\
0.1532 \\
0.1504 \\
0.1451 \\
0.1373 \\
0.1271 \\
0.1143 \\
0.0990 \\
0.0811 \\
0.0607 \\
0.0376 \\
0.0117 \\
0.0009 \\
99.9999 \\
0.0250\end{array}$ & $\begin{array}{r}\text { ORDIN } \\
\text { H } \\
\text { (IN } \\
0.0 \\
0.0 \\
99.9 \\
0.0 \\
0.1 \\
0.1 \\
0.2 \\
0.2 \\
0.2 \\
0.2 \\
0.3 \\
0.3 \\
0.3 \\
0.3 \\
0.3 \\
0.3 \\
0.3 \\
0.2 \\
0.2 \\
0.2 \\
0.2 \\
0.2 \\
0.1 \\
0.1 \\
0.0 \\
99.9 \\
0.0 \\
0.0\end{array}$ & $\begin{array}{l}{[N .)} \\
0253 \\
0476 \\
9999 \\
0908 \\
1355 \\
1750 \\
2094 \\
2391 \\
2642 \\
2848 \\
3010 \\
3130 \\
3207 \\
3243 \\
3237 \\
3190 \\
3100 \\
2969 \\
2794 \\
2575 \\
2311 \\
2000 \\
1640 \\
1229 \\
0764 \\
9999 \\
0471 \\
0250\end{array}$ & $\begin{array}{l}\text { SECTION } \\
\text { L } \\
\text { (IN.) } \\
0.0000 \\
0.0123 \\
0.0295 \\
0.1000 \\
0.2000 \\
0.3000 \\
0.4000 \\
0.5000 \\
0.6000 \\
0.7000 \\
0.8000 \\
0.9000 \\
1.0000 \\
1.1000 \\
1.2000 \\
1.3000 \\
1.4000 \\
1.5000 \\
1.6000 \\
1.7000 \\
1.8000 \\
1.9000 \\
2.0000 \\
2.1000 \\
2.2000 \\
2.2418 \\
2.2587 \\
2.2708\end{array}$ & $\begin{array}{l}{ }^{4} \mathrm{COO} \\
\mathrm{HP} \\
(1 \mathrm{~N} .) \\
0.0231 \\
99.9999 \\
0.0009 \\
0.0203 \\
0.0455 \\
0.0680 \\
0.0879 \\
0.1052 \\
0.1199 \\
0.1321 \\
0.1417 \\
0.1488 \\
0.1535 \\
0.1556 \\
0.1553 \\
0.1525 \\
0.1472 \\
0.1394 \\
0.1291 \\
0.1162 \\
0.1008 \\
0.0828 \\
0.0621 \\
0.0387 \\
0.0126 \\
0.0009 \\
99.9999 \\
0.0227\end{array}$ & $\begin{array}{l}\text { RDINATES } \\
\text { HS } \\
(I N .) \\
0.0231 \\
0.0435 \\
99.9999 \\
0.0872 \\
0.1318 \\
0.1713 \\
0.2057 \\
0.2354 \\
0.2605 \\
0.2812 \\
0.2975 \\
0.3095 \\
0.3173 \\
0.3209 \\
0.3203 \\
0.3156 \\
0.3067 \\
0.2935 \\
0.2761 \\
0.2542 \\
0.2278 \\
0.1966 \\
0.1606 \\
0.1194 \\
0.0728 \\
99.9999 \\
0.0427 \\
0.0227\end{array}$ \\
\hline
\end{tabular}



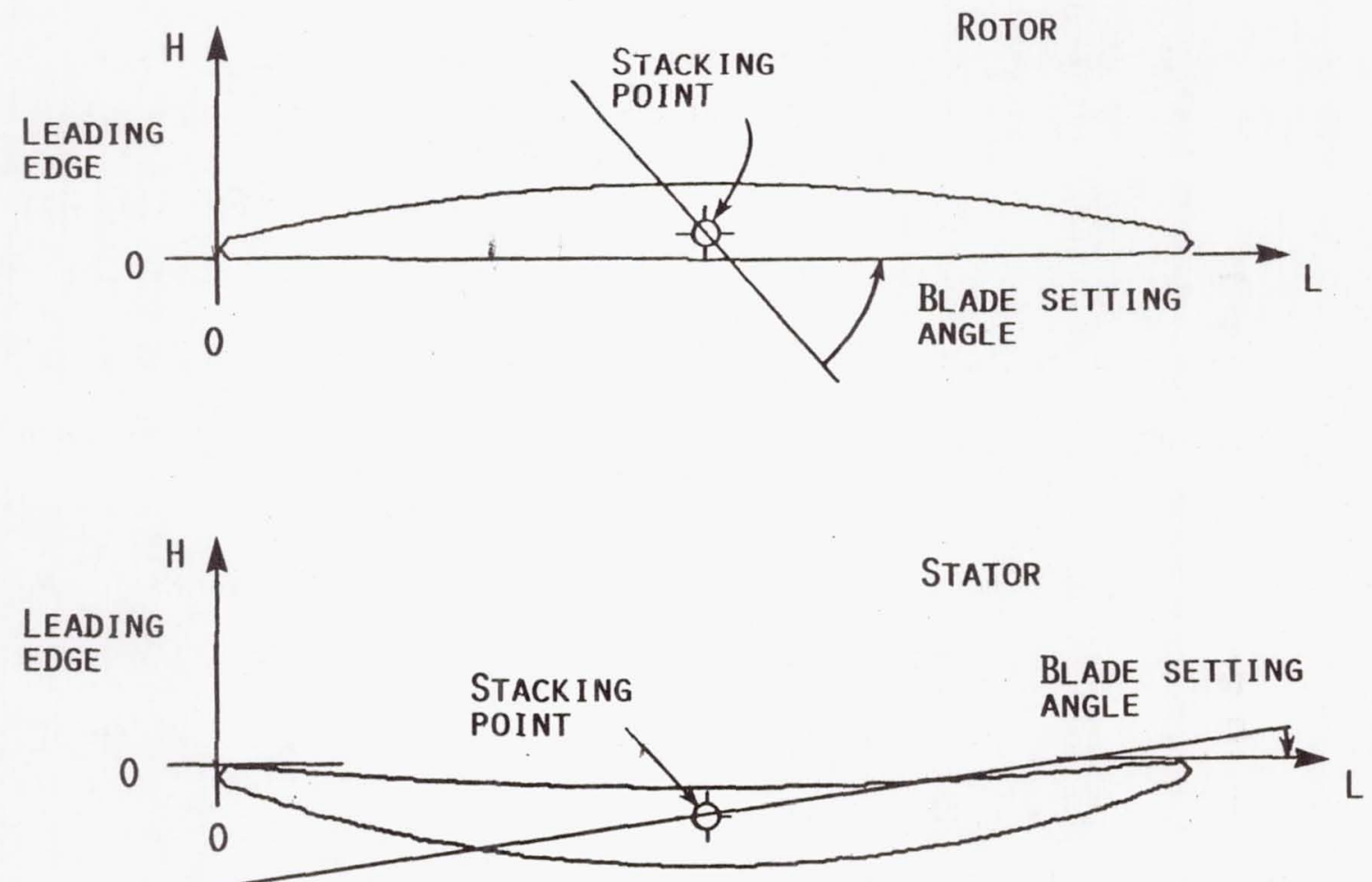

Figure 10.1 Rotor and stator blade manufacturing coordinate system used by NASA design code 
XI. APPENDIX B: STATOR- AND ROTOR-RELATIVE TIME AVERAGES

Figure 11.1 shows a "snapshot" of the rotor and stator at a particular rotor/stator orientation. The coordinate system fixed to the rotor frame of reference is denoted by $R, Z, \theta^{R}$, and the coordinate system fixed to the stator frame of reference (i.e., measurement frame of reference) is denoted by $R, Z, \theta^{S}$. The $R, Z, \theta^{R}$ coordinate system is related to the $R, Z, \theta^{S}$ coordinate system through the rotor/stator orientation, denoted by $\Omega=2 \pi(n-1) /\left(N_{R} N_{S P}\right)$, where $N_{R}$ is the number of rotor blades, $N_{S P}$ is the number of rotor shaft positions per rotor blade passage, and $n$ is the particular rotor shaft position. When the rotor trailing edge is circumferentially aligned with the stator leading edge, $\Omega=0$. Point $A$, shown on Figure 11.1, is fixed to the rotor frame of reference, and points $B$ through $K$ are fixed to the stator frame of reference. At each stator survey point $B$ to $K$, the absolute velocity has been measured at $N_{S P}=50$ consecutive rotor/stator orientations equally spaced over a rotor pitch. Therefore, at any stator survey point (e.g., B to K), stator-relative time-average quantities are readily calculated as

$\bar{G}=\sum_{i=1}^{N} \frac{G_{i}}{N_{S P}}$

where $G$ is any flow-field parameter (e.g., $\stackrel{\widetilde{m}}{\widetilde{V}}$ or ${\stackrel{\sim m}{V^{\prime}}}^{2}$ ), and the superscript - denotes the time average. Within the context of this thesis, time is not real time, but rather corresponds to the relative position of the rotor and stator (i.e., $t=\Omega / \omega$ ).

Although the data were acquired in the stator-relative (absolute) frame of reference, it is also possible to resolve a "time-averaged" 


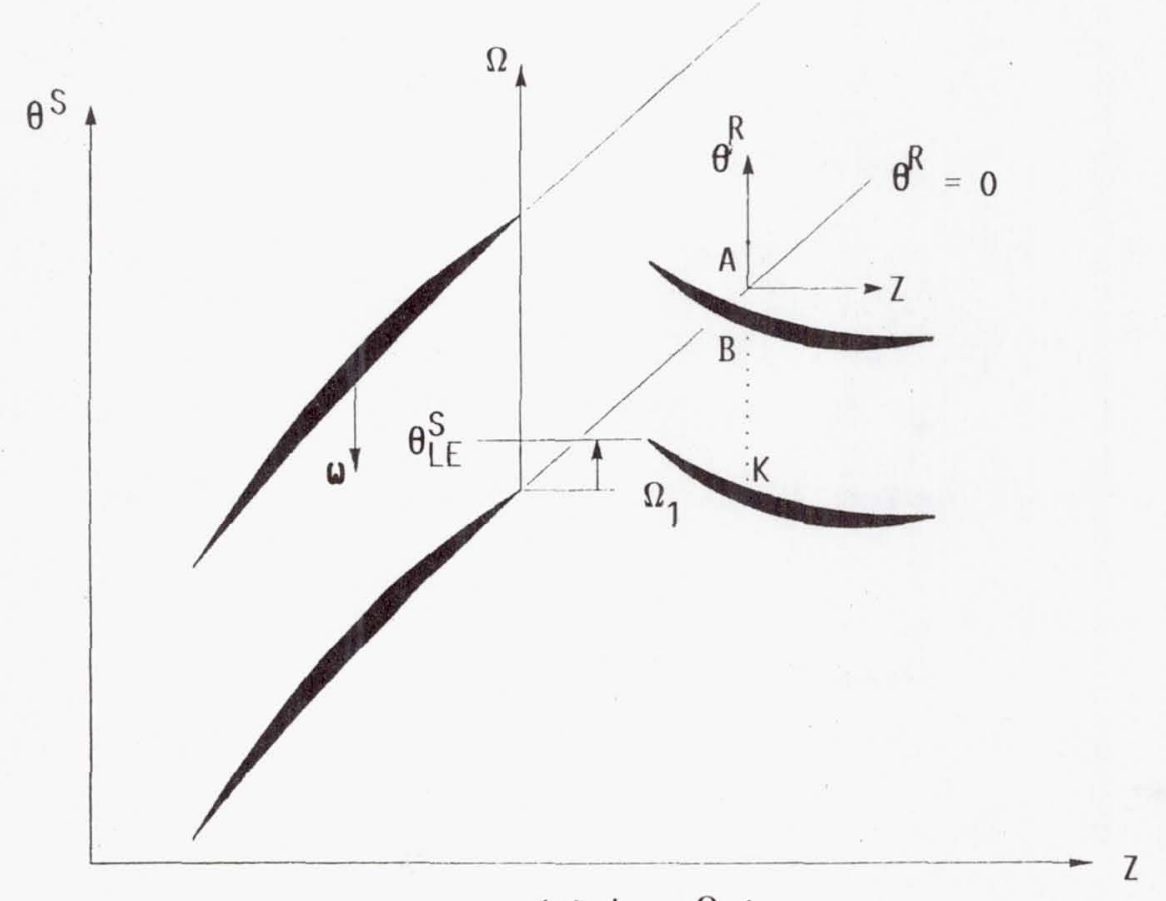

(A) $t_{1}=\Omega_{1} / \omega$.

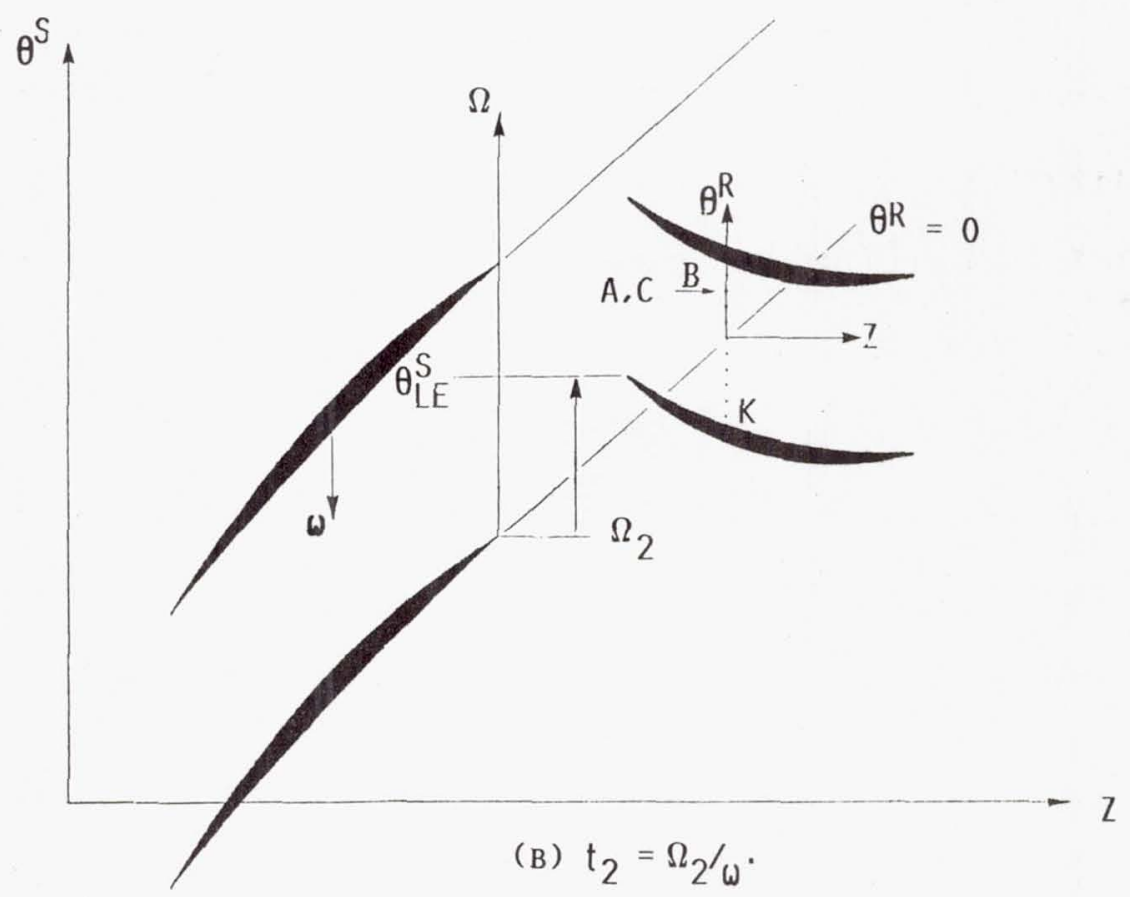

Figure 11.1 Blade-to-blade view of the rotor and stator at a particular instant in time, $t$, showing the relationship between the rotor-and stator-relative coordinate systems 
description of the absolute flow field from the perspective of an observer moving with the rotor blades. Again referring to Figure 11.1, the rotorrelative time average of the absolute velocity at point $A$, in the rotor frame of reference, can be determined from the time-resolved measurements of the absolute velocities acquired at points $B$ to $k$, in the stator frame of reference, as follows. First, the rotor/stator orientations (i.e., rotor shaft positions) which correspond to circumferential alignment of point $A$, in the rotor frame of reference, with survey points $B$ to $K$, in the stator frame of reference, are determined, see Figure 11.1(B). Next, the above determined rotor/stator orientations are used to determine the absolute velocities which an observer, sitting at point $A$ in the rotor frame of reference, would see as point $A$ became coincident with points $B$ through $K$ in the stator frame of reference. This is accomplished by using the above determined rotor shaft positions to interpolate from the measured distributions of the absolute velocities which were acquired at each point $B$ to $K$ as a function of rotor shaft position. Finally, the arithmetic average of these absolute velocities are used as an estimate of the rotor-relative time-averaged absolute velocity at point $A$. At every axial survey station, the above procedures were repeated at each of 50 equally spaced points across the rotor pitch in order to generate a complete description of the entire rotor-relative time-averaged flow field. The equation for determining any rotor-relative time average parameter from its phase lock averaged results is

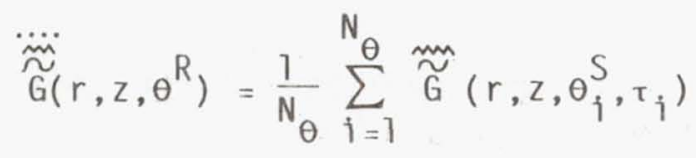

where $\tau_{i}=\left(N_{S P}-\left(\theta_{i}^{S}-0_{I E}^{S}\right) N_{R} N_{S P} / 2 \pi\right)$. 
XII. APPENDIX C: ESTIMATION OF BOUNDS ON TURBULENCE COMPONENTS

The turbulence is determined from the standard deviation of the velocities, but from the manner in which the data were acquired, it is not possible to calculate the standard deviation of the velocities in the axial and tangential directions. However, it is possible to estimate, from the measured data, the minimum and maximum bounds of the standard deviations of the velocities in the axial and tangential directions. The procedure for estimating these bounds are explained in this Appendix.

Figure 12.1 shows a sketch of the $Z, \theta^{\prime}$ measurement plane indicating the measured velocity components and the corresponding estimates of their standard deviations. The two measured fringe angle orientations are identified as $\alpha_{1}$ and $\alpha_{2}$. The ensemble average absolute velocity and flow angle are identified as $\tilde{v}_{T}$ and $\tilde{\beta}_{T}$, respectively. The measured ensemble-averaged velocities and their corresponding estimated standard deviations are identified as $\widetilde{v}_{m}$ and $S_{m}$, respectively, where $m$ is assigned the value 1 or 2 to indicate the particular velocity component. The shaded region in figure 12.1 identifies the estimated bounds, corresponding to one standard deviation $(15)$, of the fluctuations of the total absolute velocity and flow angle. The bounds of the shaded region are used to estimate the $1 S$ bounds of the standard deviations of the axial and tangential components of the total absolute velocity, as follows.

The equations of the lines which are collinear with the direction of the measured velocity components are

$\ell_{m}: \widetilde{V}_{m, z}^{n}=\widetilde{V_{m, \theta}^{n}} \tan \alpha_{m}$ 


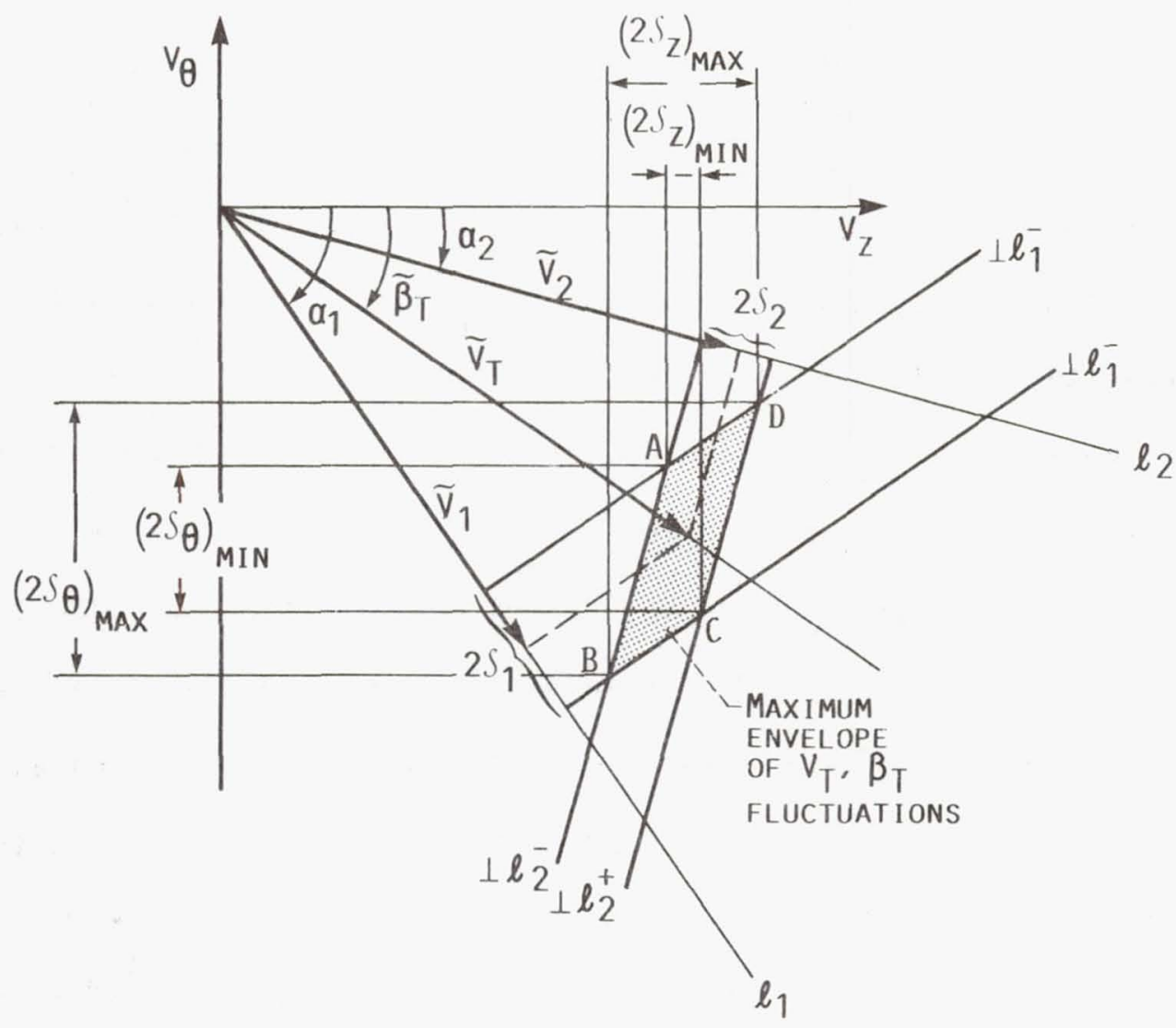

Figure 12.1 Fringe-plane view of the velocity components showing the relationship between the ensemble-average and standard deviations of the axial and tangential velocity components and the measured velocity components 
where the subscript $m$ is assigned the value 1 or 2 to denote the particular measured velocity component, and the subscripts $z$ and $\theta$ denote the axial and tangential directions, respectively. The equations of the lines which are perpendicular to lines $\ell_{m}$, and which intersect lines $\ell_{m}$ at $\left(\widetilde{V}_{m}-S_{m}\right)$ and $\left(\widetilde{V}_{m}+S_{m}\right)$ are

$\perp_{m}^{ \pm}: \quad \widetilde{V}_{m, \theta}=-\widetilde{V}_{m, z} \cot \alpha_{m}+\left(\frac{v_{m} \pm S_{m}}{\sin \alpha_{m}}\right)$

where the subscripts $\mathrm{m}, \mathrm{z}, \mathrm{t}$ are defined as in Equation (12.1), the subscript $\perp$ denotes the perpendicular to line $\ell_{m}$.

Now, assume that the true $1 S$ envelope of the $\tilde{V}_{T}, \widetilde{\beta}_{T}$ fluctuations is defined by an ellipse, which would be the case if the distribution of measured velocities were gaussian and the turbulence were nonisotropic. For isotropic turbulence the true $1 S$ envelope of the $\widetilde{v}_{\gamma}, \widetilde{\beta}_{1}$ fluctuations would defined by a circle. The above assumption is not a required condition, but does facilitate the proceeding explanation. Further, assume that the major axis of the true $T S$ ellipse of $\widetilde{V}_{T}, \widetilde{\beta}_{T}$ fluctuations contains points $B$ and $D$, which are the verticies of the shaded region illustrated in Figure 12.1. This ellipse could be, in the limit, a line to the largest ellipse which inscribes the shaded region. Note that in order to have measured the $S_{1}, S_{2}$ projections of the true $1 S$ ellipse of the $\widetilde{v}_{1}, \tilde{\beta}_{\uparrow}$ fluctuations, the $1 S$ ellipse must be tangent to all four sides of the shaded region in Figure 12.1 , but the 1.5 ellipse does not need to completely inscribe the shaded region. For example, the projection of a line segment between points $B$ and $D$ in the $\widetilde{V}_{1}$ and $\widetilde{V}_{2}$ component directions would define the extent of the $S_{1}$ and $S_{2}$ fluctuations, respectively. Conversely, the projections of a line segment between points 
$A$ and $C$ in the $\widetilde{v}_{1}$ and $\widetilde{v}_{2}$ component directions would also define the extent of the $S_{1}$ and $S_{2}$ fluctuations. Therefore, the major axis of the true $1 S$ ellipse of the $\widetilde{V}_{T}, \widetilde{\beta}_{T}$ fluctuations could be in any orientation between line segment $A-C$ to line segment $B-D$, as long as the bounds of the $1 S$ ellipse are tangent to all four sides of the perimeter of the shaded region.

The ellipse with the smallest possible area (i.e., minimum overall fluctuations) would have it's major axis collinear with line segment $A-C$, and an ellipse with the largest possible area (i.e., maximum overall fluctuations) would have it's major axis collinear with line segment B-D. Therefore, the minimum and maximum bounds of the $1 S$ fluctuations of axial and tangential velocity components are defined by the verticies of the shaded region. The verticies of the shaded region in Figure 12.1 are determined from the intersections of lines $\perp \ell_{1}^{ \pm}$and $\perp \ell_{2}^{ \pm}$as follows.

$$
\begin{aligned}
\perp \ell_{1}^{ \pm} \cap \perp \ell_{2}^{ \pm}=\left(v_{z}^{ \pm}, v_{\theta}^{\mp}\right)= & {\left[\frac{\left(\tilde{V}_{1} \pm S_{1}\right) \sin \alpha_{2}-\left(\tilde{V}_{2} \pm S_{2}\right) \sin \alpha_{1}}{\sin \left(\alpha_{2}-\alpha_{1}\right)},\right.} \\
& \left.\frac{\left(\tilde{V}_{2} \pm S_{2}\right) \cos \alpha_{1}-\left(\tilde{V}_{1} \pm S_{1}\right) \cos \alpha_{2}}{\sin \left(\alpha_{2}-\alpha_{1}\right)}\right] \\
\perp \ell_{1}^{\mp} \cap \perp \ell_{2}^{ \pm}=\left(\begin{array}{c} 
\pm \\
v_{z}^{\mp}, v_{\theta}^{\mp}
\end{array}\right)= & {\left[\frac{\left(\tilde{V}_{1} \mp S_{1}\right) \sin \alpha_{2}-\left(\tilde{V}_{2} \pm S_{2}\right) \sin \alpha_{1}}{\sin \left(\alpha_{2}-\alpha_{1}\right)},\right.} \\
& \left.\frac{\left(\tilde{V}_{2} \mp S_{2}\right) \cos \alpha_{1}-\left(\tilde{V}_{1} \pm S_{1}\right) \cos \alpha_{2}}{\sin \left(\alpha_{2}-\alpha_{1}\right)}\right]
\end{aligned}
$$

The minimum and maximum bounds of the $1 S$ fluctuations of the axial and tangential velocity components can, therefore, be determined as 


$$
\begin{aligned}
& \left(\int_{Z}\right)_{\operatorname{mix}}=A B S\left(\begin{array}{cc} 
\pm & \mp \\
V_{z}^{+} & -V_{Z}^{-}
\end{array}\right)_{\mathrm{OB}} / 2=A B S\left[\frac{\int_{1} \sin \alpha_{2} \pm \int_{2} \sin \alpha_{1}}{\sin \left(\alpha_{2}-\alpha_{1}\right)}\right] \\
& \left(\int_{\theta}\right)_{\max }=\operatorname{ABS}\left(\begin{array}{cc}
\mp & \pm \\
V_{\theta}^{-} & -v_{\theta}^{+}
\end{array}\right)_{\mathrm{OB}} / 2=\operatorname{ABS}\left[\frac{\int_{2} \cos \alpha_{1} \pm \int_{1} \cos \alpha_{2}}{\sin \left(\alpha_{2}-\alpha_{1}\right)}\right]
\end{aligned}
$$

from which the variances and the turbulence are determined. 


\section{APPENDIX D: WAKE ENHANCEMENT PROCEDURE}

Contour plots of the time-resolved turbulent kinetic energy have been previously used $[42-45,89]$ to identify the transport of wakes through a downstream blade row. However, as these wakes progress downstream they become harder to discern from the surrounding flow field, due to mixing, and therefore plots of the turbulent kinetic energy may not be sufficient to clearly delineate the wake fluid. In order to better resolve the rotor wakes throughout the stator row of the present research compressor, a procedure was developed for enhancing the rotor wake signature.

Figure 13.1 shows a typical plot of the total turbulence at two points in the stator flow field; one upstream of the stator row, and one near the stator exit. The total turbulence, $S_{T}$, is defined as

$S_{T}=\sqrt{S_{z_{\text {min }}}^{2}+S_{\theta_{\text {min }}}^{2}}$

where $\int_{z_{\min }}$ and $S_{\theta_{\min }}$ are calculated from Equations 12.3 and 12.4 , respectively. Upstream of the stator row the total turbulence within the rotor wake is very high relative to the freestream. However, near the stator exit the total turbulence within the rotor wake is only slightly higher than the freestream. Furthermore, the free-stream total turbulence varies from inlet to exit and blade to blade. Therefore, in order to enhance the rotor wakes throughout the stator passage the total turbulence is normalized such that the freestream value is zero and the maximum value, which usually occurs in the rotor wake, is one. This normalization is applied at each spatial survey point throughout the stator flow field. 

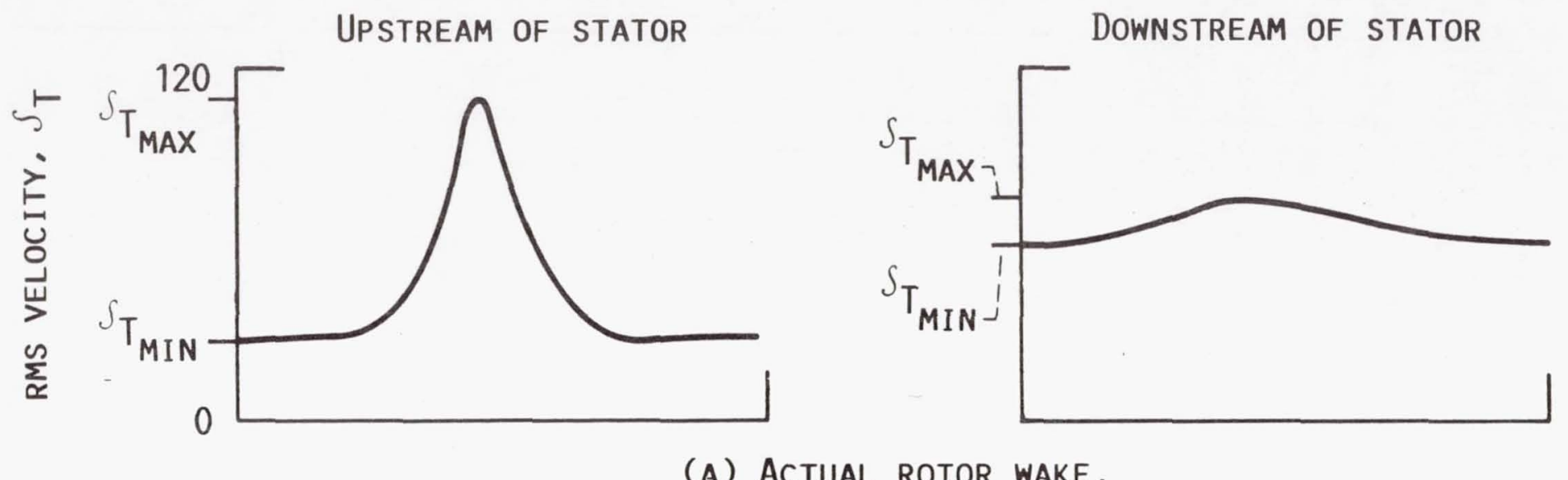

A) Actual ROtOR WAKE.

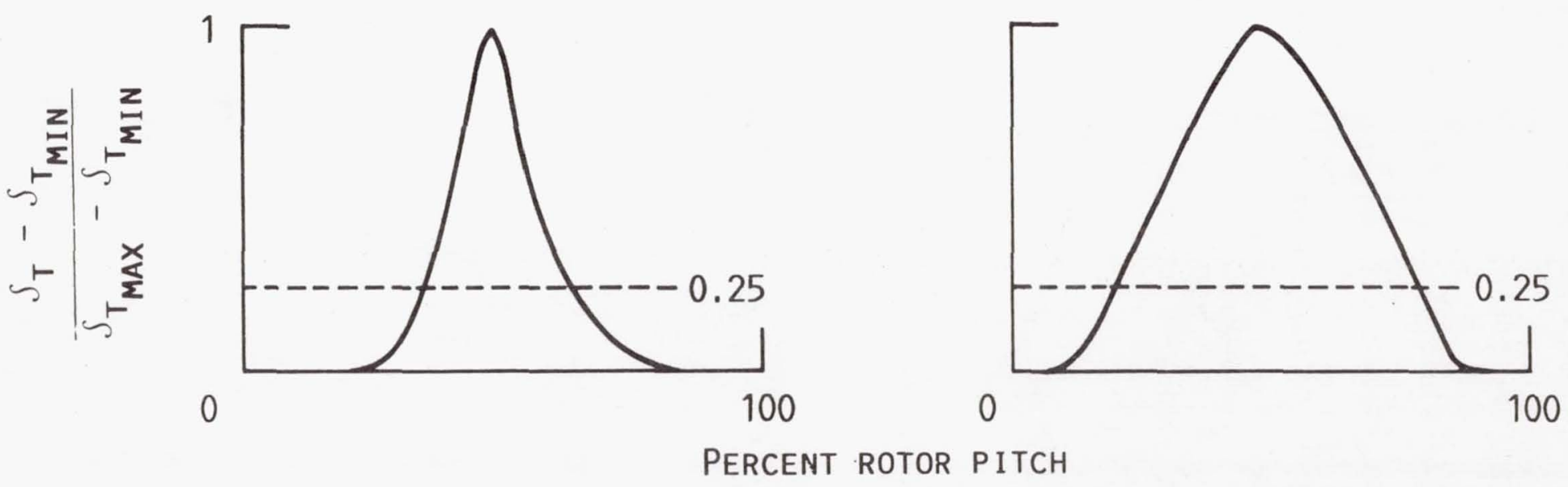

(B) NORMAL IZED ROTOR WAKE. 
As a result of the enhancement procedure, the rotor wakes have equal weight throughout the stator flow field as shown in Figure 13.1(B). Of course, any information about the dissipation of the rotor wakes is lost, but the width of the rotor wakes and their phase is preserved. Contour plots of the enhanced rotor wakes are constructed from contour levels at 0.25 of the peak value in the rotor wake (arrived at through trial and error), as shown in Figure 13.1(B). Thus, most of the rotor wake is identified within the shaded regions of figures 5.10 and 5.11 . 


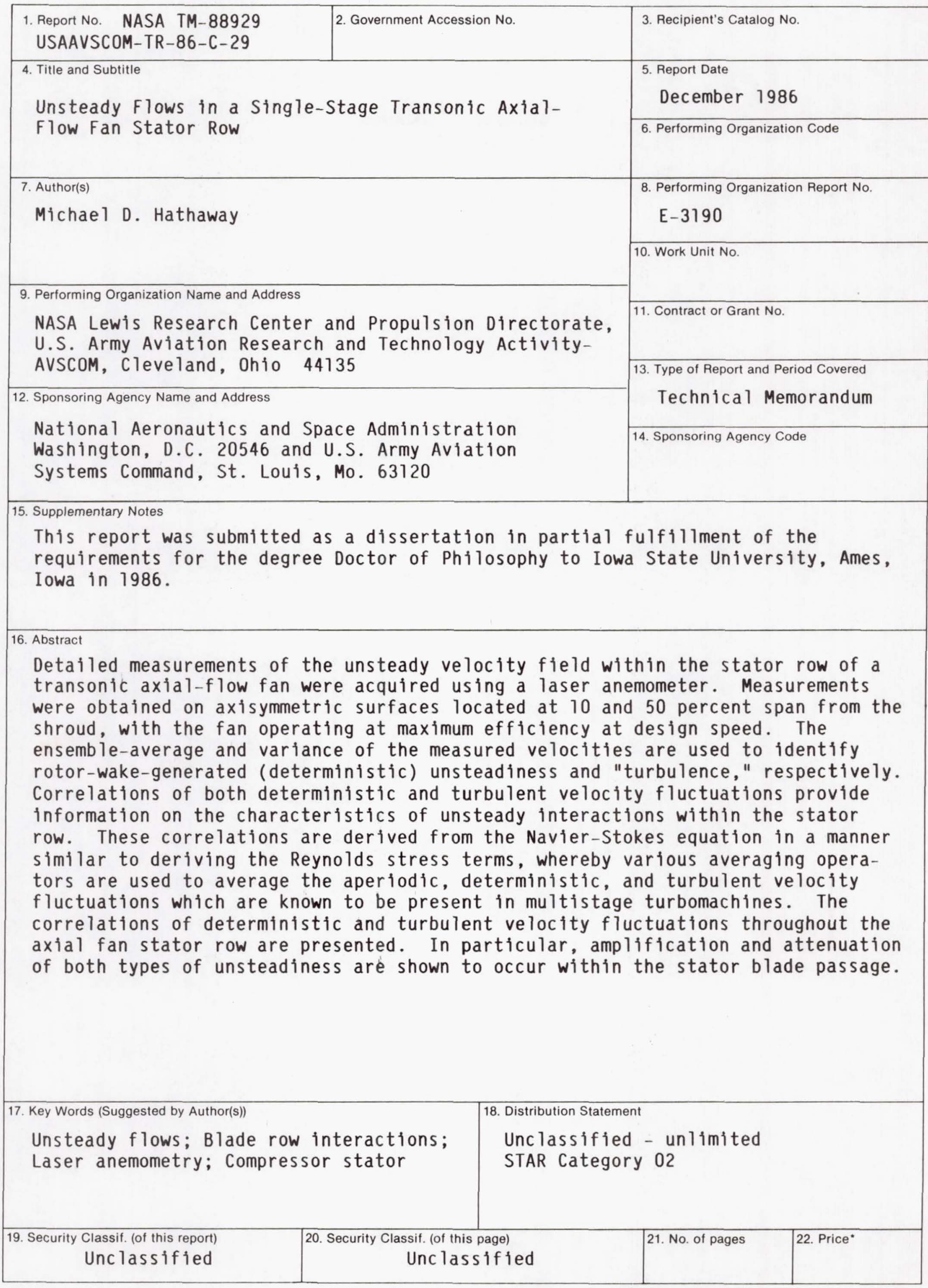

^For sale by the National Technical Information Service, Springfield, Virginia 22161 